\title{
Biochemical studies of the synaptic protein otoferlin
}

\author{
Dissertation \\ zur Erlangung des mathematisch-naturwissenschaftlichen Doktorgrades \\ „Doctor rerum naturalium" \\ der Georg-August-Universität Göttingen \\ im Promotionsprogramm "Grundprogramm Biologie" \\ der Georg-August University School of Science (GAUSS)
}

\author{
vorgelegt von \\ Sandra Meese \\ aus Holzminden \\ Göttingen, 2014
}




\section{Betreuungsausschuss}

Prof. Dr. Ralf Ficner, Molekulare Strukturbiologie, Institut für Mikrobiologie und Genetik, Georg-August-Universität Göttingen

Prof. Dr. Tobias Moser, InnerEarLab, Department of Otolaryngology, Universitätsmedizin Göttingen

Dr. Ellen Reisinger, Molecular Biology of Cochlear Neurotransmission Group, InnerEarLab, HNO-Klinik, Universitätsmedizin Göttingen

\section{Mitglieder der Prüfungskommission}

Referent: Prof. Dr. Ralf Ficner, Molekulare Strukturbiologie, Institut für Mikrobiologie und Genetik, Georg-August-Universität Göttingen

Korreferent: Prof. Dr. Tobias Moser, InnerEarLab, Department of Otolaryngology, Universitätsmedizin Göttingen

weitere Mitglieder der Prüfungskommission:

Dr. Ellen Reisinger, Molecular Biology of Cochlear Neurotransmission Group, InnerEarLab, HNO-Klinik, Universitätsmedizin Göttingen

Prof. Dr. Kai Tittmann, Bioanalytik, Albrecht-von-Haller-Institut für Pflanzenwissenschaften, Georg-August-Universität Göttingen

Prof. Dr. Jörg Stülke, Allgemeine Mikrobiologie, Institut für Mikrobiologie und Genetik, Georg-August-Universität Göttingen

PD Dr. Michael Hoppert, Allgemeine Mikrobiologie, Institut für Mikrobiologie und Genetik, Georg-August-Universität Göttingen 
Magic's just science that we don't understand yet. Arthur C. Clarke 



\section{ABSTRACT}

The $\mathrm{C}_{2}$-domain containing protein otoferlin is required for a late step in exocytosis from auditory inner hair cells and was hypothesized to act as a synaptic $\mathrm{Ca}^{2+}$-sensor. More roles for otoferlin in hair cell synaptic function have been proposed but have just begun being studied.

To address the questions for potential interaction partners of otoferlin or its overall structure several $\mathrm{C}_{2}$-domain containing protein fragments were expressed and purified from E. coli. The known ability of $\mathrm{C}_{2}$-domains to bind $\mathrm{Ca}^{2+}$ was tested using MicroScale Thermophoresis (MST) and revealed no indication for $\mathrm{Ca}^{2+}$-binding within the first three $\mathrm{C}_{2}$-domains of the protein while the otoferlin $\mathrm{C}_{2} \mathrm{~F}$-domain gave $\mathrm{a}$ distinct signal for $\mathrm{Ca}^{2+}$-binding. Additionally the roles of the present aspartate residues within the binding region were analyzed, revealing that mutations in these aspartate residues reduced $\mathrm{Ca}^{2+}$-binding to a similar degree. It seems that in all cases the structure is affected in a comparable way, leading to a 10 -fold increase in the $K_{\mathrm{d}}$. Further tested mutations known to affect hearing showed a similar decrease in $\mathrm{Ca}^{2+}$-binding. In order to identify phosphorylation sites in the protein two long otoferlin fragments were incubated with CaMKIIS which resulted in ten phosphorylation sites. $\mathrm{Ca}^{2+}$-binding studies revealed that the incorporated aspartate residues mimicking phosphorylation sites within the $\mathrm{C}_{2} \mathrm{C}$ - and $\mathrm{C}_{2} \mathrm{~F}$-domain of the protein affect the $\mathrm{Ca}^{2+}$-binding affinity in different ways. For the $\mathrm{C}_{2} \mathrm{C}$-domain an increase in the affinity to bind $\mathrm{Ca}^{2+}$ was found whereas the incorporated aspartate residues within the $\mathrm{C}_{2} \mathrm{~F}$-domain led to a ten-fold decreased affinity. Pull-down experiments were performed to get information about potential interaction partners of otoferlin which are assumed to play a role within the unknown synaptic mechanism of otoferlin action. Several of the identified interacting proteins are involved in endocytosis, exocytosis or trafficking processes. In ongoing studies these potential interaction partners are currently validated. Thermal shift experiments of the purified otoferlin $\mathrm{C}_{2}$-domains displayed that the melting temperature of a $\mathrm{C}_{2}$-domain can be increased either in presence of $\mathrm{Ca}^{2+}$ or neighboring $\mathrm{C}_{2}$-domains. This reveals that the $\mathrm{Ca}^{2+}$-binding in some $\mathrm{C}_{2}$-domains probably play an essential role in the function of the protein whereas complex forming of two or three $\mathrm{C}_{2}$-domains increases the stability of the whole protein. In addition the $\mathrm{C}_{2} \mathrm{ABC}$-I515T-mutant displayed a decrease in thermal stability in comparison to the wild type fragment, giving a molecular mechanism explaining how the I515T mutation leads to temperature sensitive deafness in humans.

For further analysis regarding the overall structure of the protein, crystals were obtained containing the first three $\mathrm{C}_{2}$-domains. Solving the structure is still an ongoing project, as it turned out that the structure cannot be solved by molecular replacement. 



\section{TABLE OF CONTENTS}

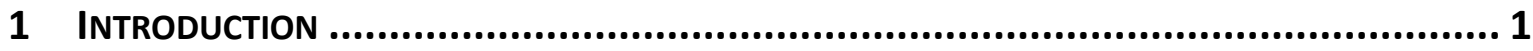

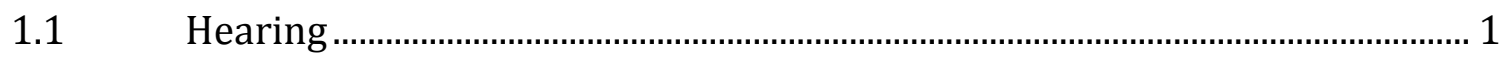

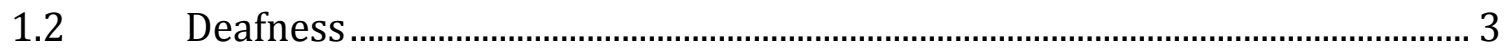

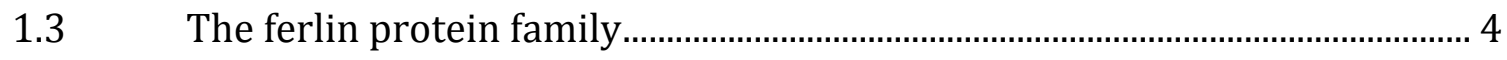

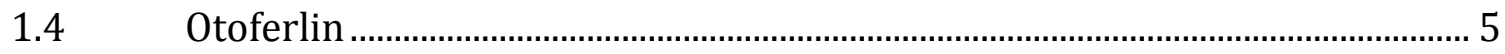

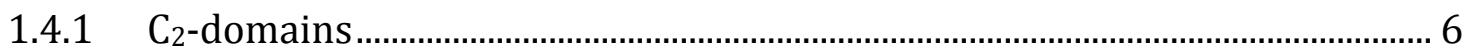

1.4.2 Structure of the otoferlin $\mathrm{C}_{2} \mathrm{~A}$-domain …………...........................................11

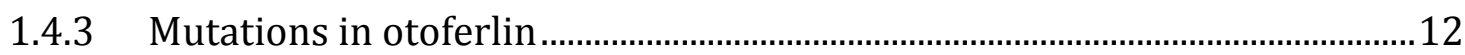

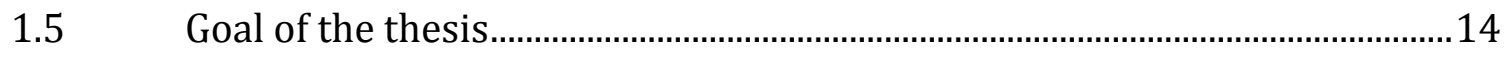

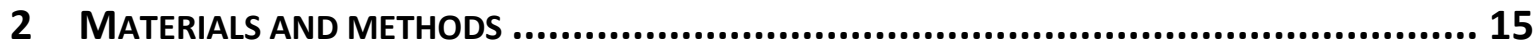

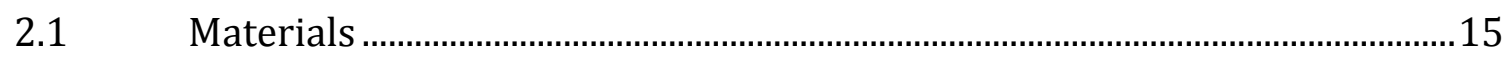

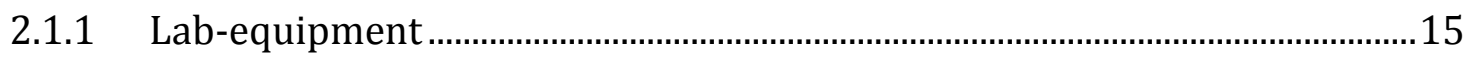

2.1.2 Chromatography systems, columns and accessories .....................................16

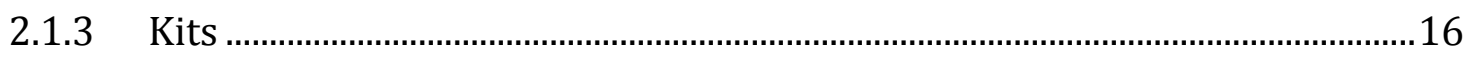

2.1.4 Size standards for proteins and DNA ……………………………………...16

2.1.5 Consumable material .....................................................................................17

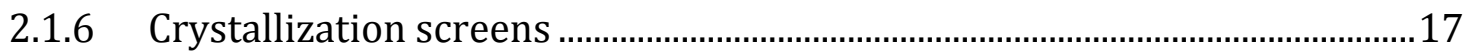

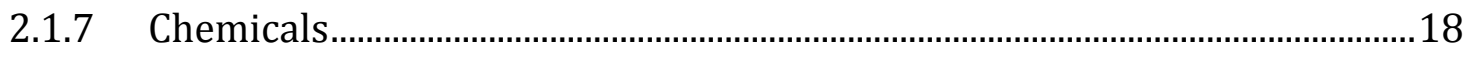

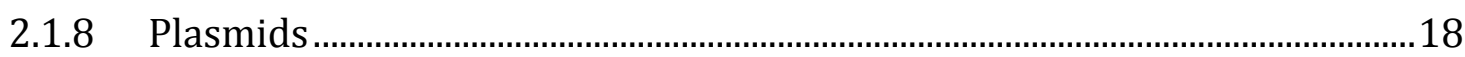

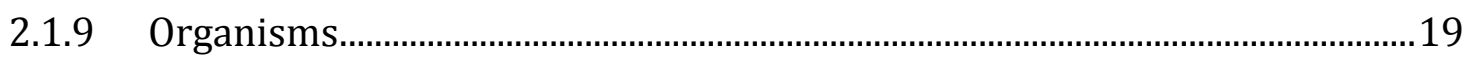

2.1.10 Enzymes and inhibitors ...........................................................................19

2.1.11 Antibiotics with working concentrations ……………………………….....19

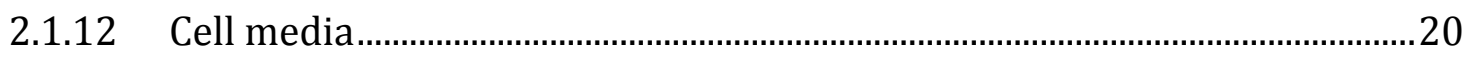

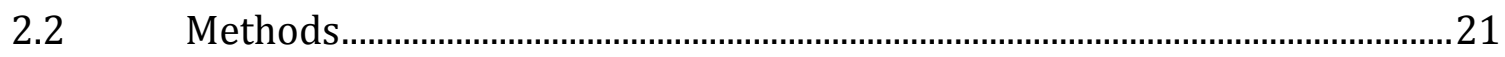

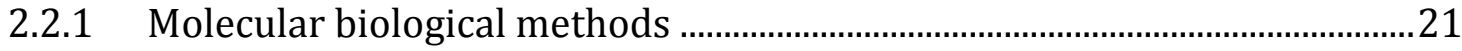

2.2.2 Proteinbiochemical methods ..........................................................................26

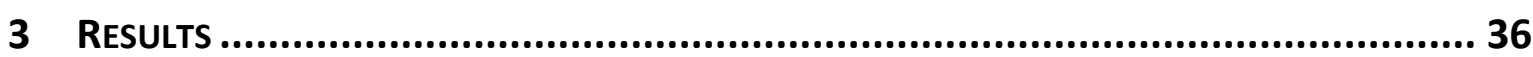

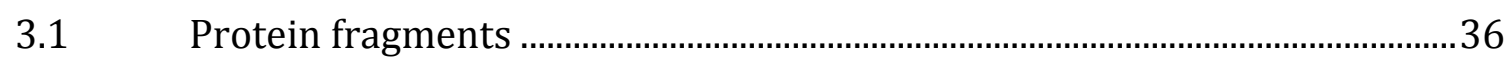

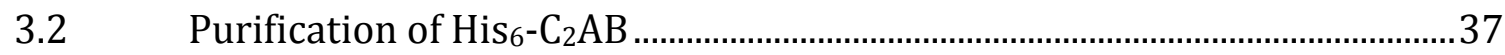

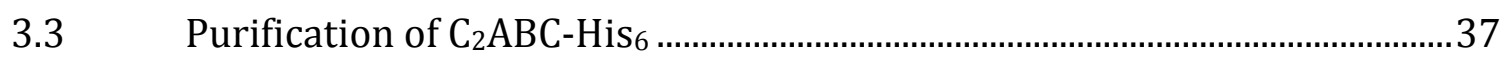

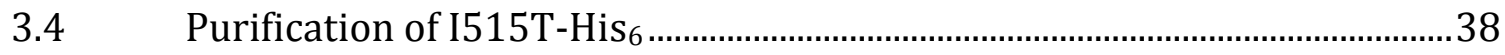

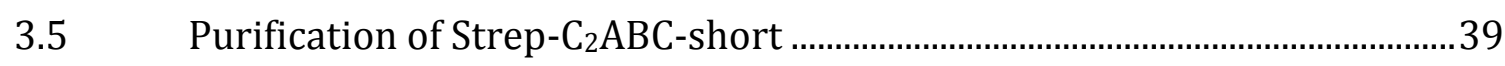

3.6 Purification of GST- $\mathrm{C}_{2} \mathrm{~B}$............................................................................. 40

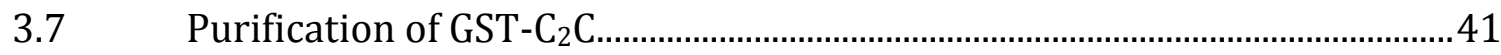

3.8 Purification of GST-C $\mathrm{C}_{2} \mathrm{C}-$ phos ...................................................................... 


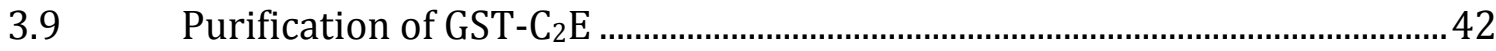

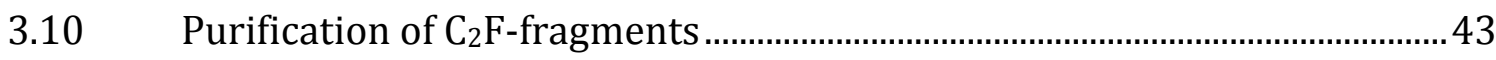

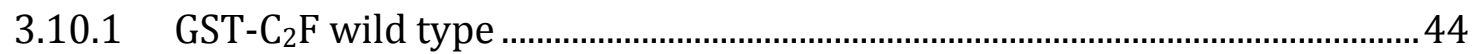

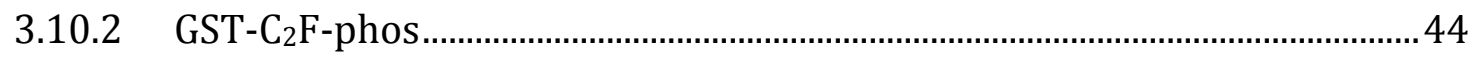

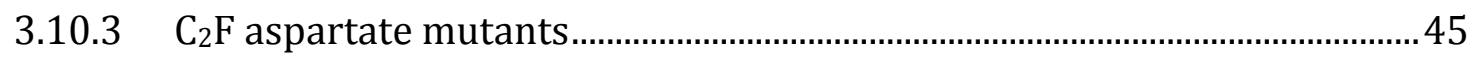

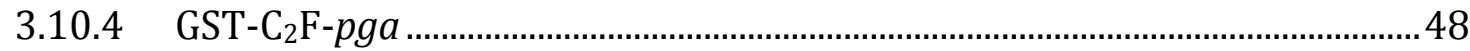

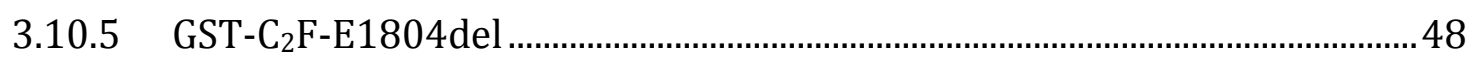

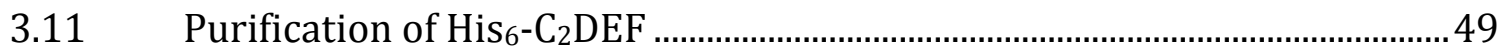

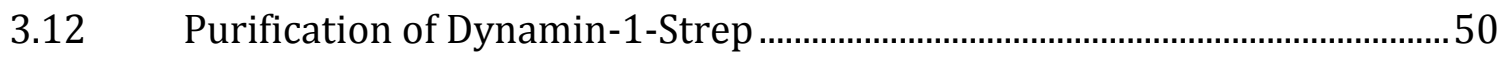

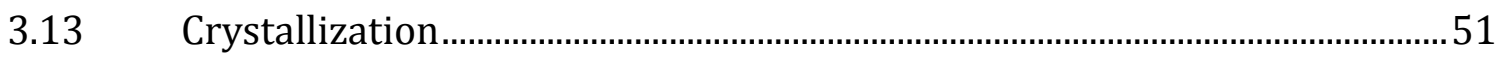

3.14 Pull-down assay to identify possible interaction partners ..............................53

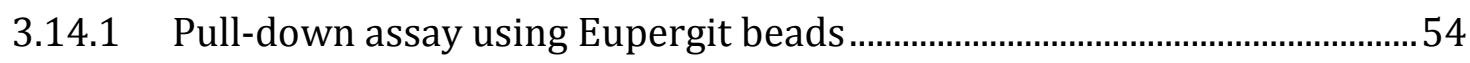

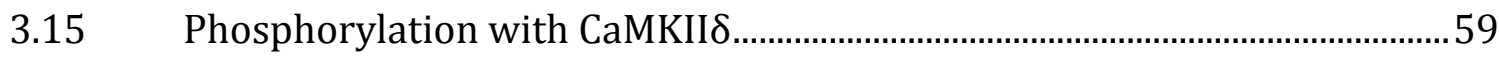

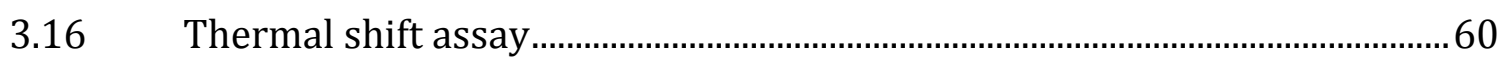

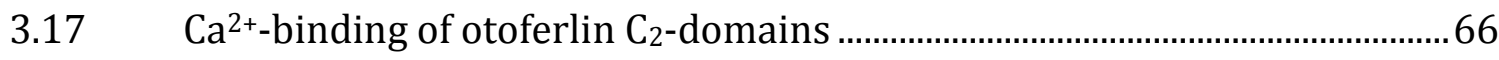

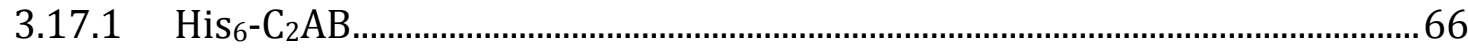

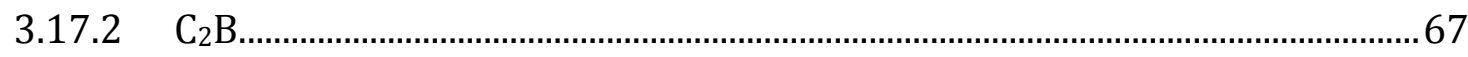

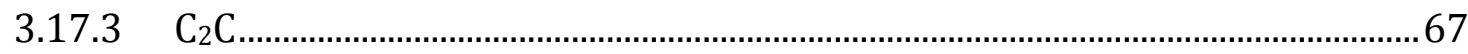

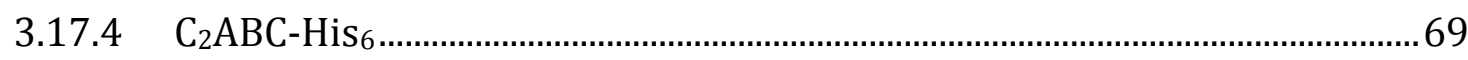

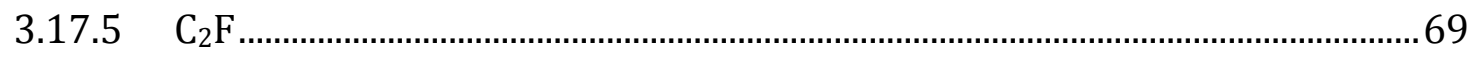

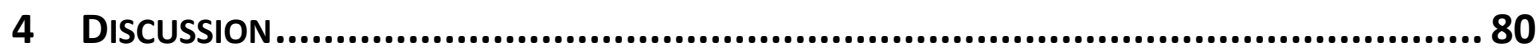

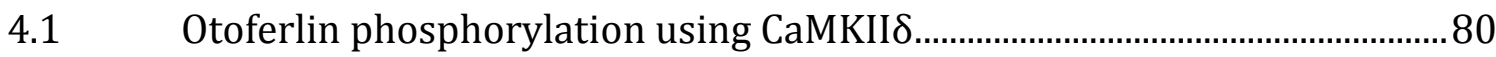

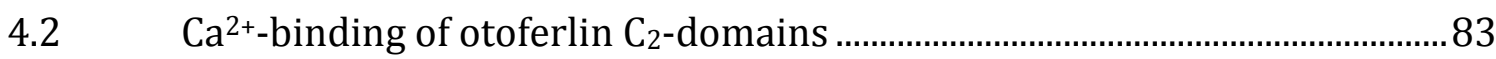

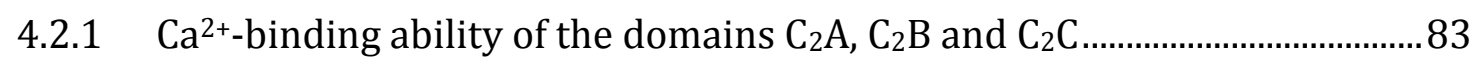

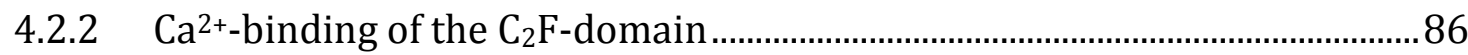

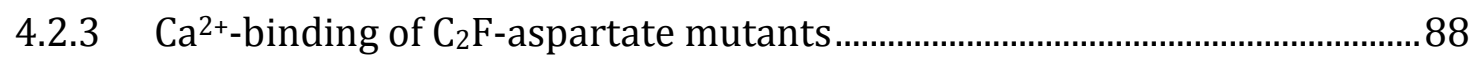

4.2.4 $\mathrm{Ca}^{2+}$-binding of $\mathrm{C}_{2} \mathrm{~F}$-mutants with mutations affecting hearing.....................89

4.3 Identification of possible interaction partners of otoferlin ............................93

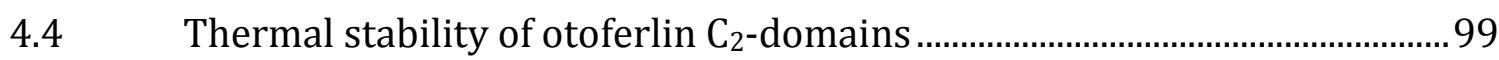

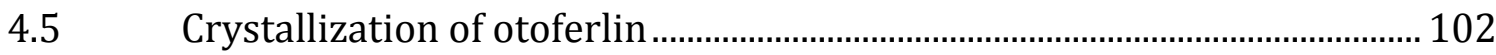

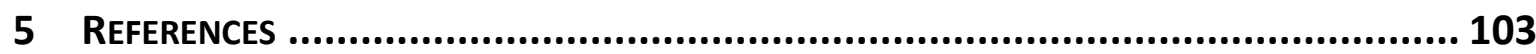

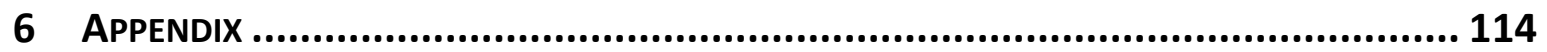

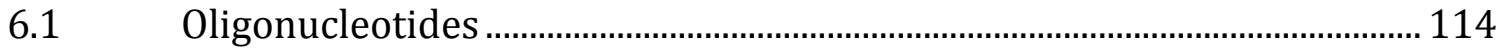

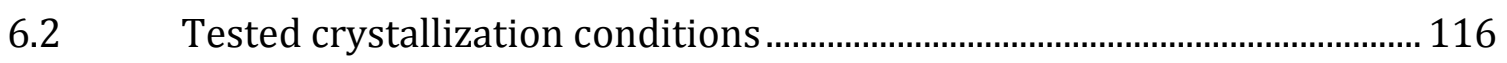

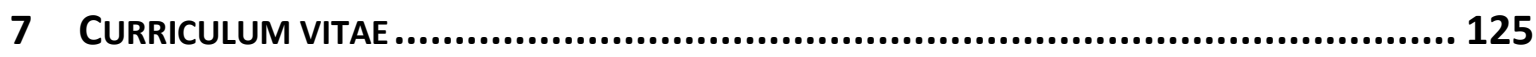




\section{TABLE OF FIGURES}

Figure 1.1-1

Figure 1.1-2

Figure 1.3-1

Figure 1.4-1

Figure 1.4-2

Figure 1.4-3

Figure 1.4-4

Figure 1.4-5

Figure 3.2-1

Figure 3.3-1

Figure 3.4-1

Figure 3.5-1

Figure 3.6-1

Figure 3.7-1

Figure 3.8-1

Figure 3.9-1

Figure 3.10-1

Figure 3.10-2

Figure 3.10-3

Figure 3.10-4

Figure 3.10-5

Figure 3.10-6

Figure 3.10-7

Figure 3.10-8

Figure 3.11-1

Figure 3.12-1

Figure 3.13-1

Figure 3.14-1

Figure 3.14-2

Figure 3.15-1

Figure 3.16-1

Figure 3.16-2

Figure 3.16-3

Figure 3.16-4

Anatomy of the mammalian cochlear 2

Model of the SNARE comples ................................................................ 3

Overview of ferlin domain topologies........................................................ 4

Scheme of otoferlin............................................................................... 5

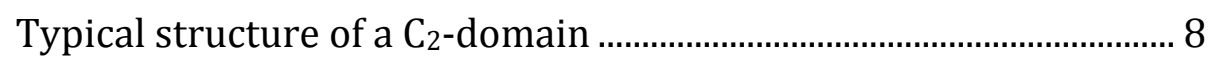

$\mathrm{Ca}^{2+}$-coordinating aspartate residues of synaptotagmin $1 \mathrm{C}_{2} \mathrm{~A} \ldots \ldots . . .9$

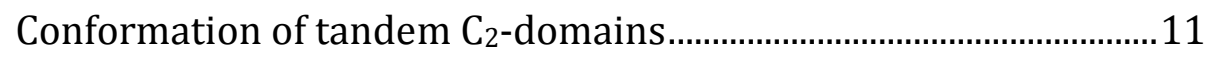

Structure of the $\mathrm{C}_{2} \mathrm{~A}$-domain of otoferlin ...........................................12

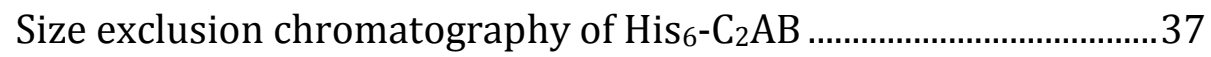

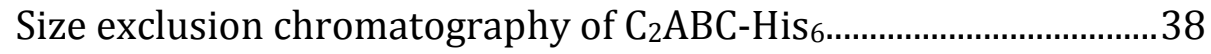

Size exclusion chromatography of I515T-His 6 …................................... 39

Strep-column chromatography of Strep-C $\mathrm{C}_{2} \mathrm{ABC}$-short .........................39

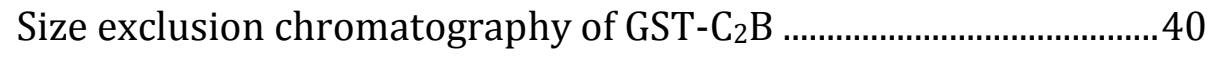

Size exclusion chromatography of GST- $\mathrm{C}_{2} \mathrm{C}$....................................... 41

Size exclusion chromatography of GST- $\mathrm{C}_{2} \mathrm{C}$-phos ..............................42

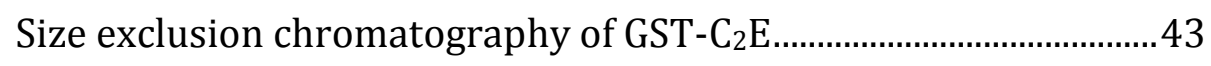

Size exclusion chromatography of GST- $\mathrm{C}_{2} \mathrm{~F}$......................................... 44

Size exclusion chromatography of GST-C $\mathrm{C}_{2} \mathrm{~F}$-phos ................................ 44

Size exclusion chromatography of GST-C2 F-D1N .................................46

Size exclusion chromatography of GST-C 2 F-D2,3N............................46

Size exclusion chromatography of GST-C ${ }_{2} \mathrm{~F}-\mathrm{D} 1,2,3 \mathrm{~N}$.......................... 47

Size exclusion chromatography of GST-C 2 F-D 4 N ................................ 47

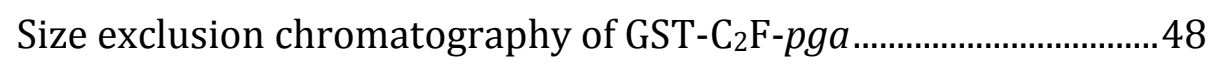

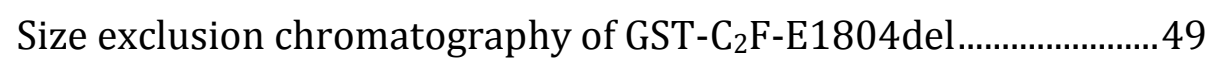

His-column chromatography of $\mathrm{His}_{6}-\mathrm{C}_{2} \mathrm{DEF}$.......................................50

Strep-column chromatography of dynamin-1-Strep...........................50

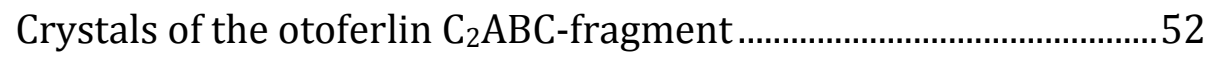

Pull-down assay with dynamin 1 and otoferlin- $\mathrm{C}_{2} \mathrm{ABC} \ldots \ldots \ldots \ldots \ldots \ldots \ldots . . . . . .54$

Gradient control gel of the Eupergit pull-down ....................................55

Phosphorylation control gel of otoferlin for mass analysis..............59

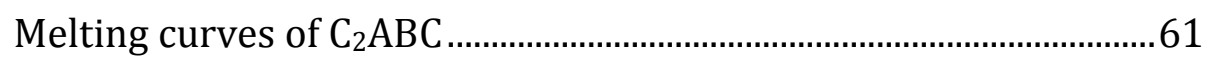

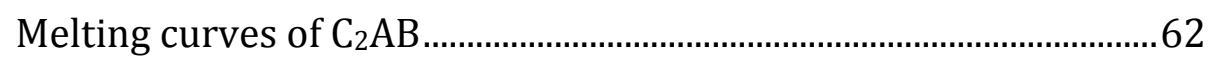

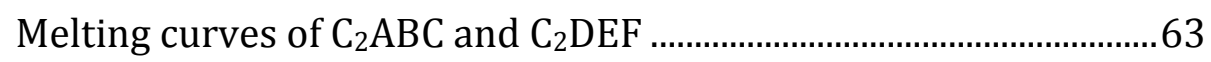

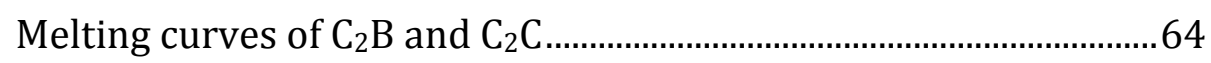


Figure 3.16-5

Figure 3.17-1

Figure 3.17-2

Figure 3.17-3

Figure 3.17-4

Figure 3.17-5

Figure 3.17-6

Figure 3.17-7

Figure 3.17-8

Figure 3.17-9

Figure 3.17-10

Figure 3.17-11

Figure 3.17-12

Figure 3.17-13

Figure 3.17-14

Figure 3.17-15

Figure 3.17-16

Figure 3.17-17

Figure 3.17-18

Figure 4.1-1

Figure 4.2-1

Figure 4.2-2

Figure 4.2-3

Figure 4.3-1
Melting curves of $\mathrm{C}_{2} \mathrm{ABC}$ and $\mathrm{I} 515 \mathrm{~T}$. .64

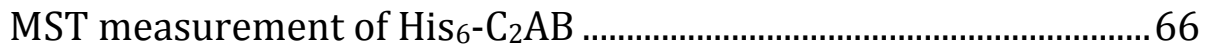

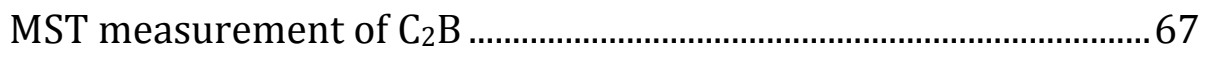

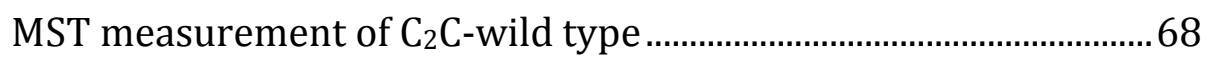

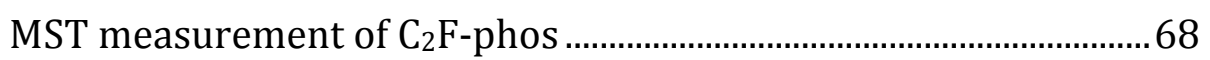

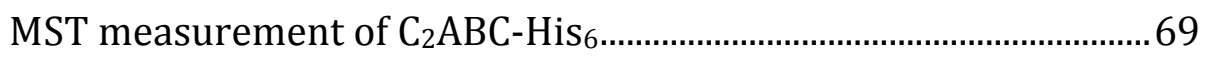

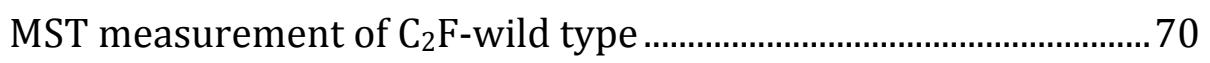

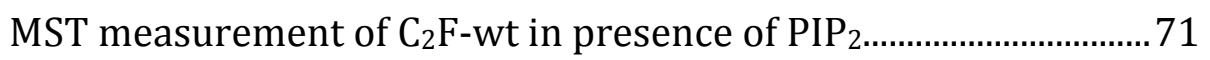

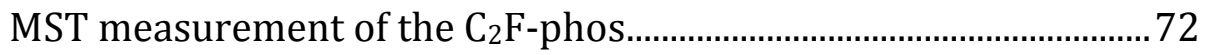

Comparison of $\mathrm{C}_{2} \mathrm{~F}$-wild type and $\mathrm{C}_{2} \mathrm{~F}$-phos MST curves................... 72

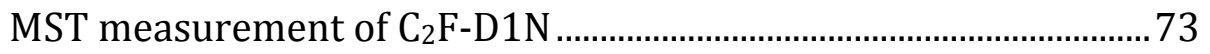

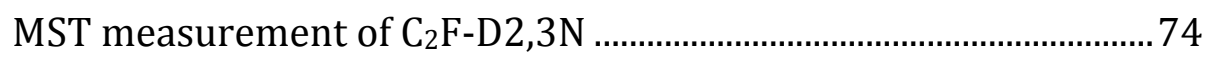

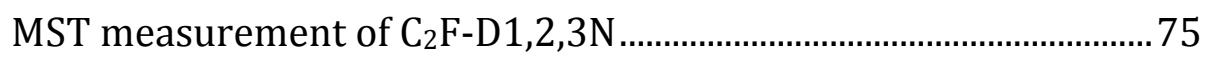

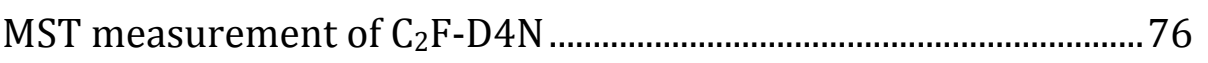

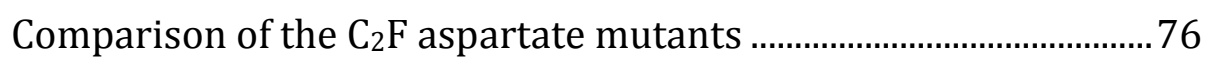

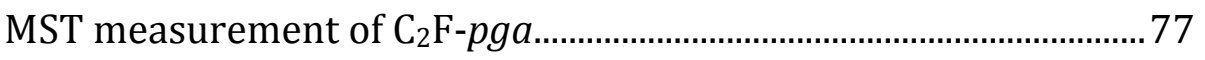

Comparison of the pga-mutant and the $\mathrm{C}_{2} \mathrm{~F}-\mathrm{wt}$.................................... 77

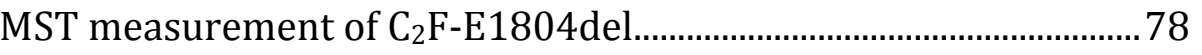

Comparison of the $\mathrm{C}_{2} \mathrm{~F}$ wt and the E1804del-mutant.......................... 79

Comparison of the found phosphorylation sites ................................. 81

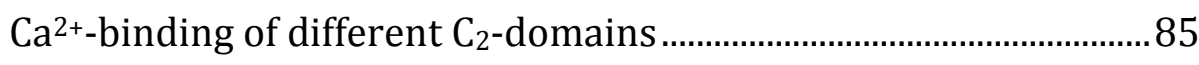

Topology model of the $\mathrm{C}_{2} \mathrm{~F}$-domain of otoferlin.................................87

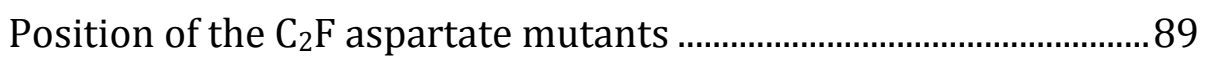

Overview of interaction partners of otoferlin....................................... 93 


\section{LIST OF TABLES}

Table 1.3-1 Phenotypes of ferlin disease and animal models ....................................... 5

Table 1.4-1 Conservation of putative $\mathrm{Ca}^{2+}$-binding amino acids................................... 9

Table 2.1-1 Plasmids used for recombinant protein expression 1 ..............................18

Table 2.1-2 Plasmids used for recombinant protein expression 2 .............................18

Table 2.1-3 Mutated otoferlin fragments for recombinant expression.....................19

Table 3.1-1 List of purified Otoferlin fragments...................................................................

Table 3.14-1 Possible interaction partners of otoferlin ................................................56

Table 3.14-2 Further proteins identified by mass spectrometry..............................57

Table 3.14-3 Proteins of the cellular respiration process............................................58

Table 3.15-1 Sites in otoferlin phosphorylated by CaMKII $\delta$.......................................60

Table 3.16-1 Melting temperatures of $\mathrm{C}_{2} \mathrm{ABC}$............................................................61

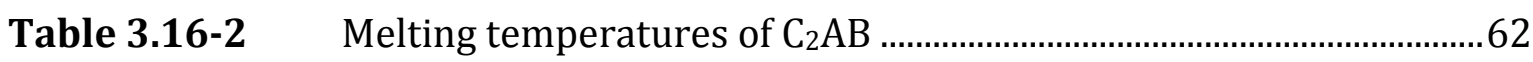

Table 3.16-3 Melting temperatures of $\mathrm{C}_{2} \mathrm{ABC}$ and $\mathrm{C}_{2} \mathrm{DEF}$........................................63

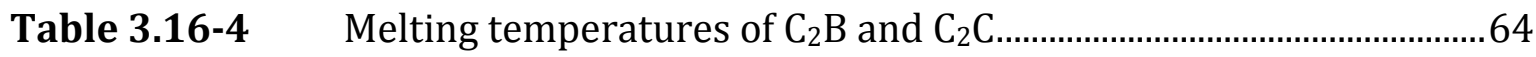

Table 3.16-5 Melting temperatures of $\mathrm{C}_{2} \mathrm{ABC}$ and I515T .......................................64

Table 4.2-1 $\quad K_{\mathrm{d}}$ values of the $\mathrm{C}_{2} \mathrm{~F}$-mutants.....................................................................

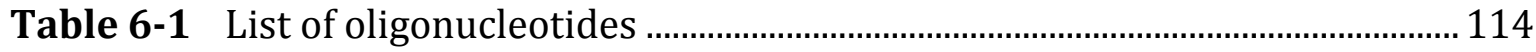

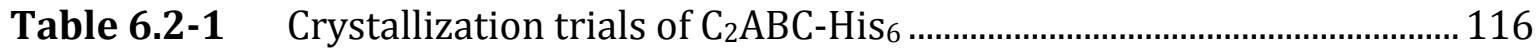

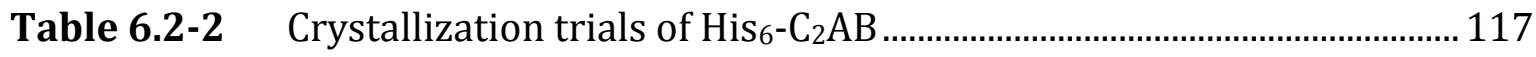

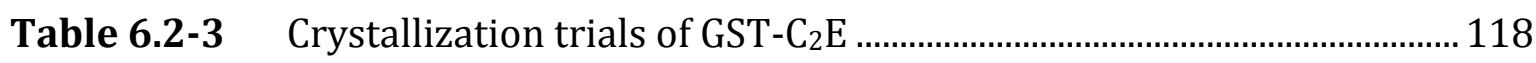

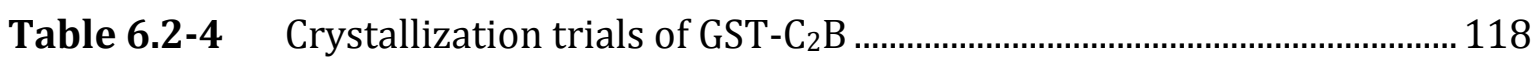

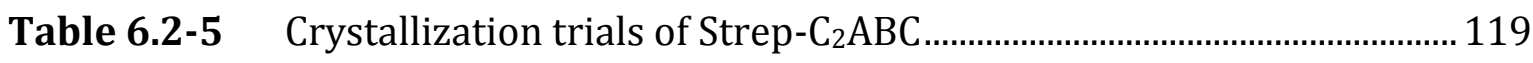

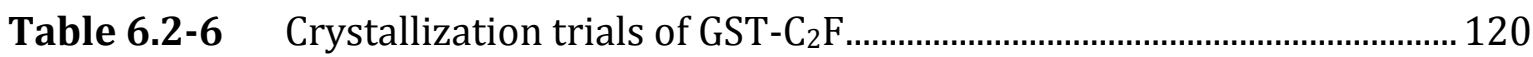

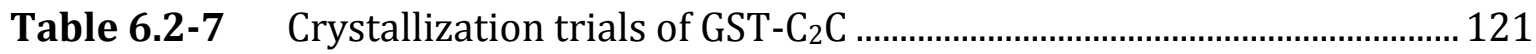

Table 6.2-8 Crystallization trials of GST-C 2 F-phos ……................................................. 121

Table 6.2-9 Crystallization trials of GST-C 2 F-D1N ...................................................... 122

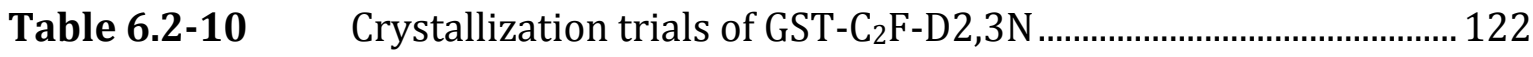

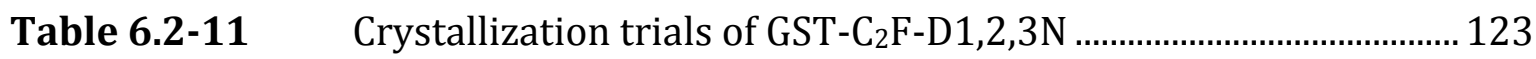

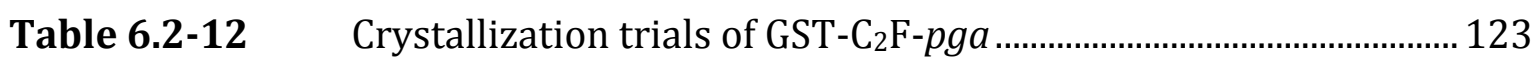

Table 6.2-13 Crystallization trials of GST-C ${ }_{2}$ F-E1804del ....................................... 124 



\section{AbBreviations}

$$
2 \mathrm{xYT}
$$

aa

ALP

AP2

APS

BAR-domain

BoNT

CaMKIII

CBD

CD

$\mathrm{COM}$

$\mathrm{CPLA}_{2}$

CV

$\mathrm{ddH}_{2} \mathrm{O}$

DDM

DFNA

DFNB

DMSO

dNTP

DTT

Dyn

Dysf

E. coli

Esyt

GSH

GST

HEPES
2xYT medium (Yeast-Tryptone)

Amino acid

Aprotinin, Leupeptin Hemisulfate, Pepstatin A

AP2 adaptor complex

Ammonium persulfate

Bin-Amphiphysin-Rvs-domain

Botulinum neurotoxin

$\mathrm{Ca}^{2+} /$ calmodulin dependent serine/threonine kinase 2 delta

Calmodulin binding domain

Circular dichroism

Complexiolyte

Cytosolic phospholipase A

Column volume

Double distilled water

Dodecyl maltoside

Deafness type A (dominant)

Deafness type B (recessive)

Dimethyl sulfoxide

Deoxynucleotide-5'-triphosphate

Dithiothreitol

Dynamin

Dysferlin

Escherichia coli

Extendet synaptotagmin

$\gamma$-L-Glutamyl-L-cysteinylglycin (Glutathione)

Glutathione-S-transferase

4-(2-hydroxyethyl)-1-piperazineethanesulfonic acid 


\begin{tabular}{|c|c|}
\hline His6-tag $_{6}$ & Tag containing six histidines in sequence \\
\hline IHC & Inner hair cell \\
\hline IPTG & Isopropyl $\beta$-D-1-thiogalactopyranoside \\
\hline ITC & Isothermal Titration Calometry \\
\hline $\mathrm{KCl}$ & Potassium chloride \\
\hline$K_{\mathrm{D}}$ & Dissociation Constant \\
\hline $\mathrm{kDa}$ & Kilo Dalton \\
\hline $\mathrm{LS}$ & Lauryl sarcosine \\
\hline M. musculus & Mus musculus \\
\hline $\mathrm{mAu}$ & Milli absorption unit \\
\hline MST & MicroScale Thermophoresis \\
\hline MWCO & Molecular weight cut off \\
\hline NMR & Nuclear magnetic resonance \\
\hline OD & Optical density \\
\hline OGP & Octyl glucopyranoside \\
\hline $\mathrm{OHC}$ & Outer hair cell \\
\hline OPA1 & Dynamin-like $120 \mathrm{kDa}$ protein \\
\hline PAGE & Polyacrylamide gel electrophoresis \\
\hline PCR & Polymerase chain reaction \\
\hline PDZ-domain & Post-synaptic density protein domain \\
\hline PEG & Polyethyleneglycol \\
\hline$P g a$ & pachanga \\
\hline PH-domain & Pleckstrin homology domain \\
\hline $\mathrm{PIP}_{2}$ & Phosphatidylinositol 4,5-bisphosphate \\
\hline PKC & Protein kinase $\mathrm{C}$ \\
\hline PLC- $\delta 1$ & Phospholipase C- $\delta 1$ \\
\hline PMSF & Phenylmethanesulfonylfluoride \\
\hline PRD & Proline-rich domain \\
\hline PTB-domain & Phosphotyrosine binding domain \\
\hline $\mathrm{Rab}$ & Rabphilin \\
\hline $\operatorname{Rcf}$ & Relative centrifugal force \\
\hline
\end{tabular}


Rpm Revolutions per minute

SDS

Sodium dodecyl sulfate

SH2-domain

Src homology 2 domain

SH3-domain

Src homology 3 domain

SNARE

soluble N-ethylmaleimide-sensitive factor attachment protein receptor

Syt 1

Synaptotagmin 1

TAE-buffer

Tris-acetate-EDTA buffer

TEMED

Tetramethylethylenediamine

$\mathrm{v} / \mathrm{v}$

Volume per volume

$\mathrm{w} / \mathrm{v}$

Weight per volume

wt

Wild type 



\section{INTRODUCTION}

\subsection{Hearing}

The ear is subdivided into three parts: the air-filled external and middle ear and the fluid-filled inner ear. Within the inner ear is the vestibular system, responsible for the sense of balance, and the cochlea which is the location of the organ of hearing. The cochlea is composed of three fluid-filled canals, namely scala vestibuli, scala tympani and scala media, which spiral up together in approximately two and a half turns in humans. The scala tympani and scala vestibuli are filled with perilymph whereas the scala media is filled with endolymph which contains a high $\mathrm{K}^{+}$-concentration (150 mM). Scala media and scala tympani are separated by the basilar membrane on which the organ of Corti is located. This organ amplifies the mechanical input signal evoked by sound and transduces it into an electrical output signal which is then transferred to the brain.

The organ of Corti comprises two sorts of hair cells, the outer hair cells (OHC) which are organized in three rows and the inner hair (IHC) cells forming only one row, both types running the length of the cochlea. Stereocilia are long extensions located on the apical part of both types of hair cells. Outer hair cell stereocilia are in direct contact with the overlaying tectorial membrane whereas the inner hair cells are not.

During the hearing process sound waves enter the outer ear and travel through the external auditory canal until they reach the tympanic membrane, causing the membrane and the attached chain of auditory ossicles to vibrate. The motion of the stapes against the oval window sets up waves in the fluid of the cochlea. Such a wave leads to oscillations of the basilar and tectorial membrane. Resulting shear movements cause the deflection of the OHC stereocilia and mechanoelectrical transduction channels in the tips of the stereocilia of the hair cells are opened. Through potassium $\left(\mathrm{K}^{+}\right)$influx the hair cell is depolarized and the OHCs undergo an oscillation-based alternation of length. These amplified oscillations are transferred back to the basilar and tectorial membrane and also to the fluid-filled interspace between the OHCs and the tectorial membrane. Movement in this endolymphatic fluid causes the depolarisation of the IHC stereocilia. The deflection of the stereocilia results like in the case of the OHCs stereocilia to transduction channel opening. $\mathrm{K}^{+}$ enters and depolarizes the cell and leads to the opening of voltage-dependent $\mathrm{Ca}^{2+}$-channels. The influx of $\mathrm{Ca}^{2+}$ results in $\mathrm{Ca}^{2+}$-dependent exocytosis of 
glutamate-filled vesicles at the ribbon synapses of the IHCs and the released glutamate binds to postsynaptic glutamate receptors. At this point the sound signal is transferred to the spiral ganglion neuron and forwarded to the brain stem [1-5].

A

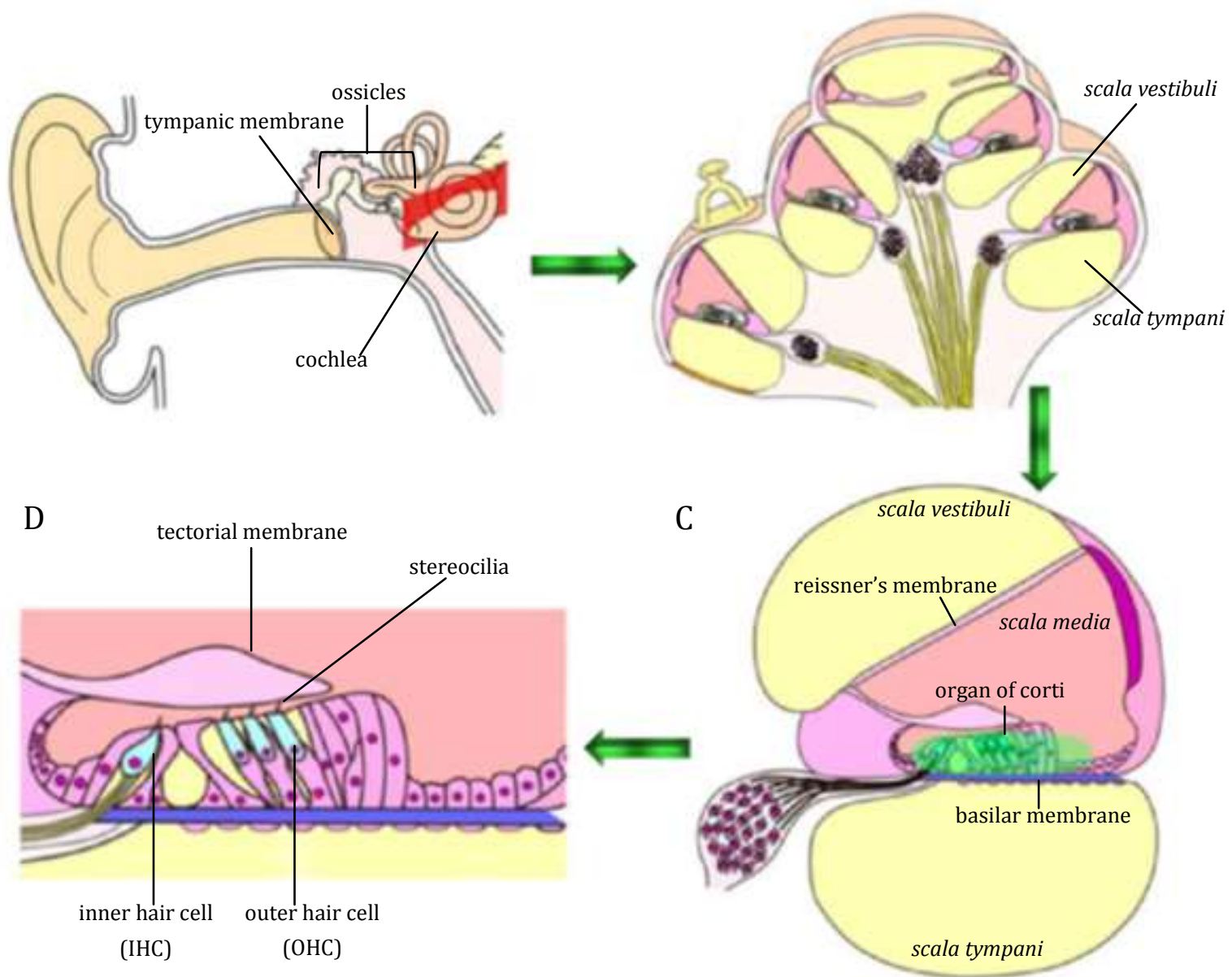

Figure 1.1-1 Anatomy of the mammalian cochlear, modified from Inaoka et al., 2011.

A Overview of the ear. Sound waves are transmitted via the tympanic membrane and the attached chain of ossicles to the cochlea.

B Cross section through the cochlea.

C Cross section of one cochlear duct with its three fluid filled channels and the organ of Corti located on the basilar membrane.

D Enlarged picture of the organ of Corti containing the inner and outer hair cells.

In conventional synapses vesicle exocytosis is known to be mediated by the soluble $\mathrm{N}$-ethylmaleimide-sensitive factor attachment protein receptor (SNARE) complex and is triggered by $\mathrm{Ca}^{2+}$-binding to synaptotagmin 1 (Syt 1 ) or Syt 2 [6,7]. The proteins synaptobrevin, syntaxin 1 and the 25-kilo Dalton (kDa) synaptosome associated protein (SNAP-25) form the SNARE complex in a parallel four-helix bundle structure $[8,9]$. In biochemical and functional studies, synaptotagmin 1 and 2 were reported as the primary $\mathrm{Ca}^{2+}$ sensors for exocytosis at neuronal synapses. In case of the mature inner hair cells neither Syt 1 nor 2 were found to be present. Therefore, another 
$\mathrm{Ca}^{2+}$-trigger was proposed [10-13]. Based on experiments which show that otoferlin $\mathrm{C}_{2}$-domains stimulate membrane fusion in a $\mathrm{Ca}^{2+}$-dependent manner as well as the binding to SNAREs and $\mathrm{Ca}^{2+}$-channels otoferlin was proposed to be the hair cell specific $\mathrm{Ca}^{2+}$-sensor for exocytosis $[11,14,15]$.

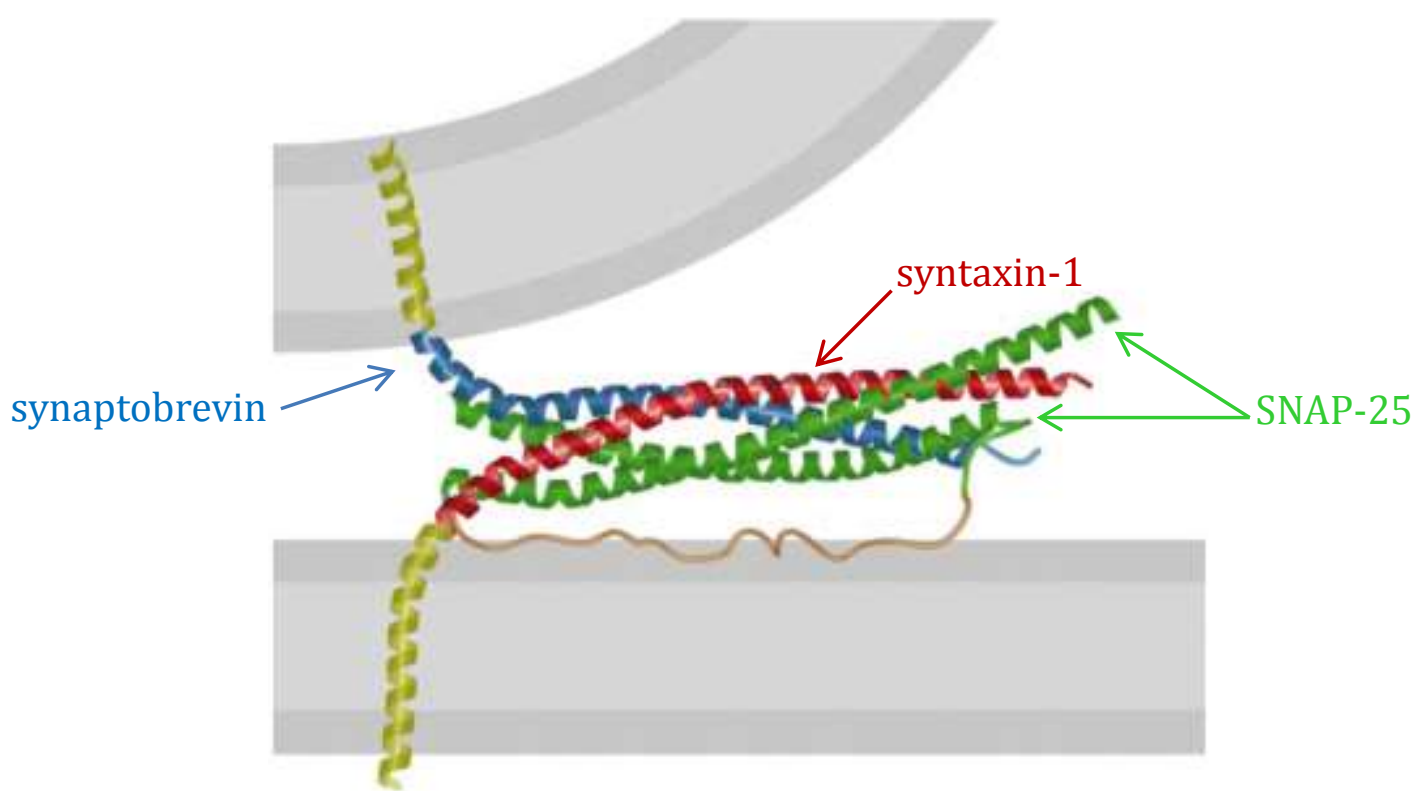

Figure 1.1-2 Model of the SNARE complex in all neuronal synapses, modified from Sutton et al., 1998.

\subsection{Deafness}

The most prevalent sensory deficit is hearing impairment. One in 1000 children is affected by severe or profound hearing loss at birth and the same number become deaf before adulthood [16]. About $50 \%$ of hearing losses have genetic reasons, which can be divided into two main categories. $10 \%$ of the hearing impaired people are affected by syndromic hearing impairment, which is accompanied by over 500 different disorders [16,17]. The remaining $90 \%$ are affected by a non-syndromic form of hearing impairment, which is not associated with other symptoms. For this type of deafness different types of inheritance are known, like the autosomal dominant deafness (DFNA), autosomal recessive deafness (DFNB) and an x-linked deafness (DFNX). About $80 \%$ of the affected people suffer from DFNB and 23 genes can be linked to it. In case of DFNB9 the affected protein was identified as otoferlin, which belongs to the ferlin family [18]. Mutations within the protein lead to moderate or profound hearing loss caused by an incorrectly transmitted auditory signal to the brain $[17,19]$. 


\subsection{The ferlin protein family}

Otoferlin is a member of the ferlin protein family comprising $200-240 \mathrm{kDa}$ proteins which are assumed to play a role in membrane trafficking and vesicle fusion. In addition to the six proteins in Table 1.3-1 more ferlin proteins (FerIL4, Fer1L5, Fer1L6) are known but their function is still uncharacterized. All family members contain multiple $\mathrm{C}_{2}$-domains, a highly conserved C-terminal $\mathrm{C}_{2} \mathrm{~B}-\mathrm{FerI}-\mathrm{C}_{2} \mathrm{C}$ motif and a single C-terminal transmembrane domain. The sequence homology is high among ferlin $\mathrm{C}_{2}$-domains but low in comparison to non-ferlin $\mathrm{C}_{2}$-domains [20]. Among the ferlin family the domains $\mathrm{C}_{2} \mathrm{E}$ and $\mathrm{C}_{2} \mathrm{~F}$ share high similarities [20,21].

Due to the absence or presence of the domains DysF and FerA, the proteins can be subdivided into two types (Figure 1.3-1). In type I ferlins, DysF and FerA are present whereas in type II both domains are lacking. FerI, FerA and FerB are ferlin-specific motifs of 60-70 residues the function of which is still unknown. Similar to otoferlin, missense mutations occur also in other ferlin proteins and result in different diseases. Misfire and Fer-1 mutations for example cause infertility in Drosophila and C. elegans, whereas the deficiency of dysferlin results in muscular dystrophy in humans [20,22].

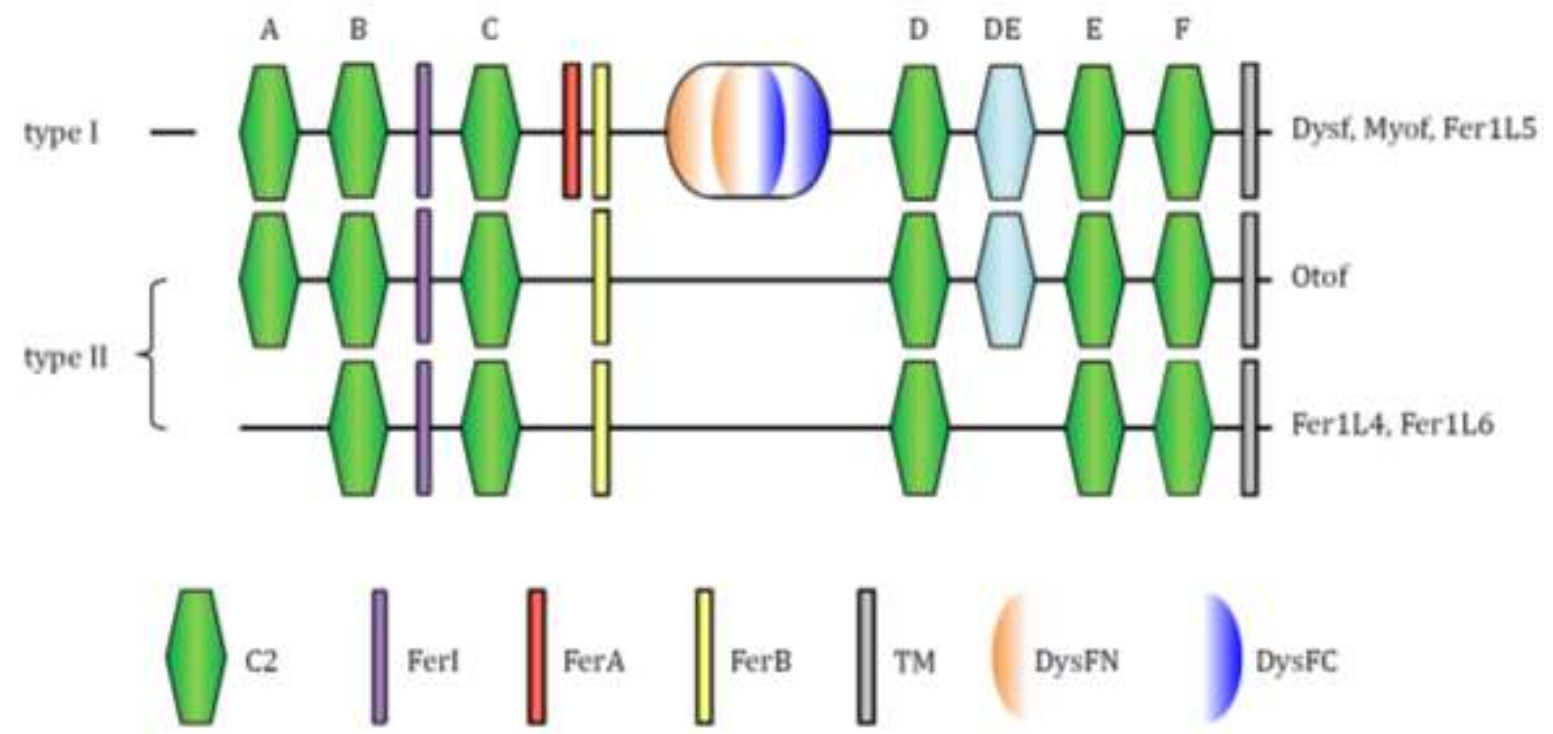

Figure 1.3-1 Overview of ferlin domain topologies, modified from Lek et al., 2012. Ferlins of the type I form contain the additional FerA and DysF domains which are missing in type II ferlins. Conserved $\mathrm{C}_{2}$-domains are shown in green, FerI domains in purple, FerB domains in yellow and the transmembrane domains in grey. The optional domains FerA and DysF are shown in red and orange/blue. Variable present $\mathrm{C}_{2}$-domains are shown in light blue. 
Table 1.3-1 Phenotypes of ferlin disease and animal models, modified from Lek et al., 2010.

\begin{tabular}{lll} 
protein & model & phenotype \\
\hline Misfire & Drosophila & Infertility \\
Fer-1 & C. elegans & Infertility \\
Sea urchin ferlin & Sea urchin & Defective exocytosis \\
Dysfelin & Mouse & - Mild progressive muscle wasting \\
& & - Severe progressive myopathy \\
& Human & Muscular dystrophy \\
Otoferlin & Mouse & Deafness \\
& Human & Deafness \\
Myoferlin & Mouse & Impaired myofibre growth and regeneration \\
\hline
\end{tabular}

\subsection{Otoferlin}

Otoferlin is a $220 \mathrm{kDa}$ protein, containing a C-terminal transmembrane domain, a coiled-coil domain, a FerB-domain in the middle and at least six $\mathrm{C}_{2}$-domains (Figure 1.4-1). The $\mathrm{C}_{2}$-domains are named from $\mathrm{A}$ to $\mathrm{F}$ starting at the $\mathrm{N}$-terminus. The seventh $\mathrm{C}_{2}$-domain is predicted to exist between the $\mathrm{C}_{2} \mathrm{D}$ - and $\mathrm{C}_{2} \mathrm{E}$-domain of the protein and thus named $\mathrm{C}_{2}$ de, however, its existence could not be proven so far $[21,23,24]$.

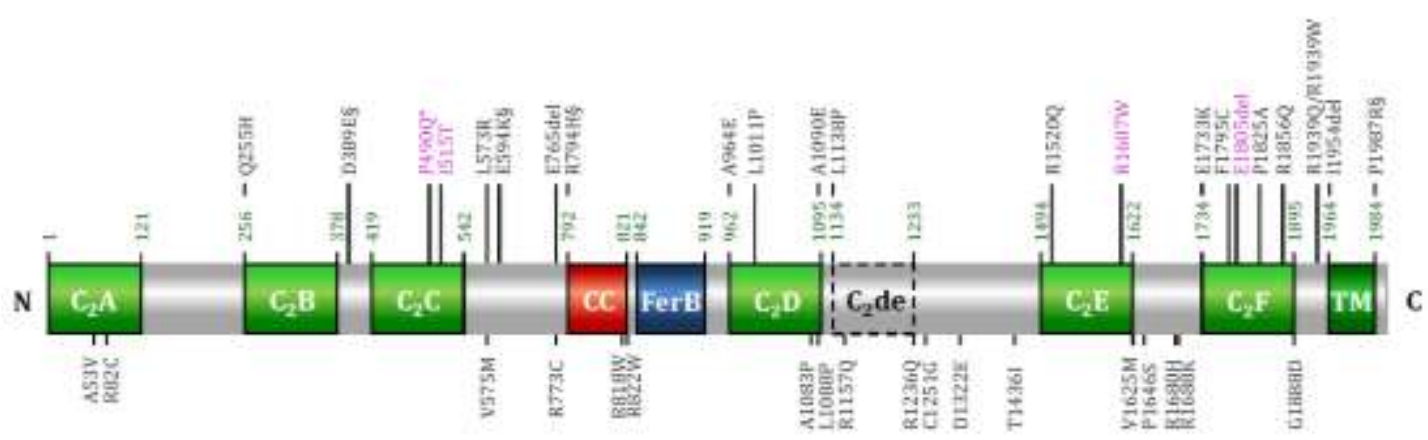

Figure 1.4-1 Scheme of otoferlin with its different domains and the known single amino acid mutations. The six confirmed $\mathrm{C}_{2}$-domains are shown in green and the predicted $\mathrm{C}_{2}$ de is marked with a dotted line. The upper mutations are pathogenic missense mutations and in-frame deletions. In the lower part sequence variants are shown. The mutations in violet result in temperature-sensitive hearing loss. Modified from Pangršič et al., 2012.

Additionally, a predicted FerI-domain was published [25] which comprises the amino acids 354 to 425 in human otoferlin. This entails that the last $\beta$-strand of the $\mathrm{C}_{2} \mathrm{~B}$-domain and the first one of the $\mathrm{C}_{2} \mathrm{C}$-domains are also parts of the FerI-domain. 
Otoferlin is found in the brain, the vestibular system and the cochlea where it is localized in the cytoplasm and at the presynaptic membrane of the inner hair cells [22].

Recent studies showed that the neuronal SNAREs are not required for exocytosis in inner hair cells $[10,26,27]$. The exocytosis in IHCs was examined in the presence of different botulinum neurotoxin serotypes (BoNT) which are known to cleave SNAP-25, syntaxin and synaptobrevin. No significant changes in IHC exocytosis were detected between samples containing BoNTs and BoNT-free samples. Single-IHC PCR experiments showed that SNARE proteins are expressed in the organ of Corti but in lower concentrations than otoferlin. The analysis of IHCs from synaptobrevin-2 and -3 double knockout mice showed normal/unaltered exocytosis. These findings lead to the assumption that SNARE proteins are present in the IHCs in a low amount, but neither the cleavage nor the knockout of SNARE proteins has significant effects on IHC exocytosis. It was concluded that exocytosis from IHCs does not require neuronal SNARE proteins [26].

The precise function of otoferlin is still unknown, however, next to the suggested role as a $\mathrm{Ca}^{2+}$-sensor some other functions were proposed $[11,14,15]$. Roux et al. showed that in the absence of otoferlin the vesicle fusion nearly vanished. This leads to the assumption that otoferlin is essential in a late step of exocytosis [11]. Pangršič et al. published a role for otoferlin in sustained exocytosis based on studies of the pachanga mutation in mice (pga). Pachanga is a point mutation (D1767G) found in a random mutagenesis screen and affects an amino acid in the $\mathrm{C}_{2} \mathrm{~F}$-domain of the protein. The exocytosis was measured using patch-clamp electrophysiology. The cells were depolarized to the potential where maximum $\mathrm{Ca}^{2+}$-currents were elicited. The sustained exocytosis evoked by long term depolarization steps ( $>10 \mathrm{~ms}$ ) was reduced compared to the wild type. One explanation for this finding could be a defect in vesicle replenishment. In a further electron microscopic experiment the cell was depolarized with high $\mathrm{K}^{+}$-concentrations for $15 \mathrm{~min}$. After this procedure the detected number of vesicles at the active zone in pga and wild type was similar. This suggested that the pga mutation has no influence on the docking process of vesicles, thus it was concluded that priming is impaired due to this mutation in otoferlin [28].

\subsection{1 $\mathrm{C}_{2}$-domains}

$\mathrm{C}_{2}$-domains are part of many proteins; the first $\mathrm{C}_{2}$-domain was found in the $\mathrm{Ca}^{2+}$-dependent isoform of protein kinase C (PKC)[29,30]. Up to now, approximately $149 \mathrm{C}_{2}$-domain sequences of human proteins are listed in data bases [31]. These 
proteins contain two to seven $\mathrm{C}_{2}$-domains [22] which are involved in membrane trafficking, signal transduction, protein-protein interaction or $\mathrm{Ca}^{2+}$-mediated phospholipid binding $[29,32]$. They are also found in processes like generation of lipid-second messengers, activation of GTPases or control of protein phosphorylation [29].

In general, $\mathrm{C}_{2}$-domains are capable to interact with several ligands. Besides $\mathrm{Ca}^{2+}$ and phospholipid binding, $\mathrm{C}_{2}$-domains also interact with src homology 2 (SH2), phosphotyrosine binding domains (PTB domains), pleckstrin homology domains (PH domains) of phosphatidylinositol phosphatases, proline-rich sequences of src homology 3 (SH3) and WW domains, and C-terminal sequences of post-synaptic density protein domains (PDZ) [32].

$\mathrm{C}_{2}$-domains consist of approximately 130 residues in length [29] and they are formed as an eight-stranded antiparallel $\beta$-sandwich, which can adopt two structural arrangements, type I and II (Figure 1.4-2). The types are related by a circular permutation which leads to a slightly different connectivity between the $\beta$-strands $[22,29,31]$. Theoretically, type I can be transformed into type II by fusion of the type I $\mathrm{N}$-terminal $\beta$-strand to the C-terminus [29]. One reason for the occurrence of two different topologies could be the influence of the relative orientation of a $\mathrm{C}_{2}$-domain with respect to its neighboring domain [32]. $\mathrm{C}_{2}$-domains share a high structural homology within their core $\beta$-sandwiches and a low similarity in the top and bottom loops [32]. The $\mathrm{Ca}^{2+}$-binding takes place exclusively at the top loops of the domain [32]. For the coordination of two to three $\mathrm{Ca}^{2+-i o n s}$ in the top loop region negatively charged residues, primarily aspartate side chains, are needed [22]. These amino acids are located at specific positions in the top loops 1 and 3 [31].

The $\mathrm{Ca}^{2+}$-ions bound to the top loops of the $\mathrm{C}_{2}$-domain often remain with unsaturated coordination sites which are available for interaction with other target molecules [32]. These free coordination sites can interact with lipids. For several $\mathrm{C}_{2}$-domains it was reported that lipid binding is mediated by $\mathrm{Ca}^{2+}[31,33]$. The binding of phospholipids can either take place simultaneously with $\mathrm{Ca}^{2+}$ to the top loops or independently of $\mathrm{Ca}^{2+}$ to the $\beta$-groove [31]. The $\beta$-groove is a cationic patch in the concave surface of the $\beta$-sandwich, which is often found in $\mathrm{C}_{2}$-domains. The electrostatic potential and the size of the $\beta$-groove vary widely among the domains. The presence of the $\beta$-groove in most $C_{2}$-domains leads to the assumption that it serves a functional or structural role [31]. 


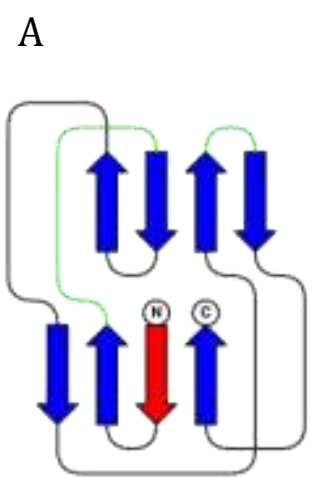

type I

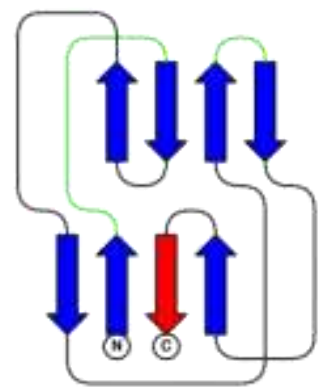

type II
B

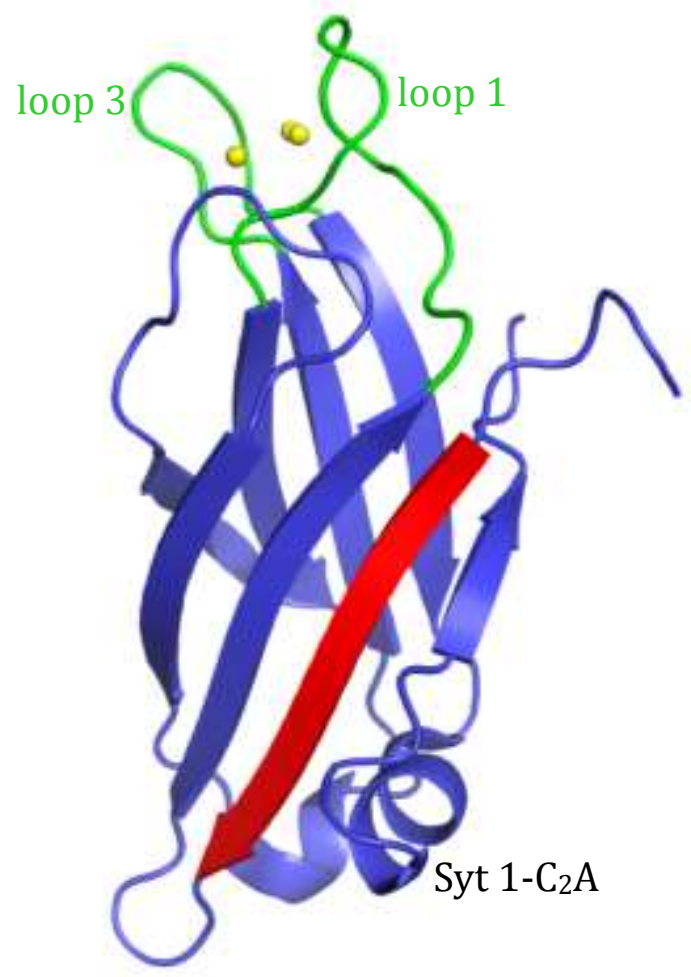

Figure 1.4-2 Typical structure of a $\mathrm{C}_{2}$-domain .

A Schematic presentation of the two possible $\mathrm{C}_{2}$-domain arrangements, modified from Nalefski et al., 1996.

B $\mathrm{C}_{2} \mathrm{~A}$ domain of synaptotagmin 1 , the bound $\mathrm{Ca}^{2+}$-ions are shown in yellow and the coordinating loops 1 and 3 in green, modified from Vrljic et al., 2010, (PDB 3HN8).

Some $\mathrm{C}_{2}$-domains were found with little or no $\mathrm{Ca}^{2+}$-affinity which suggests that they may play a role in structural arrangements or are involved in protein-protein interactions $[29,31]$. In comparison to synaptotagmin in the first three $\mathrm{C}_{2}$-domains of otoferlin several of the aspartate residues in the presumed $\mathrm{Ca}^{2+}$-binding site are missing (Table 1.4-1) [20]. In the $\mathrm{C}_{2} \mathrm{~A}$-domain only one aspartate residue is present, $\mathrm{Ca}^{2+}$-binding studies revealed that this first domain is not able to bind any $\mathrm{Ca}^{2+-i o n s}$ $[20,34]$. The $\mathrm{C}_{2} \mathrm{~B}$-domain also contains only one aspartate residue and the $\mathrm{C}_{2} \mathrm{C}$-domain contains three aspartate residues, according to predictions of the structure [20]. Thus, it was assumed that the second and third $\mathrm{C}_{2}$-domain of otoferlin are also not able to bind $\mathrm{Ca}^{2+-i o n s}[20]$. In contradiction to these predictions $\mathrm{Ca}^{2+}$-binding was experimentally shown for these domains [15], yet the question which additional amino acids beside the few present aspartate residues are involved in the $\mathrm{Ca}^{2+}$-coordination has still not been answered. In the last three $\mathrm{C}_{2}$-domains of otoferlin all predicted aspartate residues are present and the ability to bind $\mathrm{Ca}^{2+}$ was confirmed by isothermal titration calorimetry and fluorescence emission assays $[20,35]$. 
Table 1.4-1 Conservation of putative $\mathrm{Ca}^{2+}$-binding amino acids of the $\mathrm{C}_{2}$-domains. Shown is the comparison between synaptotagmin 1 and otoferlin. The numbers 1 to 5 indicate the amino acids which are located at presumed $\mathrm{Ca}^{2+}$-binding sites. Modified from Jiménez and Bashir, 2007.

\begin{tabular}{l|l|lllll}
\multicolumn{2}{c}{} & \multicolumn{1}{c}{1} & 2 & 3 & 4 & 5 \\
\hline synaptotagmin & $\mathrm{C}_{2} \mathrm{~A}$ & $\mathrm{D}$ & $\mathrm{D}$ & $\mathrm{D}$ & $\mathrm{D}$ & $\mathrm{D}$ \\
& $\mathrm{C}_{2} \mathrm{~B}$ & $\mathrm{D}$ & $\mathrm{D}$ & $\mathrm{D}$ & $\mathrm{D}$ & $\mathrm{E}$ \\
\hline otoferlin & $\mathrm{C}_{2} \mathrm{~A}$ & $\mathrm{G}$ & $\mathrm{D}$ & $\mathrm{N}$ & $\mathrm{S}$ & $\mathrm{K}$ \\
& $\mathrm{C}_{2} \mathrm{~B}$ & $\mathrm{~N}$ & $\mathrm{D}$ & $\mathrm{S}$ & $\mathrm{N}$ & $\mathrm{T}$ \\
& $\mathrm{C}_{2} \mathrm{C}$ & $\mathrm{N}$ & $\mathrm{D}$ & $\mathrm{D}$ & $\mathrm{D}$ & $\mathrm{V}$ \\
& $\mathrm{C}_{2} \mathrm{D}$ & $\mathrm{D}$ & $\mathrm{D}$ & $\mathrm{D}$ & $\mathrm{D}$ & $\mathrm{D}$ \\
& $\mathrm{C}_{2} \mathrm{E}$ & $\mathrm{D}$ & $\mathrm{D}$ & $\mathrm{D}$ & $\mathrm{D}$ & $\mathrm{D}$ \\
& $\mathrm{C}_{2} \mathrm{~F}$ & $\mathrm{D}$ & $\mathrm{D}$ & $\mathrm{D}$ & $\mathrm{D}$ & $\mathrm{D}$
\end{tabular}

Further studies of the $\mathrm{C}_{2} \mathrm{~A}$-domain of synaptotagmin 1 revealed some additional amino acids involved in the binding of three $\mathrm{Ca}^{2+}$-ions. A serine residue and three backbone carbonyl groups were identified. Using several different NMR methods the influence of selected aspartates was analyzed. During these NMR-studies the Ca1-site (Figure 1.4-3) was identified as the high affinity binding site which is proposed to induce structural stability to the domain during $\mathrm{Ca}^{2+}$-binding.

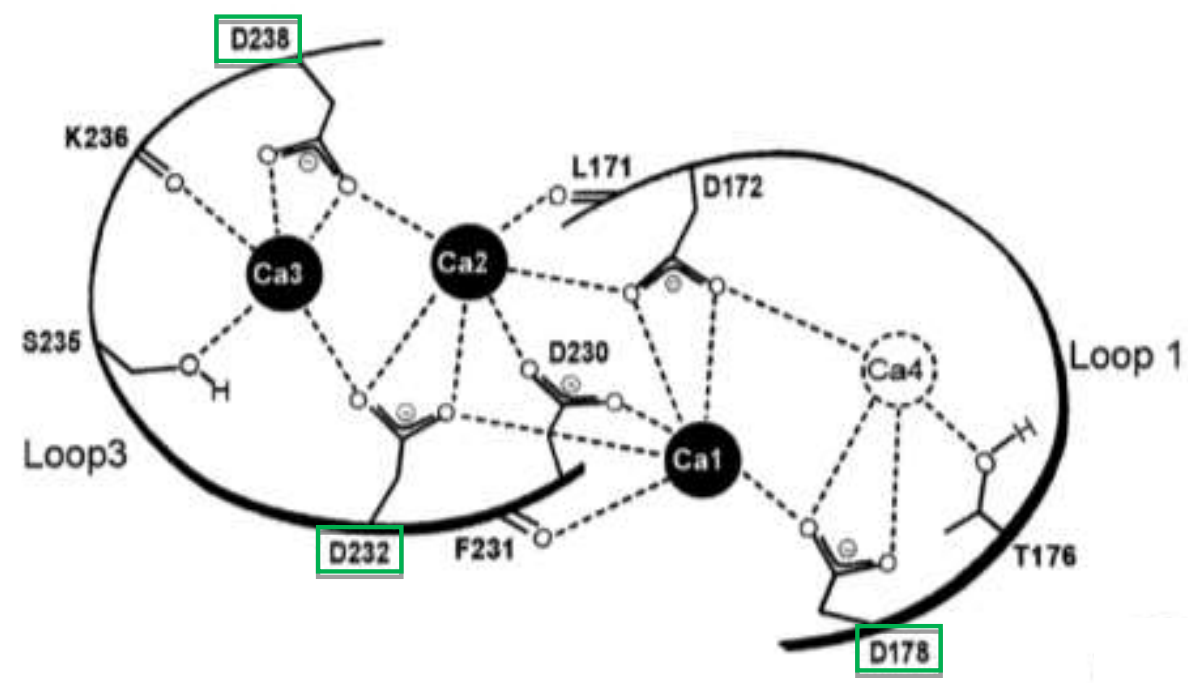

Figure 1.4-3 Overview of the $\mathrm{Ca}^{2+}$-coordinating aspartate residues in top loop 1 and 3 of the $\mathrm{C}_{2} \mathrm{~A}$-domain of synaptotagmin 1 , modified from Ubach et al., 1998. The amino acids marked by a green box were mutated to get information about their role during $\mathrm{Ca}^{2+}$-binding. 
In addition the binding of $\mathrm{Ca}^{2+}$ at this site should help to arrange the side chains of D172, D230 and D232 into the orientation required for the formation of the binding sites Ca2 and Ca3. The mutation of aspartate D178 into an asparagine disrupts the Ca1-binding site and showed a decrease in the affinity of $\mathrm{Ca} 2$ and $\mathrm{Ca} 3$. On the other hand in case of the mutations of D232 and D238 only the highest affinity site (Ca1) remains unaffected. The mutation of the S235 causes only the loss of the lowest affinity site (Ca3) [36].

To date, a conformational change induced by $\mathrm{Ca}^{2+}$-binding was only reported for the piccolo $\mathrm{C}_{2} \mathrm{~A}$-domain [37]. In case of other $\mathrm{C}_{2}$-domains it was not observed that $\mathrm{Ca}^{2+}$-binding could induce serious changes in the overall conformation $[32,38,39]$. Simple locally $\mathrm{Ca}^{2+}$-induced structural changes have been postulated or observed for a few $\mathrm{C}_{2}$-domains $[39,40]$. In case of synaptotagmin $1 \mathrm{C}_{2} \mathrm{~A}$ the binding of a single $\mathrm{Ca}^{2+}$-ion causes little or no changes within the overall structure. Only rotations of some side chains were observed but no substantial backbone rearrangements $[40,41]$.

Relating to the overall arrangement of tandem $\mathrm{C}_{2}$-domains, only examples for Syt 1 (PDB id: 2R83), Syt 3 (PDB id: 3HN8, 1DQV) and extended synaptotagmin-2 (Esyt 2, PDB id: 4P42, 4NPK, 4NPJ) are known. Their structural arrangements show distinct differences. The comparison of the Esyt 2 structure in absence and presence of $\mathrm{Ca}^{2+}$ revealed no structural changes (Figure 1.4-4, A)[42,43], whereas in case of Syt 3 two different structures were observed (Figure 1.4-4, B)[44,45]. The Esyt $2 \mathrm{C}_{2}$-domains exist in a v-shaped structure and their $\mathrm{Ca}^{2+}$-binding sites are arranged in opposite directions [42,43]. In contrast, the $\mathrm{C}_{2}$-domains of Syt 3 do not show such an arrangement, neither in the absence nor in the presence of $\mathrm{Ca}^{2+}$. In addition, the top loop regions of the Syt $3 \mathrm{C}_{2}$-domains face each other. In the presence of $\mathrm{Ca}^{2+} \mathrm{Syt} 3$ shows a so called closed conformation while the unbound state is in an open conformation $[44,45]$. For Syt $1 \mathrm{C}_{2} \mathrm{AB}$ only a $\mathrm{Ca}^{2+}$-unbound structure is known but the arrangement of these $\mathrm{C}_{2}$-domains shows another orientation to each other than the afore mentioned proteins [46]. 


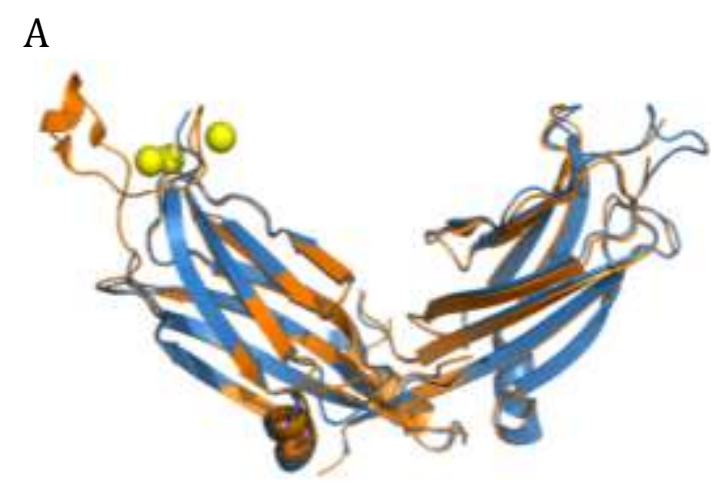

Esyt 2

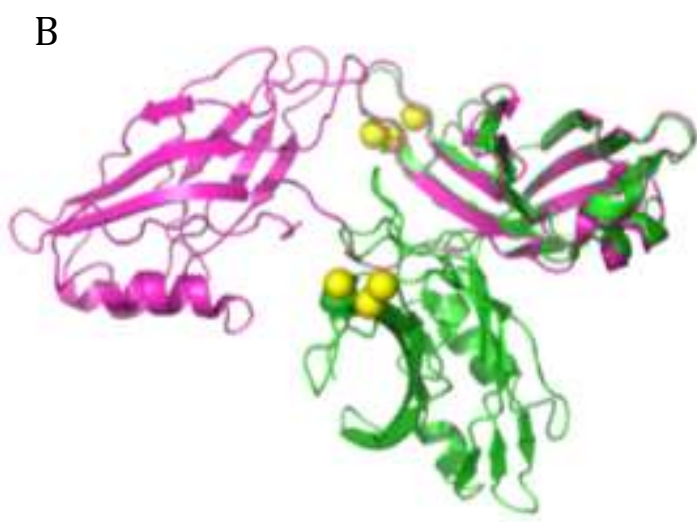

Syt 3

Figure 1.4-4 Conformation of tandem $\mathrm{C}_{2}$-domains of Esyt 2 and Syt 3.

A The superposition of the $\mathrm{Ca}^{2+}$-bound (orange) and unbound (blue) state of Esyt 2 shows no distinct differences.

B The comparison of the bound (green) and unbound (pink) conformation of Syt 3 shows that the structure is changed through $\mathrm{Ca}^{2+}$-binding.

\subsubsection{Structure of the otoferlin $\mathrm{C}_{2} \mathrm{~A}$-domain}

The structure of otoferlin $\mathrm{C}_{2} \mathrm{~A}$ was solved by crystallography [34]. As predicted before [15] this domain was demonstrated not to be able to bind any $\mathrm{Ca}^{2+}$-ions. Former sequence analysis predicted that the first $\beta$-strand of the $\mathrm{C}_{2} \mathrm{~A}$-domain is missing [47]. In contrast to these expectations the found $\mathrm{C}_{2}$-domain forms an eight stranded antiparallel $\beta$-sandwich in a type II topology. In comparison to other $\mathrm{C}_{2}$-domains there are considerable differences in the $\mathrm{Ca}^{2+}$-binding region (CBR). The otoferlin top loop 1 is much shorter and not tilted (Figure 1.4-5). The formation of the loop 3 is similar to other $\mathrm{C}_{2}$-domains. Normally, loop 1 contains two of the five coordinating aspartate residues and the other three are located in loop 3. The structure-based sequence alignment of otoferlin $\mathrm{C}_{2} \mathrm{~A}$ and synaptotagmin $1 \mathrm{C}_{2} \mathrm{~A}$ showed that only one of the expected aspartates is present in loop 1 . The second aspartate would be located in the truncated region of the loop. Despite the similarity of loop 3 to other $\mathrm{C}_{2}$-domains the three aspartate residues for $\mathrm{Ca}^{2+}$-binding are missing. They are replaced by two neutral and one positively charged amino acids (Asn 68, Ser 70 and Lys 76). Additional $\mathrm{Ca}^{2+}$-binding assays, like isothermal titration calorimetry (ITC) and circular dichroism (CD), confirmed that the first $\mathrm{C}_{2}$-domain of otoferlin is not able to bind any $\mathrm{Ca}^{2+-i o n s . ~ T h e ~ i n s e r t i o n ~ o f ~ f o u r ~ a s p a r t a t e ~ r e s i d u e s ~ b y ~ m u t a t i o n ~ i n t o ~ t h e ~}$ two top loops could not restore the $\mathrm{Ca}^{2+}$-binding ability of this domain.

For several $\mathrm{C}_{2}$-domains it was reported that they are able to bind to lipids in a $\mathrm{Ca}^{2+}$-dependent or independent way. Furthermore, there are two possible binding locations for lipids on $\mathrm{C}_{2}$-domains. Either the lipids bind to the top loop region like $\mathrm{Ca}^{2+}$ or they can bind to the $\beta$-groove. The performance of flotation assays in absence 
and presence of $\mathrm{Ca}^{2+}$ did not indicate any binding of lipids to the otoferlin $\mathrm{C}_{2} \mathrm{~A}$-domain [34].

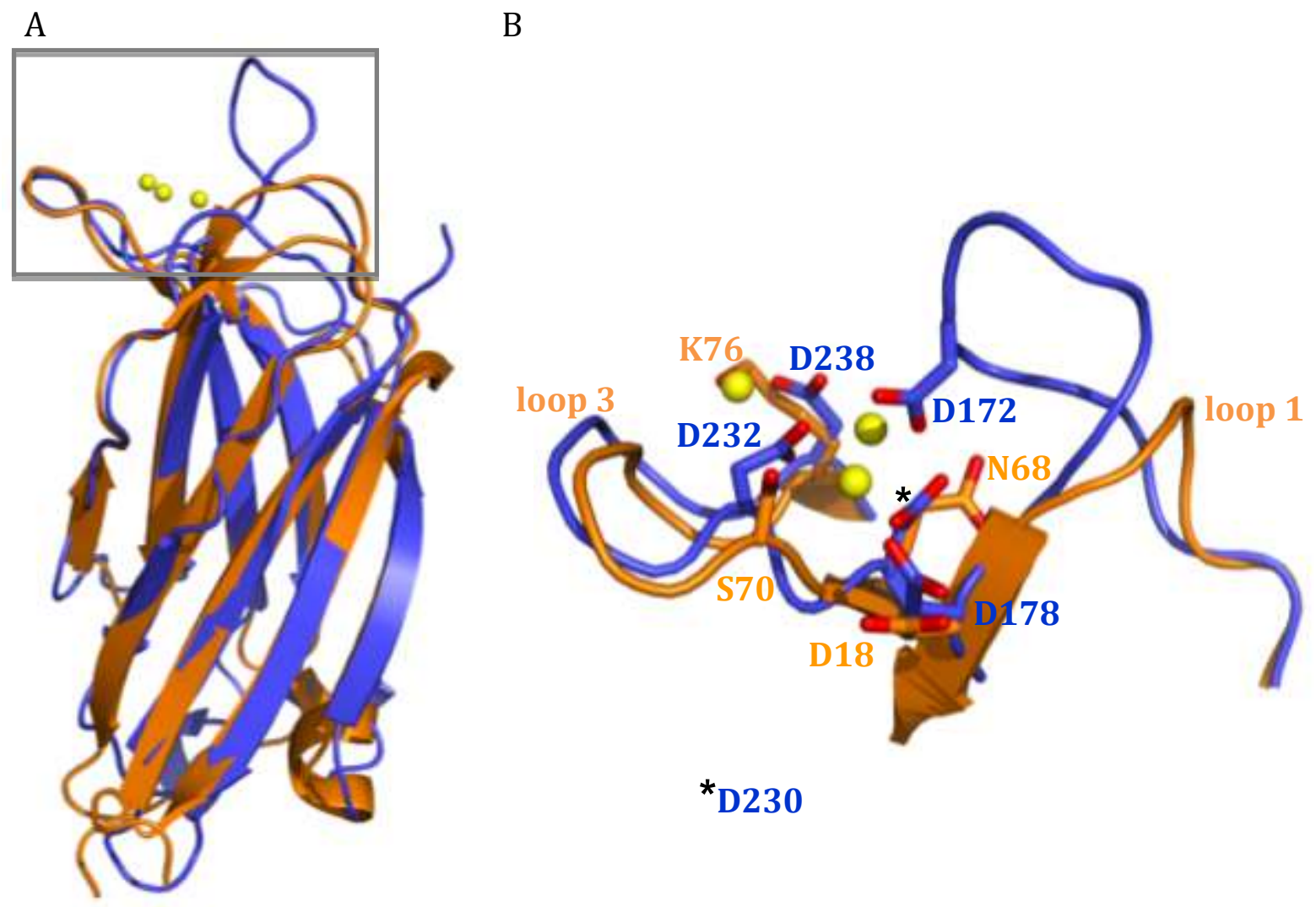

Figure 1.4-5 Structure of the $\mathrm{C}_{2} \mathrm{~A}$-domain of otoferlin. Comparison of the otoferlin $\mathrm{C}_{2} \mathrm{~A}$-domain (orange) to the $\mathrm{C}_{2} \mathrm{~A}$-domain of synaptotagmin 1 (blue). The three $\mathrm{Ca}^{2+-i o n s}$ coordinated by synaptotagmin are shown in yellow. Modified from Helfmann et al., 2011.

A Overall structure of the $\mathrm{C}_{2} \mathrm{~A}$-domains of otoferlin and synaptotagmin with distinct differences in the top loop region.

B Enlarged section of the $\mathrm{Ca}^{2+}$-binding region of both proteins. The top loop 1 of otoferlin is much shorter in comparison to the loop 1 of synaptotagmin and in addition only one of the aspartate residues (D18) for $\mathrm{Ca}^{2+}$-binding is present in both loops.

\subsubsection{Mutations in otoferlin}

Several point mutations can occur in proteins such as missense or nonsense mutations. Missense mutations appear if a base is exchanged and the sequence codes for a different amino acid. If the exchange of a base results in a premature stop codon which leads to a shorter version of the protein, the mutation is called "nonsense mutation". Insertions and deletions of bases result in a frame shift which causes the coding of a different protein sequence, which results mostly in a premature stop. Several mutations are known for the protein otoferlin, some of them are 
non-pathogenic mutations which were mostly found in the $\mathrm{C}_{2} \mathrm{~A}$-domain or in the linker regions (Figure 1.4-1) [28].

Most of the otoferlin mutations result in a homogeneous phenotype with severe to profound deafness (Figure 1.4-1) [48]. For some point mutations a rare short-term deafness was reported if the affected people became febrile and their body core temperature rose as little as $1{ }^{\circ} \mathrm{C}$ [49]. One in frame deletion and three missense mutations were so far identified to cause this form of deafness. These four known mutations are described in different sites of the protein (Figure 1.4-1) [17,50-52].

One of these temperature sensitive deafness phenotypes results from a mutation called I515T which is located in the $\mathrm{C}_{2} \mathrm{C}$-domain of the protein. At position 515 an isoleucine is replaced by a threonine. Until now it is still unknown which influence this mutation has on the structure or function of the $\mathrm{C}_{2}$-domain. According to the predictions of Jiménez and Bashir the affected position is located within the fifth $\beta$-strand of the $\mathrm{C}_{2}$-domain. Furthermore, this mutation is positioned two amino acids before the third aspartate, predicted to be involved in $\mathrm{Ca}^{2+}$-binding [20]. Thus, this mutation may influence the correct folding of the domain. Until now, the ability of the $\mathrm{C}_{2} \mathrm{C}$-domain to bind $\mathrm{Ca}^{2+}$ is still under discussion, several contradictory findings were published $[15,20,35,53]$. If this domain is able to bind $\mathrm{Ca}^{2+}$ the mutation at position 515 may influence as well the $\mathrm{Ca}^{2+}$-binding ability.

A second point mutation in the $\mathrm{C}_{2} \mathrm{C}$-domain of otoferlin is known to cause temperature sensitive deafness. This mutation affects a glycine at position 541 which is replaced by a serine [52]. According to structure predictions this point mutation is located in the last $\beta$-strand of the domain [20]. The change from this amino acid to a serine may have influence on the proper folding.

Another mutation called pachanga (D1767G) was found in mice which leads to deafness [54]. In this mutation an aspartate residue was exchanged to a glycine. Jiménez and Bashir predicted that all Ferlin $\mathrm{C}_{2}$-domains likely adopt the type II topology. According to this assumption the mutation is positioned in a loop at the opposite end of the $\mathrm{C}_{2}$-domain to the $\mathrm{Ca}^{2+}$-binding region [20]. The effect of the pga-mutation is still unsettled but based on this position an influence on the secondary structure seems more likely than one in $\mathrm{Ca}^{2+}$-binding. A direct influence on the $\mathrm{Ca}^{2+}$-binding would only occur if the domain exists in the type II topology. In this case the pga mutation would be located in the top loop I. 


\subsection{Goal of the thesis}

During my experimental thesis work, I aimed to solve the structure of the otoferlin $\mathrm{C}_{2}$-domains trough crystallization of the protein. For this the expression and purification of both single $\mathrm{C}_{2}$-domains and fragments containing more than one domain had to be established. To clarify which of the $\mathrm{C}_{2}$-domains are able to bind $\mathrm{Ca}^{2+}$ it was planned to analyze different otoferlin fragments with MicroScale Thermophoresis (MST). Knowing that CaMKII $\delta$ is able to interact with otoferlin, I tested whether the CaMKII $\delta$ is capable to phosphorylate otoferlin in vitro. Furthermore, the effect of the determined sites within the $\mathrm{Ca}^{2+}$-binding process of the $\mathrm{C}_{2}$-domains had to be analyzed by MST. To evaluate the roles of the predicted aspartate residues in the binding pocket, which are responsible for $\mathrm{Ca}^{2+}$-binding within the $\mathrm{C}_{2} \mathrm{~F}$-domain, it was planned to mutate the positions and perform again MST measurements. Moreover selected mutations known to affect hearing should be tested by MST as well. A further goal of this work was the identification of possible interaction partners of otoferlin. Therefore pull-down experiments with mouse brain tissue should be performed followed by mass spectrometry analysis. Furthermore, the investigation of the thermal stability of otoferlin $\mathrm{C}_{2}$-domains using the thermal shift assay was as well an aim of this work. 


\section{MATERIALS AND METHODS}

\subsection{Materials}

\subsubsection{Lab-equipment}

Adjustable pipets

Eppendorf

Agarose gel electrophoresis chamber

Bio-Rad

BioPhotometer

Eppendorf

Centrifuge 5415R

Eppendorf

Centrifuge Allegra 21R

Beckman Coulter

Centrifuge Avanti J-20 XPI

Beckman Coulter

Centrifuge Avanti J-30 I

Beckman Coulter

CFX 96 Real-Time System C1000 Thermal Cycler

Bio-Rad

Electrophoresis Power Supply EPS 301

Amersham pharmacia biotech

Fine balance

Sartorius

Gel Doc 2000

Bio-Rad

Incubator HT Multitron

Infors

Incubator Mytron

Schütt

Mircrofluidizer 110 S

Microfluidics

Monolith NT.LabelFree

NanoTemper Technologies

PCR-Whatman Biometra T personal

Biometra

pH-Meter Beckman

Beckman

Pipette Controller Accu-Jet

Brand

Platform Shaker Duomax 1030

Heidolf

Rotor JA-20

Beckman Coulter

Rotor JA-30.50 Ti

Beckman Coulter

Rotor JLA-8.1000

Beckman Coulter

SDS-PAGE_System Hoefer miniVe

Amersham Pharmacia Biotech

Thermo Stat plus

Eppendorf 


\subsubsection{Chromatography systems, columns and accessories}

In this work the chromatography system ÄKTA Prime (GE Healthcare) was used. The protein samples were loaded using 5, 50 or $150 \mathrm{ml}$ superloops (GE Healthcare). The following columns were used.

GSH sepharose $5 \mathrm{ml}$

GSH sepharose $15 \mathrm{ml}$

HisTrap 5 ml Ni-NTA sepharose

HiPrep Desalting 26/10

Superdex 75 (26/60)

Superdex 200 (16/60)

Superdex 200 (26/60)

StrepTaction HP sepharose $5 \mathrm{ml}$
GE Healthcare/Macherey-Nagel

GE Healthcare

GE Healthcare/Macherey-Nagel

GE Healthcare

GE Healthcare

GE Healthcare

GE Healthcare

GE Healthcare

\subsubsection{Kits}

peqGOLD Plasmid Miniprep Kit I

peqGOLD Cycle-Pure Kit

NucleoSpin Gel and PCR Clean-up

StarGate $®$ Combi Entry Cloning Set

StarGate ${ }^{\circ}$ Transfer Reagent Set
Peqlab

Peqlab

Macherey-Nagel

IBA

IBA

\subsubsection{Size standards for proteins and DNA}

Prestained Protein Molecular Weight Marker

ThermoScientific

Protein Molecular Weight Marker

ThermoScientific

GeneRuler 1kb DNA Ladder

ThermoScientific 


\subsubsection{Consumable material}

24 well crystallization plates

96 well crystallization plates

Amicon Ultra Centrifugal Filters

Crystal Clear Tape

Falcon Tubes

Half micro cuvettes

Monolith NT.LabelFree Standard Treated Capillaries

Petri dishes $92 \times 16 \mathrm{~mm}$

Pipet tips

Reaction tubes ( $0.5 \mathrm{ml}, 1.5 \mathrm{ml}, 2 \mathrm{ml})$

Sterile Filter

\subsubsection{Crystallization screens}

Ammonium sulfate suite

JBScreen Classic $(1,2,4,5)$

JBScreen Classic $(6,7,8,10)$

JBScreen Nuc-Pro HTS

JBScreen PACT++HTS

JCSG+ Suite

MIDAS MD 1-59 (1 $\mathrm{x}$ and $0.5 \mathrm{x}$ )

Morpheus

Natrix HT

PGA-LM HT 96

ProPlex
Hampton Research

Hampton Research

Merck Millipore

Henkel

Greiner Bio-One

Sarstedt

NanoTemper Technologies

Sarstedt

Sarstedt

Eppendorf

Merck Millipore
Quiagen

Jena BioScience

Jena BioScience

Jena BioScience

Jena BioScience

Newman et al. (2005)

Molecular Dimensions

Molecular Dimensions

Hampton Research

Molecular Dimensions

Radaev et al. (2006) 


\subsubsection{Chemicals}

All organic substances and fine chemicals were purchased from the companies AppliChem, Bio-Rad, Fluka, IBA, Merck, MWG Biotech, Oxoid, Roth or Sigma-Aldrich in the purity pro analysis. Generally, the provider with the lowest price was chosen.

\subsubsection{Plasmids}

Table 2.1-1 Plasmids used for recombinant protein expression. The restriction site cloning (RS) or overlap PCR (OP) of these protein fragments were performed and kindly provided by Dr. Sarah Helfmann (a) and Dr. Kirsten Reuter $(b)$.

\begin{tabular}{|c|c|c|}
\hline Name & Cloning method & Oligonucleotides \\
\hline $\mathrm{His}_{6}-\mathrm{C}_{2} \mathrm{AB}(\mathrm{pET} 28 \mathrm{a})^{a}$ & $\mathrm{RS}$ & 1,2 \\
\hline GST-C $\mathrm{C}_{2} \mathrm{~B}(\mathrm{pGEX}-6 \mathrm{P}-3)^{a}$ & RS & 3,4 \\
\hline GST-C $\mathrm{C}_{2} \mathrm{C}(\mathrm{pGEX}-6 \mathrm{P}-3)^{a}$ & RS & 5,6 \\
\hline GST- $\mathrm{C}_{2} \mathrm{E}(\mathrm{pGEX}-6 \mathrm{P}-3)^{a}$ & RS & 7,8 \\
\hline GST-C $\mathrm{C}_{2} \mathrm{~F}(\mathrm{pGEX}-6 \mathrm{P}-3)^{a}$ & RS & 9,10 \\
\hline GST-pga-kurz (pGEX-6P-3) & $\mathrm{OP}$ & $11-14$ \\
\hline
\end{tabular}

Table 2.1-2 Plasmids used for recombinant protein expression. For cloning either the StarGate Cloning Kit (SG) or restriction site cloning protocol (RS) was used. The used oligonucleotides were ordered from Sigma Aldrich and listed in the appendix (see section 6). ${ }^{1}$ The $\mathrm{C}_{2} \mathrm{~F}$-phos-fragment was ordered as a synthetic gene and transferred into the GST-tag containing vector.

\begin{tabular}{lcc} 
Name & Cloning method & Oligonucleotides \\
\hline C 2 ABC-His6 (pPSG-IBA33) $_{\text {Strep-C2ABC-short (pPSG-IBA5) }}$ & SG & 15,16 \\
His6-C DEF (pET28a) & RS & 15,17 \\
Dynamin 1-Strep (pPSG-IBA3) & SG & 18,19 \\
GST-C $_{2}$ F-phos (pGEX-6P-3) & RS & 20,21 \\
\hline
\end{tabular}


Table 2.1-3 Different mutations were inserted in the existing protein fragments. This was either performed using the QuikChange Manual (QC) or by overlap extension PCR (OP). The used oligonucleotides were ordered from Sigma Aldrich and listed in the appendix (see section 6).

\begin{tabular}{lcc} 
Name & Cloning method & Oligonucleotides \\
\hline C 2 ABC-I515T-His 6 (pPSG-IBA33) $_{2}$ & QC & 22,23 \\
C 2 ABC-G541S-His 6 (pPSG-IBA33) & QC & 24,25 \\
GST-C 2 C-phos (pGEX-6P-3) & QC & 26,27 \\
GST-C 2 F-D1N (pGEX-6P-3) & QC & 28,29 \\
GST-C 2 F-D2,3N (pGEX-6P-3) & OP & $30-33$ \\
GST-C 2 F-D1,2,3N (pGEX-6P-3) & OP & $30-35$ \\
GST-C 2 F-D4N (pGEX-6P-3) & QC & 36,37 \\
GST-C 2 F-E1804del (pGEX-6P-3) & QC & 38,39
\end{tabular}

\subsubsection{Organisms}

The used E. coli strains SoluBL21 (DE3), Rosetta 2 (DE3) and XL1 Blue were part of the Department for Molecular Structural Biology, Georg-August University Göttingen. The E. coli TOP10 cells were purchased from IBA.

\subsubsection{Enzymes and inhibitors}

ALP-Protease inhibitor mix

Phusion-DNA Polymerase

PreScission-Protease

Restriction Enzymes

T4-DNA Ligase

Shrimp alkaline phosphatase (SAP)

Calmodulin-dependent kinase II delta (CaMKII $\delta$ )
MSB, University Göttingen

ThermoScientific

GE Healthcare

ThermoScientific

ThermoScientific

ThermoScientific

Life technologies

\subsubsection{Antibiotics with working concentrations}

Ampicillin $(100 \mu \mathrm{g} / \mathrm{ml})$

Kanamycin $(50 \mu \mathrm{g} / \mathrm{ml})$
AppliChem

Roth 


\subsubsection{Cell media}

2YT-medium

\begin{tabular}{ll}
\hline $1 \%(\mathrm{w} / \mathrm{v})$ & Tryptone \\
$1 \%(\mathrm{w} / \mathrm{v})$ & Yeast extract \\
$1 \%(\mathrm{w} / \mathrm{v})$ & $\mathrm{NaCl}$ \\
\hline
\end{tabular}

$1 \times \mathrm{ZY}$-medium

\begin{tabular}{ll}
\hline $1 \%(\mathrm{w} / \mathrm{v})$ & Tryptone \\
$0.5 \%(\mathrm{w} / \mathrm{v})$ & Yeast extract \\
\hline
\end{tabular}

$50 \times \mathrm{M}$

\begin{tabular}{ll}
\hline $1.25 \mathrm{M}$ & $\mathrm{K}_{2} \mathrm{HPO}_{4}$ \\
$1.25 \mathrm{M}$ & $\mathrm{NaH}_{2} \mathrm{PO}_{4} \times \mathrm{H}_{2} \mathrm{O}$ \\
$2.5 \mathrm{M}$ & $\mathrm{NH}_{4} \mathrm{Cl}$ \\
$0.25 \mathrm{M}$ & $\mathrm{Na}_{2} \mathrm{SO}_{4} \times 10 \mathrm{H}_{2} \mathrm{O}$ \\
\hline
\end{tabular}

$50 \times 5052$

\begin{tabular}{ll}
\hline $25 \%(\mathrm{v} / \mathrm{v})$ & Glycerol \\
$2.5 \%(\mathrm{w} / \mathrm{v})$ & Glucose \\
$10 \%(\mathrm{w} / \mathrm{v})$ & $\alpha$-Lactose \\
\hline
\end{tabular}

Mixture of 11 ZYM-5052

\begin{tabular}{ll}
\hline $1 \mathrm{l}$ & $1 \times \mathrm{ZY}$ \\
$20 \mathrm{ml}$ & $50 \times \mathrm{M}$ \\
$20 \mathrm{ml}$ & $50 \times 5052$ \\
$1 \mathrm{ml}$ & $1000 \times \mathrm{MgSO}_{4}$ \\
$200 \mu \mathrm{l}$ & $5000 \times \mathrm{Trace}^{\mathrm{m}}$ elements \\
\hline
\end{tabular}

2YT-agar

\begin{tabular}{ll}
\hline $500 \mathrm{ml}$ & 2YT-medium \\
$1.5 \%(\mathrm{w} / \mathrm{v})$ & agar \\
\hline
\end{tabular}

$1000 \times \mathrm{MgSO}_{4}$

$2 \mathrm{M} \mathrm{MgSO}_{4} \times 7 \mathrm{H}_{2} \mathrm{O}$

$5000 \times$ Trace elements

\begin{tabular}{ll}
\hline $50 \mathrm{mM}$ & $\mathrm{FeCl}_{3}$ \\
$20 \mathrm{mM}$ & $\mathrm{CaCl}_{2}$ \\
$10 \mathrm{mM}$ & $\mathrm{MnCl}_{2}$ \\
$50 \mathrm{mM}$ & $\mathrm{ZnSO}_{4}$ \\
$2 \mathrm{mM}$ & $\mathrm{CoCl}_{2}$ \\
$2 \mathrm{mM}$ & $\mathrm{CuCl}_{2}$ \\
$2 \mathrm{mM}$ & $\mathrm{NiSO}_{4}$ \\
$2 \mathrm{mM}$ & $\mathrm{Na}_{2} \mathrm{MoO}_{4}$ \\
$2 \mathrm{mM}$ & $\mathrm{Na}_{2} \mathrm{SeO}_{4}$ \\
$2 \mathrm{mM}$ & $\mathrm{H}_{3} \mathrm{BO}_{4}$ \\
\hline
\end{tabular}




\subsection{Methods}

\subsubsection{Molecular biological methods}

\subsubsection{Molecular cloning}

\subsection{Restriction site based cloning}

For restriction site cloning the DNA was amplified with forward and reverse oligonucleotides containing the necessary restriction sites. After the polymerase chain reaction (PCR) the sample was purified via the peqGOLD Cycle-Pure Kit. The target-DNA and plasmid-DNA were digested using the appropriate restriction enzymes. After $1 \mathrm{~h}$ of incubation at $37^{\circ} \mathrm{C}$ the enzymes were inactivated during a heating step at $80{ }^{\circ} \mathrm{C}$ for $20 \mathrm{~min}$. For dephosphorylation of the digested vector 0.01 units per pmol DNA of the Shrimp alkaline phosphatase (SAP, ThermoScientific) was added and incubated for $1 \mathrm{~h}$ at $37^{\circ} \mathrm{C}$ followed by an inactivation step at $80{ }^{\circ} \mathrm{C}$ for $20 \mathrm{~min}$.

To ligate the two components, $200 \mathrm{ng}$ of the vector were used and mixed with a 5-fold molar excess of insert-DNA. Additionally, $1 \mu \mathrm{l}$ of T4-DNA ligase (ThermoScientific), $1 \mu \mathrm{l}$ of $10 \mathrm{mM}$ ATP and $1 \mu \mathrm{l}$ of the supplemented $10 \mathrm{x}$ T4 ligation buffer (ThermoScientific) were added. The ligation reaction took place over night at $16^{\circ} \mathrm{C}$. Afterwards the entire sample was transformed into E. coli XL1-Blue cells and plated on an agar plate with the appropriate antibiotics.

\subsection{StarGate}

In the first step of the StarGate cloning the DNA was extended at the 3'- and 5'-end with a StarCombinase site. This was done during PCR with appropriate oligonucleotides. The obtained PCR fragment was inserted into the pENTRY-IBA10 vector using special StarGate solutions (StarGate instruction manual February 2011). The mixture was incubated for $1 \mathrm{~h}$ at $30^{\circ} \mathrm{C}$ and transformed into chemically competent E. coli TOP10 cells. A control digestion with XbaI and HindIII verified the plasmid DNA of the colonies. The DNA sample was sequenced for positive results to confirm the sample correctness.

The correct target-DNA was transferred from the donor vector (pENTRY-IBA10) into the acceptor vector of choice by using special transfer reagents according to the manufacturer's protocol. The sample was incubated for $1 \mathrm{~h}$ at $30^{\circ} \mathrm{C}$ and transformed into E. coli TOP10 cells. 
Again, a digestion reaction with $\mathrm{XbaI}$ and HindIII served to control the successful transfer.

\subsubsection{Polymerase chain reaction (PCR)}

The polymerase chain reaction allows the selective amplification of a specific DNA sequence. Defining this specific sequence requires oligonucleotides with a length of 20-30 bp which have to be complementary to the 3'- and 5'-end of the amplification region. A DNA-polymerase extends the oligonucleotide sequences and creates a new complementary DNA strand.

\begin{tabular}{ll} 
Standard PCR mixture \\
\hline $200 \mathrm{ng}$ & Template-DNA \\
$10 \mathrm{mM}$ & dNTPs \\
$10 \mathrm{pmol}$ & forward primer \\
$10 \mathrm{pmol}$ & reverse primer \\
$10 \mu \mathrm{l}$ & $5 x H F$ buffer \\
$0.5 \mu \mathrm{l}$ & Phusion polymerase (ThermoScientific) \\
Add to $50 \mu \mathrm{l}$ & dd $\mathrm{H}_{2} \mathrm{O}$ \\
\hline
\end{tabular}

Standard PCR program

\begin{tabular}{|c|c|c|c|}
\hline Initial denaturation & $96^{\circ} \mathrm{C}$ & $120 \mathrm{~s}$ & \\
\hline Denaturation & $96^{\circ} \mathrm{C}$ & $30 \mathrm{~s}$ & \\
\hline Annealing of oligonucleotides & $\mathrm{x}^{\circ} \mathrm{C}$ & $30 \mathrm{~s}$ & $\times 25-30$ \\
\hline Elongation & $72^{\circ} \mathrm{C}$ & $15 \mathrm{~s} / \mathrm{kb}$ & \\
\hline Final elongation & $72{ }^{\circ} \mathrm{C}$ & $300 \mathrm{~s}$ & \\
\hline
\end{tabular}

For the specific annealing temperature $(\mathrm{x})$ a value of $3-5^{\circ} \mathrm{C}$ lower than the melting temperature of both oligonucleotides is recommended. The obtained PCR result was analyzed with agarose gel electrophoresis and purified using the peqGOLD MicroSpin Cycle-Pure Kit (PEQLAB). 


\subsubsection{Agarose gel electrophoresis}

Agarose gel electrophoresis allows the separation of DNA fragments according to their size. Within an electrical field the DNA moves towards the anode because of the negatively charged phosphate backbone.

For gel preparation $1 \%(\mathrm{w} / \mathrm{v})$ agarose was added into $1 \times \mathrm{xAE}$ buffer and boiled in the microwave. The clear solution was mixed with GelRed (1:10000, biotinum, VWR) and poured into a gel chamber with a comb. The samples were mixed with $6 \mathrm{x}$ loading dye and loaded on the cold and solid agarose gel. The gel was run with $125 \mathrm{~V}$ until the required separation was reached.

The DNA fragments were analyzed under UV light $(254 \mathrm{~nm})$ with the GelDoc system (Bio-Rad).

DNA loading dye (6x)

\begin{tabular}{ll}
\hline $10 \mathrm{mM}$ & Tris/HCl pH 7.6 \\
$0.03 \%$ & Bromphenole blue \\
$0.03 \%$ & Xylene cyanol ff \\
$60 \%$ & Glycerol \\
$60 \mathrm{mM}$ & EDTA \\
\hline
\end{tabular}

TAE buffer (50x)

\begin{tabular}{ll}
\hline $2 \mathrm{M}$ & Tris acetate $\mathrm{pH} 8.0$ \\
$50 \mathrm{mM}$ & EDTA \\
\hline
\end{tabular}

\subsubsection{DNA-Extraction from agarose Gels}

To extract DNA from an agarose gel, the appropriate band was cut out of the gel and purified using the NucleoSpin Gel and PCR Clean-up Kit (Machery-Nagel) following the manufacturer's recommendations.

\subsubsection{Preparation of plasmid DNA}

The preparation of plasmid DNA from overnight cultures was performed with the peqGOLD MiniPrep Kit 1 according to the manufacturer's protocol.

\subsubsection{Determination of the DNA concentration}

The bio photometer of Eppendorf was used to determine the DNA concentrations through absorption at $260 \mathrm{~nm}$. All DNA samples were solved in water. 


\subsubsection{Restriction enzyme digest}

Restriction enzymes are able to cut specific sequences. The restriction enzymes of choice and the appropriate buffer were added to the reaction mixture and incubated for $1 \mathrm{~h}$ at $37^{\circ} \mathrm{C}$. To inactivate the enzymes the mixture was heated at $80^{\circ} \mathrm{C}$ for $20 \mathrm{~min}$.

\subsubsection{DNA sequencing}

The plasmid DNA was send to Seqlab, GATC or the sequencing service of the Pieler department for sequencing. The data was analyzed afterwards by using Chromas (Version 1.45) and ApE (A plasmid Editor v1.17) to verify the samples.

\subsubsection{Mutagenesis}

To generate small mutations in the gene of interest site-directed mutagenesis was performed. Oligonucleotides were designed that contain 15 nucleotides on the 5 '-end and the 3 '-end flanking the mutated site. Complementary oligonucleotides were used to amplify both strands of a plasmid. The following addition of the endonuclease DpnI digested the methylated starting-DNA. The mutated DNA was transformed into E. coli XL1 blue competent cells. After a consequent plasmid preparation the DNA was sequenced to confirm the inserted mutation.

Standard mutagenesis mixture

\begin{tabular}{ll}
\hline $50 \mathrm{ng}$ & Template-DNA \\
$10 \mathrm{mM}$ & dNTPs \\
$10 \mathrm{pmol}$ & forward primer \\
$10 \mathrm{pmol}$ & reverse primer \\
$10 \mu \mathrm{l}$ & $5 \times \mathrm{HF}$ buffer \\
$0.5 \mu \mathrm{l}$ & Phusion polymerase \\
Add to $50 \mu \mathrm{l}$ & $\mathrm{ddH}_{2} \mathrm{O}$ \\
\hline
\end{tabular}


Standard mutagenesis PCR program

\begin{tabular}{lll|l}
\hline Initial denaturation & $96^{\circ} \mathrm{C}$ & $120 \mathrm{~s}$ \\
Denaturation & $96^{\circ} \mathrm{C}$ & $30 \mathrm{~s}$ & \\
Annealing of oligonucleotides & $55^{\circ} \mathrm{C}$ & $30 \mathrm{~s}$ & $\times 25-30$ \\
Elongation & $68^{\circ} \mathrm{C}$ & $\mathrm{y} \mathrm{s}$ & \\
Final elongation & $68^{\circ} \mathrm{C}$ & $300 \mathrm{~s}$ & \\
\hline
\end{tabular}

The elongation time (y) depends on the final length of the plasmid.

\subsubsection{Site directed mutagenesis by overlap PCR}

For this method two pairs of oligonucleotides are needed. One pair contain the 5 '-forward oligonucleotide which is necessary for the amplification of DNA between the 5 '-end and the mutation region and a mutation containing oligonucleotide. The second pair consist of a 3'-reverse oligonucleotide and the complementary mutation containing oligonucleotide. The 5'- and 3'-oligonucleotides also carry a restriction site which allows the cloning into the vector of choice. Both oligonucleotides pairs are used in two separate amplification reactions. The obtained fragments from these reactions contain an overlapping sequence including the inserted mutation. In the next step both obtained fragments were mixed and two cycles of annealing and elongation were performed. The annealing took place at $37^{\circ} \mathrm{C}$ for $5 \mathrm{~min}$ followed by an elongation step at $71^{\circ} \mathrm{C}$ for $5 \mathrm{~min}$. Afterwards the 5 '- and 3 '-oligonucleotides were added and a PCR with 20 cycles was done to generate the product. In the following step the gained fragment was digested by the appropriate restriction enzymes and transferred into the vector (see section 2.2.1.1.1).

\subsubsection{Transformation}

200 ng of plasmid DNA were added to chemically competent cells to transform the target DNA into E. coli cells. The solution was incubated on ice for $30 \mathrm{~min}$, followed by a heat-shock step at $42{ }^{\circ} \mathrm{C}$ for $45 \mathrm{~s}$ and incubation on ice for $2 \mathrm{~min}$. After this incubation $900 \mu \mathrm{l}$ of $2 x Y T$-medium were added to the cells. A further incubation step was conducted for $45 \mathrm{~min}$ at $37^{\circ} \mathrm{C}$. The solution was either transferred into an overnight culture (50 ml 2xYT-medium) with appropriate antibiotics or was slowly centrifuged at $1500 \mathrm{x}$ g for $3 \mathrm{~min}$; the pellet was resuspended in approximately $100 \mu \mathrm{l}$ 
residual 2xYT medium and plated on agar plates supplemented with the corresponding antibiotics.

\subsubsection{Generation of chemical competent $E$. coli cells}

A $50 \mathrm{ml}$ overnight culture was inoculated with the appropriate E. coli strain and incubated at $37^{\circ} \mathrm{C}$. In the next step, a $500 \mathrm{ml} 2 \mathrm{xYT}$-culture was inoculated with the preculture in a ratio of $1: 500$. When an $\mathrm{OD}_{600}$ of $0,6-0,8$ was reached, the cells were harvested at $2550 \mathrm{xg}$ for $10 \mathrm{~min}$ at $4{ }^{\circ} \mathrm{C}$. The pellet was resuspended in $125 \mathrm{ml}$ of $100 \mathrm{mM} \mathrm{Mg}{ }^{2+}$-chloride followed by a centrifugation step for $10 \mathrm{~min}$ at $1560 \mathrm{xg}$ and $4{ }^{\circ} \mathrm{C}$. After removing the supernatant the pellet was resuspended in $250 \mathrm{ml}$ of $100 \mathrm{mM}$ $\mathrm{Ca}^{2+}$ chloride and again centrifuged as before. The final pellet was dissolved in $5 \mathrm{ml}$ of $100 \mathrm{mM} \mathrm{Ca}{ }^{2+}$-chloride with $15 \%$ glycerol and aliquots of $50 \mu \mathrm{l}$ were frozen in liquid nitrogen and stored at $-80^{\circ} \mathrm{C}$.

\subsubsection{Proteinbiochemical methods}

\subsubsection{Recombinant expression of proteins in E. coli}

\subsection{Induction with IPTG in 2xYT-medium}

The DNA of choice was transformed into SoLuBL21 cells. $500 \mathrm{ml}$ of 2YT-medium were inoculated with the preculture in a ratio of $1: 100$ and grew at $30{ }^{\circ} \mathrm{C}$ until an $\mathrm{OD}_{600}$ of 1.2 was reached. After the addition of $500 \mathrm{ml}, 4^{\circ} \mathrm{C}$ precooled 2YT-medium IPTG was added to a final concentration of $0.5 \mathrm{mM}$. The incubation temperature was changed to $16{ }^{\circ} \mathrm{C}$ and the cultures were harvested $16-20 \mathrm{~h}$ after induction.

\subsection{Autoinduction}

Rosetta 2 (DE3) cells were used to express a protein with the autoinduction system. $500 \mathrm{ml}$ of $\mathrm{ZY}$-medium were mixed with a 50xM solution, a 50x5052 solution, $\mathrm{Mg}^{2+}$-sulfate and trace elements (see section 2.1.11). The expression culture was inoculated with preculture $(1: 100)$ and incubated at $16^{\circ} \mathrm{C}$ for $72 \mathrm{~h}$.

\subsubsection{Cell harvest and lysis}

The cell cultures were harvested using centrifugation (20 min at $5750 \mathrm{xg}$ ). The obtained cell pellets were frozen at $-20^{\circ} \mathrm{C}$ for storage or lysed for protein purification. For cell lysis the pellet was resuspended in lysis buffer; for $1 \mathrm{~g}$ cell pellet $5 \mathrm{ml}$ buffer were used. The cells were lysed using the Microfluidizer $110 \mathrm{~S}$ followed by a centrifugation step for $40 \mathrm{~min}$ at $40000 \mathrm{x}$ g to obtain a clear supernatant. The solution 
containing the protein of interest was filtrated by using a $0.2 \mu \mathrm{m}$ filter and loaded onto the appropriate affinity column.

\subsubsection{Inclusion bodies}

Protein that turned out to be completely insoluble after expression in E. coli was purified from inclusion bodies. The harvested cells were resuspended in lysis buffer and disintegrated using the Mircofluidizer followed by centrifugation (45 min at $40000 \mathrm{xg}$ ). The obtained supernatant was removed and the pellet resolved in PBS buffer containing $2 \mathrm{mM}$ DTT and $1 \%$ Triton-X. After the next centrifugation step the pellet was washed twice using PBS buffer with DTT followed by centrifugation. The pellet was solved in lysis buffer containing $8 \mathrm{M}$ UREA and incubated rotating for $1 \mathrm{~h}$ at $4{ }^{\circ} \mathrm{C}$. After incubation the sample was again centrifuged and the supernatant was loaded onto the appropriate affinity column.

\subsubsection{Protein purification}

Different affinity columns and gel filtration columns were used to purify the protein. All used columns were stored in $20 \%(\mathrm{v} / \mathrm{v})$ ethanol and washed with desalted $\mathrm{H}_{2} \mathrm{O}$ and buffer before usage. If necessary the column was regenerated after usage by washing with desalted $\mathrm{H}_{2} \mathrm{O}$ and $20 \%(\mathrm{v} / \mathrm{v}$ ) ethanol.

\subsection{Hexahistidine affinity chromatography}

Proteins containing a C- or N-terminal $\mathrm{His}_{6}$-tag were purified using Ni-NTA sepharose columns. The polyhistidine tag of the protein interacts with the immobilized $\mathrm{Ni}^{2+}$-ions on the column. The obtained supernatant after centrifugation was loaded on the column using a superloop. After binding the protein to the sepharose, the column was washed with lysis buffer containing $10 \mathrm{mM}$ imidazole to eliminate impurities. The elution of the protein was performed by using a gradient of the imidazol concentration in a certain volume $(50-250 \mathrm{ml})$ which was chosen in relation to the behavior of the protein. The regeneration of the column occurred with $0.5 \mathrm{M}$ sodium hydroxide. The samples of the chromatography were analyzed with SDS gel electrophoresis. 
Lysis buffer

\begin{tabular}{ll}
\hline $75 \mathrm{mM}$ & HEPES pH 7.4 \\
$300 \mathrm{mM}$ & $\mathrm{NaCl}$ \\
$1 \mathrm{mM}$ & PMSF \\
ALP-protease & inhibitor mix \\
$10-20 \mathrm{mM}$ & Imidazole \\
\hline
\end{tabular}

Elution buffer

\begin{tabular}{ll}
\hline $75 \mathrm{mM}$ & HEPES pH 7.4 \\
$300 \mathrm{mM}$ & $\mathrm{NaCl}$ \\
$300-500 \mathrm{mM}$ & Imidazole \\
\hline
\end{tabular}

\subsection{Glutathione-S-Transferase affinity chromatography}

For the purification of GST-tagged proteins Glutathione-sepharose 4B columns were used. The GST fusion protein adheres to glutathione which is immobilized on the matrix of the column. Proteins without this tag are not able to bind the matrix and are removed during the following washing steps. The target protein was eluted by washing the column with elution buffer which contained $30 \mathrm{mM}$ reduced glutathione. The obtained samples were analyzed using SDS-PAGE.

Lysis buffer

\begin{tabular}{ll}
\hline $75 \mathrm{mM}$ & HEPES pH 7.4 \\
$300 \mathrm{mM}$ & $\mathrm{NaCl}$ \\
$1 \mathrm{mM}$ & PMSF \\
ALP-protease inhibitor mix \\
\hline
\end{tabular}

Elution buffer

\begin{tabular}{ll}
\hline $75 \mathrm{mM}$ & HEPES pH 7.4 \\
$300 \mathrm{mM}$ & $\mathrm{NaCl}$ \\
$30 \mathrm{mM}$ & reduced glutathione \\
\hline
\end{tabular}

\subsection{StrepTactin affinity chromatography}

The binding ability of the Strep-tag and StrepTactin which is immobilized on the column matrix was used to purify Strep-tagged proteins. After loading the protein on the column a short wash step was performed. Then the protein was eluted with an elution buffer containing $2.5 \mathrm{mM}$ desthiobiotin. After usage the column had to be regenerated by washing with 2 column volumes $0.5 \mathrm{M}$ sodium hydroxide. The samples of the chromatography were analyzed with SDS gel electrophoresis. 
Lysis buffer

\begin{tabular}{lc}
\hline $75 \mathrm{mM}$ & HEPES pH 7.4 \\
$300 \mathrm{mM}$ & $\mathrm{NaCl}$ \\
$1 \mathrm{mM}$ & $\mathrm{PMSF}$ \\
\multicolumn{2}{l}{ ALP-protease inhibitor mix }
\end{tabular}

Elution buffer

\begin{tabular}{ll}
\hline $75 \mathrm{mM}$ & HEPES pH 7.4 \\
$300 \mathrm{mM}$ & $\mathrm{NaCl}$ \\
$2.5 \mathrm{mM}$ & desthiobiotin \\
\hline
\end{tabular}

\subsection{Desalting of protein solutions}

The HiPrep Desalting 26/10 column was used to exchange the buffer or to desalt a protein solution. Small molecules will enter the Sephadex G-25 Superfine beads whereas large molecules directly pass the column and elute first. The maximum sample volume which can be loaded onto this column is $12.5 \mathrm{ml}$.

\subsection{Size exclusion chromatography}

During the size exclusion chromatography the proteins are separated according to their size. Smaller molecules are able to enter deeper into the pores of the matrix than big molecules, which means that proteins with a higher molecular weight can migrate faster through the column.

The column was equilibrated with a buffer and the concentrated protein sample was loaded. SDS gel electrophoresis was used to analyze the obtained samples.

Size exclusion buffer

\begin{tabular}{ll}
\hline $10 \mathrm{mM}$ & HEPES pH 7.4 \\
$150 \mathrm{mM}$ & $\mathrm{NaCl}$ \\
\hline
\end{tabular}

\subsubsection{SDS polyacrylamide gel electrophoresis (SDS-PAGE)}

To separate and analyze proteins due to their size SDS polyacrylamide gel electrophoresis was performed. Four sets of glass and ceramic plates with spacers were packed into the Hoefer miniVE system for the gel preparation. The chamber was filled to $80 \%$ with a separating gel solution and covered with isopropyl alcohol. After the polymerization of the resolving gel the 2-propanol was removed and the stacking gel solution was added. Inserted combs created reservoirs for the protein samples. After the final polymerization the gels were directly used or stored at $4{ }^{\circ} \mathrm{C}$. 
Depending on the size of the protein different acrylamide concentrations were used to generate $5 \%, 7.5 \%, 10 \%, 12.5 \%$ or $15 \%$ resolving gels.

\begin{tabular}{ll} 
Resolving Gel & \\
\hline 7.5-15\%(w/v) & Acrylamide/Bisacrylamide (37.5:1) \\
$0.375 \mathrm{M}$ & Tris/HCl pH 8.8 \\
$0.1 \%(\mathrm{w} / \mathrm{v})$ & SDS \\
$0.1 \%(\mathrm{v} / \mathrm{v})$ & TEMED \\
$0.05 \%(\mathrm{w} / \mathrm{v})$ & APS \\
\hline
\end{tabular}

\begin{tabular}{ll} 
Stacking Gel & \\
\hline $5 \%(\mathrm{w} / \mathrm{v})$ & Acrylamide/Bisacrylamide (37.5:1) \\
$0.125 \mathrm{M}$ & Tris/HCl pH 6.8 \\
$0.1 \%(\mathrm{w} / \mathrm{v})$ & SDS \\
$0.1 \%(\mathrm{v} / \mathrm{v})$ & TEMED \\
$0.05 \%(\mathrm{w} / \mathrm{v})$ & APS \\
\hline
\end{tabular}

The protein samples were mixed with 2xLaemmli sample buffer [55] and heated for $5 \mathrm{~min}$ at $95^{\circ} \mathrm{C}$. After loading the samples into the reservoirs the gel was run at $35 \mathrm{~mA}$ for $75 \mathrm{~min}$. The finished gel was incubated with a staining solution in order to visualize the protein bands. $\mathrm{H}_{2} \mathrm{O}$ was used for destaining.

The destained gels were digitized using a scanner (Canon CanoScan 5600F).

\begin{tabular}{ll} 
2xLaemmli sample buffer \\
\hline $62.5 \mathrm{mM}$ & Tris/HCl pH 6.8 \\
$70 \mathrm{mM}$ & SDS \\
$55 \%(\mathrm{v} / \mathrm{v})$ & Glycerol \\
$0.1 \%(\mathrm{w} / \mathrm{v})$ & Bromphenol blue \\
$5 \%(\mathrm{v} / \mathrm{v})$ & 2-Mercaptoethanol
\end{tabular}




\begin{tabular}{ll} 
Running buffer & \\
\hline $25 \mathrm{mM}$ & Tris/HCl \\
$192 \mathrm{mM}$ & Glycine \\
$0.1 \%(\mathrm{w} / \mathrm{v})$ & SDS \\
\hline
\end{tabular}

Staining solution

\begin{tabular}{ll}
\hline $10 \%(\mathrm{v} / \mathrm{v})$ & Ethanol \\
$5 \%(\mathrm{v} / \mathrm{v})$ & Acetic acid \\
$0.002 \%(\mathrm{w} / \mathrm{v})$ & Coomassie Brilliant Blue G/R250 \\
\hline
\end{tabular}

\subsubsection{Proteolytic digestion with PreScission protease}

To remove the GST-tag from the corresponding $\mathrm{C}_{2}$-domain, PreScisson protease (GE Healthcare) was added in a ratio 1:100 and the solution was incubated overnight at $4{ }^{\circ} \mathrm{C}$. To confirm a successful cleavage of the fusion-protein, an SDS-PAGE was performed containing an undigested and a digested sample.

\subsubsection{Concentrating protein solutions}

Amicon concentrators (Merck Millipore) were used for protein concentration. These concentrators contain membranes with a specific molecular weight cut-off. The chosen cut-off depends on the size of the protein. During centrifugation at $4000 \mathrm{xg}$ and $4{ }^{\circ} \mathrm{C}$ small molecules like $\mathrm{H}_{2} \mathrm{O}$ or ions can pass the membrane while the target-protein remains in the upper part of the concentrator. This leads to an increased protein concentration.

\subsubsection{Determination of the protein concentration}

The protein concentration was measured using the Bradford reagent. The principle of this measurement is based on the change in absorption of Coomassie Brilliant Blue G-250 during the binding to proteins.

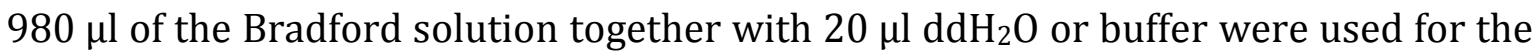
blank value. To measure the concentration $20 \mu \mathrm{l}$ of the protein solution were mixed with $980 \mu \mathrm{l}$ Bradford solution and measured at a wavelength of $595 \mathrm{~nm}$. 


\subsubsection{Phosphorylation with CaMKII $\delta$ and inhibition using CBD}

For in vitro phosphorylation the two otoferlin fragments $\left(\mathrm{C}_{2} \mathrm{ABC}\right.$ and $\mathrm{C}_{2} \mathrm{DEF}$, 21.49 pmol each) in assay buffer were incubated with the same amount of Calmodulin-dependent kinase II delta (CaMKII $\delta$ ) for $5 \mathrm{~min}$ at $30^{\circ} \mathrm{C}$. The reaction was stopped by adding $2 x$ Laemmli buffer and heating for $5 \mathrm{~min}$ at $30^{\circ} \mathrm{C}$. To test if the Calmodulin binding domain (CBD, Calbiochem, $\mathrm{IC}_{50}=52 \mathrm{nM}$ ) is able to inhibit the phosphorylation of otoferlin, the CBD was incubated together with CaMKII $\delta$ in the reaction-buffer without calmodulin. After a 5 min incubation at $30^{\circ} \mathrm{C}$ calmodulin and otoferlin were added and incubated for another $5 \mathrm{~min}$ at $30^{\circ} \mathrm{C}$. This reaction was stopped by adding $2 x$ Laemmli buffer and heating the sample at $95^{\circ} \mathrm{C}$ for $5 \mathrm{~min}$. The CBD was used in a 10 -fold excess of the $\mathrm{IC}_{50}$ value. The samples were loaded onto an SDS gel. These gels were sent to our collaborators who analyzed the bands by mass spectrometry in the lab of C. Adams, Stanford, USA.

\subsubsection{Screen for protein-protein-interactions using pull-down assays}

To look for possible interaction partners of the $\mathrm{C}_{2} \mathrm{ABC}$-fragment of otoferlin pull-down assays were performed. In the first experiment Ni-NTA sepharose beads were used. The His $_{6}$-tagged $\mathrm{C}_{2} \mathrm{ABC}$-fragment $(2 \mathrm{nmol}$ each) was incubated with appropriate beads for $8 \mathrm{~h}$ at $4{ }^{\circ} \mathrm{C}$ to immobilize the proteins onto the beads. Several careful washing steps were carried out to get rid of unbound proteins. After these washing steps $1 \mathrm{ml}$ lysed mouse brain, which was provided from Sunit Mandat (Urlaub-Lab, MPI-bpc, Göttingen), was added and incubated for $4 \mathrm{~h}$ or overnight. The beads were washed again to remove the free interaction partner. All incubation and washing steps were performed at $4{ }^{\circ} \mathrm{C}$ or on ice. For the analysis the beads-samples were loaded on an SDS-PAGE, digested and analyzed with mass spectrometry.

Due to the fact that sometimes $\mathrm{Ni}$-beads bound unspecific proteins the same experiment was performed using a shorter $\mathrm{C}_{2} \mathrm{ABC}$-fragment containing a Strep-tag which was bound to Strep-beads. The following steps were performed as described before.

Wash buffer

\begin{tabular}{ll}
\hline $10 \mathrm{mM}$ & HEPES pH 7.4 \\
$150 \mathrm{mM}$ & $\mathrm{NaCl}$ \\
\hline
\end{tabular}


In a second pull-down experiment epoxy-activated Eupergit beads were used which react with the amino- and thiol-groups of the protein. Before usage the beads were washed with water twice and treated with full power in an ultrasonic bath pulsed for about 2 min. afterwards the beads were centrifuged at 1300xg for $6 \mathrm{~min}$. The supernatant was removed and the protein solution added (15 nmol) followed by an incubation step at $4^{\circ} \mathrm{C}$ for $8 \mathrm{~h}$. After the incubation the supernatant was removed and the beads were washed with protein buffer. To block all the remaining binding sides on the beads, $1 \mathrm{M}$ glycine was added to the beads and incubated overnight at $4{ }^{\circ} \mathrm{C}$. To prepare the beads for further use, the supernatant was discarded and the beads were washed alternating with wash buffer 1 and wash buffer 2 three times each. The beads were split up into $10 \mu \mathrm{l}$ aliquots and stored at $-80^{\circ} \mathrm{C}$. In this experiment mouse synaptosomes were used for interaction partner screening. The synaptosomes were prepared from Sunit Mandat using a published protocol [56]. Different detergents (see below) were added to the synaptosomes and incubated for $1 \mathrm{~h}$ at $4{ }^{\circ} \mathrm{C}$. The lysed synaptosomes were incubated with the prepared protein containing beads overnight at $4{ }^{\circ} \mathrm{C}$. The samples were rotated during all the incubation steps. After removing the supernatant the beads were washed with protein buffer for several times and analyzed using mass spectrometry, the latter by Sunit Mandat in the lab of Henning Urlaub.

\begin{tabular}{ll} 
Protein buffer & \\
\hline $10 \mathrm{mM}$ & HEPES pH 7.4 \\
$150 \mathrm{mM}$ & $\mathrm{NaCl}$ \\
\hline
\end{tabular}

Wash buffer 1

\begin{tabular}{ll}
\hline $100 \mathrm{mM}$ & Sodium acetate $\mathrm{pH} 4.7$ \\
$500 \mathrm{mM}$ & $\mathrm{NaCl}$ \\
\hline
\end{tabular}

Wash buffer 2

\begin{tabular}{ll}
\hline $100 \mathrm{mM}$ & Tris/HCl pH 8.0 \\
$500 \mathrm{mM}$ & $\mathrm{NaCl}$ \\
\hline
\end{tabular}

beads

\begin{tabular}{lll}
\hline His Pur ${ }^{\mathrm{TM}}$ Ni-NTA Resin & ThermoScientific & His-tag \\
Strep-Tactin ${ }^{\circledR}$ Superflow ${ }^{\circledR}$ & IBA & Strep-tag \\
$\begin{array}{l}\text { Eupergit C17 methacrylate } \\
\text { microbeads }\end{array}$ & Röhm Pharmaceuticals & Amino binding \\
\hline
\end{tabular}


Detergents

\begin{tabular}{ll}
\hline Lauryl sarcosine (LS) & Sigma-Aldrich \\
Sodium dodecyl sulfate (SDS) & Carl Roth \\
Octyl glucopyranoside (OGP) & Sigma-Aldrich \\
Complexiolyte (COM) & Logopharm GmbH \\
Dodecyl maltoside (DDM) & Sigma-Aldrich \\
\hline
\end{tabular}

\subsubsection{Thermal shift assay}

To get information about the stability of the different $\mathrm{C}_{2}$-domains thermal shift assays were performed (Bio-Rad C1000/CFX96) to obtain possible melting temperatures. The proteins of interest were mixed with a fluorescent dye (Sypro ${ }^{\circledR}$ Orange, 1:1000) and heated in small steps. At a specific temperature the protein unfolds and the fluorescent dye can bind to the hydrophobic patches of the protein. In this work single $\mathrm{C}_{2}$-domains and fragments containing up to three $\mathrm{C}_{2}$-domains were used. The protein fragments were measured alone or in the presence of other $\mathrm{C}_{2}$-domains. Each experiment was performed in the presence and absence of $\mathrm{Ca}^{2+}(200 \mu \mathrm{M})$. A protein concentration of $100 \mathrm{pmol}$ was used; the second tested fragment was added in a 1:1 ration. The sample solution was pipetted into a 96-well plate and centrifuged (10 min, $1500 \mathrm{xg}$ ). For the measurement a temperature profile from $20-95^{\circ} \mathrm{C}$ was used, the temperature was increased $1{ }^{\circ} \mathrm{C}$ per step (30 s). For the data analysis MaxStAF and Origin Pro 8.5G were used.

\subsubsection{Dissociation constant determination using Microscale Thermophoresis}

To get information about the $\mathrm{Ca}^{2+}$-binding ability of otoferlin $\mathrm{C}_{2}$-domains, MircoScale Thermophoresis was performed. In this method the intrinsic tryptophan fluorescence of the molecule of interest is used for detection. When performing a MST experiment, a microscopic temperature gradient is induced by an infrared laser, and the directed movement of molecules is detected and quantified. Any binding event or conformational rearrangement leads to changes in the thermophoretic movement caused by changes in the hydration shell, size or charge of the molecule. By means of these changes it is possible to determine specific $K_{\mathrm{D}}$ values.

The protein was adjusted to a defined concentration in size exclusion buffer (see section 2.2.2.4.5) with $0.1 \%$ Tween. The $\mathrm{Ca}^{2+}$-chloride was dissolved in the same 
buffer as the protein and a series of $161: 2$ dilutions was prepared with the identical buffer, producing a ligand concentration ranging from $400 \mathrm{mM}$ to $1.2 \mu \mathrm{M}$. For the thermophoresis measurements each ligand dilution was mixed with the same volume of the tryptophan containing component, which leads to a final protein concentration of $1 \mu \mathrm{M}$ to $4 \mu \mathrm{M}$ and final $\mathrm{Ca}^{2+}$-concentrations of $200 \mathrm{mM}$ to $0.6 \mu \mathrm{M}$.

The samples were loaded in Monolith NT.LabelFree standard treated capillaries (NanoTemper Technologies $\mathrm{GmbH}$ ). The thermophoresis was measured using the NT.LabelFree instrument (NanoTemper Technologies $\mathrm{GmbH}$ ) at a constant temperature of $22{ }^{\circ} \mathrm{C}$ with $5 \mathrm{~s} / 30 \mathrm{~s} / 5 \mathrm{~s}$ laser off/on/off times. The instrument parameters were adjusted with $5 \%$ LED power and $20 \%$ MST power. Data sets of three independently pipetted measurements were analyzed using the temperature jump (T-jump) signal. The T-jump shows sensitive changes which are in close proximity to the tryptophan that is used for detection. These changes can result from a direct binding event or can be induced by a conformational change. The thermophoresis signal on the other hand provides information of the overall structure of the newly formed complex. 


\section{RESULTS}

\subsection{Protein fragments}

One goal of this work was to express and purify different single $\mathrm{C}_{2}$-domains or combinations of $\mathrm{C}_{2}$-domains from $E$. coli for crystallization and interaction studies.

Table 3.1-1 List of purified otoferlin fragments. Length and mass are given in number of amino acids and kDa. N (N-terminal) and C (C-terminal) mark the position of the tag. Fragments marked with $a$ and $b$ were kindly provided by Dr. Sarah Helfmann $(a)$ and Dr. Kirsten Reuter $(b)$. The numbers at the fragment name display the organism and the accession-number: 1 (mus musculus NP_001093865), 2 (rattus norvegicus NP_001263649), 3 (mus musculus NP_034195.2).

\begin{tabular}{|c|c|c|c|}
\hline Name & Amino acids & Mol. mass (kDa) & Affinity tag \\
\hline $\mathrm{C}_{2} \mathrm{AB}^{a, 1}$ & $1-433$ & 48.2 & $\mathrm{His}_{6}-\operatorname{tag}(\mathrm{N})$ \\
\hline $\mathrm{C}_{2} \mathrm{ABC}^{1}$ & $1-616$ & 69.8 & $\mathrm{His}_{6}-\operatorname{tag}(\mathrm{C})$ \\
\hline $\mathrm{C}_{2} \mathrm{ABC}-\mathrm{I} 515 \mathrm{~T} 1$ & $1-616$ & 69.8 & $\mathrm{His}_{6}-\operatorname{tag}(\mathrm{C})$ \\
\hline $\mathrm{C}_{2} \mathrm{ABC}$-short ${ }^{1}$ & $1-581$ & 66.9 & Strep-tag (N) \\
\hline $\mathrm{C}_{2} \mathrm{~B}^{a, 2}$ & $217-414$ & 22.3 & GST-tag (N) \\
\hline $\mathrm{C}_{2} \mathrm{C}^{a, 2}$ & $410-616$ & 23.4 & GST-tag (N) \\
\hline $\mathrm{C}_{2} \mathrm{C}-$ phos $^{2}$ & $410-616$ & 23.4 & GST-tag (N) \\
\hline $\mathrm{C}_{2} \mathrm{E}^{a, 2}$ & $1435-1658$ & 25.6 & GST-tag $(\mathrm{N})$ \\
\hline $\mathrm{C}_{2} \mathrm{~F}^{a, 2}$ & $1695-1934$ & 28.1 & GST-tag (N) \\
\hline $\mathrm{C}_{2} \mathrm{~F}-$ phos $^{1}$ & $1695-1934$ & 28.0 & GST-tag (N) \\
\hline $\mathrm{C}_{2} \mathrm{~F}-\mathrm{D} 1 \mathrm{~N}^{2}$ & $1695-1934$ & 27.9 & GST-tag (N) \\
\hline $\mathrm{C}_{2} \mathrm{~F}-\mathrm{D} 2,3 \mathrm{~N}^{2}$ & $1695-1934$ & 27.9 & GST-tag (N) \\
\hline $\mathrm{C}_{2} \mathrm{~F}-\mathrm{D} 1,2,3 \mathrm{~N}^{2}$ & $1695-1934$ & 28.0 & GST-tag (N) \\
\hline $\mathrm{C}_{2} \mathrm{~F}-\mathrm{D} 4 \mathrm{~N}$ & $1695-1934$ & 28.0 & GST-tag (N) \\
\hline $\mathrm{C}_{2} \mathrm{~F}-p g a^{b, 2}$ & $1699-1934$ & 27.2 & GST-tag (N) \\
\hline $\mathrm{C}_{2} \mathrm{~F}-\mathrm{E} 1804 \mathrm{del}^{2}$ & $1695-1934$ & 27.8 & GST-tag (N) \\
\hline $\mathrm{C}_{2} \mathrm{DEF}^{1}$ & $908-1932$ & 117.9 & GST-tag (N) \\
\hline Dynamin $1^{3}$ & $1-752$ & 87.5 & Strep-tag (C) \\
\hline
\end{tabular}


In Table 3.1-1 all proteins are shown which are described in this work. Different protein fragments containing one to three $\mathrm{C}_{2}$-domains were used. Information about the fragment length, molecular mass and the used affinity tag are given in the table.

\subsection{Purification of $\mathrm{His}_{6}-\mathrm{C}_{2} \mathrm{AB}$}

The $\mathrm{C}_{2} \mathrm{AB}$-fragment of otoferlin was cloned into the pET28a vector. The His ${ }_{6}$-tagged protein was overexpressed at $30^{\circ} \mathrm{C}$ in E. coli SoluBL21 cells. After induction with IPTG the temperature was changed to $16^{\circ} \mathrm{C}$ and the cells were harvested $16 \mathrm{~h}$ after induction. The cells were lysed with a buffer (see section 2.2.2.4.1) containing $10 \mathrm{mM}$ imidazole. The obtained supernatant after centrifugation was loaded on to $5 \mathrm{ml}$ His-Trap-columns (GE Healthcare). The eluted protein was concentrated and a S200 $(16 / 60)$ size exclusion chromatography (Figure 3.2-1) was performed. Selected fractions were analyzed by SDS-PAGE.

$$
\text { A }
$$

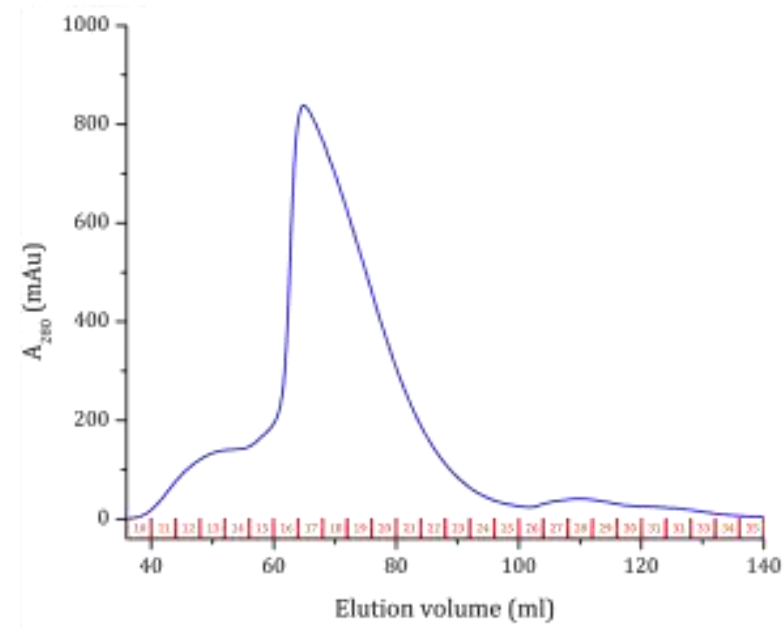

$\mathrm{B}$

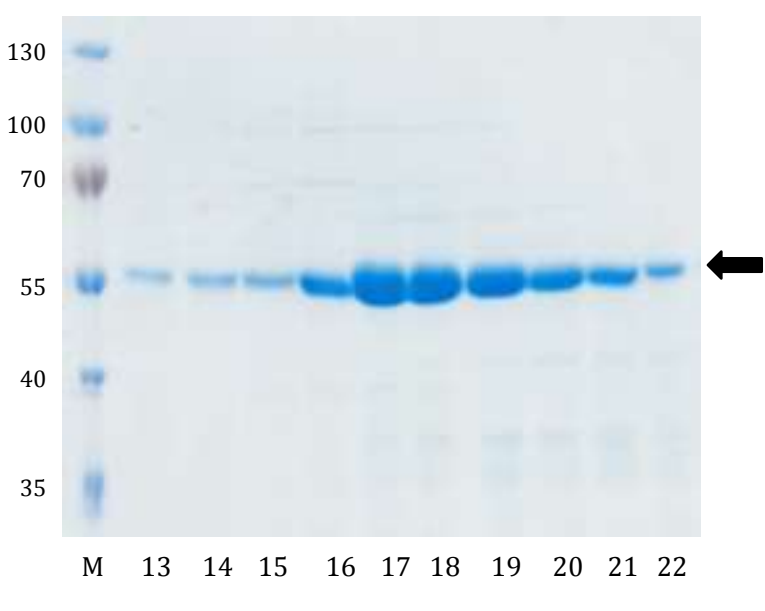

Figure 3.2-1 Size exclusion chromatography of $\mathrm{His}_{6}-\mathrm{C}_{2} \mathrm{AB}$.

A The UV absorption at $280 \mathrm{~nm}$ in the chromatogram is depicted as a blue line which is plotted against the elution volume and the fraction numbers are shown in red. The elution maximum at $70 \mathrm{ml}$ corresponds to the $\mathrm{His}_{6}-\mathrm{C}_{2} \mathrm{AB}$ monomer.

B The $12.5 \%$ coomassie-stained SDS-PAGE gel of His $_{6}-\mathrm{C}_{2} \mathrm{AB}$ contains selected fractions of the purification. $\mathrm{M}$ indicates the molecular weight marker in $\mathrm{kDa}$ and the numbers refer to the fractions of the size exclusion chromatography. The target protein is marked by an arrow.

\subsection{Purification of $\mathrm{C}_{2} \mathrm{ABC}-\mathrm{His}_{6}$}

The $\mathrm{C}_{2} \mathrm{ABC}$-fragment was cloned into the pPSG-IBA33 vector using the StarGate cloning system and overexpressed in E. coli BL21 cells. The cultures were harvested $20 \mathrm{~h}$ after induction with IPTG. The obtained supernatant after cell lysis was loaded on a His-Trap and the protein of interest was eluted using an imidazole gradient. The 
pooled protein fractions were concentrated and a S200 (16/60) size exclusion chromatography (Figure 3.3-1) was performed. Selected fractions were analyzed by SDS-PAGE.

A

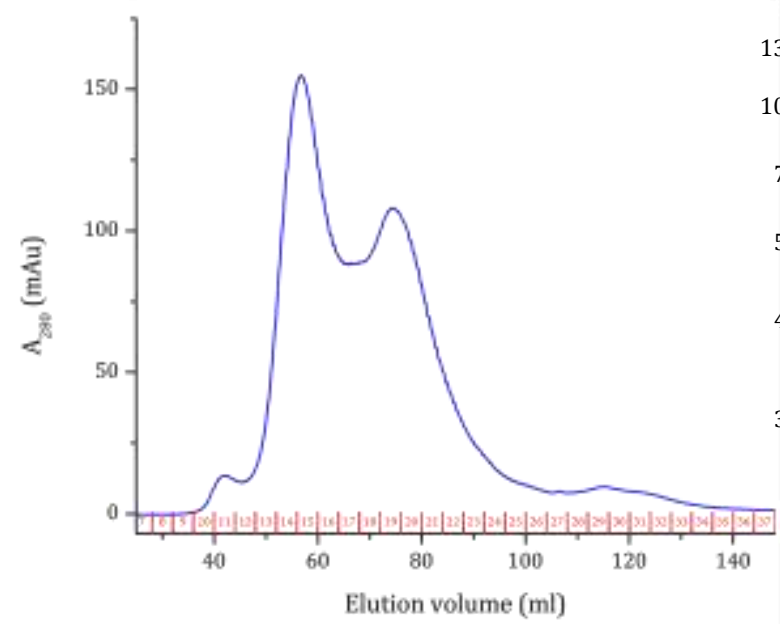

B

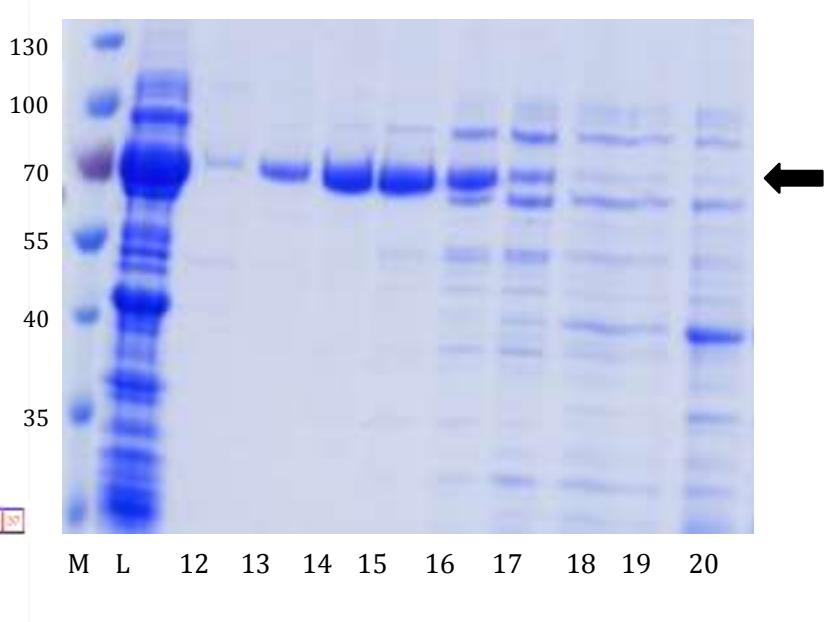

Figure 3.3-1 Size exclusion chromatography of $\mathrm{C}_{2} \mathrm{ABC}$-His6.

A The UV absorption at $280 \mathrm{~nm}$ in the chromatogram is depicted as a blue line which is plotted against the elution volume and the fraction numbers are shown in red. There is an elution maximum at $57 \mathrm{ml}$ corresponding to the $\mathrm{C}_{2} \mathrm{ABC}$-fragment.

B The $12.5 \%$ coomassie-stained SDS-PAGE gel of $\mathrm{C}_{2} \mathrm{ABC}-\mathrm{His}_{6}$ contains selected samples of the purification. $\mathrm{M}$ indicates the molecular weight marker in $\mathrm{kDa}$ and the numbers refer to the fractions of the size exclusion chromatography. The target protein is marked by an arrow. For further experiments the combined fractions 13 to 15 were used.

\subsection{Purification of I515T-His 6}

The I515T is an otoferlin mutation which leads to temperate sensitive deafness [51]. The mutation was subcloned into the $\mathrm{C}_{2} \mathrm{ABC}-\mathrm{His}_{6}$-fragment using the QuikChange protocol. At position 515 an isoleucine was replaced by a threonine, this mutation is located in the $\mathrm{C}_{2} \mathrm{C}$-domain of the protein. The expression and purification protocol was the same as for the $\mathrm{C}_{2} \mathrm{ABC}$-His6-fragment. 
A

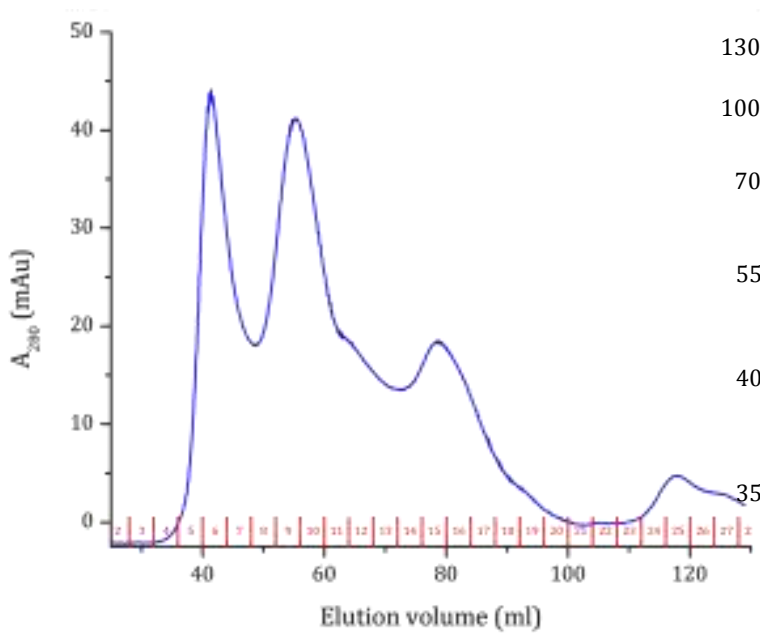

B

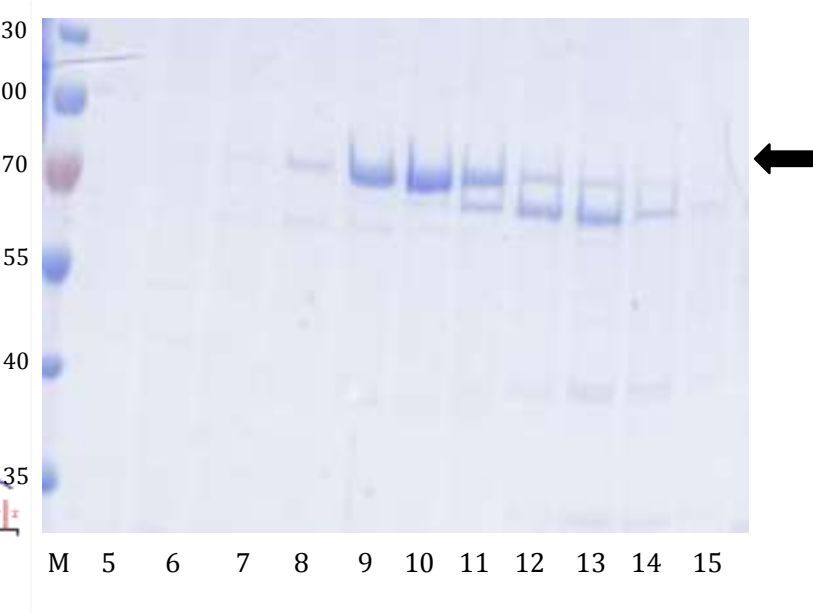

Figure 3.4-1 Size exclusion chromatography of I515T-His 6.

A The blue line displays the UV absorption at $280 \mathrm{~nm}$ which is plotted against the elution volume. The fraction numbers are shown in red. The elution maximum at $55 \mathrm{ml}$ corresponds to the I515T-fragment. B The $12.5 \%$ coomassie-stained SDS-PAGE gel of I515T-His6 contains selected samples of the purification. $\mathrm{M}$ indicates the molecular weight marker in $\mathrm{kDa}$ and the numbers refer to the fractions of the size exclusion chromatography. The target protein is marked by an arrow.

\subsection{Purification of Strep- $C_{2} A B C$-short}

A

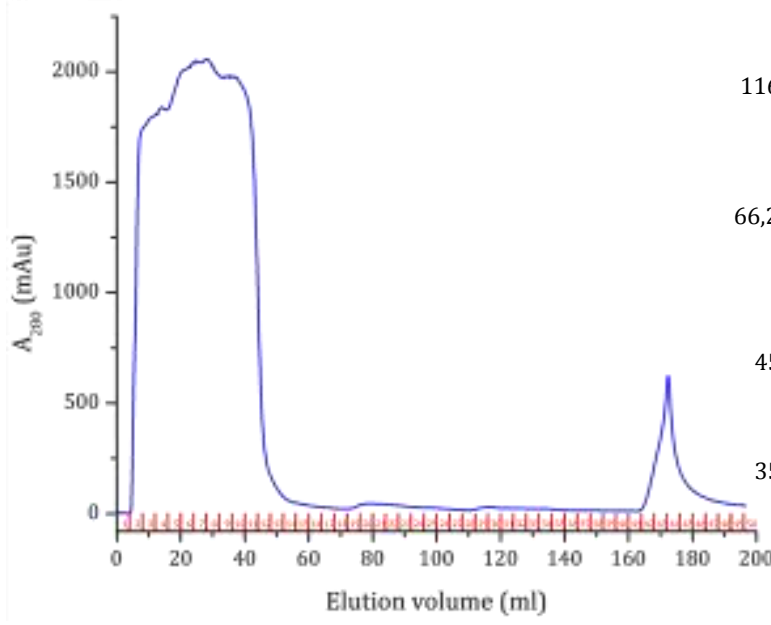

B

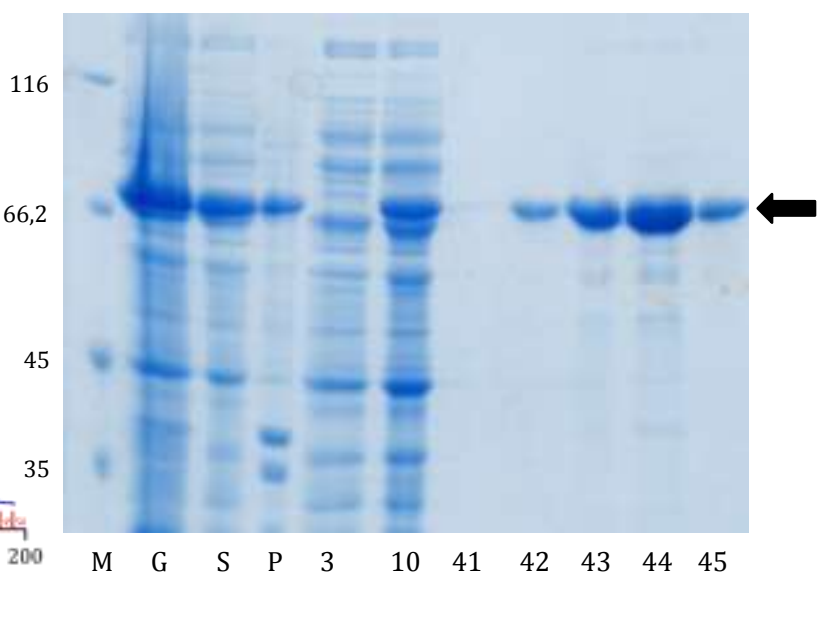

Figure 3.5-1 Strep-column chromatography of Strep- $\mathrm{C}_{2} \mathrm{ABC}$-short.

A The UV absorption at $280 \mathrm{~nm}$ in the chromatogram is depicted as a blue line which is plotted against the elution volume and the fraction numbers are shown in red. There is an elution maximum at $170 \mathrm{ml}$ corresponding to the Strep- $\mathrm{C}_{2} \mathrm{ABC}$-fragment.

B The $12.5 \%$ coomassie-stained SDS-PAGE gel of Strep- $\mathrm{C}_{2} \mathrm{ABC}$-short contains selected samples of the purification. $\mathrm{M}$ indicates the molecular weight marker in $\mathrm{kDa}, \mathrm{G}$ is a sample after cell lysis. $\mathrm{S}$ (supernatant) and P (pellet) are samples after centrifugation. The numbers refer to the fractions of the Strep-column chromatogram. Marked by an arrow the target protein is shown.

Using the StarGate cloning system, a shorter variant of the $\mathrm{C}_{2} \mathrm{ABC}$-fragment was incorporated into the Strep-tag containing pPSG-IBA5 vector. The protein was 
expressed in E. coli SoluBL21 cells, induced with IPTG and harvested $20 \mathrm{~h}$ after induction. After cell lysis and centrifugation, the obtained supernatant was loaded onto a Strep-column (Figure 3.5-1). Desthiobiotin was used to elute the protein from the column. Selected fractions were analyzed by SDS-PAGE.

\subsection{Purification of GST- $\mathrm{C}_{2} \mathrm{~B}$}

The $\mathrm{C}_{2} \mathrm{~B}$-fragment of the protein otoferlin was cloned into the pGEX-6P-3 vector and overexpressed in E. coli SoluBL21 cells. $20 \mathrm{~h}$ after induction with IPTG, the cells were harvested and lysed using the microfluidizer system. The obtained supernatant from centrifugation was loaded onto a GSH-column and the protein of interest eluted with a buffer containing reduced glutathione. The protein containing fractions were pooled and the reduced glutathione was removed using a desalting column (HiPrep Desalting 26/10). The obtained protein solution was incubated with PreScission protease at $4{ }^{\circ} \mathrm{C}$ overnight. In the next step another GSH-column was performed to separate the target protein from the cleaved GST-tag, followed by a S200 (26/60) size exclusion chromatography (Figure 3.6-1). Selected fractions were analyzed by SDS-PAGE.

A

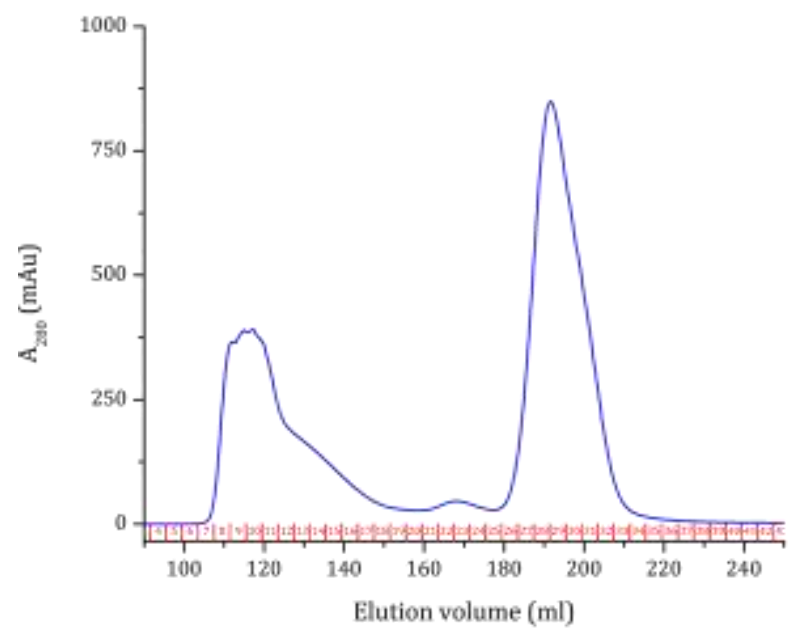

B

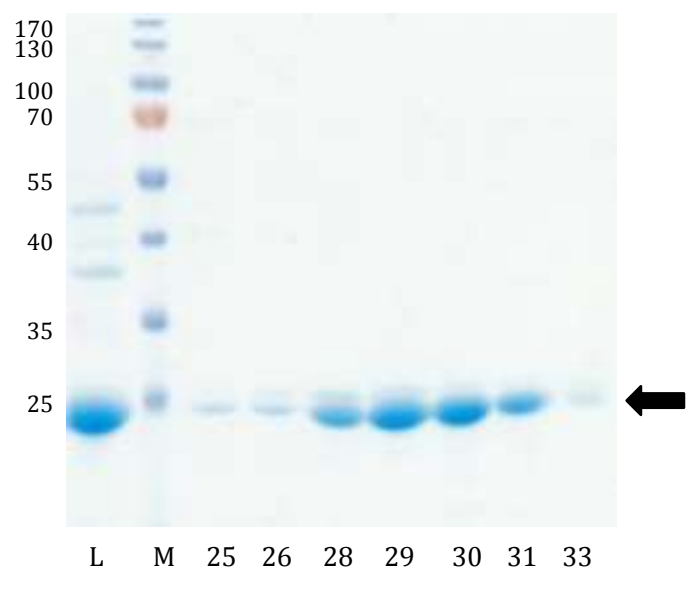

Figure 3.6-1 Size exclusion chromatography of GST- $\mathrm{C}_{2} \mathrm{~B}$.

A The blue line displays the UV absorption at $280 \mathrm{~nm}$ which is plotted against the elution volume. The fraction numbers are shown in red. The elution maximum at $195 \mathrm{ml}$ corresponds to the $\mathrm{C}_{2} \mathrm{~B}$-dimer.

B The $15 \%$ coomassie-stained SDS-PAGE gel of GST- $C_{2} B$ contains selected fractions of the purification. $\mathrm{M}$ indicates the molecular weight marker in $\mathrm{kDa}, \mathrm{L}$ is the protein sample before loading on the size exclusion column. The numbers refer to the fractions of the size exclusion chromatography and the target molecule is marked by an arrow. 


\subsection{Purification of GST- $\mathrm{C}_{2} \mathrm{C}$}

The $\mathrm{C}_{2} \mathrm{C}$-domain was expressed in E. coli Rosetta 2 (DE 3) cells using the autoinduction system (see section 2.2.2.1.2). After cell lysis, the protein solution was loaded onto a GSH-column and the target protein was eluted using reduced glutathione. The pooled elution fractions were incubated with PreScission protease at $4{ }^{\circ} \mathrm{C}$ to cleave off the GST-tag. An SDS-gel confirmed the successful cleavage and the protein was concentrated and loaded onto a S200 (16/60) size exclusion column (Figure 3.7-1). Afterwards, a second GSH-column was performed to separate the GST-tag and the $\mathrm{C}_{2}$-domain. According to their sizes both proteins eluted in the same peak from the size exclusion column. Selected fractions were analyzed by SDS-PAGE.

A

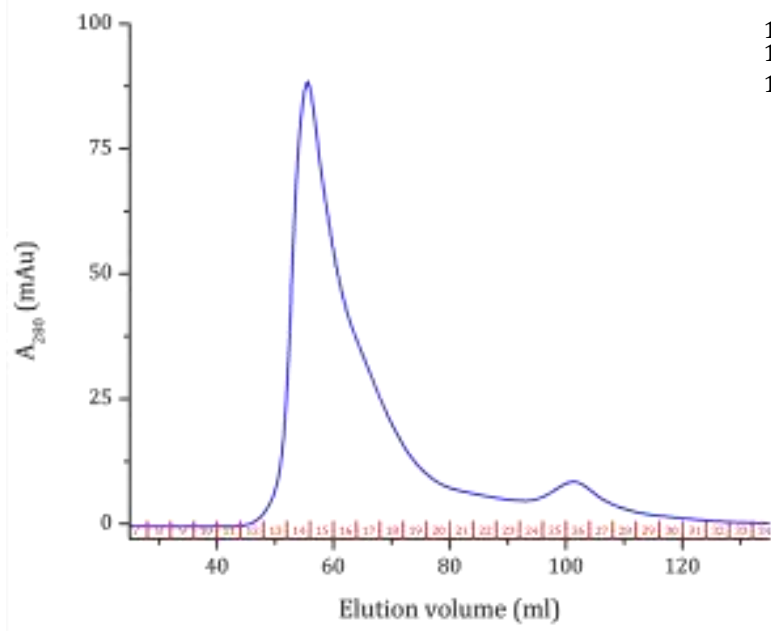

B

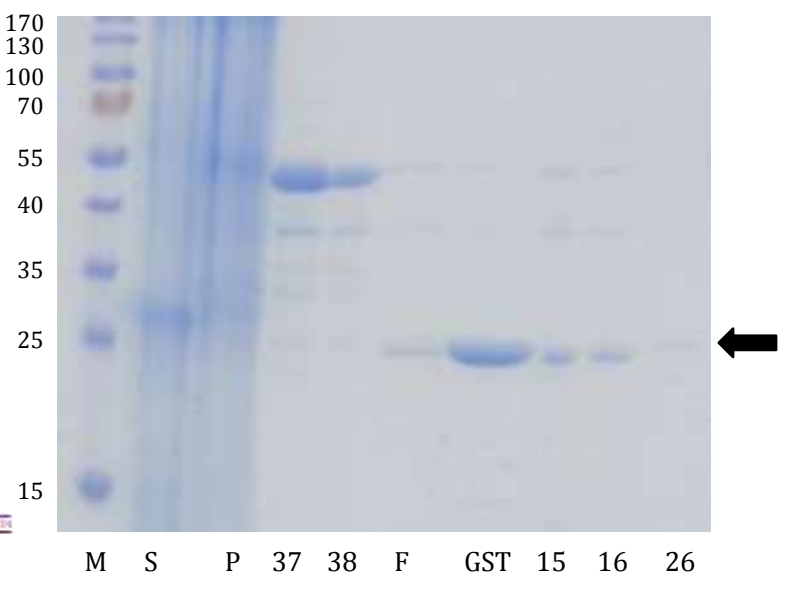

Figure 3.7-1 Size exclusion chromatography of GST- $\mathrm{C}_{2} \mathrm{C}$.

A The UV absorption at $280 \mathrm{~nm}$ in the chromatogram is depicted as a blue line which is plotted against the elution volume and the fraction numbers are shown in red. There is an elution maximum at $103 \mathrm{ml}$ corresponding to the $\mathrm{C}_{2} \mathrm{C}$-dimer.

B The $15 \%$ coomassie-stained SDS-PAGE gel of GST- $\mathrm{C}_{2} \mathrm{C}$ contains selected fractions of the purification. $\mathrm{M}$ indicates the molecular weight marker in $\mathrm{kDa}, \mathrm{S}$ (supernatant) and $\mathrm{P}$ (pellet) are samples after cell lysis. The numbers 37 and 38 are samples from the GST-column elution peak. F shows the flow-through of the second GSH-column and GST the elution peak. The numbers 15 to 26 refer to the fractions of the size exclusion chromatography. The arrow marks the target protein.

\subsection{Purification of GST-C ${ }_{2}$ C-phos}

In order to mimic a phosphorylation site identified in an experiment described in section 3.15 in the $\mathrm{C}_{2} \mathrm{C}$-domain of otoferlin the threonine at position 448 was mutated into an aspartic acid using the QuikChange protocol (see section 2.1.3). The protein was expressed and purified like the wild type form. After autoinduction expression in E. coli Rosetta 2 (DE 3), the harvested cells were lysed and the protein of interest was extracted from the protein solution using a GSH-column. The GST-tag was cleaved off 
during incubation with PreScission protease overnight at $4{ }^{\circ} \mathrm{C}$. The cleaved protein was concentrated and a S200 (16/60) size exclusion chromatography (Figure 3.8-1) was performed. The $\mathrm{C}_{2}$-domain and the GST-tag eluted in the same peak of the size exclusion chromatography due to their size. The remaining GST-tag was removed by performing a second GSH-column. Selected fractions were analyzed by SDS-PAGE.

A

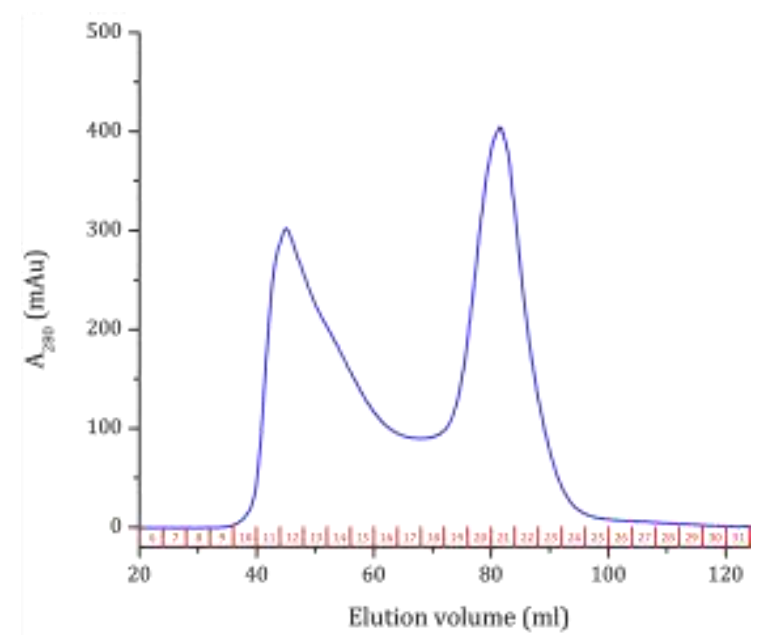

B

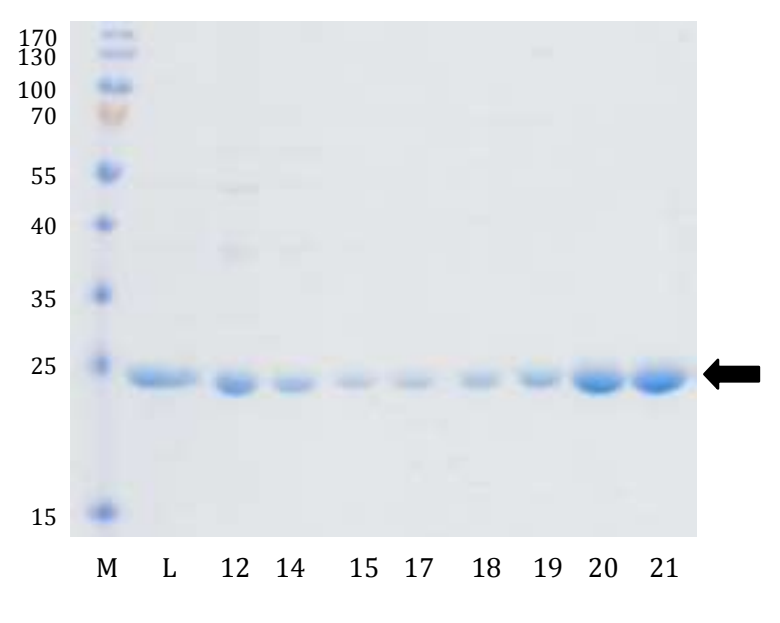

Figure 3.8-1 Size exclusion chromatography of GST-C C-phos.

A The blue line displays the UV absorption at $280 \mathrm{~nm}$ which is plotted against the elution volume. The fraction numbers are shown in red. The elution maximum at $85 \mathrm{ml}$ corresponds to the $\mathrm{C}_{2} \mathrm{C}$-phos-dimer. B The $15 \%$ coomassie-stained SDS-PAGE gel of GST- $\mathrm{C}_{2} \mathrm{C}$-phos contains selected fractions of the purification. M indicates the molecular weight marker in $\mathrm{kDa}$, $\mathrm{L}$ is the loaded protein sample and the numbers refer to the fractions of the size exclusion chromatography. The target protein is marked by an arrow.

\subsection{Purification of GST- $C_{2} E$}

The $\mathrm{C}_{2} \mathrm{E}$-domain of otoferlin was cloned into the pGEX-6P-3 vector containing a GST-tag and expressed using the autoinduction system. After cell lysis, the protein solution was loaded onto a GSH-column. The protein of interest was eluted using reduced glutathione. The GST-tag was cleaved off overnight at $4{ }^{\circ} \mathrm{C}$ by adding PreScission protease. In the following step a S200 (16/60) size exclusion chromatography (Figure 3.9-1) was performed. Due to their size the GST-tag and the $\mathrm{C}_{2}$-domain eluted in the same fractions. To separate the two proteins a second GSH-column was performed. Selected fractions were analyzed by SDS-PAGE. 
A

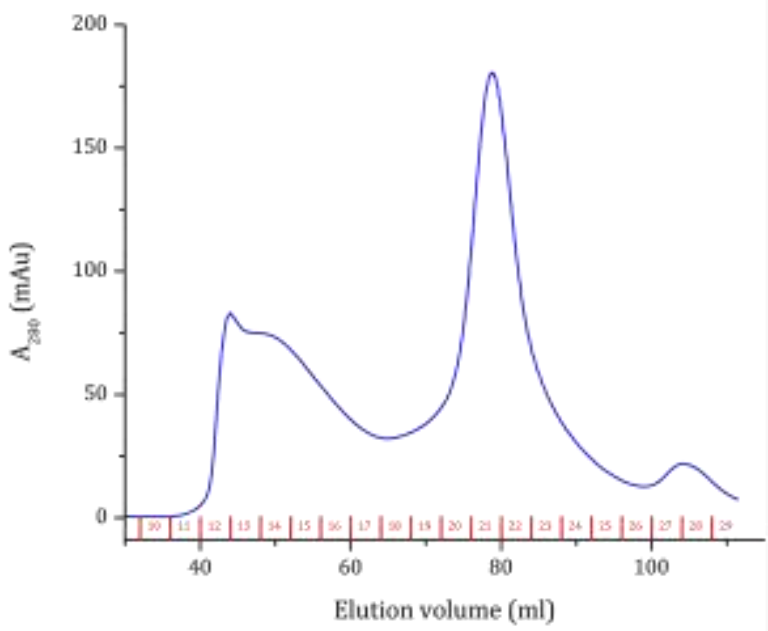

B

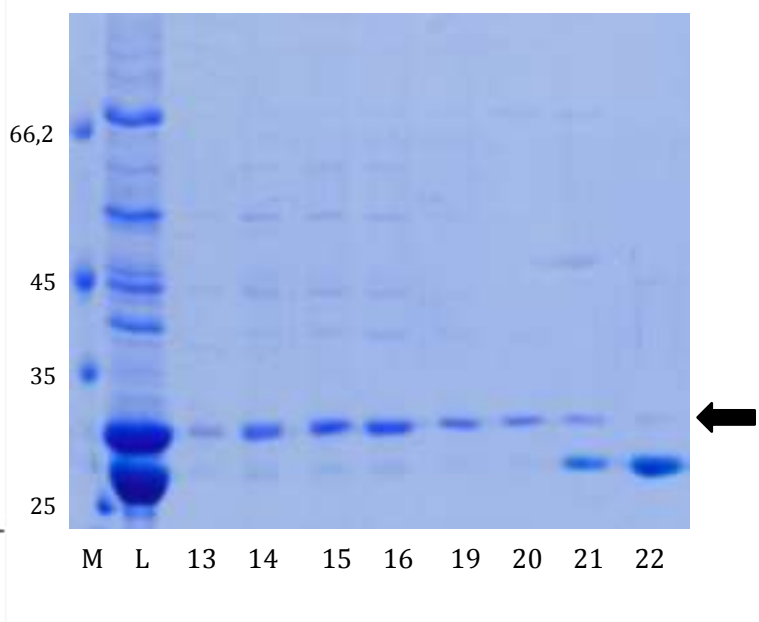

Figure 3.9-1 Size exclusion chromatography of GST- $\mathrm{C}_{2} \mathrm{E}$.

A The blue line displays the UV absorption at $280 \mathrm{~nm}$ which is plotted against the elution volume. The fraction numbers are shown in red. The elution maximum at $80 \mathrm{ml}$ corresponds to the $\mathrm{C}_{2} \mathrm{E}$-dimer.

B The $15 \%$ coomassie-stained SDS-PAGE gel of GST- $\mathrm{C}_{2} \mathrm{E}$ contains selected samples of the purification. $\mathrm{M}$ indicates the molecular weight marker in $\mathrm{kDa}$, $\mathrm{L}$ is the protein sample loaded on the size exclusion column and the numbers refer to the collected fractions.

\subsection{Purification of $\mathrm{C}_{2} \mathrm{~F}$-fragments}

All $\mathrm{C}_{2} \mathrm{~F}$-fragments shown in this work were expressed and purified following the same protocol. The proteins were cloned into the pGEX-6P-3 vector and overexpressed in E. coli Rosetta 2 (DE 3) cells using the autoinduction system. The supernatant resulting from cell lysis was loaded onto a GSH-affinity column. After elution of the target protein with a buffer containing reduced glutathione, the GST-tag was cleaved off overnight at $4{ }^{\circ} \mathrm{C}$ by adding PreScission protease. After cleavage the protein was loaded on a superdex S200 (16/60) size exclusion column. The GST-tag and the target protein eluted in the same elution peak due to their similar size and the ability to form dimers. A second GSH-column was performed to separate both proteins. Selected fractions were analyzed by SDS-PAGE. Before thermophoresis measurements, the proteins were incubated with Chelex for $1 \mathrm{~h}$ at $4{ }^{\circ} \mathrm{C}$ to remove all $\mathrm{Ca}^{2+}$-ions. 


\subsubsection{GST- $C_{2} F$ wild type}

A

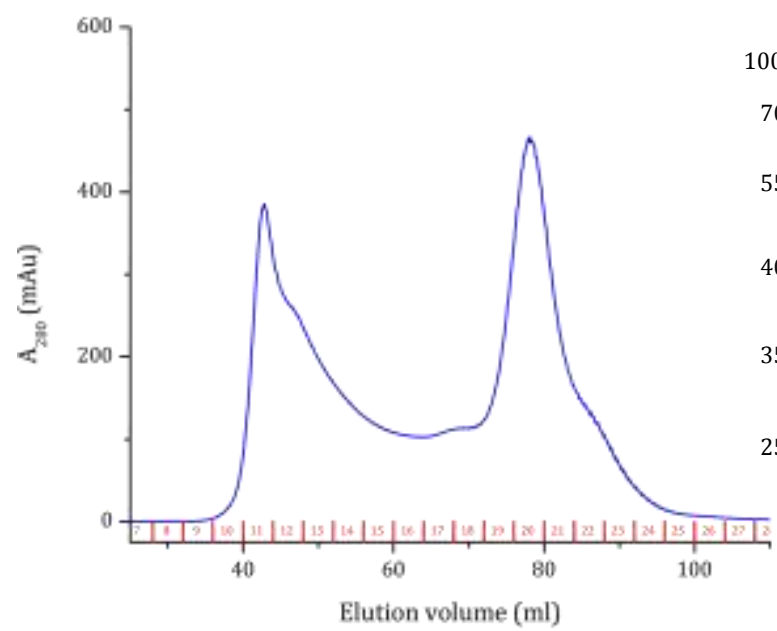

B

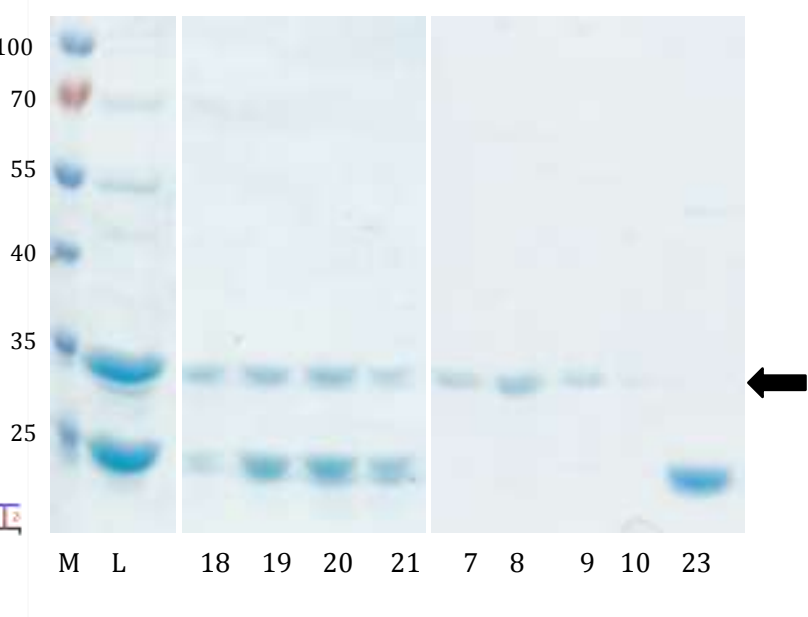

Figure 3.10-1 Size exclusion chromatography of GST- $\mathrm{C}_{2} \mathrm{~F}$.

A The UV absorption at $280 \mathrm{~nm}$ in the chromatogram is depicted as a blue line which is plotted against the elution volume and the fraction numbers are shown in red. There is an elution maximum at $80 \mathrm{ml}$ corresponding to the $\mathrm{C}_{2} \mathrm{~F}$-dimer.

B The $15 \%$ coomassie-stained SDS-PAGE of GST- $\mathrm{C}_{2} \mathrm{~F}$ contains selected samples of the purification. M indicates the molecular weight marker in $\mathrm{kDa}$ and $\mathrm{L}$ is the loaded protein sample. The numbers 18 to 21 refer to the fractions of the size exclusion chromatography. Numbers 7 to 10 represents the protein samples after the second GSH-column and the GST elution peak (23). The target protein is marked by an arrow.

\subsubsection{GST-C ${ }_{2}$ F-phos}

A

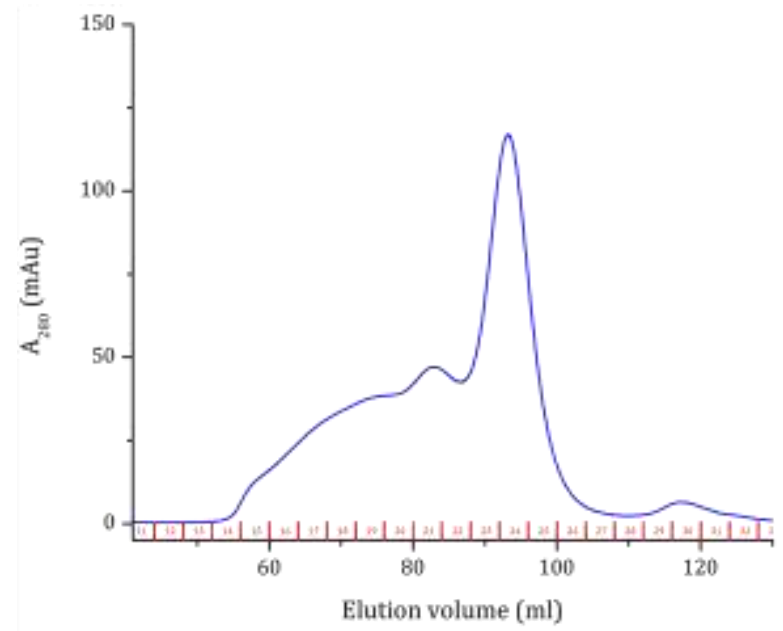

B

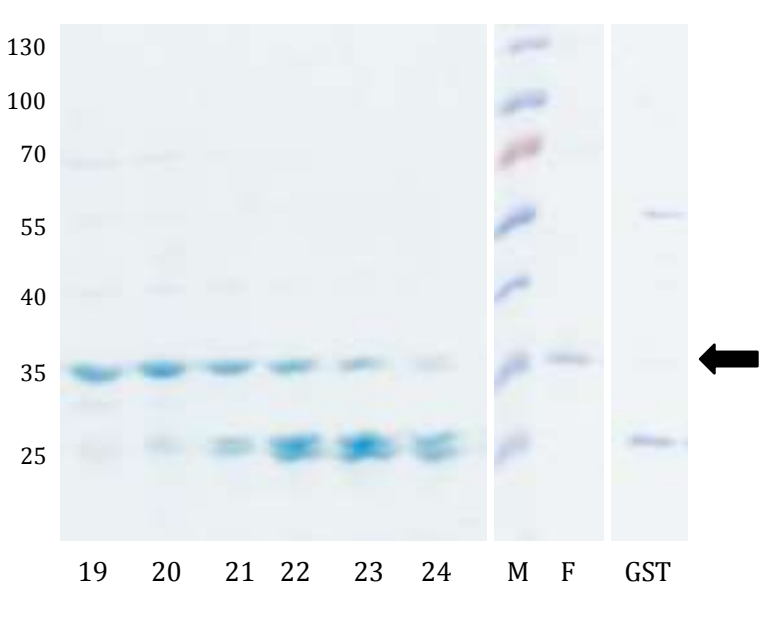

Figure 3.10-2 Size exclusion chromatography of GST- $\mathrm{C}_{2} \mathrm{~F}$-phos.

A The blue line displays the UV absorption at $280 \mathrm{~nm}$ which is plotted against the elution volume. The fraction numbers are shown in red. The elution maximum at $85 \mathrm{ml}$ corresponds to the $\mathrm{C}_{2} \mathrm{~F}$-phos-dimer. B The $15 \%$ coomassie-stained SDS-PAGE gel of $\mathrm{C}_{2} \mathrm{~F}$-phos contains selected samples of the purification. The samples 19 to 24 indicate the fractions of the size exclusion chromatography. $\mathrm{M}$ is the molecular weight marker in $\mathrm{kDa}$, the numbers refer to the fractions of the size exclusion. $\mathrm{F}$ is the flow through of the second GSH-column containing the protein of interest and GST is the elution peak of the second GSH-column containing the GST-tag and not cleaved protein. The target protein is marked by an arrow. 
The $\mathrm{C}_{2} \mathrm{~F}$-phos-fragment contains three mutations (S1777D, S1808D and T1860D). These positions were found to be phosphorylated by the CaMKII $\delta$ during a phosphorylation assay (see section 3.15). In order to simulate these phosphorylation sites a synthetic gene was ordered (GeneArt $\AA$, lifetechnologies) in which the three amino acids were replaced by aspartate residues.

\subsection{3 $\quad \mathrm{C}_{2} \mathrm{~F}$ aspartate mutants}

In case of synaptotagmin $1 \mathrm{C}_{2} \mathrm{~A}$ the necessity of five specific aspartate residues for the $\mathrm{Ca}^{2+}$-binding process was detected (see section 1.4.1) [36]. The first aspartate residue in the otoferlin $\mathrm{C}_{2} \mathrm{~F}$-domain is embedded in an EDDDF motif. At the position of the fifth aspartate the sequence contains two aspartate residues next to each other (SADDF). Only one aspartate residue in the sequence is present at the positions two, three and four. To check the influence of the predicted aspartate residues in the binding region of the $\mathrm{C}_{2} \mathrm{~F}$-domain of otoferlin four mutants were created in which the second to fifth predicted residues were mutated. In case of the aspartate at position five the additional aspartates in the direct neighborhood may substitute the mutated residue and a coordination of $\mathrm{Ca}^{2+}$ might still be possible. Due to this situation both aspartates at position five were mutated to prevent that the other aspartate is inheriting this function. By mutating the selected position to an asparagine and subsequent thermophoresis measurements, the influence of a specific aspartate during the $\mathrm{Ca}^{2+}$-binding process could be analyzed. The expression and purification was equal for all three mutants.

\begin{tabular}{ll} 
Name & Position of the mutations \\
\hline D1N & D1760N \\
D2,3N & D1835,1837N \\
D1,2,3N & D1760,1835,1837N \\
D4N & D1842,1843N \\
\hline
\end{tabular}




\subsubsection{GST-C ${ }_{2} F-D 1 N$}

A

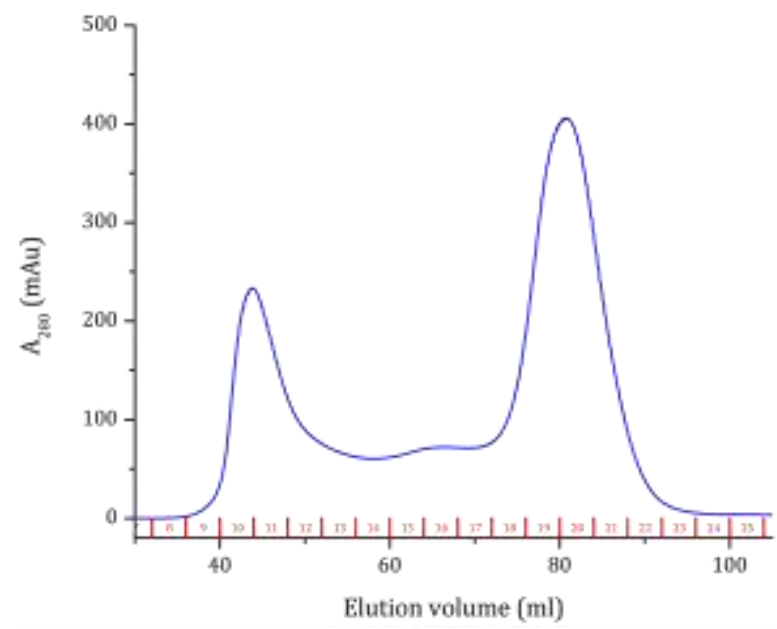

B

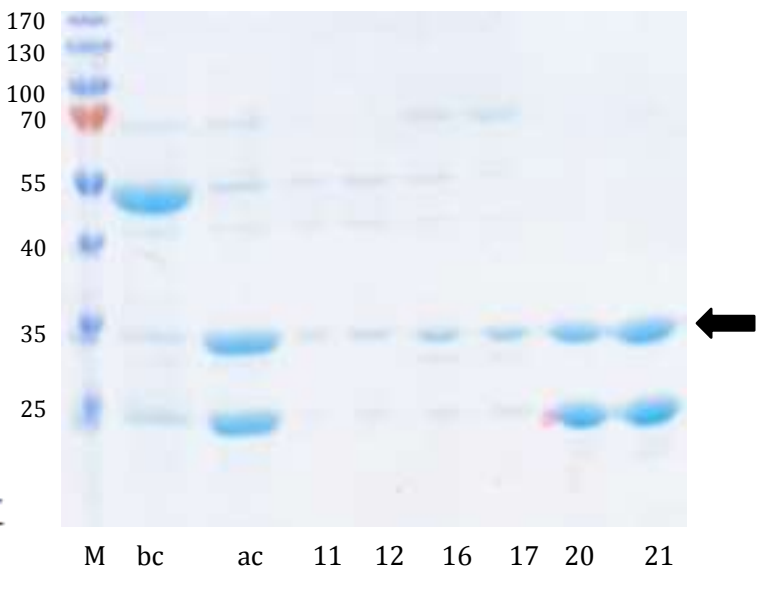

Figure 3.10-3 Size exclusion chromatography of GST-C $\mathrm{C}_{2} \mathrm{~F}-\mathrm{D} 1 \mathrm{~N}$.

A The UV absorption at $280 \mathrm{~nm}$ in the chromatogram is depicted as a blue line which is plotted against the elution volume and the fraction numbers are shown in red. There is an elution maximum at $180 \mathrm{ml}$ corresponding to the $\mathrm{C}_{2} \mathrm{~F}-\mathrm{D} 1 \mathrm{~N}$-dimer.

B The $12.5 \%$ coomassie-stained SDS-PAGE gel of GST-C $\mathrm{C}_{2} \mathrm{~F}-\mathrm{D} 1 \mathrm{~N}$ contains selected samples of the purification. $\mathrm{M}$ indicates the molecular weight marker in $\mathrm{kDa}$, "bc" is the protein before cleavage of the GST-tag and "ac" the sample after the cleavage reaction. The numbers refer to the fractions of the size exclusion chromatography. The target protein is marked by an arrow.

\subsubsection{GST-C ${ }_{2}$ F-D2,3N}

A

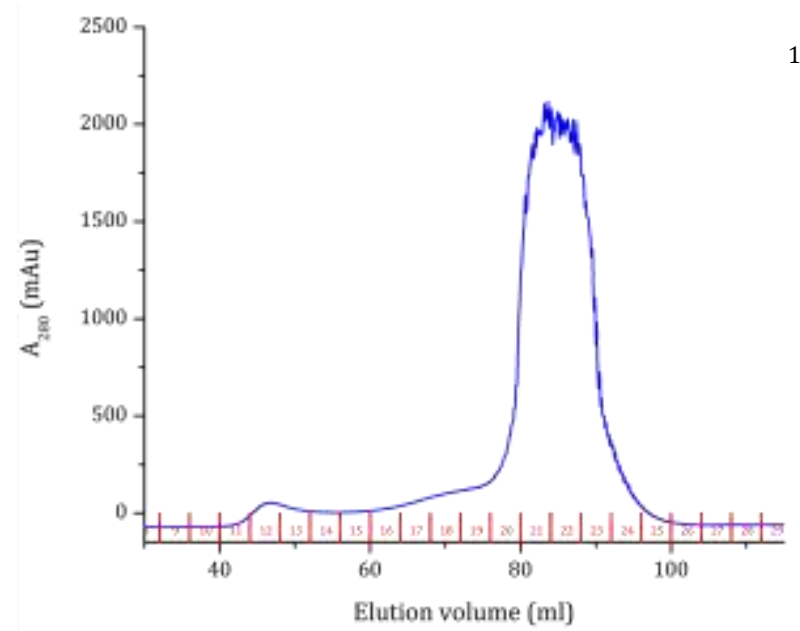

B

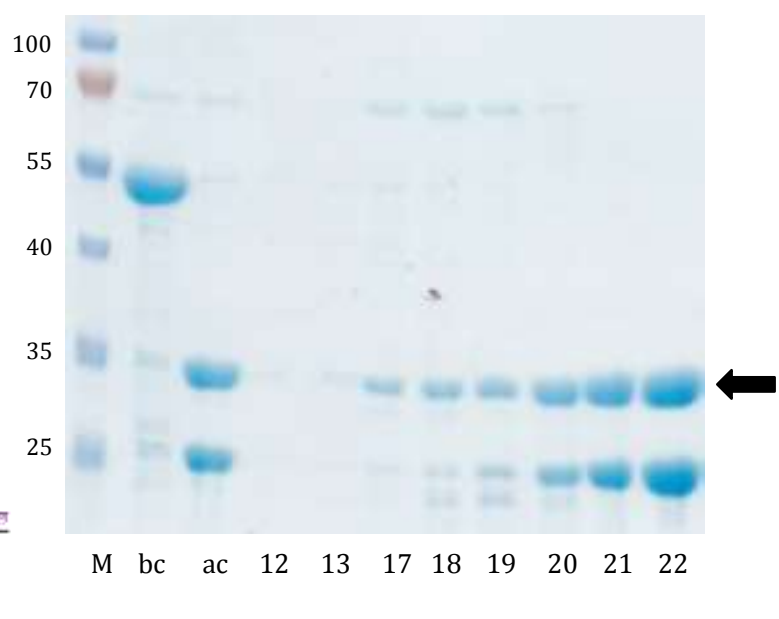

Figure 3.10-4 Size exclusion chromatography of GST-C $\mathrm{C}_{2} \mathrm{~F}-\mathrm{D} 2,3 \mathrm{~N}$.

A The blue line displays the UV absorption at $280 \mathrm{~nm}$ which is plotted against the elution volume. The fraction numbers are shown in red The elution maximum at $85 \mathrm{ml}$ corresponds to the $\mathrm{C}_{2} \mathrm{~F}-\mathrm{D} 2,3 \mathrm{~N}$-dimer.

B The $12.5 \%$ coomassie-stained SDS-PAGE gel of GST- $\mathrm{C}_{2} \mathrm{~F}-\mathrm{D} 2,3 \mathrm{~N}$ contains selected samples of the purification. $\mathrm{M}$ indicates the molecular weight marker in $\mathrm{kDa}$, "bc" the protein before cleavage of the GST-tag and "ac" the sample after the cleavage reaction. The numbers refer to the fractions of the size exclusion chromatography. The target protein is marked by an arrow. 


\subsubsection{GST-C $C_{2}$ F-D1,2,3N}

A

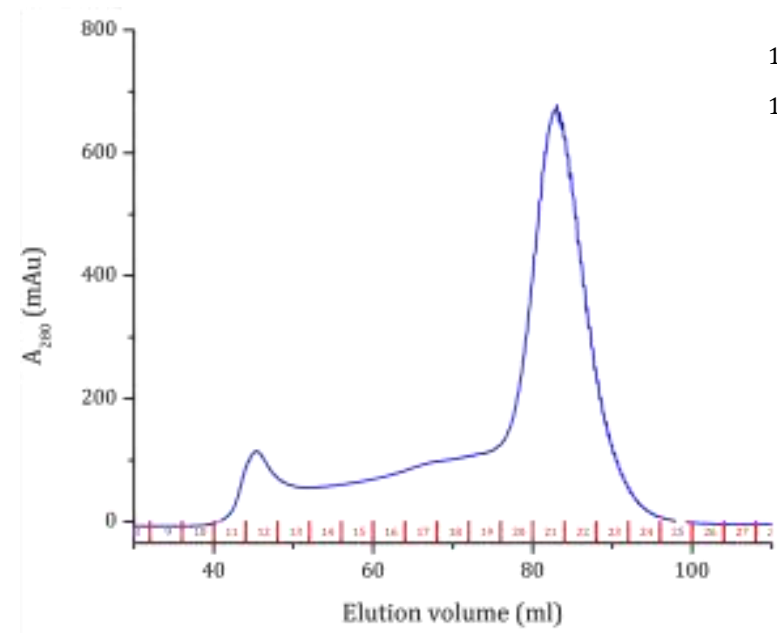

B

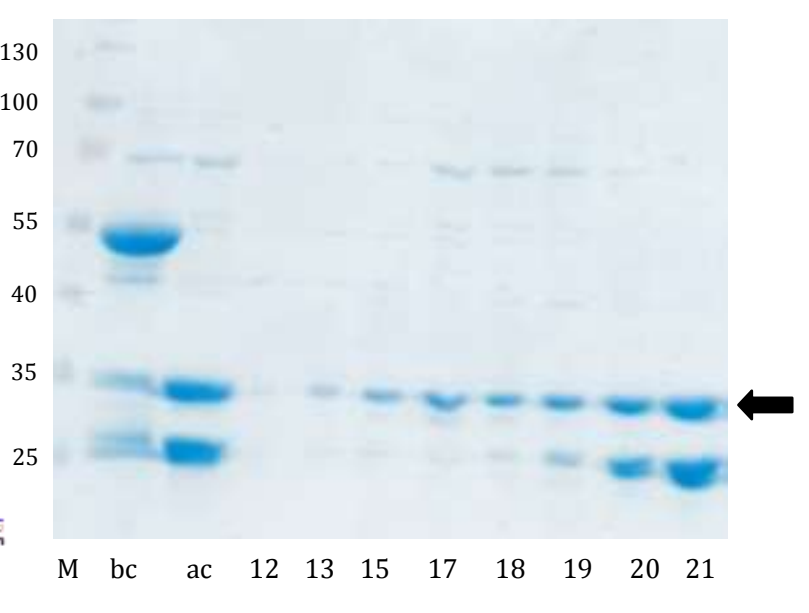

Figure 3.10-5 Size exclusion chromatography of GST-C $\mathrm{C}_{2} \mathrm{~F}-\mathrm{D} 1,2,3 \mathrm{~N}$.

A The UV absorption at $280 \mathrm{~nm}$ in the chromatogram is depicted as a blue line which is plotted against the elution volume and the fraction numbers are shown in red. There is an elution maximum at $85 \mathrm{ml}$ corresponding to the $\mathrm{C}_{2} \mathrm{~F}-\mathrm{D} 1,2,3 \mathrm{~N}$-dimer.

B The $12.5 \%$ coomassie-stained SDS-PAGE of GST- $\mathrm{C}_{2} \mathrm{~F}-\mathrm{D} 1,2,3 \mathrm{~N}$ contains selected samples of the purification. $\mathrm{M}$ indicates the molecular weight marker in $\mathrm{kDa}$, "bc" the protein before cleavage of the GST-tag and "ac" the sample after the cleavage reaction. The numbers refer to the fractions of the size exclusion chromatography and the target protein is marked by an arrow.

\subsubsection{GST-C F-D4N}

A

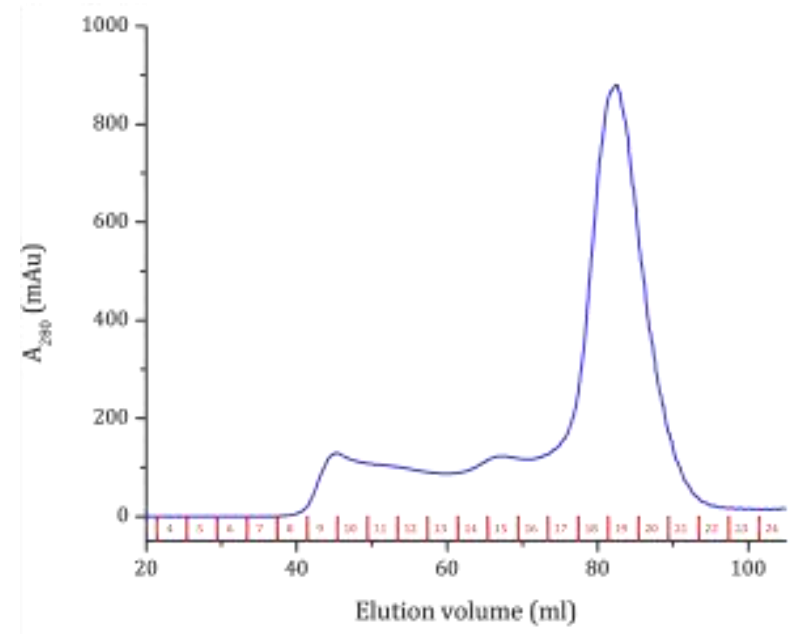

B

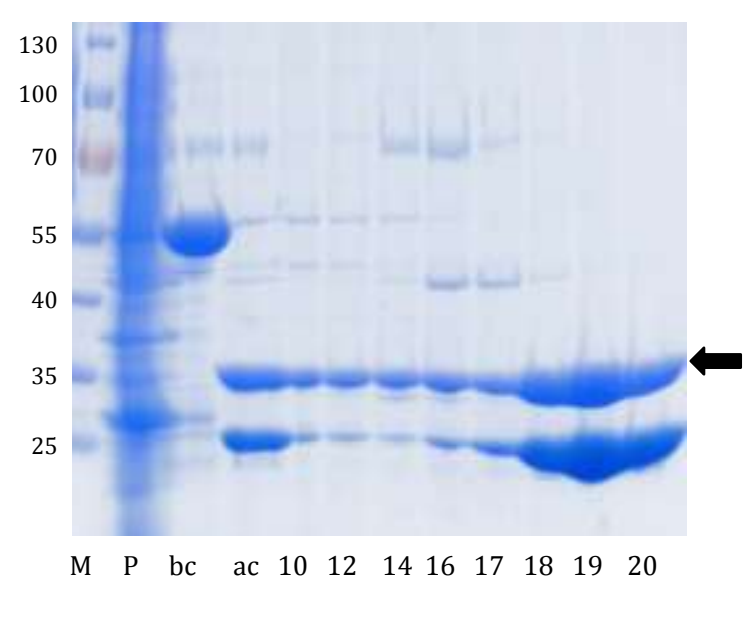

Figure 3.10-6 Size exclusion chromatography of GST-C 2 F-D4N.

A The blue line displays the UV absorption at $280 \mathrm{~nm}$ which is plotted against the elution volume. The fraction numbers are shown in red. The elution maximum at $83 \mathrm{ml}$ corresponds to the $\mathrm{C}_{2} \mathrm{~F}-\mathrm{D} 4 \mathrm{~N}$-dimer. B The $12.5 \%$ coomassie-stained SDS-PAGE of GST-C $\mathrm{C}_{2} \mathrm{~F}-\mathrm{D} 4 \mathrm{~N}$ contains selected samples of the purification. $\mathrm{M}$ indicates the molecular weight marker in $\mathrm{kDa}, \mathrm{P}$ (pellet), "bc" the protein before cleavage of the GST-tag and "ac" the sample after the cleavage reaction. The numbers refer to the fractions of the size exclusion chromatography and the target protein is marked by an arrow. 


\subsubsection{GST- $\mathrm{C}_{2} \mathrm{~F}-\mathrm{pga}$}

The pga mutation affects an aspartate in the $\mathrm{C}_{2} \mathrm{~F}$-domain of the protein which is mutated to a glycine. Mice which are carrying this mutation are deaf [54]. According to predictions from Jiménez and Bashir [20] this mutation is located in the loop region between $\beta$-strands two and three. Due to considerations that ferlin $\mathrm{C}_{2}$-domains exist in the type II topology the affected loop is located on the opposite end than the $\mathrm{Ca}^{2+}$-binding region.

A

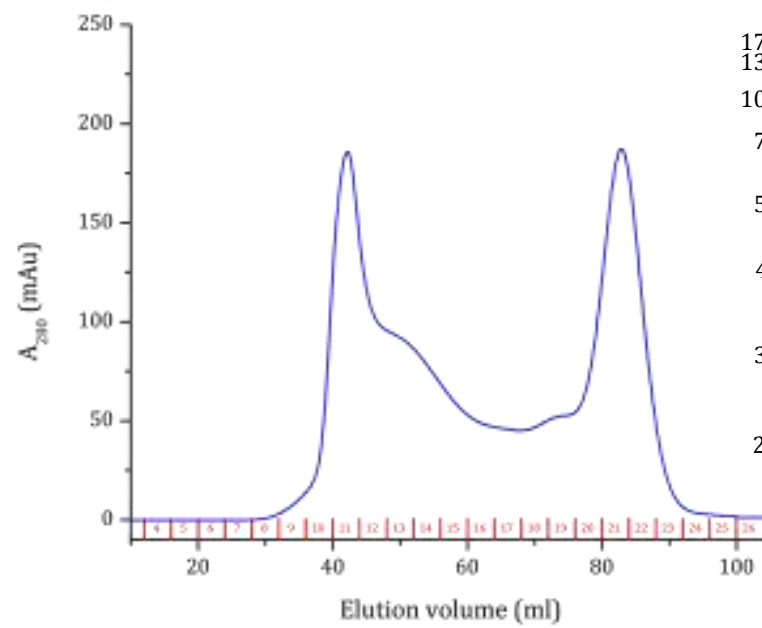

B

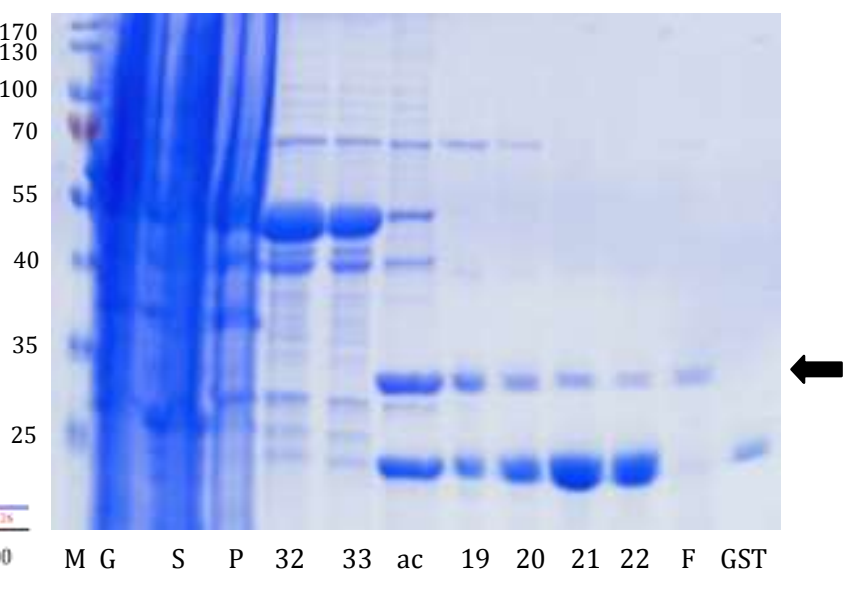

Figure 3.10-7 Size exclusion chromatography of GST- $\mathrm{C}_{2} \mathrm{~F}-p g a$.

A The UV absorption at $280 \mathrm{~nm}$ in the chromatogram is depicted as a blue line which is plotted against the elution volume and the fraction numbers are shown in red. There is an elution maximum at $85 \mathrm{ml}$ corresponding to the $\mathrm{C}_{2} \mathrm{~F}-$ pga-dimer.

B The $12.5 \%$ coomassie-stained SDS-PAGE gel of GST- $\mathrm{C}_{2} \mathrm{~F}-\mathrm{pga}$ contains selected samples of the purification. $\mathrm{M}$ indicates the molecular weight marker in $\mathrm{kDa}, \mathrm{G}$ is the sample after cell lysis, $\mathrm{S}$ (supernatant) and $\mathrm{P}$ (pellet) are samples after centrifugation and the numbers 32 and 33 are samples of the GSH-column elution peak. "Ac" is the sample after cleavage of the GST-tag, the numbers 19 to 22 refer to the fractions of the size exclusion chromatography and F (flow-through) and GST are samples of the second GSH-column. The target protein is marked by an arrow.

\subsubsection{GST-C ${ }_{2}$ F-E1804del}

The E1804del mutation in the $\mathrm{C}_{2} \mathrm{~F}$-domain was initially found in humans having a temperature sensitive deafness if the body core temperature rises as little as $1^{\circ} \mathrm{C}$. If the affected people become afebrile the hearing status return to normal [17]. The deletion of the glutamic acid in the $\mathrm{C}_{2} \mathrm{~F}$-fragment was created using the QuikChange protocol. 
A

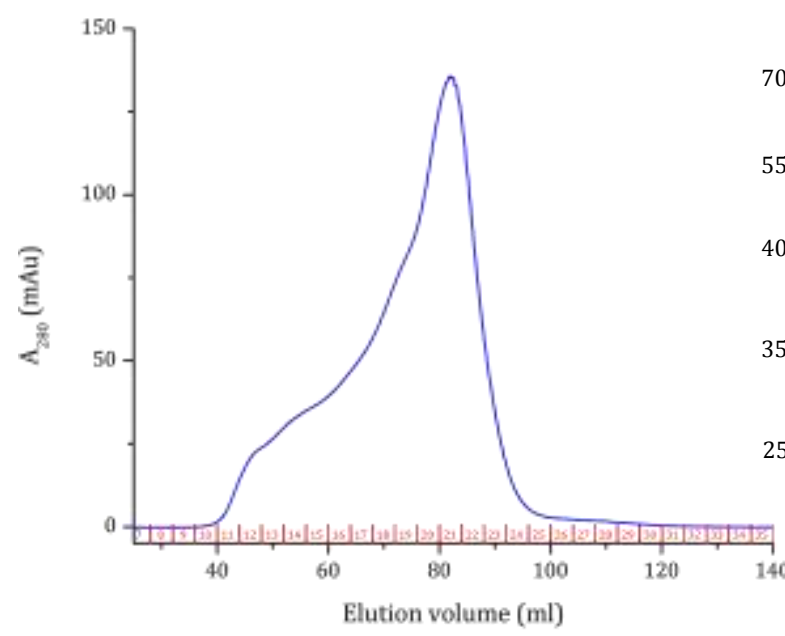

B

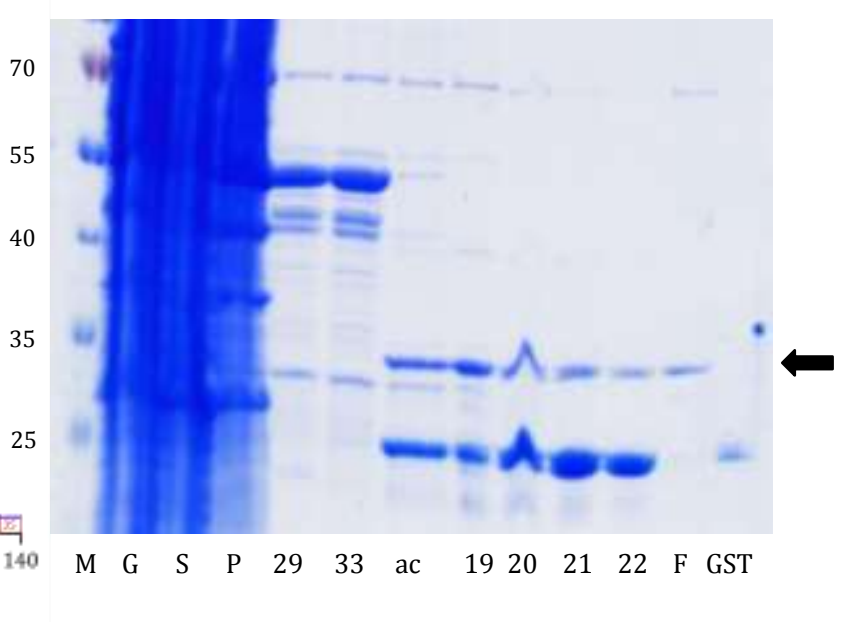

Figure 3.10-8 Size exclusion chromatography of GST-C ${ }_{2}$ F-E1804del.

A The blue line displays the UV absorption at $280 \mathrm{~nm}$ which is plotted against the elution volume. The fraction numbers are shown in red. The elution maximum at $85 \mathrm{ml}$ corresponds to the $\mathrm{C}_{2} \mathrm{~F}-\mathrm{E} 1804$ del-dimer.

B The $12.5 \%$ coomassie-stained SDS-PAGE of GST-C 2 F-E1804del contains selected samples of the purification. $\mathrm{M}$ indicates the molecular weight marker in $\mathrm{kDa}, \mathrm{G}$ is the sample after cell lysis, $\mathrm{S}$ (supernatant) and P (pellet) are samples after centrifugation and the numbers 29 and 33 are samples of the GSH-column elution peak. "Ac" is the sample after cleavage of the GST-tag, the numbers 19 to 22 refer to the fractions of the size exclusion chromatography and F (flow through) and GST are samples of the second GSH-column. The target protein is marked by an arrow.

\subsection{Purification of $\mathrm{His}_{6}-\mathrm{C}_{2} \mathrm{DEF}$}

The otoferlin fragment containing the last three $\mathrm{C}_{2}$-domains was cloned into the pET28a vector and expressed in E. coli Rosetta 2 (DE3) by autoinduction (see section 2.2.2.1.2) [57]. The protein was purified from inclusion bodies (see section 2.2.2.3). The protein containing supernatant was loaded onto a His-Trap (Figure 3.11-1) and the protein was eluted using an imidazole gradient. Selected fractions were analyzed by SDS-PAGE. 
A

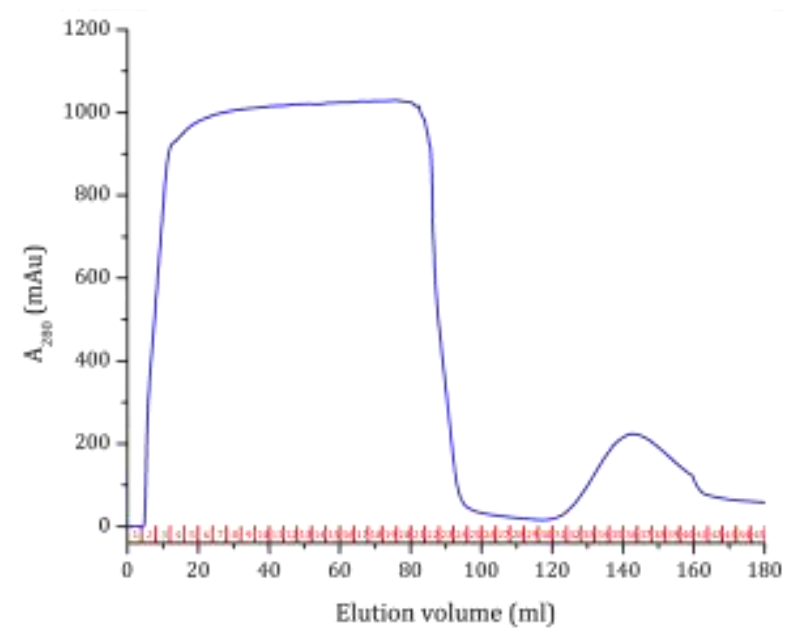

B

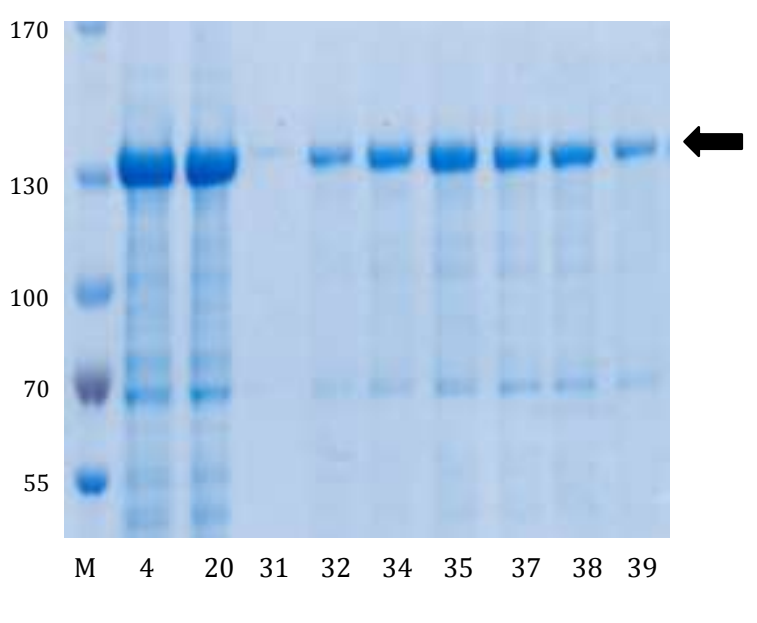

Figure 3.11-1 His 6 -column chromatography of $\mathrm{His}_{6}-\mathrm{C}_{2} \mathrm{DEF}$.

A The UV absorption at $280 \mathrm{~nm}$ in the chromatogram is depicted as a blue line which is plotted against the elution volume and the fraction numbers are shown in red. There is an elution maximum at $145 \mathrm{ml}$ corresponding to the $\mathrm{His}_{6}-\mathrm{C}_{2}$ DEF-fragment.

B The $7.5 \%$ coomassie-stained SDS-PAGE gel of $\mathrm{His}_{6}-\mathrm{C}_{2} \mathrm{DEF}$ contains selected samples of the purification. $\mathrm{M}$ indicates the molecular weight marker in $\mathrm{kDa}$ and the numbers refer to the fractions of the His-Trap chromatogram. The target protein is marked by an arrow.

\subsection{Purification of Dynamin-1-Strep}

A

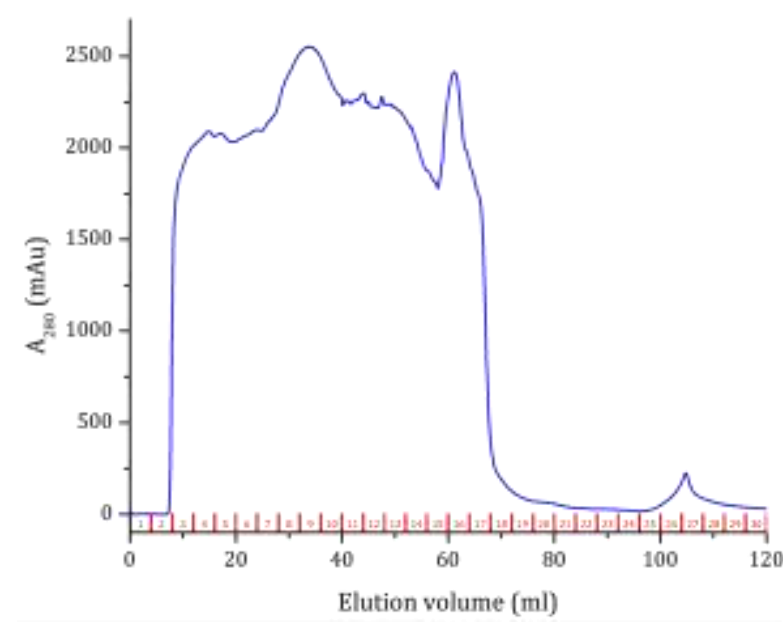

B

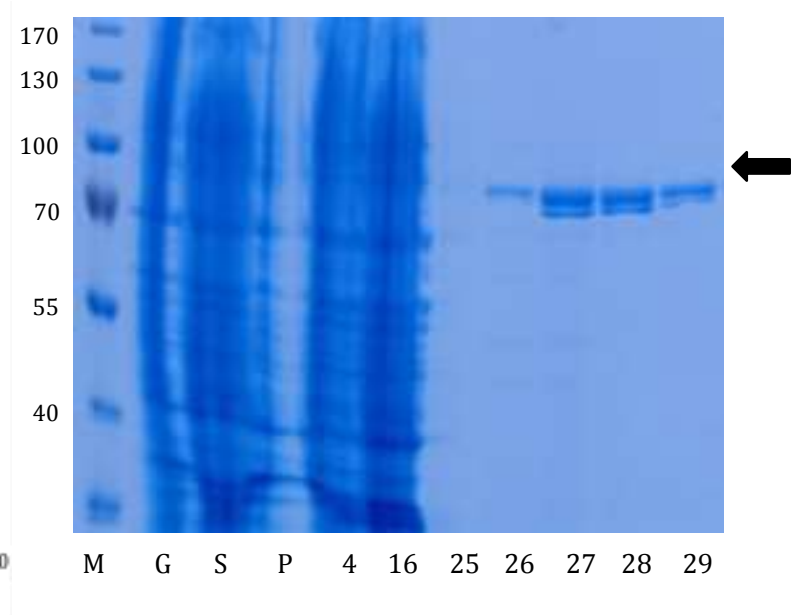

Figure 3.12-1 Strep-column chromatography of dynamin-1-Strep.

A The blue line displays the UV absorption at $280 \mathrm{~nm}$ which is plotted against the elution volume. The fraction numbers are shown in red. The elution maximum at $105 \mathrm{ml}$ corresponds to the dynamin-1-Strep-fragment.

B The $12.5 \%$ coomassie-stained SDS-PAGE of dynamin-1-Strep contains selected samples of the purification. $\mathrm{M}$ indicates the molecular weight marker in $\mathrm{kDa}, \mathrm{G}$ is a sample after cell lysis and the samples $S$ (supernatant) and $P$ (pellet) are samples after centrifugation. The numbers refer to the fraction of the Strep-column and the target protein is marked with an arrow. 
The dynamin-1 was cloned into the pPSG-IBA5 vector containing a Strep-tag using the StarGate cloning kit. The Strep-tagged protein was expressed in E. coli SoluBL21 cells and harvested $16 \mathrm{~h}$ after induction with IPTG. After cell lysis the obtained supernatant was loaded onto a Strep-column (Figure 3.12-1) and the protein of interest was eluted using desthiobiotin. Selected fractions were analyzed by SDS-PAGE.

\subsection{Crystallization}

Except for dynamin-1 and the otoferlin $\mathrm{C}_{2}$ DEF-fragment all purified proteins described in section 3.2 to 3.10 .5 were tested in several crystal screens (see section 2.1.6). For these trials different protein concentrations and temperatures were tested (see section 6). For the $\mathrm{C}_{2} \mathrm{~B}$-domain a few very small crystals were obtained which unfortunately did not diffract.

Initial crystallization screenings of the native $\mathrm{C}_{2} \mathrm{ABC}$-fragment were done in 96-well plates pipetted by the PHENIX IRE pipetting robot (Rigaku). Eleven crystallization screens (see section 2.1.6) were tested. At protein concentrations of $4 \mathrm{mg} / \mathrm{ml}$ small $\mathrm{C}_{2} \mathrm{ABC}$ crystals were obtained in the condition E8 of the JBScreen Classic $(1,2,4,5)$ $(0.5 \mathrm{M} \mathrm{KCl}, 10 \%$ glycerol, $12 \%$ PEG8000). Crystal optimization was done using the sitting-drop vapour-diffusion technique (24-well sitting drop crystallization plate). Droplets with a volume of $2 \mu \mathrm{l}$ were obtained by mixing protein and reservoir solution in a 1:1 ratio. For optimization different concentrations of glycerol (6\%-12\%) and PEG8000 (6\%-12\%) were tested. Well diffracting crystals were obtained from a condition containing $0.5 \mathrm{M} \mathrm{KCl}, 6 \%$ glycerol and $12 \%$ PEG8000. The crystals were washed in cryoprotectant solution containing reservoir solution and additionally $12.5 \%$ glycerol before flash-cooling in liquid nitrogen. Diffraction images were collected at the Bessy Beamline 14.1 (Berlin, Germany) equipped with a PILATUS 6M detector. The measured crystal diffracted to a resolution of $1.6 \AA$. The obtained data were indexed, integrated and merged using the XDS package [58,59]. The $\mathrm{C}_{2} \mathrm{ABC}$-fragment crystallized in space group $\mathrm{P} 2{ }_{1}$ (estimated based on systematic absences) with unit cell constants of $\mathrm{a}=74.14 \AA, \mathrm{b}=172.20 \AA$ and $\mathrm{c}=123.31 \AA$, $\beta=104.34^{\circ}$. The determined Matthews coefficients of $2.76 \AA^{3} / \mathrm{Da}$ (corresponds to $55.49 \%$ solvent content) or $2.21 \AA^{3} / \mathrm{Da}$ (44.36\% solvent content) indicates that four or five molecules are present in the asymmetric unit. Molecular replacement trials were performed using the known structure of the otoferlin $\mathrm{C}_{2} \mathrm{~A}$-domain (PDB id: 3L9B) and other known $\mathrm{C}_{2}$-domains (dysferlin PDB id: 4IQH, synaptotagmin-1 PDB id: 2R83) with PHASER. These trials were not successful because the used search 
model of the $\mathrm{C}_{2} \mathrm{~A}$-domain comprised less than $7 \%$ of all protein atoms occupying the asymmetric unit. Because of this the results of the translation function search did not gave a clear true solution which would be distinguishable from many other false ones as all of the solutions have similar Z-scores.

As an alternative, $500 \mathrm{mM}$ of $\mathrm{KCl}$ in the crystallization condition was partly (30 to $50 \%$ ) or completely replaced by $\mathrm{KI}$ or $\mathrm{KBr}$ in order to obtain derivative crystals with incorporated heavier halide atoms which could be used to solve the phase problem using SIR/SIRAS or SAD/MAD method.

The production of seleno-methionine derivatised protein failed because no protein was expressed in minimal medium. In addition heavy metal soaks $\left(\mathrm{HgCl}_{2}, \mathrm{~K}_{2} \mathrm{PtCl}_{4}\right)$ were done to obtain derivative crystals.
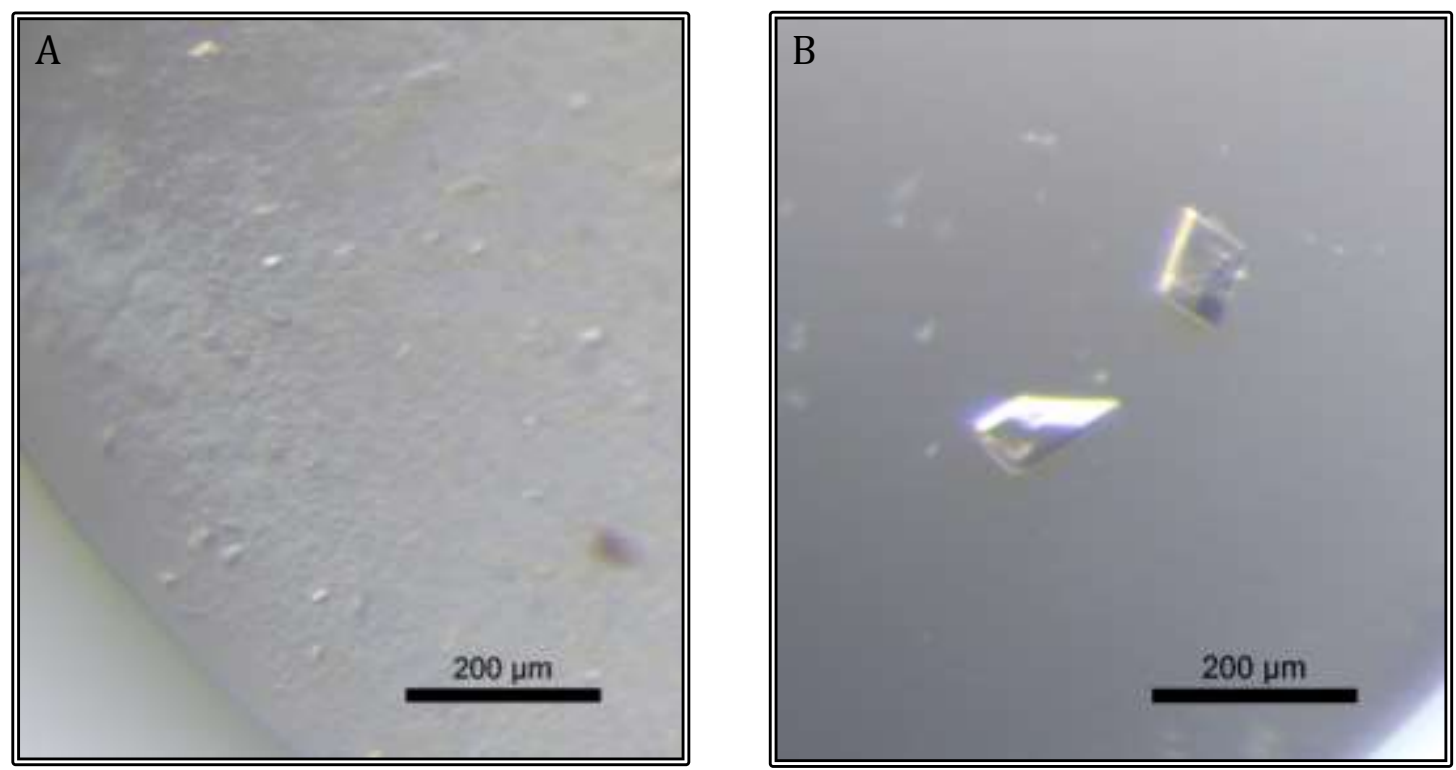

Figure 3.13-1 Crystals of the otoferlin $\mathrm{C}_{2} \mathrm{ABC}$-fragment.

A First $\mathrm{C}_{2} \mathrm{ABC}$-fragment containing crystals were obtained in a condition containing $0.5 \mathrm{M} \mathrm{KCl}, 10 \%$ glycerol and $12 \%$ PEG8000.

B Through optimization of the crystallization condition with $0.5 \mathrm{M} \mathrm{KCl}, 6 \%$ glycerol and $12 \%$ PEG8000 bigger and nice diffracting crystals were gained. 


\subsection{Pull-down assay to identify possible interaction partners}

To get information about possible interaction partners of otoferlin, pull-down assays were performed and the products analyzed by mass spectrometry. The spectrometry measurements and data analysis were done by Sunit Mandad in the lab of Prof. Henning Urlaub.

In the first experiment, $\mathrm{His}_{6}$-tagged $\mathrm{C}_{2} \mathrm{ABC}$ was bound to $\mathrm{Ni}^{2+}$-beads and incubated with lysed mouse brain. The pull-down samples were loaded onto a gradient-SDS gel, digested with trypsin and analyzed by mass spectrometry.

Amongst others dynamin-1, dynamin-3, dynamin-like $120 \mathrm{kDa}$ protein (OPA1) and the dynamin-1-like protein were identified as potential interaction partners. The identified dynamins are interesting potential interaction partners because of their known function in endocytosis [60-62].

Due to possible unspecific binding of proteins to the used $\mathrm{Ni}^{2+}$-beads a second shorter $\mathrm{C}_{2} \mathrm{ABC}$-fragment containing a Strep-tag was tested. As before, the $\mathrm{C}_{2} \mathrm{ABC}$ was bound to the Strep-beads and incubated with lysed mouse brain. Again the digestion and mass analysis was performed by Sunit Mandad. The Strep-based pull-down revealed again dynamin-1 and the dynamin-like $120 \mathrm{kDa}$ protein (OPA1) as potential interaction partners.

Due to the results that dynamin was found in both performed pull-down assays it was cloned into a vector containing a Strep-tag. The last part of the protein was not included for cloning because proline-rich regions are known to be unstructured and very difficult to crystallize [63].

In the next step, the $\mathrm{His}_{6}$-tagged $\mathrm{C}_{2} \mathrm{ABC}$ and the Strep-dynamin 1 were tested for interaction. Each protein was bound to its tag-specific beads and incubated with the other one.

The Ni-beads with the bound $\mathrm{C}_{2} \mathrm{ABC}$ were incubated with the Strep-tagged dynamin 1-fragment. The sample analysis with SDS-PAGE showed a dynamin band in the negative control of $\mathrm{Ni}$-beads with dynamin 1 . Usually no protein should be bound but it seems that dynamin 1 is able to bind unspecific to Ni-beads. In the second experiment dynamin 1 bound to Strep-beads was incubated with the His $_{6}$-tagged $\mathrm{C}_{2} \mathrm{ABC}$. This time, no unspecific binding to the beads was detected and the Strep pull-down was performed again. Lane 2 on the following gel (Figure 3.14-1) contains the pull-down sample after incubation of both proteins showing only one band. In comparison to lane 1 in which only dynamin on Strep-beads was loaded, the band in 
lane 2 shows only dynamin 1 . This suggests that that no interaction takes place between the two tested proteins. In comparison in lane 6 both proteins were added.

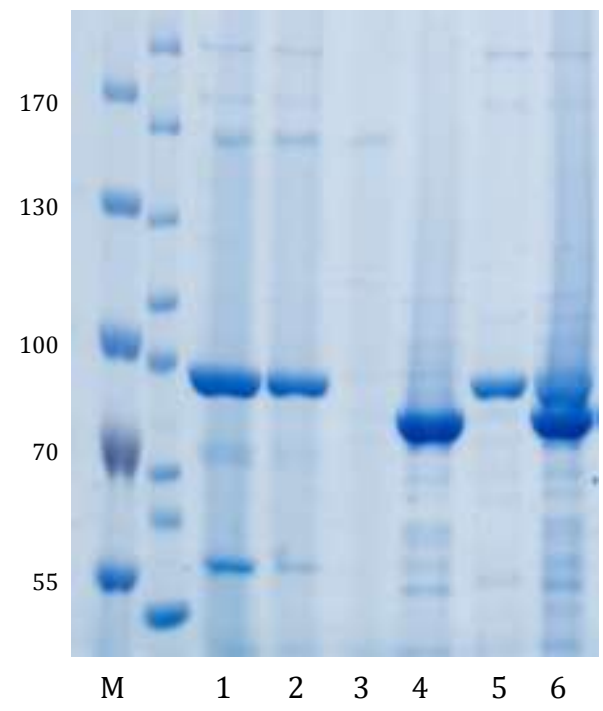

Figure 3.14-1 Pull-down assay with dynamin 1 and otoferlin- $\mathrm{C}_{2} \mathrm{ABC}$. $\mathrm{M}$ indicates the molecular weight marker in $\mathrm{kDa}$. Lane 1 contains dynamin 1 bound to Strep-beads, lane 2 is the pull-down sample where $\mathrm{C}_{2} \mathrm{ABC}$ was added to the bound dynamin 1 , no bands of otoferlin $\mathrm{C}_{2} \mathrm{ABC}$ were found. Lane 4 and 5 contain samples of dynamin 1 and $\mathrm{C}_{2} \mathrm{ABC}$ alone. In lane 6 both proteins were mixed.

\subsubsection{Pull-down assay using Eupergit beads}

To analyze if the previous pull-down results were detergent dependent, five different detergents were tested for lysing brain synaptosomes in the next experiment. Additionally, another type of beads was used. The amino and thiol groups of the proteins can react with the oxirane groups of these Eupergit beads by nucleophilic attack and form very stable C-N and C-S bonds [64]. Remaining binding sites on the beads were blocked through incubation with glycine.

In the first step, the $\mathrm{His}_{6}$ - and Strep-tagged versions of $\mathrm{C}_{2} \mathrm{ABC}$ were bound to the Eupergit beads, followed by the incubation with possible interaction partners. In this experiment synaptosomes (prepared by Sunit Mandad) from mouse brain were mixed with different detergents and added to the Eupergit bound proteins and incubated overnight. For the negative control Eupergit beads treated with glycine were also mixed with synaptosomes. After several washing steps, the samples were digested with trypsin and analyzed by mass spectrometry by Sunit Mandad. The control gel (Figure 3.14-2) showed that the pull-down was successful. B marks the samples containing the beads with bound $\mathrm{C}_{2} \mathrm{ABC}$ after incubation with the mouse synaptosomes. Well defined bands of the two different $\mathrm{C}_{2} \mathrm{ABC}$-fragments were present and additional bands of possible interaction partners could be found. 


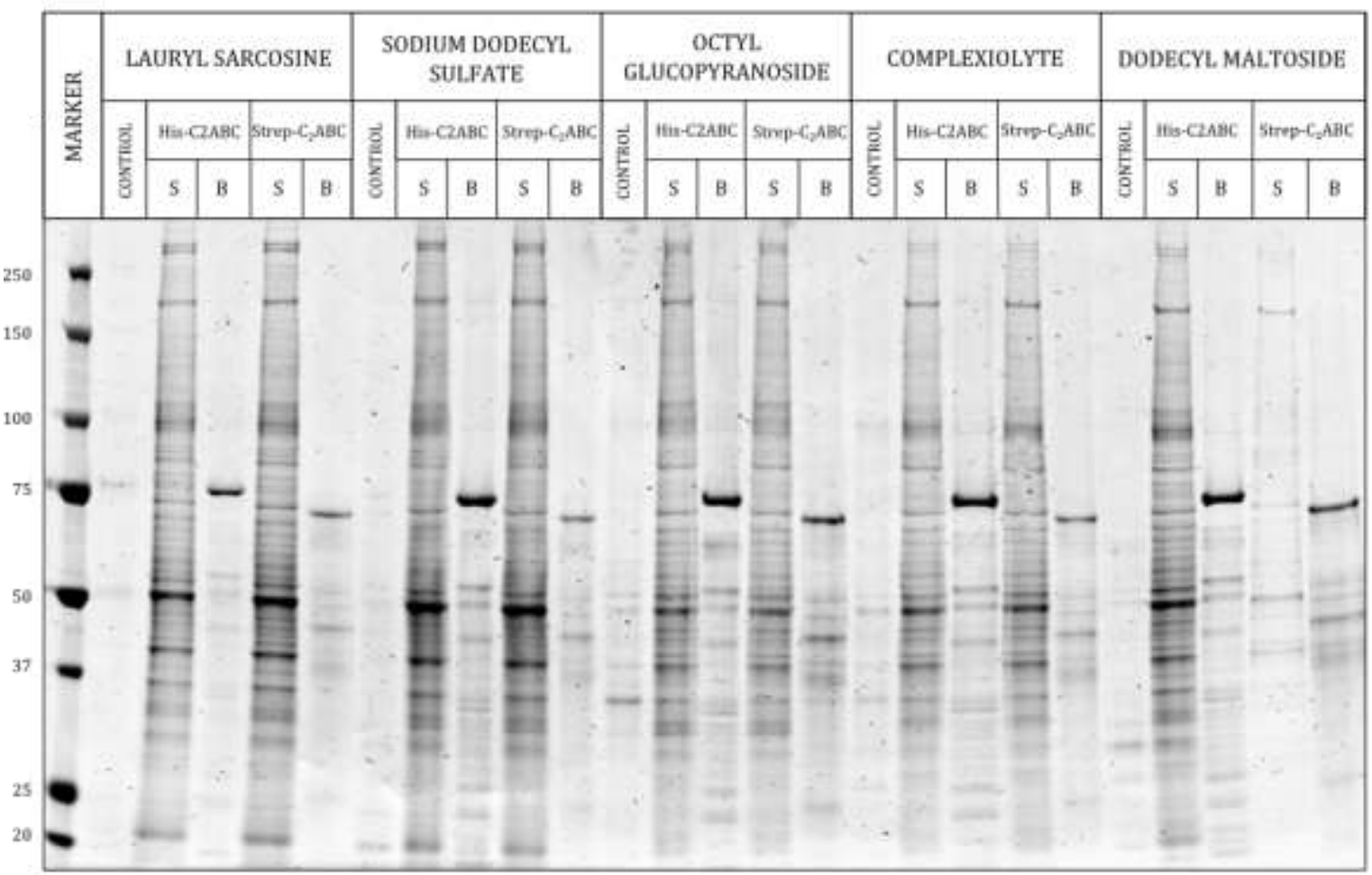

Figure 3.14-2 Gradient control gel of the Eupergit pull-down. The control lane contains the glycine treated Eupergit beads incubated with lysed synaptosomes. S indicates the removed supernatant of synaptosomes after incubation. B indicates the final sample of beads treated with protein and incubated with lysed synaptosomes.

The Table 3.14-1, Table 3.14-2 and Table 3.14-3 show proteins which were identified as candidates for interaction partners of otoferlin. All considered proteins were found at least in three independent samples of all performed pull-down experiments (Table 3.14-1). In case of dynamin, AP2 and the 14-3-3 protein different isoforms or subunits were detected. All seven isoforms of the 14-3-3 protein were identified by mass spectrometry due to their high sequence similarity [65], and all are considered to interact with otoferlin. The AP2 adaptor complex consists of five subunits [66]; in our pull-down experiments we identified four of them, only the subunit $\sigma$ is missing. Dynamin was found in all three existing forms $[67,68]$. In one experiment only fragments of dynamin were identified which are identical in all three forms. To get further information about the possible interaction partners of otoferlin proximity ligation assay, co-immunoprecipitaion assays or yeast-to-hybrid experiments could provide insight. The third table (Table 3.14-3) contains proteins which play a role in cellular respiration; due to this fact they are likely no specific interaction partners for otoferlin. Table 3.14-2 shows proteins which probably are not potential interaction partners of otoferlin based on their function or location. Therefore, a further analysis of the proteins in Table 3.14-3 and Table 3.14-2 is not planned. 
Table 3.14-1 Identified proteins from three different detergent samples analyzed by mass spectrometry. In this table proteins are listed which were found at least three times. Additionally their known function and location distinguish these proteins as reasonable interaction partners of otoferlin. For some proteins different isoforms were identified.

Identified proteins

UniProt entry

\begin{tabular}{|c|c|c|}
\hline \multirow[t]{4}{*}{ AP2 complex } & Subunit $\alpha-1$ & P17426 \\
\hline & Subunit $\alpha-2$ & P17427 \\
\hline & Subunit $\beta$ & Q9DBG2-2 \\
\hline & Subunit $\mu$ & P84091 \\
\hline \multirow[t]{3}{*}{ Dynamin } & Dynamin-1 & P39053 \\
\hline & Dynamin-2 & P39054 \\
\hline & Dynamin-3 & Q8BZ98 \\
\hline \multirow[t]{7}{*}{ 14-3-3 protein } & Isoform $\alpha / \beta$ & Q9CQV8 \\
\hline & Isoform $\gamma$ & P61982 \\
\hline & Isoform $\zeta / \delta$ & P63101 \\
\hline & Isoform $\eta$ & P68510 \\
\hline & Isoform $\theta$ & F6VW30 \\
\hline & Isoform $\sigma$ & 070456 \\
\hline & Isoform $\varepsilon$ & P62259 \\
\hline Endophilin-A1 & & A2ALV3 \\
\hline Ras-related protein $\mathrm{Rab}-3 \mathrm{~A}$ & & P63011 \\
\hline Ras-related protein Rab-7a & & P51150 \\
\hline Synaptosomal-associated protein 25 & & P60879 \\
\hline
\end{tabular}


Table 3.14-2 Identified proteins from three different detergent samples analyzed by mass spectrometry. Due to their function and cellular localization, the proteins in this table are currently beyond the research focus of the involved groups.

Identified proteins UniProt entry

Peptidyl-prolyl cis-trans isomerase A

$\mathrm{P} 17742$

Tubulin beta-5 chain

P99024

Septin-5

Q9Z2Q6

Microtubule-associated protein 1A

A2ARP8

Carbonic anhydrase

P00920

Aspartate aminotransferase

P05201

Histone H2B type 1-P

Q8CGP2-2

Glutathione S-transferase P

P19157

Stathmin

P54227

Far upstream element-binding protein 2

Q3U0V1

Cytoplasmic FMR1-interacting protein 2

Q5SQX6

Intercellular adhesion molecule 5

Q60625

Heat shock 70

Q3U2G2

Dihydropteridine reductase

Q8BVI4

Peroxiredoxin-5

H3BJQ7

Peroxiredoxin-2

Q61171

Neurofascin

Q810U3

Protein Slc8a2

Q8K596

Dihydropyrimidinase-related protein 1

Q6P1J1

Microtubule-associated protein 2

P20357

Sodium- and chloride-dependent GABA transporter 1

P31648 
Table 3.14-3 Identified proteins from three different detergent samples analyzed by mass spectrometry. The table contains proteins which are involved in the cellular respiration process.

Identified proteins UniProt entry

L-lactate dehydrogenase G5E8N5

Hexokinase-1 P17710

Triosephosphate isomerase P17751

2-oxoglutarate dehydrogenase Q60597-3

Succinate dehydrogenase iron-sulfur subunit, Q9CQA3 mitochondrial

Cytochrome b-c1 complex subunit 1, mitochondrial Q9CZ13 Phosphoglycerate mutase 1 Q9D6J6 NADH dehydrogenase 1 alpha subcomplex subunit 8 Q9DCJ5

In summary several proteins were identified as potential interaction partners of otoferlin. Some endocytotic proteins were found which are reasonable candidates for an interaction with otoferlin. In case of dynamin-1 and OPA1 Alexandra Müller of the lab of Ellen Reisinger is performing proximity ligation assays (see section 4.3). 


\subsection{Phosphorylation with CaMKII}

Former studies of Meike Herget (Stanford University/School of Medicine) showed that the $\mathrm{Ca}^{2+}$ /calmodulin dependent serine/threonine kinase II delta (CaMKII $\delta$ ) is a likely interaction partner of otoferlin in chicken utricles [69]. Further experiments from Meike Herget confirmed the interaction of heterologously expressed otoferlin and CaMKII $\delta$ in HEK cells and revealed a $<40 \mathrm{~nm}$ distance of CaMKII $\delta$ and otoferlin in rat inner hair cells. In vitro binding studies showed that the combined $\mathrm{C}_{2} \mathrm{ABC}$ and $\mathrm{C}_{2} \mathrm{DEF}$ have a higher affinity to bind the kinase than the individual fragments.

To test if the interaction of CaMKII $\delta$ with otoferlin also results in phosphorylation of the protein, an in vitro phosphorylation assay was performed. Due to the absence of a posttranslational modification machinery in E.coli, expressed proteins are not phosphorylated [70]. Therefore, $E$ coli expressed $\mathrm{C}_{2} \mathrm{ABC}$ - and $\mathrm{C}_{2} \mathrm{DEF}$-fragments of the protein were mixed (21 pmol each) and added to a reaction buffer containing $\mathrm{Ca}^{2+}$-chloride and calmodulin followed by an incubation step with CaMKII $\delta$ (life technologies) for $5 \mathrm{~min}$ or $60 \mathrm{~min}$ at $30^{\circ} \mathrm{C}$. The samples were loaded onto an SDS-PAGE gel and analyzed by mass spectrometry.

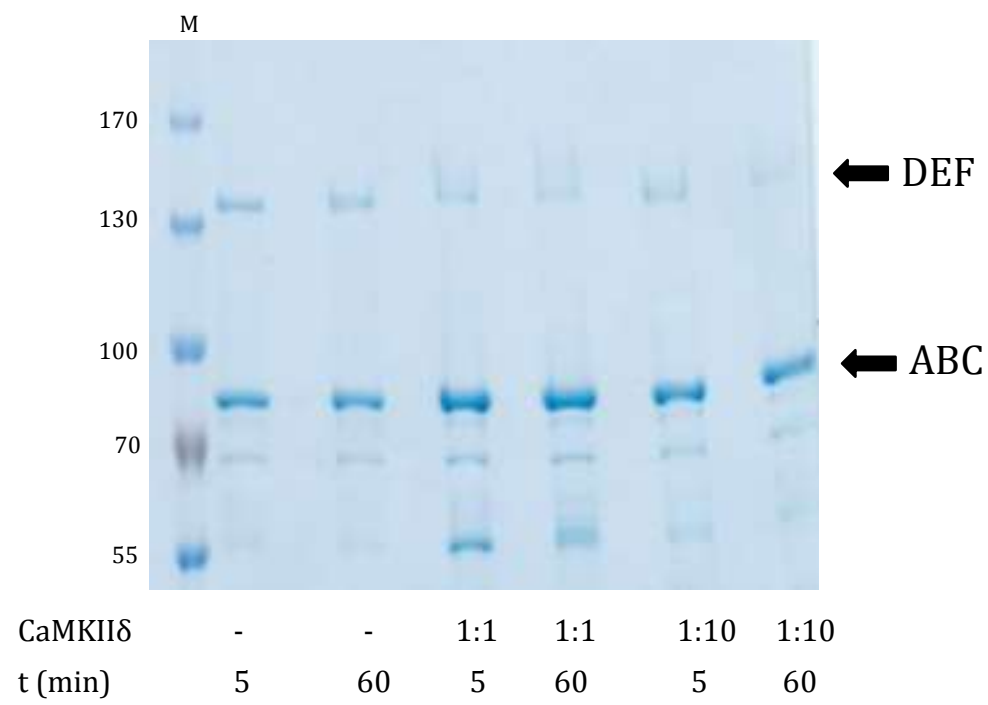

Figure 3.15-1 Phosphorylation control gel of otoferlin for mass analysis. M indicates the molecular weight marker in $\mathrm{kDa}$. The lane below the gel displays in which ratio the kinase was used and at which time points the reaction was quenched.

Three independent experiments were performed and only phosphorylation sites found in all cases were considered. Both otoferlin fragments were found to be phosphorylated by CaMKII $\delta$. For the negative control, the experiment was performed without adding the kinase. In total, ten phosphorylation sites were found. Five of the found phosphorylation sites are located within $C_{2}$-domains (Table 3.15-1)[20]. One 
phosphorylation site is located downstream of the $\mathrm{C}_{2} \mathrm{C}$, two in the putative $\mathrm{C}_{2}$ de-domain and two in the linker region between the domains $\mathrm{C}_{2}$ de and $\mathrm{C}_{2} \mathrm{E}$.

Table 3.15-1 Sites in otoferlin phosphorylated by CaMKII $\delta$. The phosphorylation sites are numbered form P1 to P10, the position indicates the phosphorylated amino acid position in the protein and the location describes in which structural areas these amino acids are located. Phosphorylation sites found within $\mathrm{C}_{2}$-domains are underlined.

\begin{tabular}{lll} 
phosphorylation site & position & location \\
\hline$\underline{\mathrm{P} 1}$ & $\underline{\mathrm{T} 448}$ & $\underline{\mathrm{C}_{2}} \underline{\mathrm{C} \text { domain }}$ \\
$\mathrm{P} 2$ & $\mathrm{~T} 561$ & Downstream $\mathrm{C}_{2} \mathrm{C}$ \\
$\underline{\mathrm{P} 3}$ & $\underline{\mathrm{S} 985}$ & $\underline{\mathrm{C}_{2}} \underline{\mathrm{D} \text { domain }}$ \\
$\mathrm{P} 4$ & $\mathrm{~S} 1184$ & Putative $\mathrm{C}_{2}$ de domain \\
P5 & $\mathrm{T} 1197$ & Putative $\mathrm{C}_{2}$ de domain \\
$\mathrm{P} 6$ & $\mathrm{~S} 1308$ & Linker region between $\mathrm{C}_{2}$ de and $\mathrm{C}_{2} \mathrm{E}$ \\
$\mathrm{P} 7$ & $\mathrm{~S} 1344$ & Linker region between $\mathrm{C}_{2}$ de and $\mathrm{C}_{2} \mathrm{E}$ \\
$\underline{\mathrm{P} 8}$ & $\underline{\mathrm{S} 1777}$ & $\underline{\mathrm{C}_{2}} \underline{\mathrm{F} \text { domain }}$ \\
$\underline{\mathrm{P} 9}$ & $\underline{\mathrm{S} 1808}$ & $\underline{\mathrm{C}_{2}} \underline{\mathrm{F} \text { domain }}$ \\
$\underline{\mathrm{P} 10}$ & $\underline{\mathrm{T} 1860}$ & $\underline{\mathrm{C}_{2}} \underline{\mathrm{F} \text { domain }}$ \\
\hline
\end{tabular}

\subsection{Thermal shift assay}

To obtain information about the thermal stability of the available $\mathrm{C}_{2}$-domains of otoferlin thermal shift assays were performed. Using the thermal shift assay it is possible to distinguish between a folded and an unfolded state of the protein. If the protein is proper folded no fluorescence signal of the added dye is detectable because no hydrophobic patches are available. With increasing temperatures the protein starts to melt. This leads to the exposure of the hydrophobic areas of a protein where the fluorescent dye can bind and change the fluorescence signal [71]. Selected domains in the absence and presence of $\mathrm{Ca}^{2+}$ were tested to analyze the ability of $\mathrm{Ca}^{2+}$ to stabilize the protein. To test the stability of $\mathrm{C}_{2}$-domains in presence of other domains different combinations were measured. For each tested $\mathrm{C}_{2}$-domain $100 \mathrm{pmol}$ were used and in all cases $\mathrm{Ca}^{2+}$ was added in a final concentration of $200 \mu \mathrm{M}$. For the samples containing two otoferlin fragments $1: 1$ ratios were used. SYPRO ${ }^{\circledR}$ Orange 
was used as a hydrophobic fluorophore. All tested protein combinations were measured in sets at least six independent trials.

In the first experiment the $\mathrm{C}_{2} \mathrm{ABC}$-fragment was measured alone and in combination with other single $\mathrm{C}_{2}$-domains (Figure 3.16-1). In an additional experiment $\mathrm{Ca}^{2+}$ was added to the protein mixture. In case of $\mathrm{C}_{2} \mathrm{ABC}$ alone in presence and absence of $\mathrm{Ca}^{2+}$ the obtained curves look comparable. No differences were obtained in the melting temperatures in absence or presence of $\mathrm{Ca}^{2+}$. To analyze the significance of the obtained melting temperatures a t-test was performed. This compares the measured values of two separate protein samples. The combination of $\mathrm{C}_{2} \mathrm{ABC}$ and $\mathrm{C}_{2} \mathrm{~B}$ results in an increase of approximately $1{ }^{\circ} \mathrm{C}(\mathrm{p}=0.004)$. All other tested combinations result in similar values than the $\mathrm{C}_{2} \mathrm{ABC}$ except the combination with $\mathrm{C}_{2} \mathrm{E}$ and $\mathrm{Ca}^{2+}$. For that combination a slight increase in melting temperature was obtained which shows the tendency not to be significant. In case of the single $\mathrm{C}_{2}$-domains only the $\mathrm{C}_{2} \mathrm{D}$ is missing. Unfortunately no attempt to express or purify this domain was successful.

Table 3.16-1 Melting temperatures of $\mathrm{C}_{2} \mathrm{ABC}$ in combination with other $\mathrm{C}_{2}$-domains. Continuous lines show samples measured in absence of $\mathrm{Ca}^{2+}$ whereas the dotted lines show samples with $\mathrm{Ca}^{2+}$. In the right column of the table the mean values for the melting temperatures and standard deviations are given.

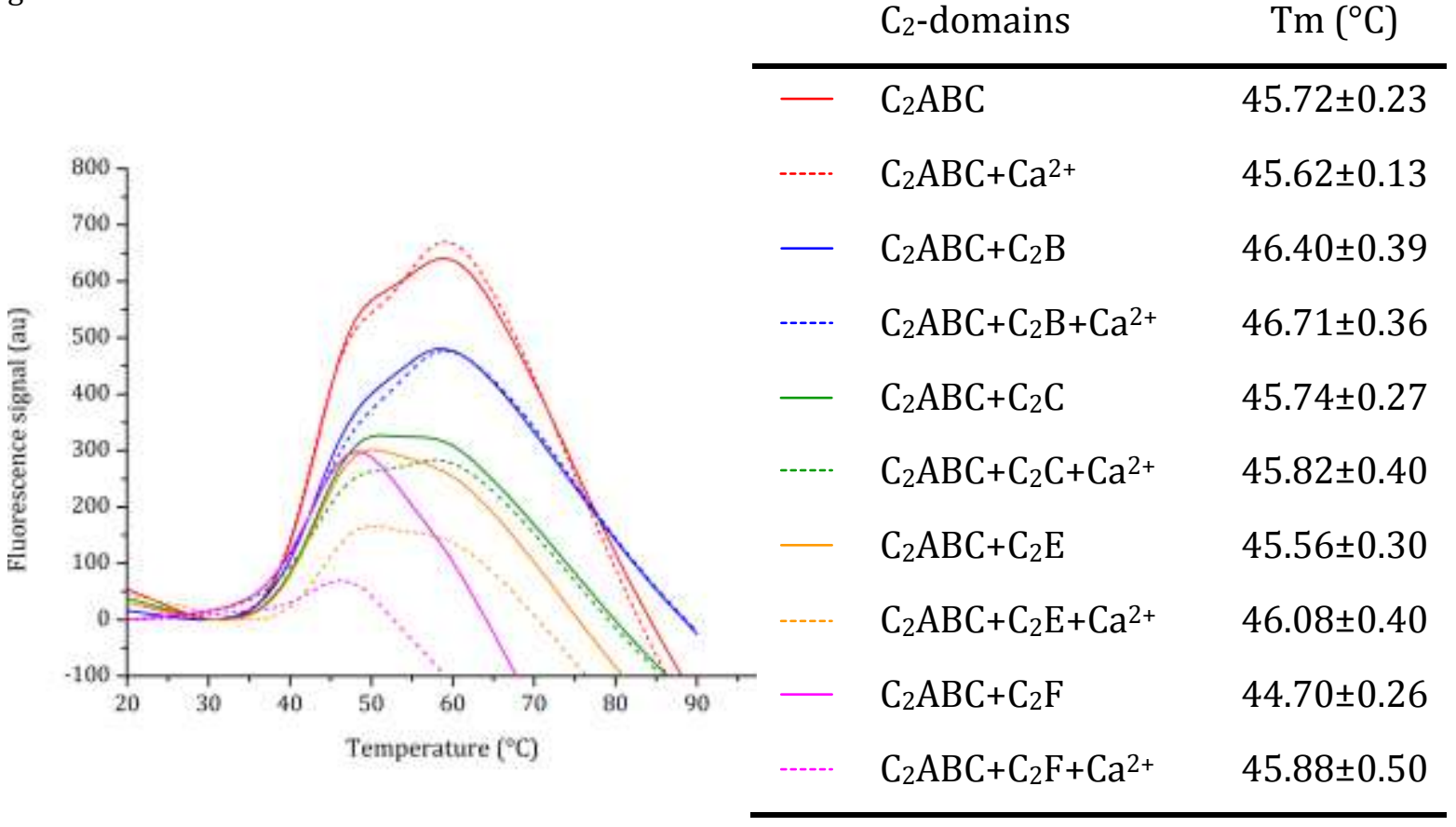

Figure 3.16-1 Melting curves of $\mathrm{C}_{2} \mathrm{ABC}$ in combination with other $\mathrm{C}_{2}$-domains obtained performing thermal shift assays. On the $y$-axis the fluorescence signal is shown and the temperature is displayed on the $\mathrm{x}$-axis. Only $\mathrm{C}_{2} \mathrm{E}$ and $\mathrm{C}_{2} \mathrm{~F}$ show distinct temperature changes in the presence of $\mathrm{Ca}^{2+}$.

The same experiments as for the $\mathrm{C}_{2} \mathrm{ABC}$-fragment were done with a protein fragment containing only the first two domains of otoferlin (Figure 3.16-2). The obtained 
melting temperatures of $\mathrm{C}_{2} \mathrm{AB}$ alone and in presence of $\mathrm{Ca}^{2+}$ differ in about $0.8{ }^{\circ} \mathrm{C}$ $(\mathrm{p}=0.018)$. The combination of $\mathrm{C}_{2} \mathrm{AB}$ with $\mathrm{C}_{2} \mathrm{~B}$ or $\mathrm{C}_{2} \mathrm{C}$ both in absence and presence of $\mathrm{Ca}^{2+}$ led to an increase in the melting temperature of approximately 2 to $3{ }^{\circ} \mathrm{C}$ were observed $\left(p=0.00038\right.$ for $C_{2} A B C$ vs $C_{2} A B+C_{2} B$ and $p=0.00011$ for $C_{2} A B C$ vs $\mathrm{C}_{2} \mathrm{AB}+\mathrm{C}_{2} \mathrm{C}$ ). This leads to the assumption that either one or both domains form $\mathrm{a}$ stable complex with the $\mathrm{C}_{2} \mathrm{AB}$-fragment. The measurement of $\mathrm{C}_{2} \mathrm{AB}$ together with $\mathrm{C}_{2} \mathrm{E}$ again showed a higher melting temperature in the presence of $\mathrm{Ca}^{2+}$ which however was not significant in comparison to the measurement without $\mathrm{Ca}^{2+}$. The increase in presence of $\mathrm{Ca}^{2+}$ indicates that $\mathrm{Ca}^{2+}$ stabilized the protein which could be due to binding to the presumed $\mathrm{Ca}^{2+}$-binding site formed by the top loops of the $\mathrm{C}_{2} \mathrm{E}$-domain (see Figure 1.4-2).

Table 3.16-2 Melting temperatures of $\mathrm{C}_{2} \mathrm{AB}$ in combination with other $\mathrm{C}_{2}$-domains. Continuous lines show samples measured in absence of $\mathrm{Ca}^{2+}$ whereas the dotted lines show samples with $\mathrm{Ca}^{2+}$. In the right column of the table the mean values and standard deviation are given.

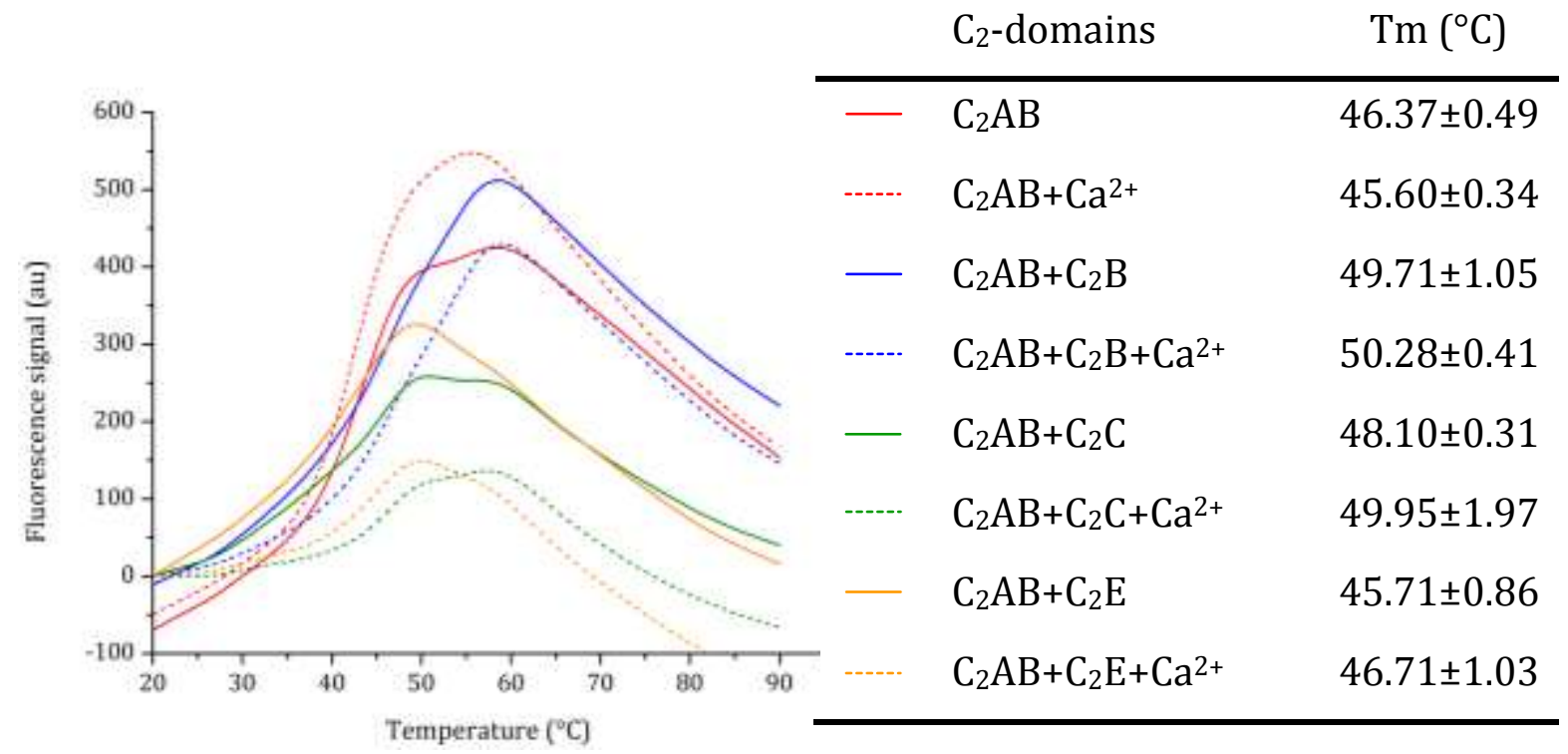

Figure 3.16-2 Melting curves of $\mathrm{C}_{2} \mathrm{AB}$ in combination with other $\mathrm{C}_{2}$-domains obtained performing thermal shift assays. On the $y$-axis the fluorescence signal is shown and the temperature is displayed on the x-axis. All tested fragments show fluorescence changes in presence of $\mathrm{Ca}^{2+}$ except for the single $\mathrm{C}_{2} \mathrm{AB}$ sample all combinations show a higher melting temperature in the presence of $\mathrm{Ca}^{2+}$.

Next, the $\mathrm{C}_{2} \mathrm{DEF}$ as well was analyzed by thermal shift assays. It was not possible to get evaluable data for the experiment with $\mathrm{Ca}^{2+}$ therefore only one curve is displayed in Figure 3.16-3. The measured melting temperature is $2{ }^{\circ} \mathrm{C}$ below the melting temperature of $\mathrm{C}_{2} \mathrm{ABC}$. The combination of both fragments resulted in a temperature which is in between the obtained values for each fragment alone. The addition of $\mathrm{Ca}^{2+}$ to the mixed fragments increased the temperature of approximately $1^{\circ} \mathrm{C}$. This suggests that the fragments are not more stable in presence of $\mathrm{Ca}^{2+}$. 
The comparison of the melting temperatures of the combined $\mathrm{C}_{2} \mathrm{ABC}-$ and $\mathrm{C}_{2}$ DEF-fragment in absence and presence of $\mathrm{Ca}^{2+}$ showed that both temperatures are significantly different $(\mathrm{p}=0.0013)$.

Table 3.16-3 Melting temperatures of $\mathrm{C}_{2} \mathrm{ABC}$ and $\mathrm{C}_{2} \mathrm{DEF}$. Continuous lines show samples measured in absence of $\mathrm{Ca}^{2+}$ whereas the dotted lines show samples with $\mathrm{Ca}^{2+}$. In the right column of the table the mean values and standard deviation are given.

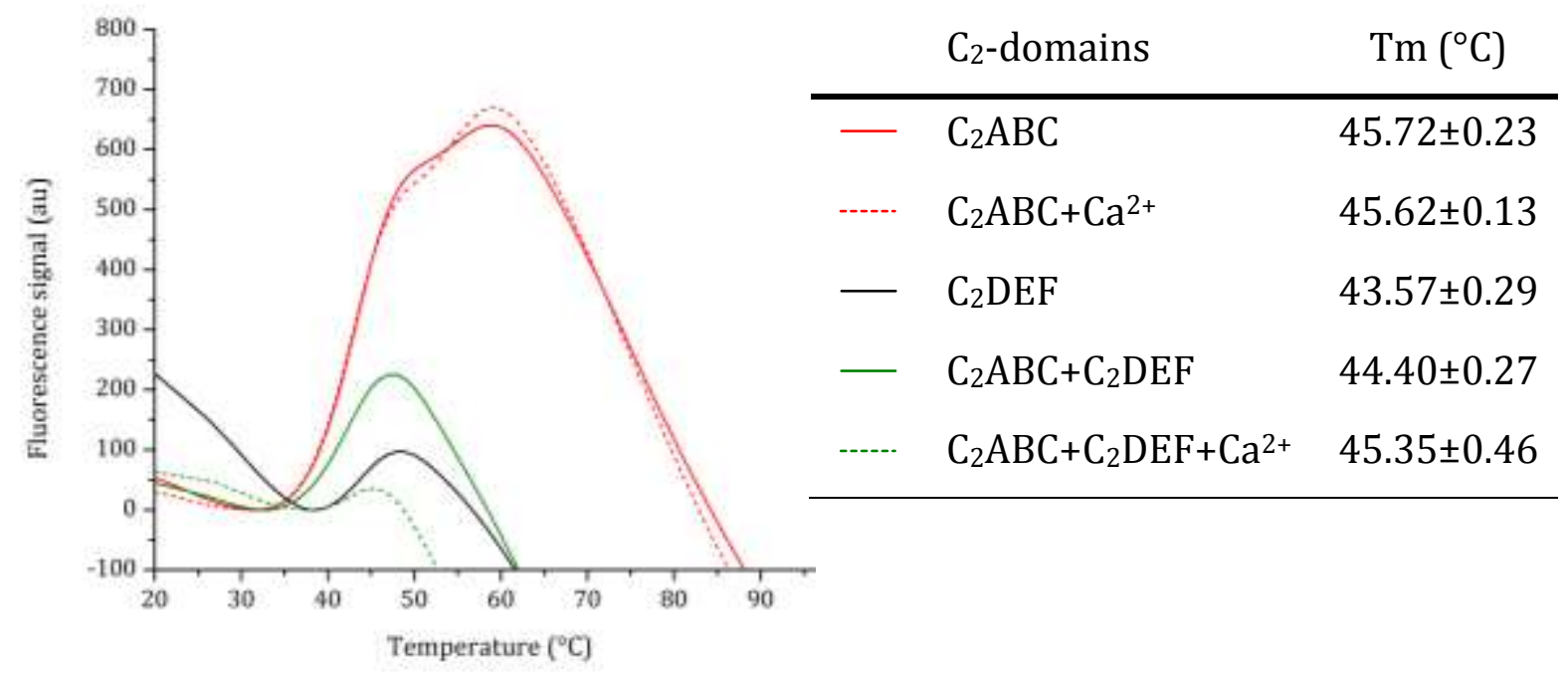

Figure 3.16-3 Melting curves of $\mathrm{C}_{2} \mathrm{ABC}$ and $\mathrm{C}_{2} \mathrm{DEF}$ obtained performing thermal shift assays. On the $\mathrm{y}$-axis the fluorescence signal is shown and the temperature is displayed on the $\mathrm{x}$-axis. No higher melting temperature was detected if both otoferlin fragments were combined.

In the combination with $\mathrm{C}_{2} \mathrm{ABC}$ and $\mathrm{C}_{2} \mathrm{AB}$ the $\mathrm{C}_{2}$-domains $\mathrm{B}$ and $\mathrm{C}$ showed an increase in the melting temperature (Figure 3.16-1, Figure 3.16-2). Therefore both $\mathrm{C}_{2}$-domains were analyzed alone, in combination and as well in the presence and absence of $\mathrm{Ca}^{2+}$ (Figure 3.16-4). The melting temperatures of the single domains without $\mathrm{Ca}^{2+}$ differ in $1{ }^{\circ} \mathrm{C}$ whereby $\mathrm{C}_{2} \mathrm{~B}$ shows the higher value. In case of the combined domains the temperature is $1.5^{\circ} \mathrm{C}$ higher than the single $\mathrm{C}_{2} \mathrm{~B}(\mathrm{p}=0.0040$ for $\mathrm{C}_{2} \mathrm{~B}$ vs. $\mathrm{C}_{2} \mathrm{~B}+\mathrm{C}_{2} \mathrm{C}$ and $\mathrm{p}=3.38 \times 10^{-8}$ for $\mathrm{C}_{2} \mathrm{C}$ vs. $\mathrm{C}_{2} \mathrm{~B}+\mathrm{C}_{2} \mathrm{C}$ ). Adding $\mathrm{Ca}^{2+}$ to the single or combined domains result only in a small change of the melting temperature. 
Table 3.16-4 Melting temperatures of $\mathrm{C}_{2} \mathrm{~B}$ and $\mathrm{C}_{2} \mathrm{C}$. Continuous lines show samples measured in absence of $\mathrm{Ca}^{2+}$ whereas the dotted lines show samples with $\mathrm{Ca}^{2+}$. In the right column of the table the mean values and standard deviation are given.

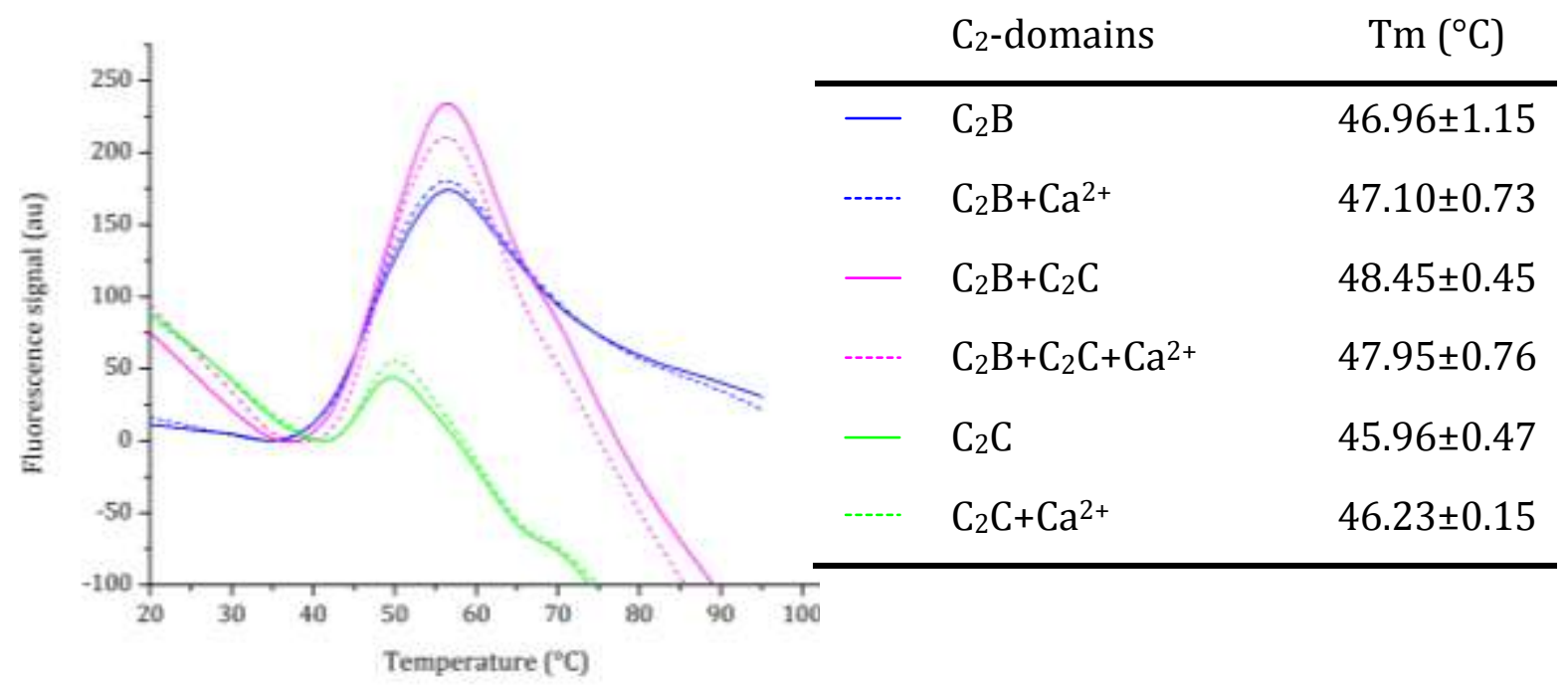

Figure 3.16-4 Melting curves of $\mathrm{C}_{2} \mathrm{~B}$ and $\mathrm{C}_{2} \mathrm{C}$ obtained performing thermal shift assays. On the y-axis the fluorescence signal is shown and the temperature is displayed on the $\mathrm{x}$-axis. The combination of the $\mathrm{C}_{2} \mathrm{~B}$ - and $\mathrm{C}_{2} \mathrm{C}$-domains resulted in a higher thermal stability than for the individual domains.

Table 3.16-5 Melting temperatures of $\mathrm{C}_{2} \mathrm{ABC}$ and $\mathrm{C}_{2} \mathrm{ABC}-\mathrm{I} 515 \mathrm{~T}$. The color code refers to the curve in the neighboring graph. Continuous lines show samples measured in absence of $\mathrm{Ca}^{2+}$ whereas the dotted lines show samples with $\mathrm{Ca}^{2+}$. In the right column of the table the mean values and standard deviation are given.

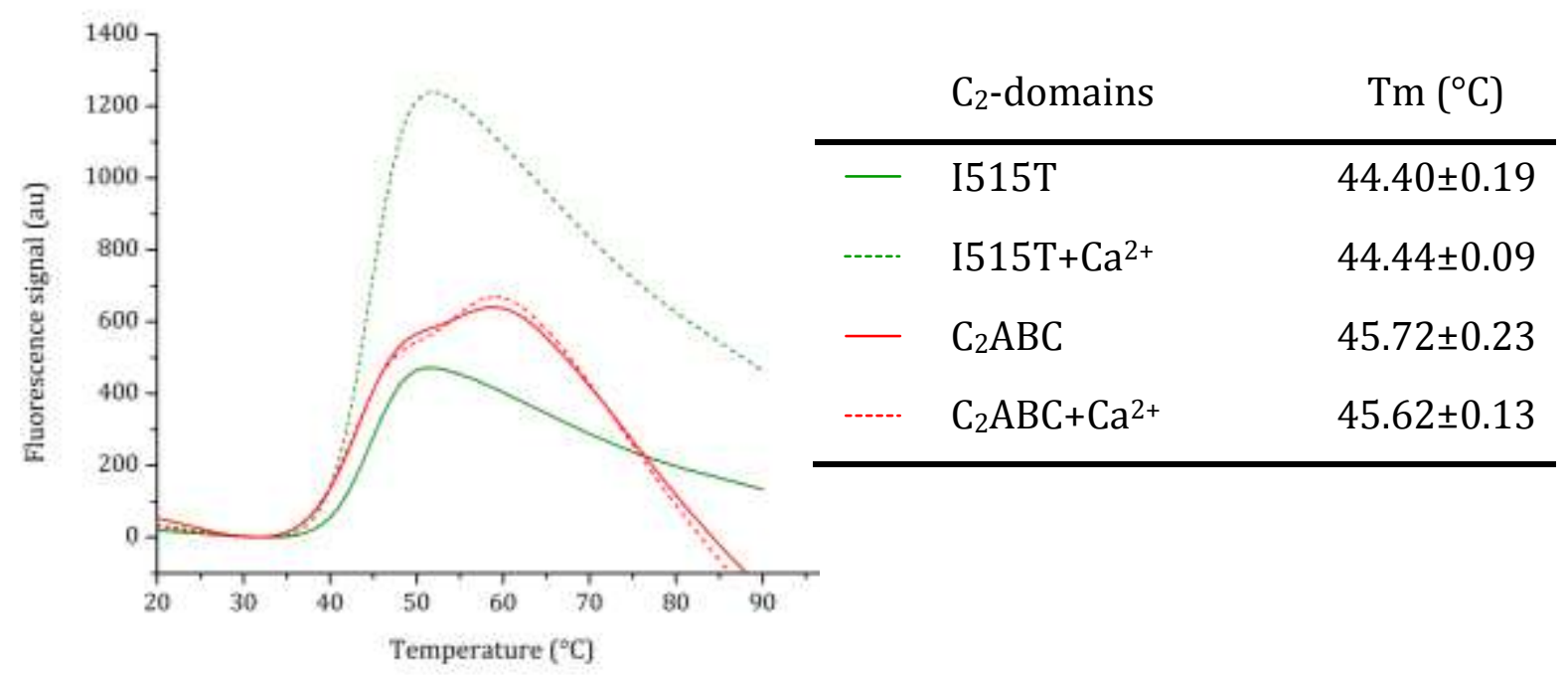

Figure 3.16-5 Melting curves of $\mathrm{C}_{2} \mathrm{ABC}$ and $\mathrm{I} 515 \mathrm{~T}$ obtained performing thermal shift assays. On the $\mathrm{y}$-axis the fluorescence signal is shown and the temperature is displayed on the $\mathrm{x}$-axis. The $\mathrm{C}_{2} \mathrm{ABC}-\mathrm{I515T}$-mutant shows a different melting temperature in absence and presence of $\mathrm{Ca}^{2+}$ compared to the wild type fragment. 
The melting temperature of the temperature sensitive mutant I515T which was inserted into the $\mathrm{C}_{2} \mathrm{ABC}$-fragment was as well analyzed by thermal shift assays (Figure 3.16-5). In comparison to the wild type $\mathrm{C}_{2} \mathrm{ABC}$ the mutant showed a decrease in the melting temperature $\left(\mathrm{p}=3.57 \times 10^{-8}\right)$. This was observed in the absence and presence of $\mathrm{Ca}^{2+}$. Due to the similarity of both values the presence of $\mathrm{Ca}^{2+}$ seems not to have an influence on the stability of the I515T-mutant.

The performed assay showed that some $\mathrm{C}_{2}$-domains are more stable at higher temperatures than others. The addition of $\mathrm{Ca}^{2+}$ to the sample increases the melting temperature in some cases. For others no change could be detected in the absence or presence of $\mathrm{Ca}^{2+}$. Furthermore, the combination of some selected $\mathrm{C}_{2}$-domain-fragments results in a higher thermal stability. The temperature sensitive $\mathrm{C}_{2} \mathrm{ABC}-\mathrm{I515T}$-mutant showed an expected lower melting temperature than the wild type fragment. 


\subsection{7 $\mathrm{Ca}^{2+}$-binding of otoferlin $\mathrm{C}_{2}$-domains}

MicroScale Thermophoresis (MST) was used to determine $K_{\mathrm{d}}$ values for $\mathrm{Ca}^{2+}$-binding of different $\mathrm{C}_{2}$-domains (see section 2.2.2.12). This method detects changes in the hydration shell, charge or size of the molecules. Using an infrared-laser a precise microscopic temperature gradient is generated in the glass capillaries which are filled with the sample of choice. The intrinsic tryptophan fluorescence of the protein is used to monitor its motion along the temperature gradient. Binding events change the hydration shell of the molecule which affects the thermophoretic movements.

All measured proteins were incubated with Chelex for $1 \mathrm{~h}$ at $4{ }^{\circ} \mathrm{C}$ to remove all bivalent cations. The size exclusion buffer (10 mM HEPES pH 7.4, $150 \mathrm{mM} \mathrm{NaCl}$, $0.1 \%$ Tween) was used for each tested $\mathrm{C}_{2}$-domain. All measurements took place at a constant temperature of $22{ }^{\circ} \mathrm{C}$ at the Monolith NT.LabelFree instrument.

For all measurements the temperature jump (T-jump) data were analyzed. The $\mathrm{T}$-jump is sensitive for changes in close proximity to the detected tryptophan. These changes can either indicate a direct binding event but can also be caused by a conformational change.

Each experiment was repeated three times with individual samples and the mean average was determined. The data were fitted in OriginPro 8.5G using the Hill equation $\left(f(c)=\right.$ unbound $+($ bound-unbound $) /\left(1+(E C 50 / c)^{\wedge} n\right)$.

\subsection{1 $\mathrm{His}_{6}-\mathrm{C}_{2} \mathrm{AB}$}

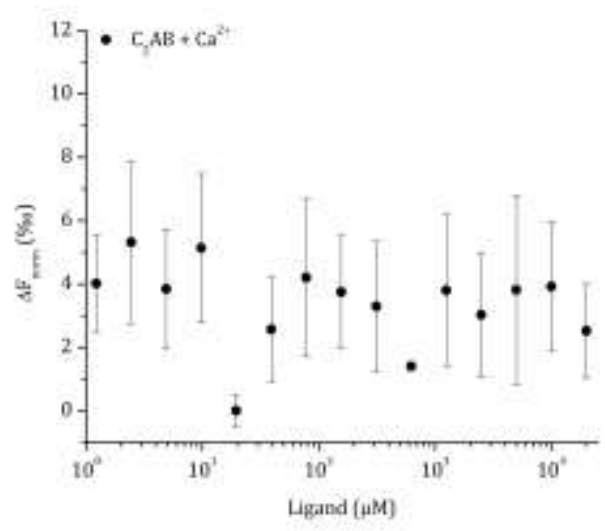

Figure 3.17-1 MST measurement of $\mathrm{His}_{6}-\mathrm{C}_{2} \mathrm{AB}$. On the $\mathrm{y}$-axis the changes in normalized fluorescence

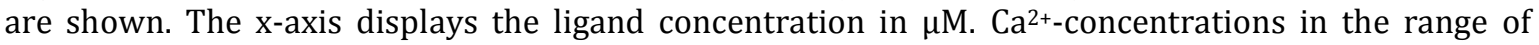
$0.6 \mu \mathrm{M}$ to $20 \mathrm{mM}$ were tested at a final protein concentration of $1 \mu \mathrm{M}$. The tested $\mathrm{C}_{2} \mathrm{AB}$-fragment showed no indication of $\mathrm{Ca}^{2+}$-binding.

The His-tagged $\mathrm{C}_{2} \mathrm{AB}$-fragment was measured at a final protein concentration of $1 \mu \mathrm{M}$. $\mathrm{Ca}^{2+}$ was tested in concentrations of $0.6 \mu \mathrm{M}$ to $20 \mathrm{mM}$ (Figure 3.17-1). Neither the 
data derived from the thermophoresis nor the T-jump indicated any binding event which would result in a dose-dependent change of the thermophoresis rate.

\subsection{2 $\quad C_{2} B$}

The $\mathrm{C}_{2} \mathrm{~B}$-fragment of otoferlin was measured at a final protein concentration of $1 \mu \mathrm{M}$. $\mathrm{Ca}^{2+}$-concentrations of $0.6 \mu \mathrm{M}$ to $20 \mathrm{mM}$ were added. During the measurement no dose-dependent change in thermophoresis could be detected which would indicate a binding event between $\mathrm{Ca}^{2+}$ and the otoferlin $\mathrm{C}_{2} \mathrm{~B}$-domain (Figure 3.17-2).

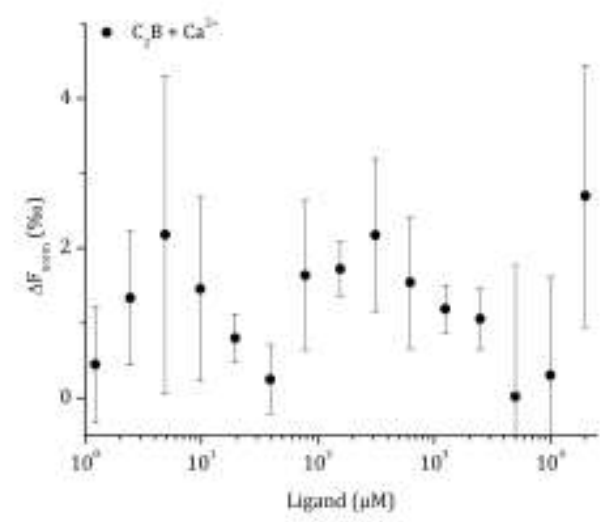

Figure 3.17-2 MST measurement of $\mathrm{C}_{2} \mathrm{~B}$. On the $\mathrm{y}$-axis the changes in normalized fluorescence are shown. The $\mathrm{x}$-axis displays the ligand concentration in $\mu \mathrm{M}$. $\mathrm{Ca}^{2+}$-concentrations in the range $0.6 \mu \mathrm{M}$ to $20 \mathrm{mM}$ were tested at a final protein concentration of $1 \mu \mathrm{M}$. No binding to $\mathrm{Ca}^{2+}$ could be detected for the $\mathrm{C}_{2} \mathrm{~B}$-domain.

\subsection{3 $\quad \mathrm{C}_{2} \mathrm{C}$}

\subsubsection{1 $\quad \mathrm{C}_{2} \mathrm{C}$-wild type}

The $\mathrm{C}_{2} \mathrm{C}$-wild type domain of otoferlin was measured at a concentration of $4 \mu \mathrm{M}$, the highest $\mathrm{Ca}^{2+}$-concentration added was $200 \mathrm{mM}$. Only a slight increase in the signal was detected. In comparison with the negative measurements with $500 \mathrm{mM}$ EDTA there is no significant difference between the two measurements (Figure 3.17-3). Because of the similarity of both curves it seems that the $\mathrm{C}_{2} \mathrm{C}$-wild type is not able to bind any $\mathrm{Ca}^{2+-i o n s .}$ 


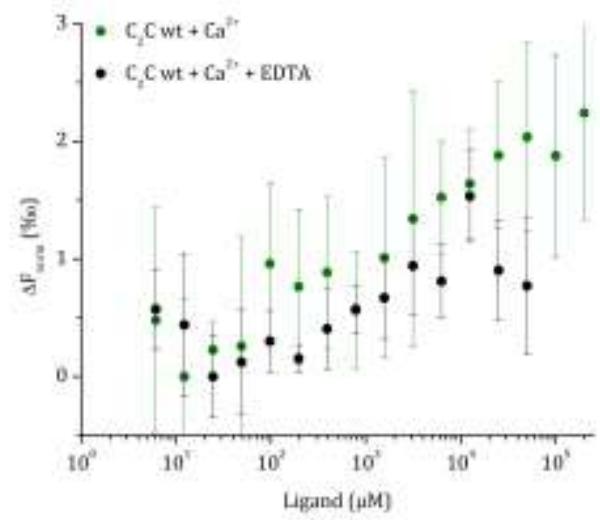

Figure 3.17-3 MST measurement of $\mathrm{C}_{2} \mathrm{C}$-wild type. On the $\mathrm{y}$-axis the changes in normalized fluorescence are shown. The $\mathrm{x}$-axis displays the ligand concentration in $\mu \mathrm{M}$. Protein concentrations of $4 \mu \mathrm{M}$ and $\mathrm{Ca}^{2+}$-concentrations of $6.1 \mu \mathrm{M}$ to $200 \mathrm{mM}$ were used. The wild type protein is shown in green and the negative control with EDTA in black. Due to the similarity to the negative control it can be assumed that the $\mathrm{C}_{2} \mathrm{C}$-wild type domain is not able to bind $\mathrm{Ca}^{2+}$.

\subsubsection{2 $\quad \mathrm{C}_{2} \mathrm{C}-$ phos}

The $\mathrm{C}_{2} \mathrm{C}$-phos contains an additional aspartate residue in the top loops of the domain. This aspartate was inserted to mimic the found phosphorylation site at this position (see section 3.15). A final protein concentration of $1 \mu \mathrm{M}$ was used and $\mathrm{Ca}^{2+}$-concentrations ranging between $6.1 \mu \mathrm{M}$ and $200 \mathrm{mM}$. For this modified domain a binding curve was obtained and resulted in a $K_{\mathrm{d}}$ of $9.1 \pm 0.6 \mathrm{mM}$. The negative control was measured in the presence of $500 \mathrm{mM}$ EDTA which showed no binding event (Figure 3.17-4).

A

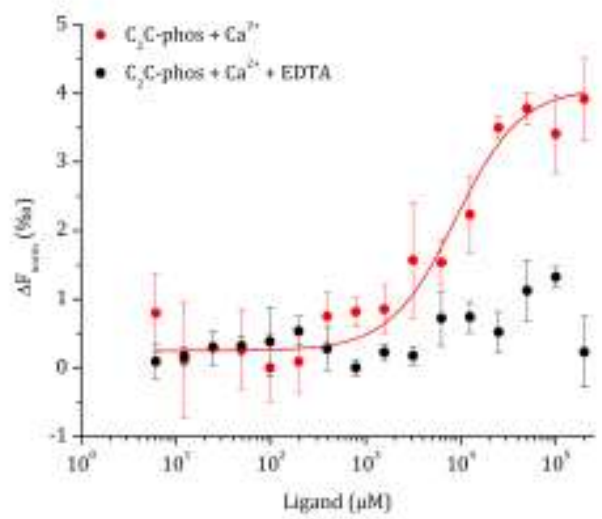

B

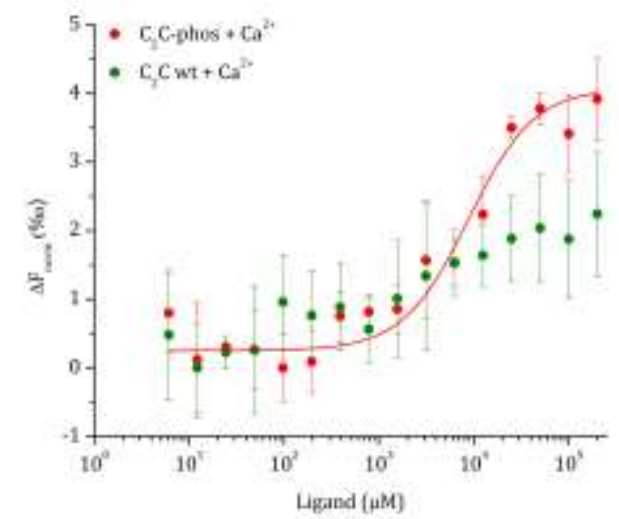

Figure 3.17-4 MST measurement of $\mathrm{C}_{2} \mathrm{C}$-phos. On the $\mathrm{y}$-axis the changes in normalized fluorescence are shown. The $\mathrm{x}$-axis displays the ligand concentration in $\mu \mathrm{M}$. The protein concentration was set to $1 \mu \mathrm{M}$ and $6.1 \mu \mathrm{M}$ to $200 \mathrm{mM} \mathrm{Ca}^{2+}$ was added.

A The binding curve for the $\mathrm{C}_{2} \mathrm{C}$-phos is shown in red and the negative control in black.

B The comparison of the wild type $\mathrm{C}_{2} \mathrm{C}$-domain (green) and the pseudo-phosphorylated domain (red) shows that the integration of another aspartate into the binding region of the $\mathrm{C}_{2} \mathrm{C}$-domain enables the $\mathrm{Ca}^{2+}$-binding. 


\subsection{4 $\quad \mathrm{C}_{2} \mathrm{ABC}-\mathrm{His}_{6}$}

The protein fragment containing the first three $\mathrm{C}_{2}$-domains of the protein was measured at a final protein concentration of $1 \mu \mathrm{M}$. $\mathrm{Ca}^{2+}$ was added in concentrations of $0.6 \mu \mathrm{M}$ to $20 \mathrm{mM}$. The green data points indicate the measurement of $\mathrm{C}_{2} \mathrm{ABC}$ and $\mathrm{Ca}^{2+}$. The negative control with $50 \mathrm{mM}$ EDTA is presented in black indicating no binding event (Figure 3.17-5). Both measurements show a minor fluorescence change. However, based on the similarity to the negative control the $\mathrm{C}_{2} \mathrm{ABC}$-fragment did not show any binding to $\mathrm{Ca}^{2+}$.

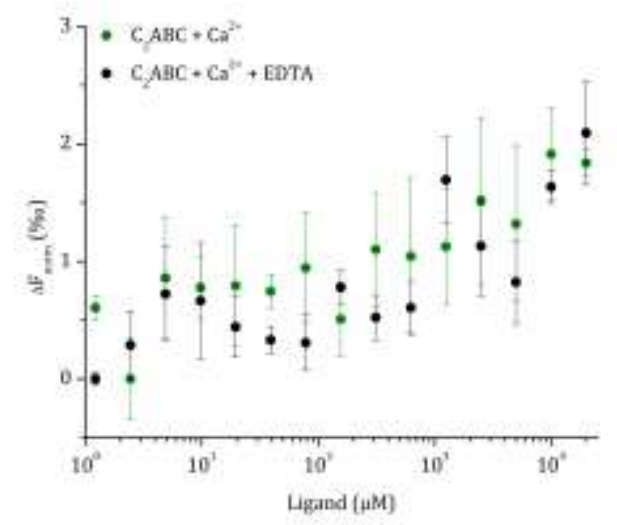

Figure 3.17-5 MST measurement of $\mathrm{C}_{2} \mathrm{ABC}-\mathrm{His}_{6}$. On the $\mathrm{y}$-axis the changes in normalized fluorescence are shown. The $\mathrm{x}$-axis displays the ligand concentration in $\mu \mathrm{M}$. $\mathrm{C}_{2} \mathrm{ABC}$ was measured at a concentration of $1 \mu \mathrm{M}$ and $\mathrm{Ca}^{2+}$ was added in the range of $0.6 \mu \mathrm{M}$ to $20 \mathrm{mM}$. The thermophoresis measurement of $\mathrm{C}_{2} \mathrm{ABC}$ and $\mathrm{Ca}^{2+}$ is shown in green and the EDTA negative control in black. No $\mathrm{Ca}^{2+-b i n d i n g ~ e v e n t ~ c o u l d ~}$ be detected.

\subsection{5 $\quad C_{2} F$}

During this work several fragments of the $\mathrm{C}_{2} \mathrm{~F}$-domain were expressed and purified. Next to the wild type domain a fragment containing three pseudo-phosphorylation sites was generated with aspartate residues replacing phosphorylated serine or threonine residues. Additionally four mutants were created in which the important aspartates for $\mathrm{Ca}^{2+}$-binding were replaced by asparagine residues to analyze the influence of each aspartate within the $\mathrm{Ca}^{2+}$-binding process. With $\mathrm{C}_{2} \mathrm{~F}$-pga and $\mathrm{C}_{2} \mathrm{~F}-\mathrm{E} 1804 \mathrm{del}$ two mutants were investigated which are known to result in hearing impairment in mice or humans. All these fragments were tested for $\mathrm{Ca}^{2+}$-binding with MST (Table 4.2-1). 


\subsubsection{1 $\quad \mathrm{C}_{2} \mathrm{~F}$ wild type}

For the $\mathrm{C}_{2} \mathrm{~F}$ wild type, the protein was measured at $1 \mu \mathrm{M}$ and the used $\mathrm{Ca}^{2+}$-concentrations ranged between $0.6 \mu \mathrm{M}$ and $20 \mathrm{mM}$. The obtained binding curve was fitted with the Hill Fit and resulted in a $K_{\mathrm{d}}$ value of $449 \pm 20.8 \mu \mathrm{M}$. As negative control $50 \mathrm{mM}$ EDTA was added to the reaction mixture. By adding $\mathrm{Mg}^{2+}$ it was possible to obtain a binding curve with much less affinity than with $\mathrm{Ca}^{2+}$. Up to $20 \mathrm{mM}$ $\mathrm{Mg}^{2+}$ no saturation could be reached and no $K_{\mathrm{d}}$ value could be obtained (Figure 3.176).

By increasing the salt concentration in the buffer to $300 \mathrm{mM} \mathrm{NaCl}$ it was possible to obtain a more distinct plateau for the bound state (Figure 3.17-7). This resulted in a different dissociation constant $\left(K_{\mathrm{d}}=290+/-14.4 \mu \mathrm{M}\right)$. It is known from literature that the addition of phosphatidylinositol 4,5-bisphosphate $\left(\mathrm{PIP}_{2}\right)$ to the $\mathrm{C}_{2} \mathrm{~F}$-domain of syt- 1 decreases the $K_{\mathrm{d}}$ by 10 - to 40 -fold $[53,72]$. The addition of $20 \mu \mathrm{M} \mathrm{PIP} 2$ in this case did not improve the measurement or the $K_{\mathrm{d}}$. No saturation state for the $\mathrm{Ca}^{2+} / \mathrm{PIP}_{2}$ binding could be obtained therefore no $K_{\mathrm{d}}$ value could be calculated.

A

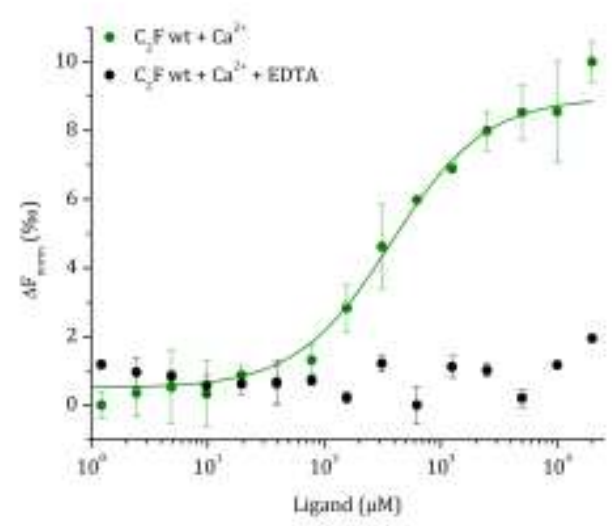

B

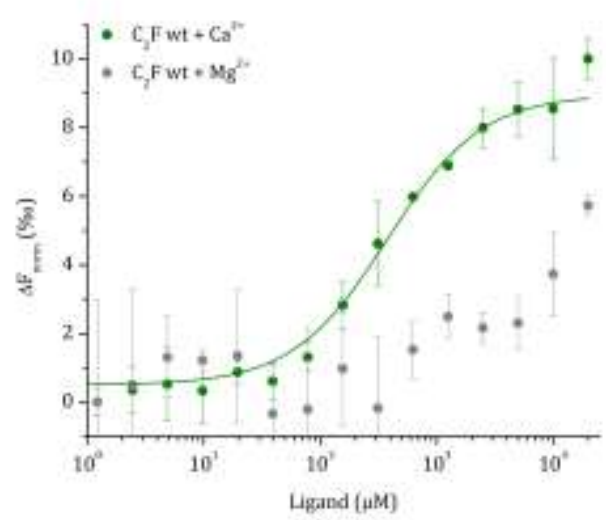

Figure 3.17-6 MST measurement of $\mathrm{C}_{2} \mathrm{~F}$-wild type. On the $\mathrm{y}$-axis the changes in normalized fluorescence are shown. The $\mathrm{x}$-axis displays the ligand concentration in $\mu \mathrm{M}$. The green curve shows the binding of $\mathrm{C}_{2} \mathrm{~F}$-wild type in a concentration of $1 \mu \mathrm{M}$ and $\mathrm{Ca}^{2+}$-concentrations between $0.6 \mu \mathrm{M}$ and $20 \mathrm{mM}$.

A The negative control with 50 mM EDTA is shown in black.

B The comparison of the $\mathrm{Mg}^{2+}$ (grey) and $\mathrm{Ca}^{2+}$ (green) binding curves shows that the $\mathrm{C}_{2} \mathrm{~F}$-domain has a higher affinity to bind $\mathrm{Ca}^{2+}$ than $\mathrm{Mg}^{2+}$. 
A

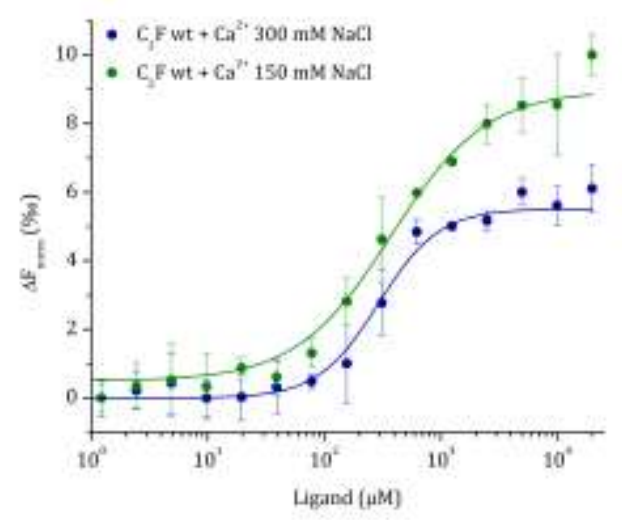

B

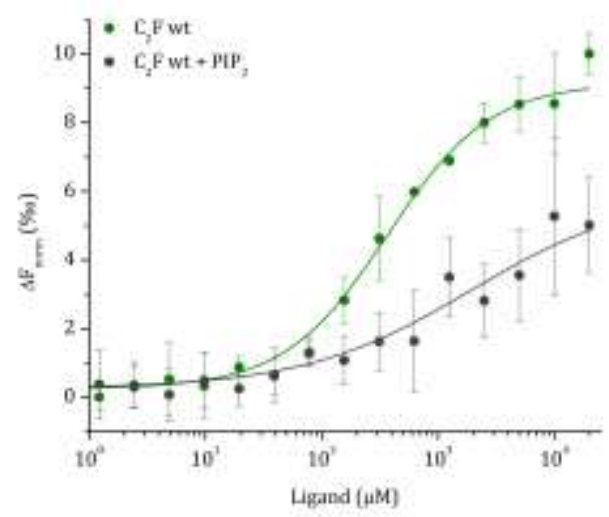

Figure 3.17-7 MST measurement of $\mathrm{C}_{2} \mathrm{~F}$-wild type with different salt concentrations and $\mathrm{PIP}_{2}$. On the $\mathrm{y}$-axis the changes in normalized fluorescence are shown. The $\mathrm{x}$-axis displays the ligand concentration in $\mu \mathrm{M}$.

A Different salt concentration in the buffer resulted in slightly different dissociation constants. The green curve represents a measurement with a buffer containing $150 \mathrm{mM} \mathrm{NaCl}\left(K_{\mathrm{d}}=449 \pm 20.8 \mu \mathrm{M}\right)$ and the blue one contained $300 \mathrm{mM} \mathrm{NaCl}\left(K_{\mathrm{d}}=290+/-14.4 \mu \mathrm{M}\right)$.

B The addition of $\mathrm{PIP}_{2}$ did not result in an improvement of the $K_{\mathrm{d}}$. No saturation could be obtained during MST measurements.

\subsubsection{2 $\quad C_{2}$ F-phos}

The $\mathrm{C}_{2} \mathrm{~F}$-phos-fragment was measured at a concentration of $1 \mu \mathrm{M}$. In contrast to the wild type the $\mathrm{Ca}^{2+}$-chloride concentration was increased up to $200 \mathrm{mM}$ to reach an evaluable plateau for the bound state. The fitted data resulted in a $K_{\mathrm{d}}=6.3 \pm 0.4 \mathrm{mM}$. The negative control was measured in the presence of $500 \mathrm{mM}$ EDTA and also for this modified $\mathrm{C}_{2}$-domain a binding affinity to $\mathrm{Mg}^{2+}$ was found. $\mathrm{The}^{\mathrm{Mg}^{2+}}$ was added in a concentration of $200 \mathrm{mM}$. The affinity to $\mathrm{Ca}^{2+}$ is much higher than the affinity to $\mathrm{Mg}^{2+}$ (Figure 3.17-8).

In comparison to the wild type domain the $\mathrm{C}_{2} \mathrm{~F}$-phos shows a lower affinity to bind $\mathrm{Ca}^{2+}$. Additional to the normal $\mathrm{Ca}^{2+}, \mathrm{Mg}^{2+}$ and EDTA-measurements an experiment with $20 \mu \mathrm{M} \mathrm{PIP} 2$ was done. A decrease in the amplitude of the signal was detected and the obtained $K_{\mathrm{d}}$-value with $5.26 \pm 0.36 \mathrm{mM}$ is in the same range as without $\mathrm{PIP}_{2}$ (Figure 3.17-9). 
A

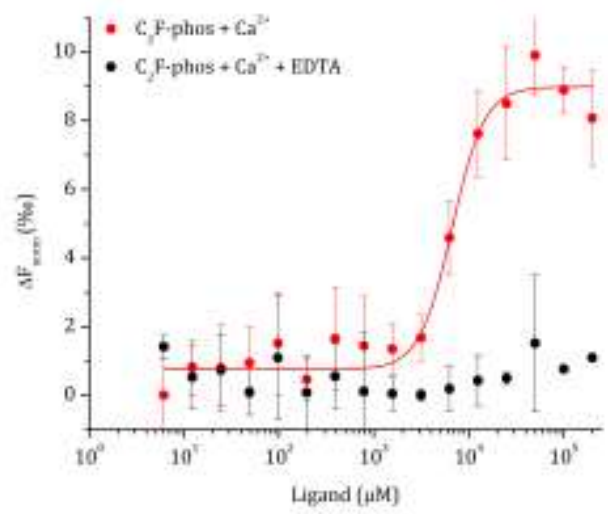

B

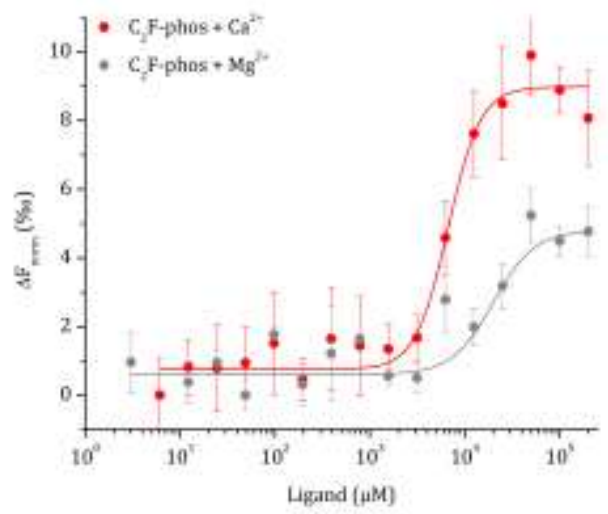

Figure 3.17-8 MST measurement of the $\mathrm{C}_{2} \mathrm{~F}$-phos. On the $\mathrm{y}$-axis the changes in normalized fluorescence are shown. The $\mathrm{x}$-axis displays the ligand concentration in $\mu \mathrm{M}$.

A The $\mathrm{C}_{2} \mathrm{~F}$-phos (red) was measured in a concentration of $1 \mu \mathrm{M}$ and mixed with $\mathrm{Ca}^{2+}$-concentrations ranging from $6.1 \mu \mathrm{M}$ to $200 \mathrm{mM}$. The negative control with $500 \mathrm{mM}$ EDTA is shown in black.

B The addition of concentrations up to $200 \mathrm{mM} \mathrm{Mg}^{2+}$ (grey) resulted in a lower binding affinity than for $\mathrm{Ca}^{2+}$.

A

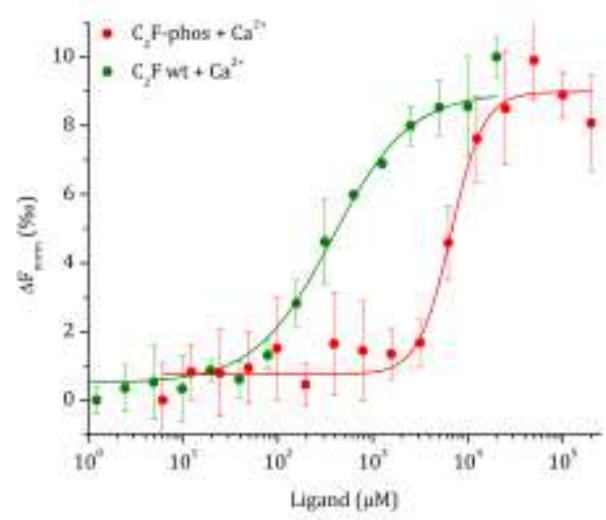

B

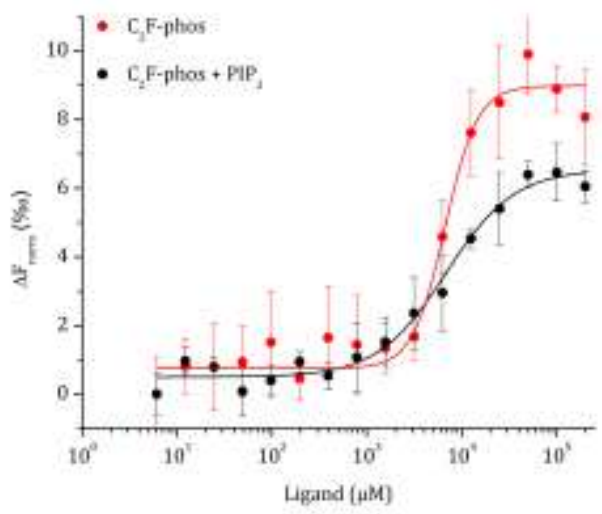

Figure 3.17-9 Comparison of $\mathrm{C}_{2} \mathrm{~F}$-wild type and $\mathrm{C}_{2} \mathrm{~F}$-phos MST curves.

A The wild type binding curve is shown in red. The red curve shows the $\mathrm{C}_{2} \mathrm{~F}$-domain in which the three phosphorylation sites were mutated into aspartate residues. In comparison to the wild type domain the pseudo-phosphorylated $\mathrm{C}_{2} \mathrm{~F}$ shows a lower affinity to bind $\mathrm{Ca}^{2+}$.

B MST measurement of $\mathrm{C}_{2} \mathrm{~F}$-phos in presence of $20 \mu \mathrm{M}$ PIP $\mathrm{P}_{2}$, no increase of the $K_{\mathrm{d}}$ could be observed.

\subsubsection{Aspartate mutants of $\mathrm{C}_{2} \mathrm{~F}$}

Selected aspartate residues in synaptotagmin $1 \mathrm{C}_{2} \mathrm{~A}$ seem to have specific influence of the $\mathrm{Ca}^{2+}$-binding ability [36]. The high affinity binding site of the synaptotagmin 1 $\mathrm{C}_{2} \mathrm{~A}$-domain is disrupted if the aspartate at position 178 is replaced by an asparagine. This position corresponds in the $\mathrm{C}_{2} \mathrm{~F}$-domain of otoferlin to the position 1760 the mutation of which was called D1N. If this would also be the residue responsible for the high affinity binding site the $K_{\mathrm{d}}$ of the D1N-mutant would be expected to be much 
higher than the value measured for the wild type. In case of the mutant containing three replaced aspartate residues nearly no $\mathrm{Ca}^{2+}$-binding is expected. The D2,3N-mutant contains two mutations which should affect the second and the third $\mathrm{Ca}^{2+}$-binding site but should not have sufficient influence to affect the high affinity site. Next to the fifth aspartate residue predicted to form the $\mathrm{Ca}^{2+}$-binding site is another aspartate located. In the D4N-mutant both aspartates were replaced. According to the structural situation within the synaptotagmin binding region this mutation should mostly affect the $\mathrm{Ca}^{2+}$-binding site three, therefore an influence on the high affinity binding site is not expected.

\subsubsection{1 $\quad \mathrm{C}_{2} \mathrm{~F}-\mathrm{D} 1 \mathrm{~N}$}

$\mathrm{C}_{2} \mathrm{~F}-\mathrm{D} 1 \mathrm{~N}$ was measured in a final protein concentration of $1 \mu \mathrm{M}$. $\mathrm{Ca}^{2+}$-concentrations were added in the range of $200 \mathrm{mM}$ to $6.1 \mu \mathrm{M}$. These high $\mathrm{Ca}^{2+}$-concentrations were necessary to obtain the saturation in MST assays. A binding curve could be obtained for the D1N-mutant (Figure 3.17-10) whereas the negative control with EDTA did not show any increase in the fluorescence. For $\mathrm{Ca}^{2+}$-binding a $K_{\mathrm{d}}$ of $3.7 \pm 0.19 \mathrm{mM}$ was calculated. The addition of $\mathrm{Mg}^{2+}-$ ions instead of $\mathrm{Ca}^{2+}$ also resulted in a binding event. $\mathrm{Mg}^{2+}$ showed a much less affinity to the $\mathrm{C}_{2} \mathrm{~F}-\mathrm{D} 1 \mathrm{~N}$ than $\mathrm{Ca}^{2+}$. The obtained $K_{\mathrm{d}}$ value for $\mathrm{Mg}^{2+}$-binding is $10.5 \pm 8.06 \mathrm{mM}$.

A

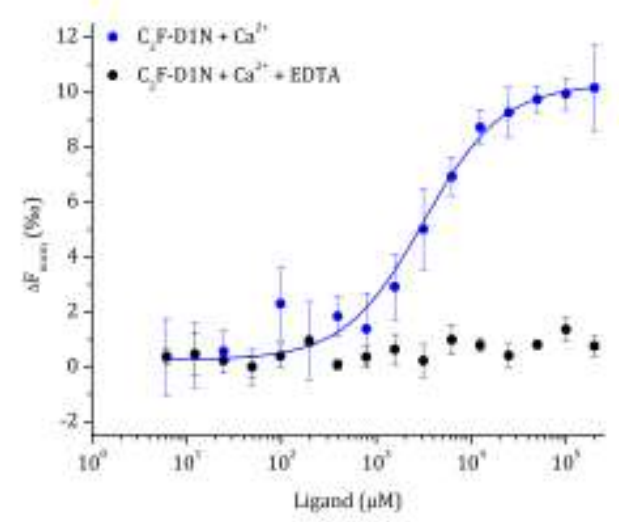

B

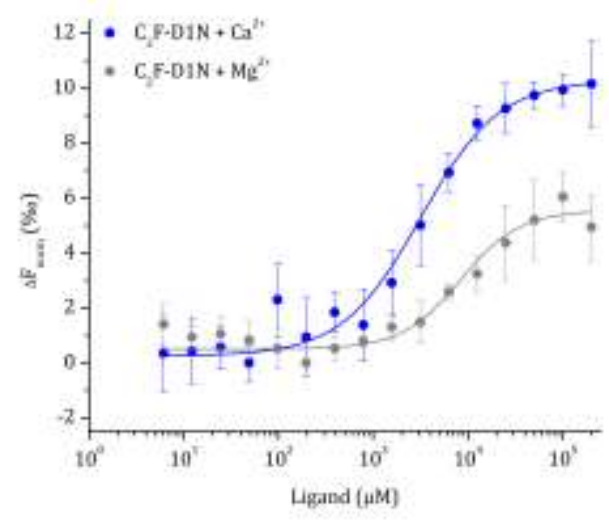

Figure 3.17-10 MST measurement of $\mathrm{C}_{2} \mathrm{~F}-\mathrm{D} 1 \mathrm{~N}$. On the $\mathrm{y}$-axis the changes in normalized fluorescence are shown. The $\mathrm{x}$-axis displays the ligand concentration in $\mu \mathrm{M}$. The D1N-mutant was measured at $1 \mu \mathrm{M}$ and the $\mathrm{Ca}^{2+}$-concentrations range between $6.1 \mu \mathrm{M}$ and $200 \mathrm{mM}$.

A The binding curve of D1N is shown in blue and the negative control with EDTA in black.

B The comparison between the $\mathrm{Ca}^{2+}$ (blue) and the $\mathrm{Mg}^{2+-}$ binding curve (grey) reveals a lower binding affinity for $\mathrm{Mg}^{2+}$. 


\subsubsection{2 $\quad \mathrm{C}_{2} \mathrm{~F}-\mathrm{D} 2,3 \mathrm{~N}$}

The second aspartate mutant was measured under the same conditions as the D1N. As before a final protein concentration of $1 \mu \mathrm{M}$ was used and $\mathrm{Ca}^{2+}$ was added up to $200 \mathrm{mM}$. A saturation of the binding curve was reached and results in a $K_{\mathrm{d}}$ value of $4.6 \pm 0.15 \mathrm{mM}$. The addition of EDTA to the reaction mixture was measured as a negative control and showed no indication of any binding event. In a second experiment, the binding affinity of $\mathrm{Mg}^{2+}$ was measured. An increase in the fluorescence signal was observed but the addition of $\mathrm{Mg}^{2+}$ up to $200 \mathrm{mM}$ was not sufficient to reach the saturation. Thus a $K_{\mathrm{d}}$ value for $\mathrm{Mg}^{2+}$ could not be obtained (Figure 3.17-11).

A

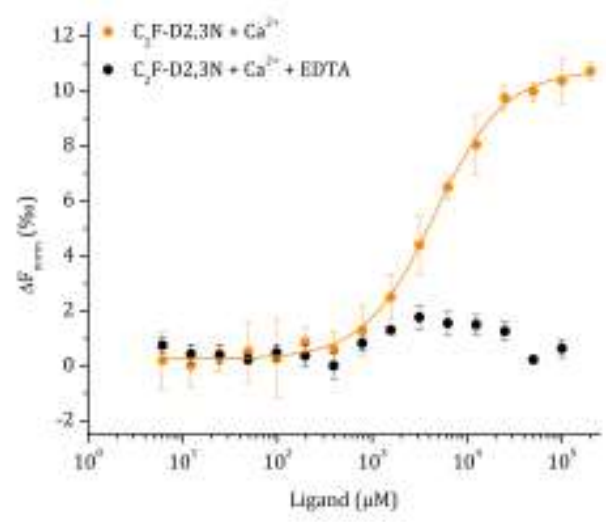

B

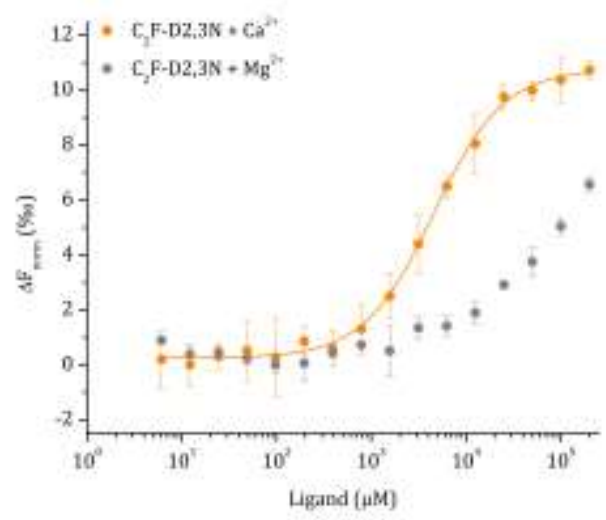

Figure 3.17-11 MST measurement of $\mathrm{C}_{2} \mathrm{~F}-\mathrm{D} 2,3 \mathrm{~N}$. On the $\mathrm{y}$-axis the changes in normalized fluorescence are shown. The $\mathrm{x}$-axis displays the ligand concentration in $\mu \mathrm{M}$. The protein was measured at a concentration of $1 \mu \mathrm{M}$ and $\mathrm{Ca}^{2+}$ was added from $6.1 \mu \mathrm{M}$ up to $200 \mathrm{mM}$.

A Shown in orange is the binding curve of $\mathrm{Ca}^{2+}$ to the $\mathrm{C}_{2} \mathrm{~F}-\mathrm{D} 2,3 \mathrm{~N}$ aspartate mutant with an obtained $K_{\mathrm{d}}$ of $4.6 \pm 0.15 \mathrm{mM}$. The negative control with EDTA is shown in black.

B For $\mathrm{Mg}^{2+-b i n d i n g ~(g r e y) ~ n o ~} K_{\mathrm{d}}$ value could be obtained. 
A

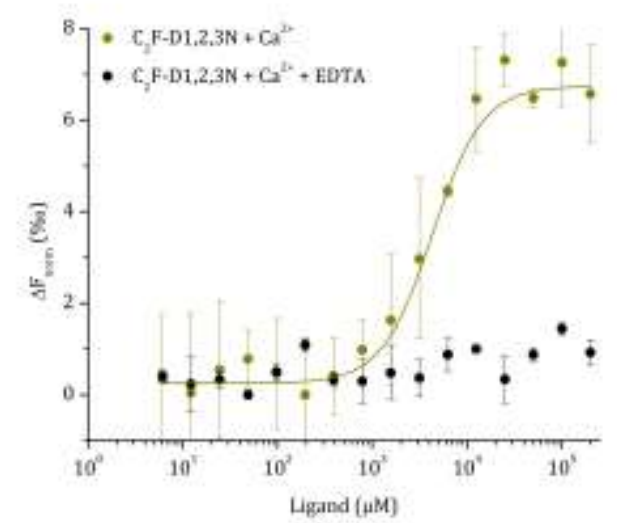

B

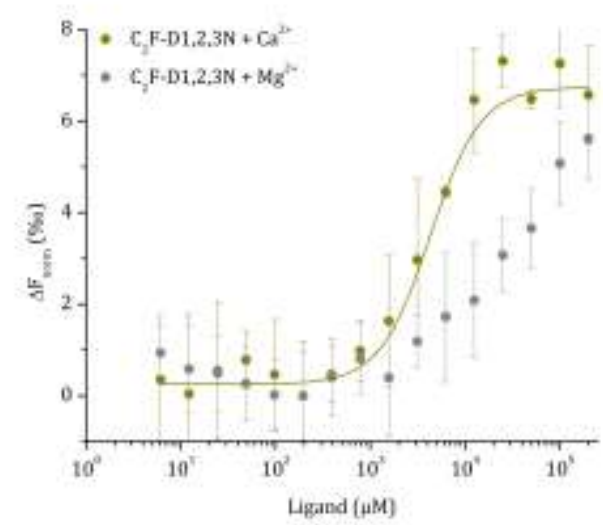

Figure 3.17-12 MST measurement of $\mathrm{C}_{2} \mathrm{~F}-\mathrm{D} 1,2,3 \mathrm{~N}$. On the $\mathrm{y}$-axis the changes in normalized fluorescence are shown. The $\mathrm{x}$-axis displays the ligand concentration in $\mu \mathrm{M}$. The protein was measured at a concentration of $1 \mu \mathrm{M}$ and $\mathrm{Ca}^{2+}$ was added from $6.1 \mu \mathrm{M}$ up to $200 \mathrm{mM}$.

A The binding curve of $\mathrm{Ca}^{2+}$ is shown in light green together with the EDTA negative control in black.

B Comparison of the binding curves of $\mathrm{Mg}^{2+}$ in grey and $\mathrm{Ca}^{2+}$ in light green. The used $\mathrm{Mg}^{2+}$-concentrations were not sufficient to reach saturation. This shows that the tested domain has a higher affinity to bind $\mathrm{Ca}^{2+}$ than $\mathrm{Mg}^{2+}$.

For $\mathrm{C}_{2} \mathrm{~F}-\mathrm{D} 1,2,3 \mathrm{~N}$ protein concentrations of $1 \mu \mathrm{M}$ were used and $\mathrm{Ca}^{2+}$ was added in a range of $6.1 \mu \mathrm{M}$ to $200 \mathrm{mM}$. Saturation was reached and the fitted data results in a $K_{\mathrm{d}}$ value of $4.2 \pm 0.3 \mathrm{mM}$. The negative control was performed by adding $500 \mathrm{mM}$ EDTA to the reaction mixture which showed no binding event during the measurement (Figure 3.17-12). The D1,2,3N-mutant also showed an affinity for $\mathrm{Mg}^{2+}$ but the highest concentration of $200 \mathrm{mM}$ did not suffice to reach a saturation. From these data no $K_{\mathrm{D}}$ value could be obtained.

\subsubsection{4 $\quad \mathrm{C}_{2} \mathrm{~F}-\mathrm{D} 4 \mathrm{~N}$}

The protein concentration of the $\mathrm{C}_{2} \mathrm{~F}-\mathrm{D} 4 \mathrm{~N}$-mutant was set to $1 \mu \mathrm{M}$ and $\mathrm{Ca}^{2+}$-concentrations between $6.1 \mu \mathrm{M}$ and $200 \mathrm{mM}$ were added. In the presence of $\mathrm{Ca}^{2+}$ a binding curve was obtained which resulted in a $K_{\mathrm{d}}$ of $9.8 \pm 0.6 \mathrm{mM}$. For a negative control $500 \mathrm{mM}$ EDTA were added to the sample to confirm that no binding curve is obtained in the absence of $\mathrm{Ca}^{2+}$ (Figure 3.17-13). In comparison to $\mathrm{Ca}^{2+}, \mathrm{Mg}^{2+}$ was tested as well. No $K_{\mathrm{d}}$ value could be calculated because the used $\mathrm{Mg}^{2+}$-concentrations did not result in a saturation plateau. 
A

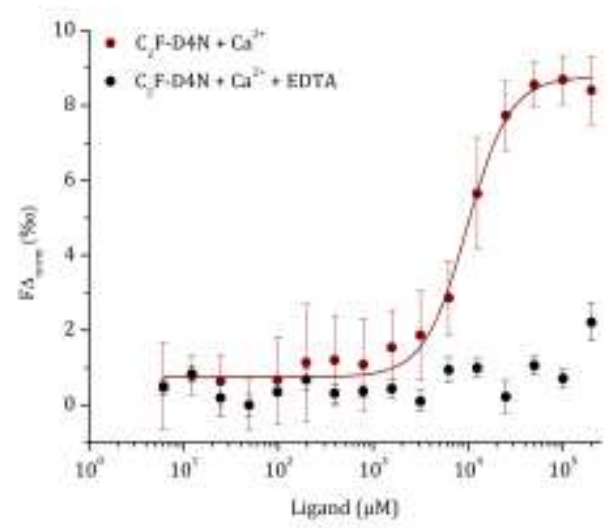

B

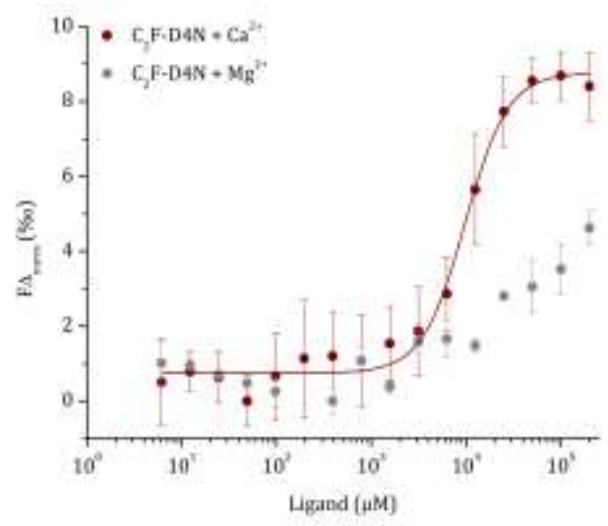

Figure 3.17-13 MST measurement of $\mathrm{C}_{2} \mathrm{~F}-\mathrm{D} 4 \mathrm{~N}$. On the $\mathrm{y}$-axis the changes in normalized fluorescence are shown. The $\mathrm{x}$-axis displays the ligand concentration in $\mu \mathrm{M}$. The protein was measured at a concentration of $1 \mu \mathrm{M}$ and $\mathrm{Ca}^{2+}$ was added from $6.1 \mu \mathrm{M}$ up to $200 \mathrm{mM}$.

A The $\mathrm{Ca}^{2+}$-binding of the $\mathrm{C}_{2} \mathrm{~F}-\mathrm{D} 4 \mathrm{~N}$-mutant is shown in brown and the negative control containing EDTA in black.

B Comparison of the binding curves of $\mathrm{Mg}^{2+}$ in grey and the $\mathrm{Ca}^{2+}$ in brown. Based on the lower affinity to $\mathrm{Mg}^{2+}$ no saturation plateau could be reached.

The comparison of the obtained curves for all four mutants shows a similar shape (Figure 3.17-14). All created mutants are able to bind $\mathrm{Ca}^{2+}$ under the used conditions. The obtained $K_{\mathrm{d}}$ values for $\mathrm{C}_{2} \mathrm{~F}-\mathrm{D} 1 \mathrm{~N}, \mathrm{C}_{2} \mathrm{~F}-\mathrm{D} 2,3 \mathrm{~N}$ and $\mathrm{C}_{2} \mathrm{~F}-\mathrm{D} 1,2,3 \mathrm{~N}$ are very similar. They range between 3.7 and $4.6 \mathrm{mM}$. For the $\mathrm{C}_{2} \mathrm{~F}-\mathrm{D} 4 \mathrm{~N}$-fragment the $K_{\mathrm{d}}$ increased to $9.8 \pm 0.6 \mathrm{mM}$ which suggests a lower affinity to bind $\mathrm{Ca}^{2+}$ than for the other three tested fragments.

A

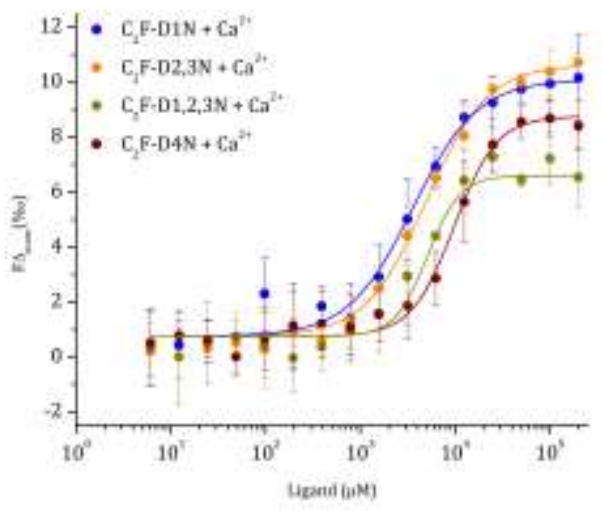

B

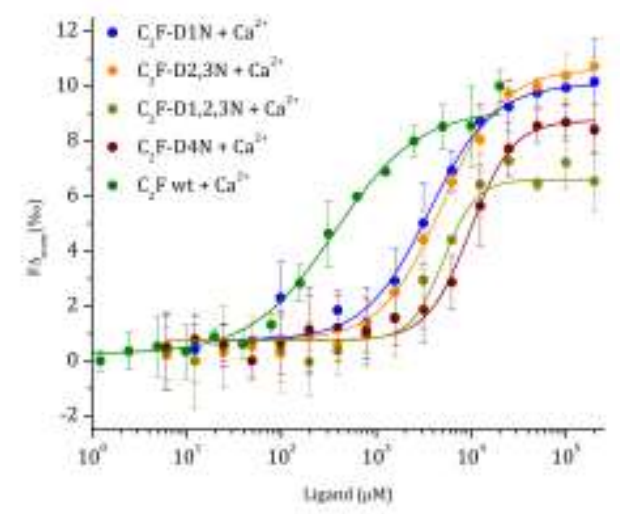

Figure 3.17-14 Comparison of the $\mathrm{C}_{2} \mathrm{~F}$ aspartate mutants.

A All four fragments were measured at a protein concentration of $1 \mu \mathrm{M}$ and $\mathrm{Ca}^{2+}$-concentrations between $6.1 \mu \mathrm{M}$ and $200 \mathrm{mM}$. The D1N is shown in blue, D2,3N in orange, D1,2,3N in light green and the D4N in brown.

B Comparison of the aspartate mutants with the $\mathrm{C}_{2} \mathrm{~F}$ wild type curve in green. All tested mutants show a lower affinity to bind $\mathrm{Ca}^{2+}$ than the wild type domain. 


\subsubsection{4 $\quad \mathrm{C}_{2} \mathrm{~F}-p g a$}

A

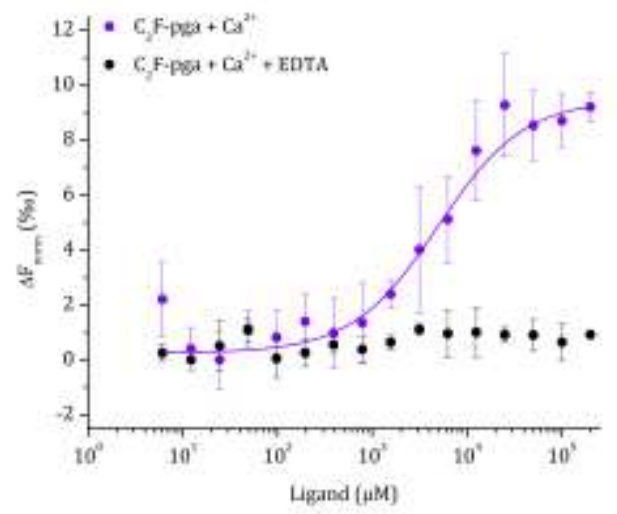

B

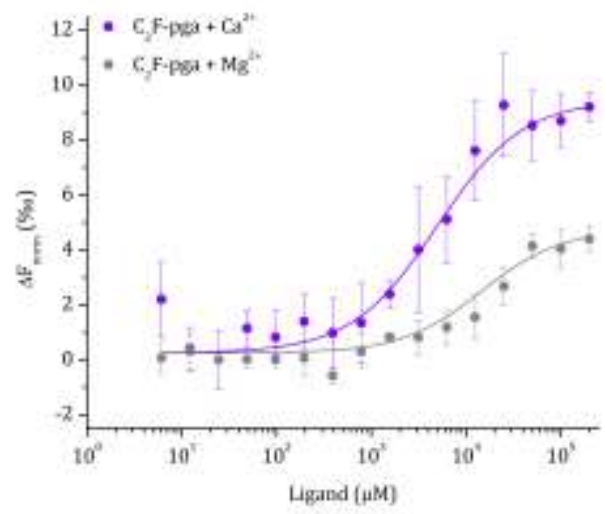

Figure 3.17-15 MST measurement of $\mathrm{C}_{2} \mathrm{~F}-\mathrm{pga}$. On the $\mathrm{y}$-axis the changes in normalized fluorescence are shown. The $\mathrm{x}$-axis displays the ligand concentration in $\mu \mathrm{M}$. For all measurements protein concentrations of $1 \mu \mathrm{M}$ were used, $\mathrm{Ca}^{2+}$ was added in concentrations of $6.1 \mu \mathrm{M}$ to $200 \mathrm{mM}$.

A The binding curve of the pga-mutant is shown in purple and the negative control with $500 \mathrm{mM}$ EDTA in black.

B The $\mathrm{Mg}^{2+}$ affinity shown in grey is lower than the $\mathrm{Ca}^{2+}$-affinity in purple.

The pga-mutant (D1767G) was measured with $\mathrm{Ca}^{2+}$-concentrations of $6.1 \mu \mathrm{M}$ to $200 \mathrm{mM}$ and the protein concentration was set to $1 \mu \mathrm{M}$. Depicted in purple is the thermophoresis measurement of pga which results in a plateau for the bound state. A

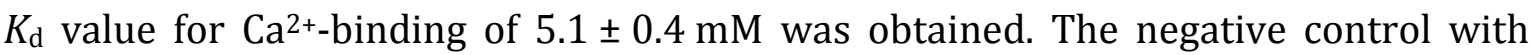
500 mM EDTA, shown in black, did not indicate any binding events (Figure 3.17-15). In comparison to $\mathrm{Ca}^{2+}$ the affinity to bind $\mathrm{Mg}^{2+}$ is much lower. A $K_{\mathrm{d}}$ of $18.9 \pm 1.1 \mathrm{mM}$ was calculated.

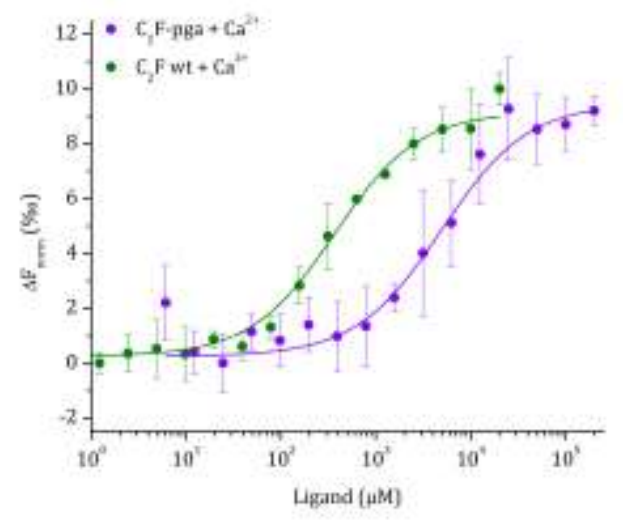

Figure 3.17-16 Comparison of the pga-mutant and the wild type $\mathrm{C}_{2} \mathrm{~F}$. Both proteins were measured at identical concentrations but the $\mathrm{Ca}^{2+}$-concentration for the mutant was increased to the highest concentration of $200 \mathrm{mM}$. The wild type $\mathrm{C}_{2} \mathrm{~F}$-domain is shown in green and the $p g a$-mutant in purple. The curves display a lower $\mathrm{Ca}^{2+}$-binding affinity for the $p g a$-mutant. 
The comparison of the pga-mutant with the wild type domains shows a weaker affinity to bind $\mathrm{Ca}^{2+}$ for the mutant (Figure 3.17-16).

\subsubsection{5 $\quad C_{2}$ F-E1804del}

A

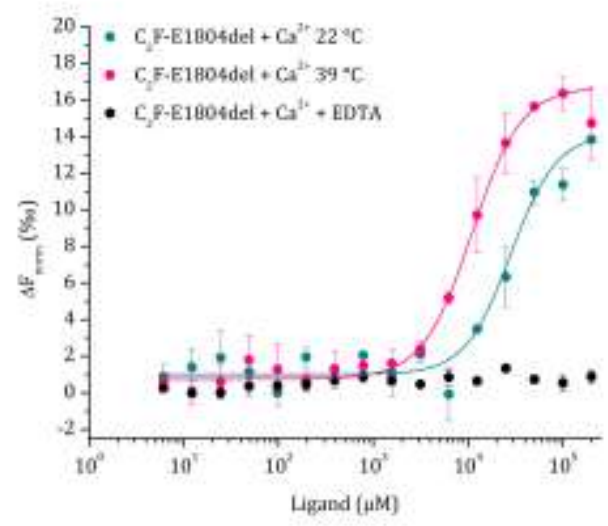

B

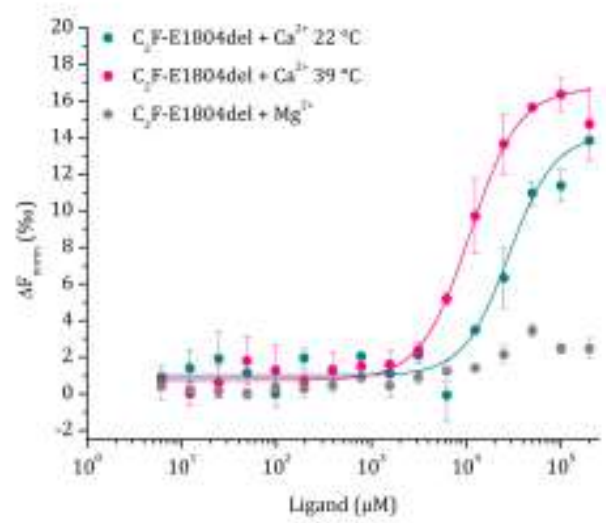

Figure 3.17-17 MST measurement of $\mathrm{C}_{2}$ F-E1804del. On the y-axis the changes in normalized

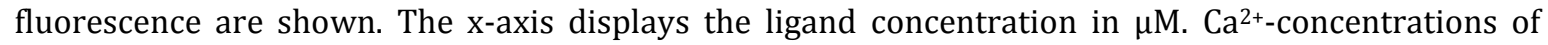
$6.1 \mu \mathrm{M}$ to $200 \mathrm{mM}$ were used at a protein concentration of $1 \mu \mathrm{M}$.

A The pink curve indicates a measurement at $39^{\circ} \mathrm{C}$ and the turquoise curve was measured at $22^{\circ} \mathrm{C}$. The EDTA negative control is shown in black.

B In comparison to the colored $\mathrm{Ca}^{2+}-$ measurements the measurement of $\mathrm{Mg}^{2+}$ is shown in grey.

For the temperature sensitive mutant $\mathrm{C}_{2} \mathrm{~F}-\mathrm{E} 1804 \mathrm{del}$ the measurement was performed at two different temperatures (Figure 3.17-17). Shown in pink is the measurement at $22^{\circ} \mathrm{C}$; this temperature was chosen to compare this mutant with other $\mathrm{C}_{2}$-domain-fragments. It was reported in the literature that a $1^{\circ} \mathrm{C}$ higher body core temperature could cause a temperature dependent hearing impairment [17]. Because of this information the second experiment, shown in turquoise, was measured at $39^{\circ} \mathrm{C}$. In both experiments protein concentrations of $1 \mu \mathrm{M}$ were used and $\mathrm{Ca}^{2+}$ was added in range of $6.1 \mu \mathrm{M}$ to $200 \mathrm{mM}$. Each measurement reached a saturation which resulted in the following $K_{\mathrm{d}}$ values: $8.4 \pm 0.3 \mathrm{mM}$ for the $39{ }^{\circ} \mathrm{C}$ measurement and $10.2 \pm 0.3 \mathrm{mM}$ for the room temperature experiment. The negative control was performed as before by adding $500 \mathrm{mM}$ EDTA to the reaction mixture. By adding $\mathrm{Mg}^{2+}$ to the temperature dependent sensitive mutant no binding could be observed.

The direct comparison of both curves from the E1804del-mutant with the $\mathrm{C}_{2} \mathrm{~F}$ wild type show a seriously decreased affinity for $\mathrm{Ca}^{2+}$-binding (Figure 3.17-18). 


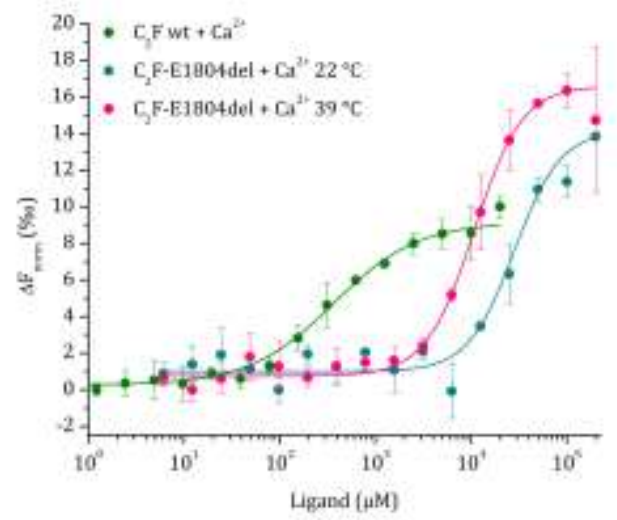

Figure 3.17-18 Comparison of the $\mathrm{C}_{2} \mathrm{~F}$ wild type and the E1804del-mutant. In contrast to the obtained curves for the E1804del-mutant the $\mathrm{C}_{2} \mathrm{~F}$-wildtype shows a higher affinity to bind $\mathrm{Ca}^{2+}$. The mutant was measured at two different temperatures $22^{\circ} \mathrm{C}$ (turquoise) and $39^{\circ} \mathrm{C}$ (pink). 


\section{DISCUSSION}

The exact molecular function of the synaptic protein otoferlin has not been elucidated so far. It is proposed to play an important role in exocytosis, endocytosis and active zone clearance. Currently only the structure of the $\mathrm{C}_{2} \mathrm{~A}$-domain of otoferlin is available. The aim of this thesis was to express and purify several otoferlin fragments and further perform analysis regarding the ability to bind $\mathrm{Ca}^{2+}$-ions, binding studies to identify potential interaction partners as well as trying to crystallize the otoferlin fragments. Additionally the thermal stability of the $\mathrm{C}_{2}$-domains was measured and experiments to identify phosphorylation sites and their influence on the $\mathrm{Ca}^{2+}$-binding were done.

\subsection{Otoferlin phosphorylation using CaMKIII}

Proteins are known to be highly regulated by posttranslational modifications. In this work we focused on phosphorylation sites which are known to play an important role in regulation of the protein function [73]. Experiments performed by Meike Herget (Stanford University/School of Medicine) identified the $\mathrm{Ca}^{2+} /$ calmodulin dependent serine/threonine kinase II delta (CaMKIII) as interaction partner of otoferlin. At the inner hair cells $\mathrm{Ca}^{2+}$-ions enter through voltage-dependent $\mathrm{Ca}^{2+}$-channel which are opening during acoustic stimulation. The present $\mathrm{Ca}^{2+}$ can activate the CaMKII $\delta$ in the next step. Beside this fact further experiments showed that otoferlin and CaMKII $\delta$ are in close proximity within the inner hair cells which led to the hypothesis that the kinase may phosphorylate otoferlin [69]. This was investigated by incubating two otoferlin fragments which contain the $\mathrm{C}_{2} \mathrm{ABC}$ - and $\mathrm{C}_{2}$ DEF-domains of the protein with the CaMKII $\delta$. Ten phosphorylation sites were identified by mass spectrometry in three independent experiments. Five of these sites are located within the $\mathrm{C}_{2}$-domains whereas the others are part of the linker regions between the $\mathrm{C}_{2}$-domains (Table 3.15-1). The comparison of the found phosphorylation sites with otoferlin sequences of other organisms revealed that P1, P2, P3, P5, P8 and P9 are conserved in all species (Figure 4.1-1). The serine at position P4 was found only in human, mouse and rat otoferlin, whereas in case of zebra fish and chicken otoferlin an alanine is present at this position. At the position of P10 either a threonine or a serine is found, which could both be a target for the CaMKII $\delta$. The phosphorylation sites P6 and P7 seem not 
to be conserved as they are only present in rat and mouse otoferlin. In the $\mathrm{C}_{2} \mathrm{~F}$-domain two of the three found phosphorylation sites are conserved among several ferlin proteins, including dysferlin, myoferlin, FER4 and FER5 [20]. The serine at position P8 is highly conserved in afore mentioned proteins whereas P10 is only partially conserved. The phosphorylated peptides of P1, P2, P6, P9 and P10 contain the CaMKII consensus sequence R/K-X-X-S/T [74]. In case of the five other phosphorylation sites the basic amino acid $(\mathrm{R} / \mathrm{K})$ at the $\mathrm{P}-3$ positions is missing. However, former studies with other CaMKII substrates showed that the mentioned consensus motif is not necessary for phosphorylation in all cases [75,76].

\begin{tabular}{|c|c|c|c|c|}
\hline $\begin{array}{l}\text { otoferlin (homo sapiens) } \\
\text { otoferlin (rattus norwegicus) } \\
\text { otoferlin (mus musculus) } \\
\text { otoferlin (danio rerio) } \\
\text { otoferlin (gallus gallus) }\end{array}$ & P1 & 439 & $\begin{array}{l}\text { YRAEGLPRMNISLMANVKKAF } \\
\text { YRAEGLPRMNTSLMANVKKAF } \\
\text { YRAEGLPRMNTSLMANVKKAF } \\
\text { YRAEGLPRMNTSI MANVKKAF } \\
\text { YRAEGLPRMNTSI MANVKKAL }\end{array}$ & 459 \\
\hline $\begin{array}{l}\text { otoferlin (homo sapiens) } \\
\text { otoferlin (rattus norwegicus) } \\
\text { otoferlin (mus musculus) } \\
\text { otoferlin (danio rerio) } \\
\text { otoferlin (gallus gallus) }\end{array}$ & P2 & 552 & $\begin{array}{l}\text { VNMYGSTRNYTL DEHQDLNE } \\
\text { VNMYGSTRNYTLL DEHQDLNE } \\
\text { VNMYGSTRNYTLL DEHQDLNE } \\
\text { VNMYGSTRNYTLMDEHQDLNE } \\
\text { VNMYGSTRNYILMDEHQELNE }\end{array}$ & 572 \\
\hline $\begin{array}{l}\text { otoferlin (homo sapiens) } \\
\text { otoferlin (rattus norwegicus) } \\
\text { otoferlin (mus musculus) } \\
\text { otoferlin (danio rerio) } \\
\text { otoferlin (gallus gallus) }\end{array}$ & P3 & 979 & $\begin{array}{l}\text { QLRAHMYQARSLFAADSSGLS } \\
\text { QLRAHMYQARSLFAADSTGLS } \\
\text { QLRAHMYQARSLFAADSSGLS } \\
\text { QLRAHMYQARSLFAADTSGLS } \\
\text { QLRAHMYQARSLFAADSSGLS }\end{array}$ & 999 \\
\hline $\begin{array}{l}\text { otoferlin (homo sapiens) } \\
\text { otoferlin (rattus norwegicus) } \\
\text { otoferlin (mus musculus) } \\
\text { otoferlin (danio rerio) } \\
\text { otoferlin (gallus gallus) }\end{array}$ & P4/P5 & 1188 & $\begin{array}{l}\text { IECAGKGVQSSLIHNYKKNPNFN } \\
\text { IECAGKGVQSSLIHNYKKNPNFN } \\
\text { IECAGKGVQSSLIHNYKKNPNFN } \\
\text { IECAGKGVQSALIONYKKNPNFS } \\
\text { IECAGKGVQSALIONYKKNPNFSI }\end{array}$ & $\begin{array}{l}\text { TLVKWFEV } 1208 \\
\text { TLVKWFEV } \\
\text { TLVKWFEV } \\
\text { TLVKWFEV } \\
\text { TLVKWFEV }\end{array}$ \\
\hline $\begin{array}{l}\text { otoferlin (homo sapiens) } \\
\text { otoferlin (rattus norwegicus) } \\
\text { otoferlin (mus musculus) } \\
\text { otoferlin (danio rerio) } \\
\text { otoferlin (gallus gallus) }\end{array}$ & P6 & 1323 & $\begin{array}{lr}\text { KKKKKKGTA } & \text { EEPEEE } \\
\text { R-KKKKKKGPS- } & \text { EEPEEE } \\
\text { R-KKKKKKGPS- EEAEEE } \\
\text { KEKKKKKKKKG_. EEVEEE } \\
\text { KEKKKKKKGGGGGGGGEEVEEE }\end{array}$ & $\begin{array}{l}\text { EEPDE } 1343 \\
\text { EEPDE } \\
\text { EPPDE } \\
\text { EPDE } \\
\text { EPDE }\end{array}$ \\
\hline $\begin{array}{l}\text { otoferlin (homo sapiens) } \\
\text { otoferlin (rattus norwegicus) } \\
\text { otoferlin (mus musculus) } \\
\text { otoferlin (danio rerio) } \\
\text { otoferlin (gallus gallus) } \\
\end{array}$ & P7 & 1359 & $\begin{array}{l}\text { MKEQLRQQEPSGIDLEEKEEV } \\
\text { MKEQLRQHETSGIDLEEKEEM } \\
\text { MKEQLRQHETSGTDLEEKEEM } \\
\text { MMENLRAQEAAQAEAEEREDL } \\
\text { MKEQLRQQEAAAAEAEEKEDL }\end{array}$ & 1379 \\
\hline $\begin{array}{l}\text { otoferlin (homo sapiens) } \\
\text { otoferlin (rattus norwegicus) } \\
\text { otoferlin (mus musculus) } \\
\text { otoferlin (danio rerio) } \\
\text { otoferlin (gallus gallus) }\end{array}$ & P8 & 1797 & $\begin{array}{l}\text { DKQDTDVHYHSLTGEGNFNW } \\
\text { DKQDTDVHYHSLTGEGNFNW } \\
\text { DKQDTDVHYHSLTGEGNFNW } \\
\text { DKQDTDVHYHSLTGEGNFNW } \\
\text { DKQDTDVHYHSLTGEGNFNW }\end{array}$ & 1816 \\
\hline $\begin{array}{l}\text { otoferlin (homo sapiens) } \\
\text { otoferlin (rattus norwegicus) } \\
\text { otoferlin (mus musculus) } \\
\text { otoferlin (danio rerio) } \\
\text { otoferlin (gallus gallus) }\end{array}$ & P9 & 1828 & $\begin{array}{l}\text { EEKIV ISKKESMFSWDETEYK } \\
\text { EEKIVMSKKESMFSWDETEYK } \\
\text { EEKIVMSKKESMFSWDETEYK } \\
\text { EEKIV ISKKESMFSWDETEYK } \\
\text { EEKIV ISKKESMFSWDETEYK }\end{array}$ & 1848 \\
\hline $\begin{array}{l}\text { otoferlin (homo sapiens) } \\
\text { otoferlin (rattus norwegicus) } \\
\text { otoferlin (mus musculus) } \\
\text { otoferlin (danio rerio) } \\
\text { otoferlin (gallus gallus) }\end{array}$ & P10 & 1880 & $\begin{array}{l}\text { PRGAKTAKQCTMEMATGEVDV } \\
\text { PRGAKTAKQCTMEMATGEVDV } \\
\text { PRGAKTAKQCTMEMATGEVDV } \\
\text { PRGAKTAKQCSL DMVLKEHEL } \\
\text { PRGAKTSKQCSL EMVTNEAEL. }\end{array}$ & 1900 \\
\hline
\end{tabular}

Figure 4.1-1 Comparison of the found phosphorylation sites in different organisms. The phosphorylation sites are marked in red. The figure was kindly provided by Meike Herget.

Only in very few cases phosphorylation sites were identified within $\mathrm{C}_{2}$-domains, namely synaptotagmin 4 (Syt 4) [77], protein kinase C (PKC) [78], cytosolic 
phopholipase $\mathrm{A}_{2} \quad\left(\mathrm{CPLA}_{2}\right)$ [79] and rice small $\mathrm{C}_{2}$-domain proteins [80]. These phosphorylation sites were shown to influence the binding to phosphatidylserine in case of Syt 4 or affect membrane translocation for PKC and CPLA2 [77-80]. In none of these studies the influence of phosphorylation sites on the $\mathrm{Ca}^{2+}$-binding was investigated. In this study the wild type domains of the otoferlin $\mathrm{C}_{2} \mathrm{C}$ - and $\mathrm{C}_{2} \mathrm{~F}$-domain were tested for $\mathrm{Ca}^{2+}$-binding by MST and compared with pseudo-phosphorylated domains generated by mutating phosphorylated sites into aspartate residues. The obtained results showed for the first time that the incorporation of amino acids which mimic the phosphorylated state in the two $\mathrm{C}_{2}$-domains of otoferlin affect the $\mathrm{Ca}^{2+}$-affinity (see sections 3.17.5.1 and 3.17.5.2).

It is most likely that other kinases are also able to phosphorylate otoferlin but so far no further kinases were tested on this purpose. Additional phosphorylation sites might lead to a different behaviour in $\mathrm{Ca}^{2+}$-binding of otoferlin. Moreover, it might be possible that different phosphorylation sites within the protein might affect specific functions of the protein differently. To make an overall assumption about the general influence of phosphorylation sites in $\mathrm{C}_{2}$-domains further kinases and their phosphorylation sites have to be tested. 


\section{2 $\mathrm{Ca}^{2+}$-binding of otoferlin $\mathrm{C}_{2}$-domains}

Otoferlin belongs to the family of $\mathrm{Ca}^{2+}$-binding proteins. These proteins participate in numerous cellular functions and have the ability to bind $\mathrm{Ca}^{2+}$-ions in specific domains [81]. The characteristic parts for $\mathrm{Ca}^{2+}$-binding within otoferlin are its $\mathrm{C}_{2}$-domains. In this work most of the purified protein fragments of otoferlin were tested for $\mathrm{Ca}^{2+}$-binding using MicroScale Thermophoresis (see section 3.17).

\subsection{1 $\mathrm{Ca}^{2+}$-binding ability of the domains $C_{2} A, C_{2} B$ and $C_{2} C$}

For the single $\mathrm{C}_{2} \mathrm{~B}$ - and $\mathrm{C}_{2} \mathrm{C}$-domain and the three domains containing fragment $\mathrm{C}_{2} \mathrm{ABC}-\mathrm{His}_{6}$ no $\mathrm{Ca}^{2+-}$-binding could be detected. Former studies already showed that at least the $\mathrm{C}_{2} \mathrm{~A}$-domain is not able to bind $\mathrm{Ca}^{2+}$ because of the missing aspartate residues for ion coordination and a shorter loop 1 in the binding region $[15,34,35]$. Based on alignments of the ferlin $\mathrm{C}_{2}$-domains $[15,20]$ it was shown that in case of the $\mathrm{C}_{2} \mathrm{~B}$-domain also only one aspartate is present in the binding region. Considering these finding it is conclusive why it was not possible to obtain a $\mathrm{Ca}^{2+}$-binding curve for this domain. Within the $\mathrm{C}_{2} \mathrm{C}$-domain a similar situation was found; in the predicted $\mathrm{Ca}^{2+-b i n d i n g ~ r e g i o n ~ o n l y ~ t h r e e ~ a s p a r t a t e ~ r e s i d u e s ~ a r e ~ p r e s e n t . ~ A l s o ~ f o r ~ t h i s ~ d o m a i n ~ n o ~}$ $\mathrm{Ca}^{2+-b i n d i n g ~ c o u l d ~ b e ~ d e t e c t e d ~ u s i n g ~ M S T . ~ A ~ r e a s o n ~ c o u l d ~ b e ~ t h a t ~ i n ~ c a s e ~ o f ~ t h e ~}$ otoferlin $\mathrm{C}_{2} \mathrm{C}$-domain three aspartate residues are not sufficient to bind one to three $\mathrm{Ca}^{2+}$-ions. Another matter could be that the $\mathrm{Ca}^{2+}$-binding within this domain does not change the MST signal, which was reported for Syt 1- $\mathrm{C}_{2} \mathrm{~A}$ [82]. In principal, it could be possible that three aspartate residues are enough to establish a binding to $\mathrm{Ca}^{2+}$. This is the case for the cytosolic phospholipase $\mathrm{A} 2\left(\mathrm{CPLA}_{2}\right)$. Only two aspartate residues are present in the top loop 1 and one in top loop 3 (Figure 4.2-1, E). Within the loop 3 an asparagine residue, which is located at an aspartate position in Syt 1 , is involved in the $\mathrm{Ca}^{2+}$-coordination. Additionally, an asparagine located in the top loop 2 provides a coordination site [83]. The involvement of this asparagine was also shown for the phosphoinositide-specific phospholipase C- $\delta 1$ (PLC- $\delta 1$ ) (Figure 4.2-1, D) [38]. If we take a closer look into the sequence of the second loop in the binding region of otoferlin we can find such an asparagine within the $\mathrm{C}_{2} \mathrm{~A}-$ and $\mathrm{C}_{2} \mathrm{~B}$-domain but not in the $\mathrm{C}_{2} \mathrm{C}$-domain [20]. Instead two serines are located in the loop 2 of the $\mathrm{C}_{2} \mathrm{C}$-domain. In case of Syt $1-\mathrm{C}_{2} \mathrm{~A}$ it was reported that a serine in loop 3 is involved in the coordination of $\mathrm{Ca}^{2+}$ [36]. Dependent on the structural arrangement of the otoferlin $\mathrm{C}_{2} \mathrm{C}$ loop 2 one or two serines may provide a coordination site. Based on the results of the non-existing $\mathrm{C}_{2} \mathrm{~B}$ and $\mathrm{C}_{2} \mathrm{C} \mathrm{Ca}^{2+}$-binding obtained from MST measurements in this work and in addition with the published data of the $\mathrm{C}_{2} \mathrm{~A}$-domain [34] it was expected 
that the $\mathrm{C}_{2} \mathrm{ABC}$-fragment is also not able to bind $\mathrm{Ca}^{2+}$ which was confirmed by MST measurements. A former study of Johnson et al. showed $\mathrm{Ca}^{2+}$-binding for $\mathrm{C}_{2} \mathrm{~B}$ and $\mathrm{C}_{2} \mathrm{C}$ by measuring the fluorescence spectra as well as performing isothermal titration calorimetry [15,53]. According to the predictions of Jiménez and Bashir the $\mathrm{C}_{2} \mathrm{~B}$-domain of otoferlin contains the amino acids 256 to 378 [20]. The $\mathrm{C}_{2} \mathrm{~B}$-domain used by Johnson et al. ends at amino acid 370 which may cause a different structural orientation in comparison to the fragment that was used in this work (aa 217 to 414). Due to predictions the seven missing amino acids in the Johnson-fragment are part of the last $\beta$-strand $[15,20]$.

A comparison of the $\mathrm{C}_{2} \mathrm{C}$-fragment (aa 410 to 616 ) from this work to the Johnson-fragment shows that they used different lengths of the linker-region in front and behind the $\mathrm{C}_{2} \mathrm{C}$-domain [15]. This may result in the different observed $\mathrm{Ca}^{2+}$-binding abilities. In the Johnson paper only one Ni-NTA-column is described as a purification step which leads to the question if the used protein for $\mathrm{Ca}^{2+}$-binding measurements is pure enough to exclude interactions of $\mathrm{Ca}^{2+}$-ions to remaining impurities. Altogether our obtained results, the data published in literature and the predictions made about the first three $\mathrm{C}_{2}$-domains of otoferlin are most contradictory. Solving the structure of these domains would provide information about the actual structure of the binding regions and their ability to bind $\mathrm{Ca}^{2+}$-ions.

A performed phosphorylation assay with CaMKII $\delta$ of the $\mathrm{C}_{2} \mathrm{ABC}$-fragment of otoferlin revealed a phosphorylation site (P1) within the $\mathrm{C}_{2} \mathrm{C}$-domain of otoferlin (see section 3.15). By mutating the found threonine into an aspartate residue to mimic the space and charge of a phosphorylation site and performing MST measurements $\mathrm{Ca}^{2+}$-binding could be detected [69]. The phosphorylated threonine is located in the top loop 1 next to an asparagine the position of which was predicted to be involved in $\mathrm{Ca}^{2+}$-binding $[15,20]$. The three aspartate residues present in the $\mathrm{Ca}^{2+}$-binding region of the $\mathrm{C}_{2} \mathrm{C}$-domain probably are not sufficient to bind $\mathrm{Ca}^{2+}$-ions. But the insertion of an additional aspartate residue into the top loop 1 seems to create a structure which is capable to bind one or more $\mathrm{Ca}^{2+-i o n s . ~ I n ~ c o n s i d e r a t i o n ~ o f ~}$ potentially more existing phosphorylation sites as posttranslational modifications in the native protein it is possible that they influence the overall structure and change the $\mathrm{Ca}^{2+}$-binding abilities [84,85]. The used $\mathrm{Ca}^{2+}$-concentrations for MST measurements range between $6.1 \mu \mathrm{M}$ and $200 \mathrm{mM}$ and resulted in a $K_{\mathrm{d}}$ value of

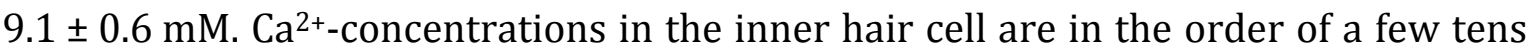
of $\mu \mathrm{M}$ [86]. Because of this fact the $\mathrm{C}_{2} \mathrm{C}$-phos-mutant would not bind $\mathrm{Ca}^{2+}$ under physiological conditions. 
A

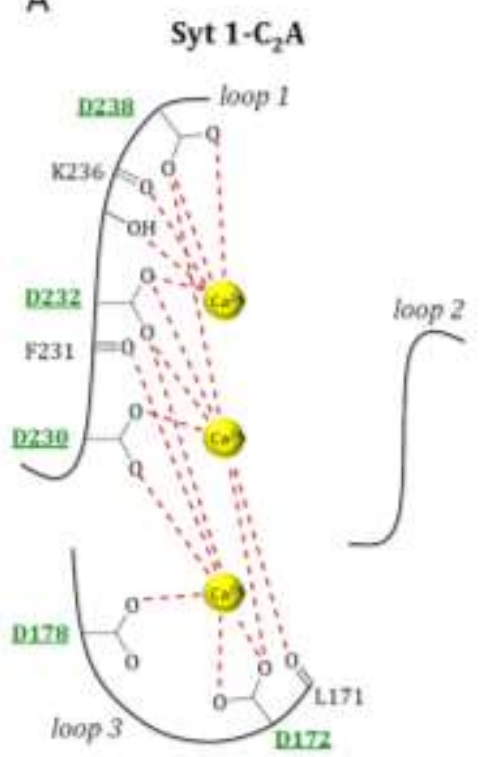

B

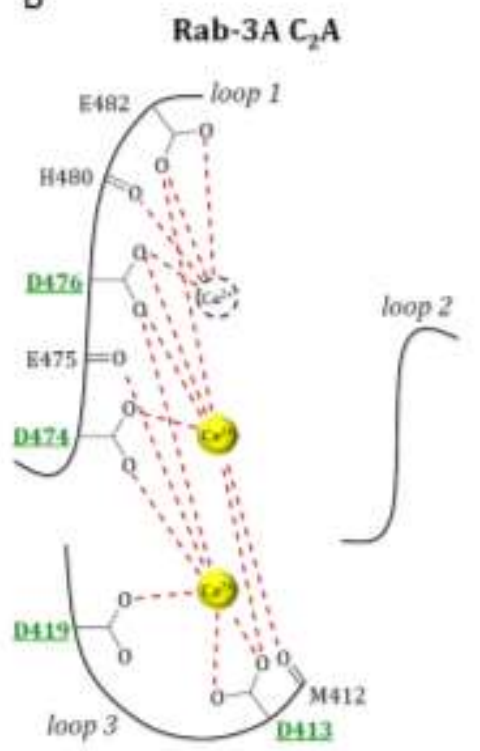

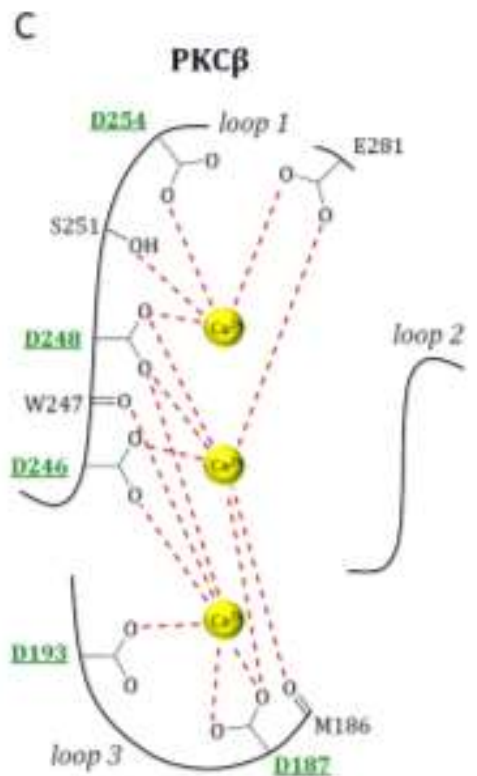

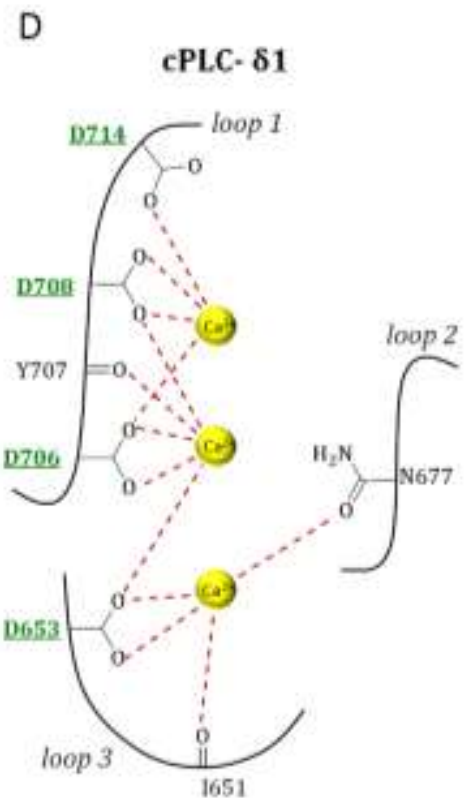

E

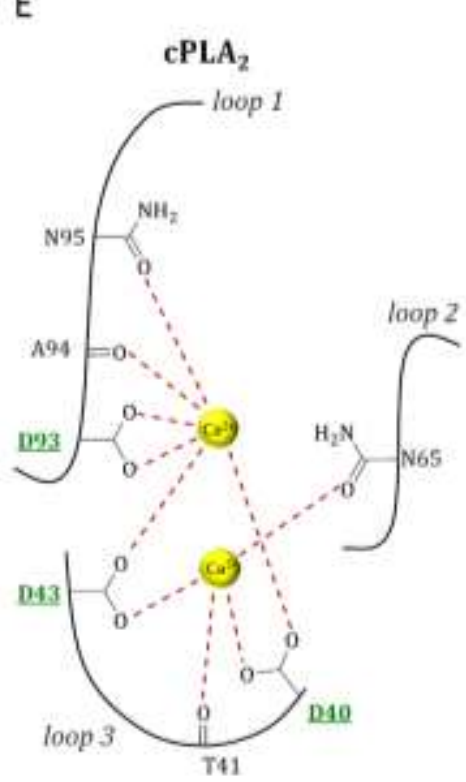

Figure 4.2-1 $\mathrm{Ca}^{2+-b i n d i n g ~ s i t u a t i o n ~ i n ~ t h e ~} \mathrm{C}_{2}$-domain top loop regions of different proteins. Shown in yellow are the two or three $\mathrm{Ca}^{2+}$-ions which are coordinated (red dotted line) by different number of aspartate residues. Additionally two or three backbone carbonyl groups are involved in the $\mathrm{Ca}^{2+-}$-coordination.

A In the Syt 1- $\mathrm{C}_{2} \mathrm{~A}$-domain five aspartate residues are involved in the binding of three $\mathrm{Ca}^{2+-i o n s}$.

B In case of Rab-3A C $2 \mathrm{~A}$ two $\mathrm{Ca}^{2+}$-ions were found in a structure solved by NMR. The $\mathrm{Ca}^{2+}$ at the third position marked with a black dotted line was calculated to be present but could not be identified in the structure. Four aspartate residues and one asparagine residue (E482) play a role in $\mathrm{Ca}^{2+}$-binding.

C In the $\mathrm{C}_{2}$-domain of PKC $\beta$ five aspartate residues are present and coordinate three $\mathrm{Ca}^{2+}$ ions. The E281 belongs to a second $\mathrm{C}_{2}$-molecule in the asymmetric unit of the crystal.

D The coordination of three $\mathrm{Ca}^{2+}$-ions in the $\mathrm{CPCL}-\delta 1$-domain involves four aspartate residues and an asparagine located on loop 2 of the $\mathrm{Ca}^{2+}$-binding region.

$\mathbf{E}$ In the $\mathrm{C}_{2}$-domain of $\mathrm{CPLA}_{2}$ only three aspartates are present further coordination sites are provided by two asparagine residues which are located in loop 1 and loop 2.

Figure adapted from Perisic et al., 1998; Essen et al., 1996; Sutton and Sprang, 1998; Coudevylle et al., 2008 and Ubach et al., 1998. 


\subsection{2 $\mathrm{Ca}^{2+}$-binding of the $\mathrm{C}_{2} \mathrm{~F}$-domain}

Another three phosphorylation sites were found in the $\mathrm{C}_{2} \mathrm{~F}$-domain of the protein. To incorporate amino acids into the wild type domain to mimic the phosphorylation sites a synthetic gene was ordered. The affinity of the wild type $\mathrm{C}_{2} \mathrm{~F}$-domain and the pseudo-phosphorylated fragment were tested for $\mathrm{Ca}^{2+}$-binding with MicroScale Thermophoresis. The obtained $K_{\mathrm{d}}$ value for $\mathrm{Ca}^{2+}$-binding of the wild type $\mathrm{C}_{2} \mathrm{~F}$-domain was $449 \pm 21 \mu \mathrm{M}$. Increasing the salt concentration to $300 \mathrm{mM}$ resulted in a much lower $K_{\mathrm{d}}$ of $290 \pm 14 \mu \mathrm{M}$ which is similar to already published data about the $\mathrm{Ca}^{2+}$-binding of this domain. Ramakrishnan et al. measured the $\mathrm{Ca}^{2+-b i n d i n g ~ a b i l i t y ~}$ using ITC at a salt concentration of $250 \mathrm{mM}$ and obtained a $K_{\mathrm{d}}$ of $267 \mu \mathrm{M}$ which is in good agreement with the $K_{\mathrm{d}}$ value obtained with MST [35]. Nevertheless, the decreased $K_{\mathrm{d}}$ of $290 \mu \mathrm{M}$ in high salt buffer was still not in the range of physiological $\mathrm{Ca}^{2+}$-concentrations in inner hair cells [86]. The $\mathrm{Ca}^{2+}$-binding $K_{\mathrm{d}}$ for synaptotagmin $1 \mathrm{C}_{2} \mathrm{~B}$ was reported in the same order of magnitude $\left(K_{\mathrm{d}} \sim 200 \mu \mathrm{M}\right)$ $[72,87]$. Due to the presence of negatively charged phospholipids the $\mathrm{Ca}^{2+}$-affinity of synaptotagmin and protein kinase $\mathrm{C}$ is increased $[72,88,89]$. This leads to the assumption that the binding of phospholipids has as well an influence on $\mathrm{Ca}^{2+}$-binding in case of otoferlin. Furthermore, additional interaction partners or posttranslational modifications $[84,85]$ can play a role in this process. The integration of negatively charged aspartate residues at the found phosphorylation sites resulted in an approximately 10 -fold affinity decrease for $\mathrm{Ca}^{2+}\left(K_{\mathrm{d}}=6.3 \pm 0.4 \mathrm{mM}\right)$. Two of the three pseudo-phosphorylation sites are predicted to be located within the $\beta$-strands three and seven whereas the third occupies a position in a bottom loop between $\beta$-strand four and five [20] (Figure 4.2-2). Because of these positions a direct influence like in case of the $\mathrm{C}_{2} \mathrm{C}$-domain can be excluded. More likely is the assumption that the phosphorylation sites within the $\beta$-strands cause a change in the structure compared to the wild type. Changes in the structure of the core component of the domain probably lead to rearrangements of the binding loops as well. In case of synaptotagmin it was reported that a single mutation of a coordinating aspartate residue can disrupt the highest affinity $\mathrm{Ca}^{2+}$-binding site which leads to a serious decrease in $\mathrm{Ca}^{2+}$-affinity for the whole domain. The explanation for this behavior is based on the hypothesis that during high affinity $\mathrm{Ca}^{2+}$-binding the surrounding amino acids undergo conformational changes in which the binding of a second and third $\mathrm{Ca}^{2+}$-ion is facilitated [36]. If a high affinity binding site is also present in the $\mathrm{C}_{2} \mathrm{~F}$-domain of otoferlin it is possible that loop reorganization affects this site which would be a possible explanation for the serious decrease in case of the pseudo-phosphorylated domain. In this experiment only the phosphorylation of 
CaMKII $\delta$ was considered despite the presence of many other kinases. It is likely that more phosphorylation sites are located within otoferlin as well as other posttranslational modifications which also can influence the structure [84,85]. This leads to the question if the $E$. coli expressed $\mathrm{C}_{2}$-domain can be compared to a $\mathrm{C}_{2}$-domain in native conditions.

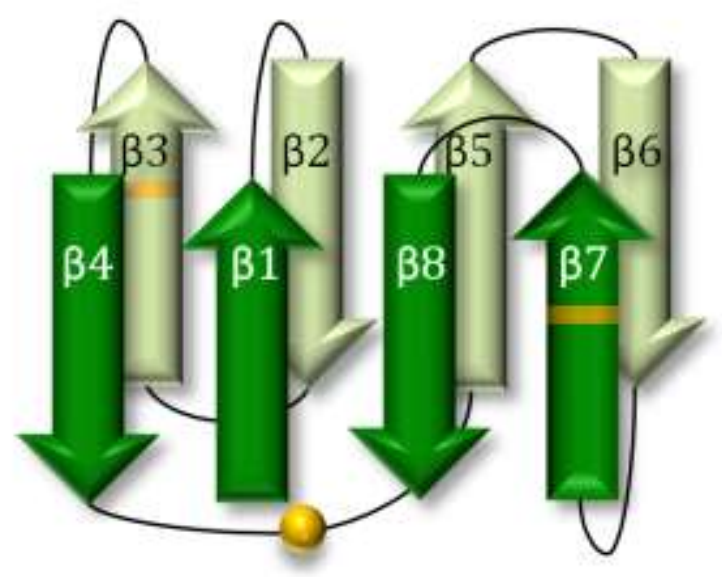

Figure 4.2-2 Topology model of the $\mathrm{C}_{2} \mathrm{~F}$-domain of otoferlin. The eight $\beta$-strands are shown in green and the loop regions in black. In orange the positions of the phosphorylation sites are indicated.

In this work an aspartate residue was chosen to mimic the phosphorylated serine or threonine residues. An alternative could be to incorporate a glutamate residue. It was reported that in specific cases one amino acid is a better candidate than the other one [90]. Additionally, there are findings that two acidic residues are needed to mimic one phosphorylation event [91]. To assure that the obtained results are not dependent on the aspartate residue, which was used for replacement, the effect of glutamate should be tested in future studies.

An often reported phospholipid involved in $\mathrm{C}_{2}$-domain binding is phosphatidylinositol 4,5-bisphosphate $\left(\mathrm{PIP}_{2}\right)$. The interaction of $\mathrm{PIP}_{2}$ with synaptotagmin 1 increased the affinity to bind $\mathrm{Ca}^{2+}$ [72]. Similar findings were reported for the $\mathrm{C}_{2} \mathrm{~F}$-domain of otoferlin [53]. Two explanations are discussed for this behavior. Phospholipids are able to bind at the unsaturated coordination sites of the $\mathrm{Ca}^{2+}$-ions or can interact with the cationic patch in the concave face of the $\beta$-sandwich, called the $\beta$-groove [31]. In this work the addition of $\mathrm{PIP}_{2}$ to the $\mathrm{C}_{2} \mathrm{~F}$ wild type domain was tested but did not lead to unambiguous results. An increase of the fluorescence change was detected but did not reach the saturation plateau, therefore no $K_{\mathrm{d}}$ was obtained. It might be possible that the presence of $\mathrm{PIP}_{2}$ causes a higher affinity for a second $\mathrm{Ca}^{2+}$-binding event, leading to a further increase in fluorescence change. In this case it is obviously not possible to detect the separate events with MST 
measurements. The same experiment was repeated for the pseudo-phosphorylated $\mathrm{C}_{2} \mathrm{~F}$-domain of otoferlin. The addition of $\mathrm{PIP}_{2}$ during MST measurements resulted in a similar $K_{\mathrm{d}}$ as without $\mathrm{PIP}_{2}$. If the $\mathrm{Ca}^{2+}$-binding ability is influenced by the incorporated pseudo-phosphorylation sites maybe not enough $\mathrm{Ca}^{2+-i o n s}$ or free coordination sites at the ions are available for $\mathrm{PIP}_{2}$ binding. If the $\mathrm{PIP}_{2}$ binding does not occur through free coordination sites of $\mathrm{Ca}^{2+}$ but through the $\beta$-groove maybe the structural rearrangements introduced by the incorporation of the pseudo-phosphorylation sites might prevent this binding event. In addition, the negative charge of the pseudo-phosphorylation sites might inhibit the binding of the negatively charged phospholipids. It is likely that the CaMKII $\delta$ phosphorylation sites are not the only posttranslational modifications within this $\mathrm{C}_{2}$-domain.

\subsection{3 $\mathrm{Ca}^{2+}$-binding of $\mathrm{C}_{2} \mathrm{~F}$-aspartate mutants}

In order to analyze the influence of the five binding aspartate residues within the $\mathrm{C}_{2} \mathrm{~F}$-domain of otoferlin mutants were created in which one, two or three aspartate residues were replaced by asparagine (Figure 4.2-3). MicroScale Thermophoresis was used to measure the $\mathrm{Ca}^{2+}$-binding. According to the role of the different aspartates in Syt $1-\mathrm{C}_{2} \mathrm{~A}$ [36] it was estimated that in case of the D1N-mutant the ability to bind $\mathrm{Ca}^{2+}$ would show a severe decrease. Assuming that the aspartate residues in otoferlin- $\mathrm{C}_{2} \mathrm{~F}$ play a similar role as in Syt $1-\mathrm{C}_{2} \mathrm{~A}$ the high affinity $\mathrm{Ca}^{2+}$-binding site would be affected in the D1N-mutant. This would lead to a reduction in the $\mathrm{Ca}^{2+}$-binding affinity or maybe to a complete disruption of the binding site. Furthermore, the D2,3N-mutant should mostly affect the $\mathrm{Ca} 2$ and $\mathrm{Ca} 3$ binding sites and to minor degree the Ca1 site. The mutation of three aspartates in the D1,2,3N-mutant was expected to show a similar observation like the D1N. Surprisingly, all measured $K_{\mathrm{d}}$ values were in the same magnitude ( 3.7-4.6 mM) which suggested that all three mutated aspartates play a comparable important role in $\mathrm{Ca}^{2+}$-binding.

The gained $K_{\mathrm{d}}$ for the D4N-mutant is higher than the three tested mutants before. Due to these observations it has to be considered that the highest affinity binding site could be located at another position than in Syt 1- $C_{2} A$. If in case of otoferlin the highest affinity binding site would be located at the position of $\mathrm{Ca} 3$ of Syt $1-\mathrm{C}_{2} \mathrm{~A}$ this would explain at least the severe changes when D2N, D3N or D4N are involved. Unfortunately this hypothesis does not include the D1N. Based on comparisons of the $\mathrm{Ca}^{2+-}$ binding regions of Syt $1-\mathrm{C}_{2} \mathrm{~A}$ [36], Rabphilin-3A (Rab-3A) [92], PKC [93], PLA 2 [83] and PLC- $\delta 1$ [38] all binding regions show a similar structure and coordination of $\mathrm{Ca}^{2+}$-ions. In case of PLA2 and Rab-3A only two $\mathrm{Ca}^{2+-i o n s}$ were identified $[83,92]$ 
whereas for Rab-3A the binding of a third $\mathrm{Ca}^{2+}$ was predicted [92]. The coordination of the $\mathrm{Ca}^{2+-i o n s}$ through aspartate residues, backbone carbonyls and other additional amino acids is very similar in all cases. Only slight differences in the coordination can be detected in these $\mathrm{C}_{2}$-domains. The shown coordination of $\mathrm{Ca}^{2+}$ to Syt $1-\mathrm{C}_{2} \mathrm{~A}, \mathrm{PKC}$ and Rab-3A is almost identical $[36,92,93]$ whereas PLC and PLA 2 show minor differences (Figure 4.2-1) [38,83]. For PLC and PLA 2 one or two aspartates are

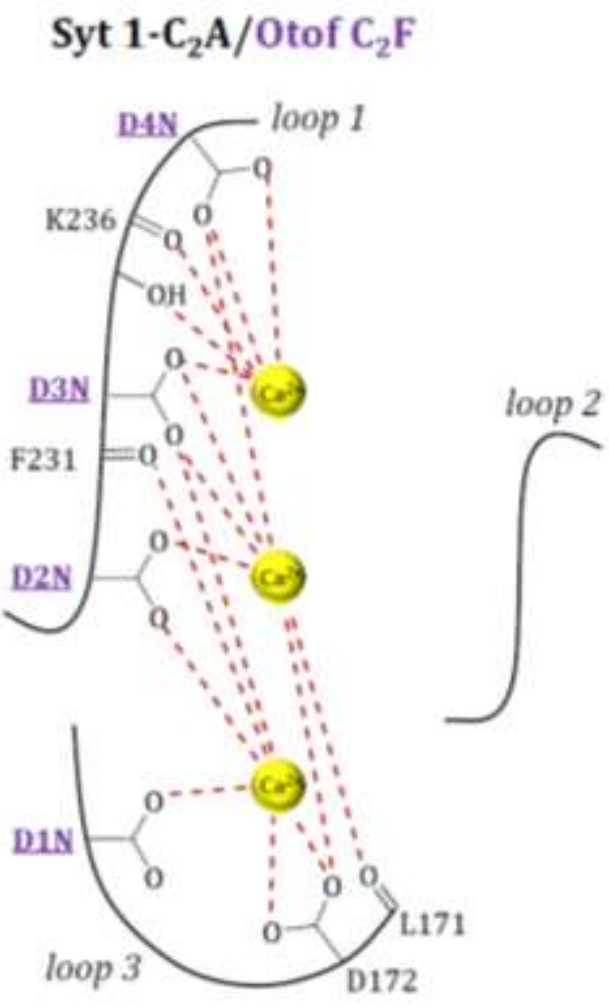
missing and in both domains an asparagine residue in the top loop 3 seems to compensate the missing coordination sites [38,83]. Unfortunately for PKC, PLA2, PLC- $\delta 1$ and Rab-3A no data are published in which the high affinity binding site was analyzed. Such studies could provide insight if the highest affinity site is protein specific. Summarized it is likely that otoferlin has not the same high affinity binding site than Syt $1-\mathrm{C}_{2} \mathrm{~A}$. To get more information about the binding region of otoferlin an analysis by NMR, like it was done for Syt $1-\mathrm{C}_{2} \mathrm{~A}$ by Ubach et al., would be helpful.

Figure 4.2-3 Position of the $\mathrm{C}_{2} \mathrm{~F}$ aspartate mutants in the respected structure of Syt 1- $\mathrm{C}_{2} \mathrm{~A}$. The tested otoferlin mutants are shown in violet.

\subsection{4 $\mathrm{Ca}^{2+}$-binding of $\mathrm{C}_{2} \mathrm{~F}$-mutants with mutations affecting hearing}

Two mutations - known to affect hearing - in the $\mathrm{C}_{2} \mathrm{~F}$-domain of the protein were also analyzed for their ability to bind $\mathrm{Ca}^{2+}$. Mice which carry the pga mutation within the $\mathrm{C}_{2} \mathrm{~F}$-domain of otoferlin are deaf [54]. In a loop region located at the opposite site of the $\mathrm{Ca}^{2+}$-binding region an aspartate residue was replaced by a glycine (D1767G) [20]. The position of this amino acid indicates that the mutation has no influence on $\mathrm{Ca}^{2+}$-binding. Whether or not the exchange of this amino acid in a flexible loop region is enough to influence the overall structure of the $\mathrm{C}_{2}$-domain is questionable. Due to the position in a flexible bottom loop it is unlikely that this mutation is able to cause such a change in the structure that the $\mathrm{Ca}^{2+}$-binding is influenced. The performed MicroScale Thermophoresis measurements showed a decrease of $\mathrm{Ca}^{2+}$-affinity for the pga-fragment in comparison with the wild type $\mathrm{C}_{2} \mathrm{~F}$ (Figure 3.17-16). With a higher 
$K_{\mathrm{d}}$ value as the wild type the pga-mutant is not able to bind $\mathrm{Ca}^{2+}$ under physiological conditions [86]. Ramakrishnan et al. as well reported a diminished $\mathrm{Ca}^{2+}$-binding for $\mathrm{C}_{2} \mathrm{~F}-$ pga [35].

The E1804del-mutation was found in the human $\mathrm{C}_{2} \mathrm{~F}$-domain of otoferlin. The deletion of glutamic acid at position 1804 leads to temperature sensitive deafness [17]. For MicroScale Thermophoresis this mutation was inserted into the $\mathrm{C}_{2} \mathrm{~F}$-domain. Two different temperatures were tested in MST measurements. The first sample was measured at $22^{\circ} \mathrm{C}$ for comparability with the wild type and other measured $\mathrm{C}_{2}$-domains. In this case a binding curve for $\mathrm{Ca}^{2+}$ was obtained. In consideration that this deletion leads to temperature sensitive deafness above $38^{\circ} \mathrm{C}$ the measurement was repeated at $39{ }^{\circ} \mathrm{C}$. As well a Ca ${ }^{2+}$-binding were detected. The obtained $K_{\mathrm{d}}$ for $39^{\circ} \mathrm{C}$ $(8.4 \pm 0.3 \mathrm{mM})$ is a little bit lower than the value for $22^{\circ} \mathrm{C}(10.2 \pm 0.3 \mathrm{mM})$. In comparison to the wild type curve $\left(K_{\mathrm{d}}=290+/-14 \mu \mathrm{M}\right)$ (Figure 3.17-18) both E1804del curves display a much lower affinity for $\mathrm{Ca}^{2+}$. Due to the physiological $\mathrm{Ca}^{2+}$-concentrations in the order of a few tens of $\mu \mathrm{M}$ [86] the E1804del-mutant is not able to bind $\mathrm{Ca}^{2+}$ neither at $22^{\circ} \mathrm{C}$ nor $39^{\circ} \mathrm{C}$.

In both cases it has to be considered that the native protein would likely contain different post-translational modifications which can lead to a different folding of the domain and consequently to a different behavior. In this case as well interactions with phospholipids or other proteins might have an effect as well.

In the following Table 4.2-1 all measured $K_{\mathrm{d}}$ values for the wild type and the different mutations of the $\mathrm{C}_{2} \mathrm{~F}$-domain are listed. It seems that all tested mutations affect the $\mathrm{C}_{2} \mathrm{~F}$-domain in a similar manner. Typically, it would be expected that the aspartate mutants have a much higher effect on the $\mathrm{Ca}^{2+}$-binding than the pga-mutant but all obtained $K_{\mathrm{d}}$ values are in the same order of magnitude. Except for the wild type domain none of the mutants seems able to bind $\mathrm{Ca}^{2+}$ under physiological conditions. 
Table 4.2-1 Overview of the obtained $K_{\mathrm{d}}$ values of the different $\mathrm{C}_{2} \mathrm{~F}$-mutants. All measurements took place in a sample buffer containing $10 \mathrm{mM}$ HEPES $\mathrm{pH} 7.4,150 \mathrm{mM} \mathrm{NaCl}$ and $0.1 \%$ Tween at a temperature of $22^{\circ} \mathrm{C}$. A final protein concentration of $1 \mu \mathrm{M}$ was used and the highest used $\mathrm{Ca}^{2+}$-concentration was set to $200 \mathrm{mM}$.

a The highest $\mathrm{Ca}^{2+}$-concentration was changed to $20 \mathrm{mM}$.

$\mathrm{b}$ This measurement was performed in the presence of $300 \mathrm{mM} \mathrm{NaCl}$.

c For the E1804del-mutant a second set of samples at $39^{\circ} \mathrm{C}$ were measured.

\begin{tabular}{ll}
$\mathrm{C}_{2}$-domain-fragment & Dissociation constant $\left(K_{\mathrm{d}}\right)$ \\
\hline $\mathrm{C}_{2}$ F wild type & $449 \pm 20.8 \mu \mathrm{M}^{\mathrm{a}}\left(290 \pm 14.4 \mu \mathrm{M}^{\mathrm{b}}\right)$ \\
$\mathrm{C}_{2}$ F-phos & $6.3 \pm 0.4 \mathrm{mM}$ \\
$\mathrm{C}_{2}$ F-D1N & $3.7 \pm 0.2 \mathrm{mM}$ \\
$\mathrm{C}_{2}$ F-D2,3N & $4.6 \pm 0.2 \mathrm{mM}$ \\
$\mathrm{C}_{2}$ F-D1,2,3N & $4.2 \pm 0.3 \mathrm{mM}$ \\
$\mathrm{C}_{2}$ F-D4N & $9.8 \pm 0.6 \mathrm{mM}$ \\
$\mathrm{C}_{2}$ F-pga & $5.1 \pm 0.4 \mathrm{mM}$ \\
$\mathrm{C}_{2}$ F-E1804del & $10.2 \pm 0.3 \mathrm{mM}\left(8.4 \pm 0.3 \mathrm{mM}^{\mathrm{c}}\right)$ \\
\hline
\end{tabular}

It is known that $\mathrm{C}_{2}$-domains bind one to three $\mathrm{Ca}^{2+}$-ions through aspartate coordination. In case of Syt 1 the aspartate residues form the binding sites with different affinities for $\mathrm{Ca}^{2+}$. Selected mutations showed that it is possible to mutate specific aspartates without any influence on the high affinity binding site [36]. Based on the possibility to bind more than one $\mathrm{Ca}^{2+}$-ion it might be the case that the obtained $K_{\mathrm{d}}$ value of the wild type comprise two binding events which cannot be detected separately using MicroScale Thermophoresis. The resulted $K_{\mathrm{d}}$ values of the tested aspartate mutants in this work lead to the hypothesis that all aspartates share a similar role within the binding process in otoferlin. The mutation of one aspartate could affect the whole $\mathrm{Ca}^{2+}$-binding process. It is likely that all present aspartates are interconnected to each other and the required conformational change of the involved aspartates for $\mathrm{Ca}^{2+}$ coordination is disturbed by a single mutation.

The influence of at least the two pseudo-phosphorylation sites integrated in the $\beta$-strands of the $\mathrm{C}_{2} \mathrm{~F}$-domain probably cause a slightly different folding than for the wild type. Therefore it seems likely that the positions of the top loops are changed to an arrangement in which no $\mathrm{Ca}^{2+}$-binding under physiological conditions would be possible.

For the pga-mutant another hypothesis was made. According to predictions based on homology between $\mathrm{C}_{2}$-domains of closely related proteins the pga-mutation is located in the flexible bottom loop of the $\mathrm{C}_{2}$-domain. It is known that mutations which are not 
part of the active site, interaction areas or binding sites often affect the protein fold or decrease the stability of the functional conformation [94]. The incorrect folding can lead to degradation or aggregation of the protein. In comparison to the other expressed and purified $\mathrm{C}_{2} \mathrm{~F}$-fragments the pga-mutant showed a much lower expression level. This leads to the assumption that the exchanged amino acid is relevant for the correct folding of the domain. Furthermore a misfolding of the protein is likely to cause a different conformation of the top loops which might not be able to bind $\mathrm{Ca}^{2+}$ anymore. Moreover the made predictions could be different to the actual structure of the native $\mathrm{C}_{2} \mathrm{~F}$-domain. Because no structure of the otoferlin $\mathrm{C}_{2} \mathrm{~F}$-domain is known so far the location of the pga-mutation in a structured part of the domain cannot be excluded.

The before mentioned problems during folding can also be caused by in-frame deletions like the E1804del which is positioned in a bottom loop of the domain. The misfolding resulting from this deletion would explain why no changes in the $\mathrm{Ca}^{2+}$-affinity could be detected performing MST measurements at different temperatures. The temperature sensitive mutant should show a different behavior at temperatures higher than the body temperature in comparison to the tested $22^{\circ} \mathrm{C}$. But if the protein was folded incorrectly during expression it is no wonder that we did not observe two different affinities at the two tested temperatures.

In summary all tested mutant $\mathrm{C}_{2} \mathrm{~F}$-domains seem to be present in conformations which are different to the wild type $\mathrm{C}_{2} \mathrm{~F}$-domain. It is unlikely that the aspartate mutants influence the folding of the $\beta$-sheet consisting core component of the $\mathrm{C}_{2}$-domain. The change in $\mathrm{Ca}^{2+}$-binding probably results from a rearrangement of the top loops. The inserted pseudo-phosphorylation sites as well as the mutation/deletion known to affect hearing presumably cause a different folding of the entire domain. All tested mutations have in common that no $\mathrm{Ca}^{2+}$-binding occurs under physiological conditions. 


\subsection{Identification of possible interaction partners of otoferlin}

Based on the so far not clearly affirmed function of otoferlin, interaction partners within the inner hair cell could provide an indication for its precise molecular action in hearing. To identify these possible interaction partners pull-down experiments were performed in which recombinant otoferlin was incubated with lysed synaptosomes from mouse brain [56]. Based on the fact that samples from the whole mouse brain were used and not specific parts of the inner ear several proteins were identified as potential interaction partners which might not be present in the inner hair cells. Only proteins which were found at least three times out of nine pull-down experiments were considered as potential hits (Table 3.14-1). Figure 4.3-1 shows a network of proteins which are related to otoferlin, endocytosis or exocytosis. Beside the proteins of Table 3.14-1 clathrin, amphiphysin, synaptojanin, Rab-3A and Rab-3C were included. Each of them was found once or twice in our pull-down experiments. Furthermore the interactions between some of these proteins were already described in the literature. The black lines in Figure 4.3-1 show already published interactions and the red dotted lines display the potential interactions that were detected in the performed pull-down experiments of this work.

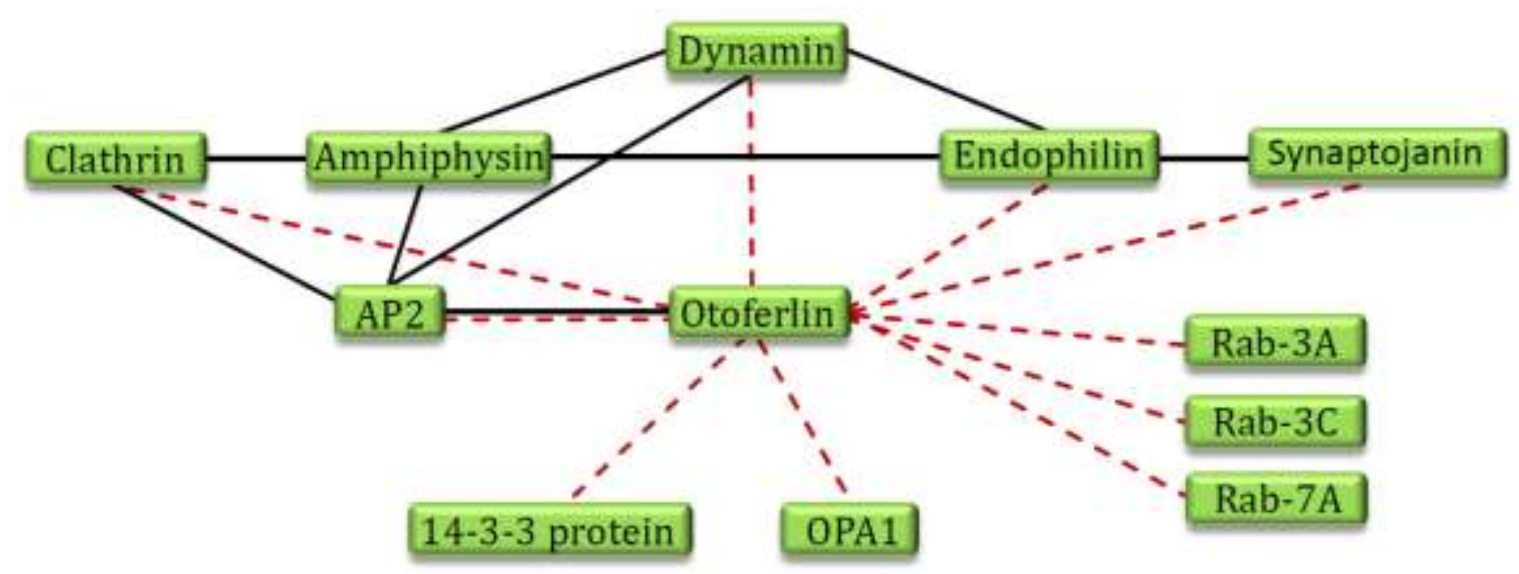

Figure 4.3-1 Overview of interaction partners of otoferlin. The green boxes show otoferlin and proteins which are potential interaction partners or known to interact with each other from literature [66,95-105]. The red dotted lines indicate the proteins which were identified in the pull-down experiments of this study. Already known interactions between proteins are displayed by solid black lines.

Clathrin, the AP2-complex and dynamin are known to function as core components of the clathrin-mediated endocytosis [106]. The AP2 adaptor complex consists of an $\alpha$-adaptin-, a $\beta 2$-adaptin-, a $\sigma 2$ - and a $\mu 2$-subunit $[98,107]$ and belongs to the family of heterotetrameric clathrin adaptor complexes. Members of this family are known to play a role in different vesicle trafficking pathways within the cells. Each of the four 
subunits of AP2 has a specific function. Through the $\alpha$-adaptin subunit the AP2-complex is targeted to the plasma membrane. There the assembly of clathrin is mediated by the AP2- $\beta 2$-subunit while the $\mu 2$-subunit directly interacts with sorting motifs on cargo molecules. For the $\sigma 2$-subunit no specific role is known so far but it is assumed that it plays a role in stabilization of the core domain [66]. The interaction of AP2 with otoferlin was published by Duncker et al. [97]. They identified AP2 as interaction partner using high-resolution liquid chromatography coupled with mass spectrometry. These findings were confirmed by co-immunoprecipitation assays in mature hair cells [97]. In this work the $\alpha$-subunit of AP2 was found in six of nine experiments and the $\mu$ - and $\beta$-subunits were identified four times. Only the $\sigma$-subunit could not be detected in the performed experiments.

Moreover, it was published that beside otoferlin, AP2 also interacts with amphiphysin $[95,96]$ and dynamin [98]. The hydrophilic and acidic protein amphiphysin was found in the brain and contains amongst others an adaptor domain and a SH3-domain [96]. Due to the identified interactions of amphiphysin with the $\alpha$-subunit of AP2 amphiphysin was suggested to play a role in synaptic vesicle endocytosis. It might participate in the recruiting or regulation process of proteins which are involved in budding and fission reactions [99]. In our pull-down experiments, amphiphysin was identified only once possibly resulting from its role as indirect interaction partner through AP2. In this case an indirect interaction with otoferlin can be assumed.

Like AP2, amphiphysin interacts through its SH3-domain with dynamin [95,96,99]. Dynamin itself is a $100 \mathrm{kDa}$ enzyme of the highly conserved GTPase superfamily. It is composed of an N-terminal GTPase domain followed by the middle-, PH- and the GTPase effector domain and a C-terminal proline-rich domain. [61,63,67,108]. Dynamin is involved in scission of clathrin-coated vesicles from the plasma membrane [61]. In this process, it is recruited to the necks of the coated pits, assembles in form of a spiral on these necks, and mediates the membrane fission [106]. Dynamin exists in three isoforms, dynamin- 1 and -3 are brain-specific whereas dynamin-2 is expressed ubiquitously [61,109]. In our investigations we identified dynamin-1 as well as dynamin-3 as potential otoferlin interaction partner. One experiment resulted in identified peptides of dynamin which are equal in all three isoforms; thus it might be possible that otoferlin can bind to more than one isoform. Studies of dynamin-1 and -3 showed that they have overlapping functions in nerve terminals. The suggestion that the two proteins also share a set of common binding partners was confirmed by western blot analysis [109].

To test the direct interaction of dynamin- 1 with the N-terminal part of otoferlin, dynamin-1 was cloned into a Strep-tag containing vector and purified from E. coli. 
The subcloned dynamin-fragment lacks the C-terminal proline-rich domain. These domains are known to be mostly unstructured and very flexible. Furthermore, it is very difficult to crystallize proline-rich regions $[63,110]$ and therefore, this domain was not included. The direct pull-down of otoferlin and dynamin-1 did not show any indications of an interaction between the two tested proteins. It was assumed that the binding/interaction of the two proteins would be mediated through the pleckstrin homology domain of dynamin [111]. Due to lack of structural information about interactions of otoferlin with other proteins, no specific region of otoferlin can be proposed to be essential for binding. Studies of Anggono et al. showed that during synaptic vesicle endocytosis dynamin-1 is dephosphorylated at serine 774 and serine 778. Both phosphorylation sites are located in the proline-rich domain of the protein [112,113]. The protein phosphatase calcineurin was reported to dephosphorylate these sites, which was suggested to be a key step in dynamin activation. The functional role of the dynamin phosphorylation in small vesicle endocytosis is still unclear but it is likely that the interaction with the SH3-domain containing proteins is regulated by the phosphorylation sites [112]. A hypothesis is that dynamin dephosphorylation stimulates the formation of protein complexes for endocytosis but this assumption could not be confirmed in vivo [113]. Amphiphysin and endophilin are two potential candidates for phosphorylation dependent dynamin-1 binding. These data result from experiments with single domains or in vitro experiments but it was not confirmed with endogenous proteins in intact cells [100-102]. Furthermore, in a dephosphorylated state, dynamin-1 recruits syndapin-1 for small vesicle endocytosis [114]. It thus seems that dynamin is able to bind different proteins depending on its phosphorylation [113].

The fact that we were not able to show a binding between dynamin-1 and otoferlin is probably caused by the absence of the proline-rich domain. In some studies it was reported that proteins interact via a SH3-domain with the proline-rich domain of dynamin. Otoferlin does not contain a SH3-domain. Consequently it might be possible that an alternative binding motif is present but no information about this is known so far. It is possible that the interaction might be mediated by one of the present $\mathrm{C}_{2}$-domains. Unfortunately, we could not test whether otoferlin binds to the phosphorylated or unphosphorylated state of dynamin because of the missing of the two specific phosphorylation sites in the proline-rich domain in our construct. Furthermore, it has to be considered that other posttranslational modifications in otoferlin might be necessary to establish a binding. In this case also the possibility that this interaction is simply an indirect interaction mediated by another protein had to be kept in mind. Recent proximity ligation assays done by Alexandra Müller at the 
lab of Dr. Ellen Reisinger showed that otoferlin exists in close proximity ( $\leq 40 \mathrm{~nm}$ ) of dynamin. For further information about a direct or indirect interaction these proteins have to be tested in co-immunoprecipitation experiments.

To address more proteins which are known to be involved in endocytosis clathrin, endophilin and synaptojanin have to be considered. As described before, clathrin is a main component in endocytosis and it forms so called triskelion structures which are composed of three clathrin heavy chains and three light chains. These clathrin triskelions assemble into a lattice to deform the plasma membrane into coated pits which are released through fission by dynamin from the plasma membrane [106]. In our studies the clathrin heavy chain was found in three of nine pull-down experiments. Because of the known interaction between the $\beta 2$-subunit of AP2 and clathrin, which enables the formation of the clathrin structure, two possibilities of interactions have to be considered. On the one hand it might be possible that otoferlin directly interacts with clathrin while on the other hand it is likely that it is an indirect interaction mediated for example by AP2 or amphiphysin, which are known to interact with clathrin $[95,106,115]$.

The accessory protein endophilin was reported to interact with dynamin and synaptojanin which are known to be involved in scission and uncoating events in the synapse $[103,104]$. It is a member of the Bin-Amphiphysin-Rvs (BAR) domain protein family. This BAR-domain is able to sense curvature in the membrane and can also generate these curvatures [116,117]. BAR-domain containing proteins acting in endocytic transport processes and the binding to dynamin occurs through the SH3-domain of endophilin to the proline-rich domain of dynamin $[114,118,119]$. Due to the binding to the two mentioned proteins it is assumed that endophilin acts as a molecular switch linking the fission process and the uncoating of vesicles during recycling but the exact mechanism is still unknown [104].

Vesicle uncoating after fission is mainly facilitated by an interaction of endophilin with synaptojanin $[104,105,120]$. Synaptojanin is an inositol-5-phosphatase which is enriched in nerve terminals, it is as well able to bind to the SH3-domains of amphiphysin [121]. Moreover, synaptojanin interacts with amphiphysin, which in this process binds to the proline-rich tail of synaptojanin [103,122]. Recent studies suggest that synaptojanin might play a direct role in the actual fission reaction [104]. Our pull-down studies identified endophilin three times and synaptojanin two times. Due to the suggested role of otoferlin to function in a late step of exocytosis and the so far known function of endophilin and synaptojanin both are feasible interaction partners of otoferlin. Still, an indirect interaction cannot be excluded in this case. 
All the proteins identified from pull-downs and discussed above are involved in different steps of endocytosis. Most of them interact with each other and all are potential interaction partners of otoferlin. The interaction between AP2 and otoferlin was reported as a direct interaction but in all other cases both a direct and an indirect interaction has to be considered. For further information about the ability to bind to otoferlin more individual studies should be done.

Three other proteins were identified in our studies, one of them being the protein 14-3-3. The 14-3-3 family consists of seven isoforms which show high sequence similarity. The results of our pull-down experiments show all seven isoforms of the 14-3-3 protein. The interaction between proteins involved in the regulation of the cell cycle, intracellular trafficking/targeting, signal transduction, cytoskeletal structure and transcription is modulated by the 14-3-3 protein. In regulatory processes of 14-3-3 the involved proteins often show a distinct preference for a specific isoform [65]. These interactions are often dependent on phosphorylation sites of the interacting protein or the 14-3-3 isoforms themself [123]. Three isoforms of the 14-3-3 protein $(\beta / \alpha, \zeta, \theta)$ have been identified as highly enriched in hair cells [124]. In our studies out of nine experiments the $\theta$ isoform was found five times, $\varepsilon$ and $\beta / \alpha$ four times, $\eta$ and $\zeta / \delta$ three times, $\gamma$ twice and $\sigma$ only once. It might be possible that the 14-3-3 protein interacts with otoferlin or the indirect interaction is mediated by another protein. Furthermore it needs to be tested if all existing isoforms are potential interaction partners.

In five out of nine experiments Rab-7A was identified as potential interaction partner. Rab proteins form the largest subgroup within the Ras-super-family. They are small monomeric GTPases/GTP-binding proteins and have been identified in several cellular functions like growth, protein trafficking, transmembrane signal transduction as well as targeting and fusion of membrane bound organelles [125,126]. The Rab-7 isoforms are involved in the control of late endocytic trafficking [127]. Additionally, we found the Rab-3A and Rab-3C in two experiments. Both isoforms were suggested to function in vesicle docking or exocytosis $[9,128]$. This could be a good indication for a possible interaction with otoferlin.

The last identified protein was OPA1. OPA1 belongs to the dynamin family and shares a number of structural features with the other family members. Like dynamin, OPA consists of the GTPase-, the middle and the GTPase effector domain. It lacks the C-terminal proline-rich and the pleckstrin homology domain but contains a mitochondrial import sequence (MIS), two hydrophobic sequences and a coiled-coil domain at the N-terminal part [129]. OPA1 has an important role in mitochondrial fission. The OPA1 knock-out is lethal; the mice lose viability around embryonic day 
nine. Therefore the importance of OPA1 during early development is assumed [130]. Furthermore OPA1 plays a role in autosomal dominant optic atrophy which affects the retinal ganglion cells and the axons forming the optic nerve and leads to progressive visual loss. Recently some OPA1 mutations were identified to occur in the GTPase domain of the protein resulting in deafness beside visual loss [131]. In case of OPA1 an additional proximity ligation assay was performed by Alexandra Müller which confirms that otoferlin and OPA1 exist in close proximity. Again co-immunoprecipitation assays in HEK-cells could give information about a direct or indirect interaction.

In summary, we identified a group of potential interaction partners which are involved in trafficking processes, endocytosis or exocytosis. In consideration of the proposed function of otoferlin all of them would be reasonable candidates. Further studies have to be done to confirm these assumptions. 


\subsection{Thermal stability of otoferlin $\mathrm{C}_{2}$-domains}

Thermal shift assays were performed to analyze the thermal stability of otoferlin fragments in absence and presence of $\mathrm{Ca}^{2+}$. A low $\mathrm{Ca}^{2+}$-concentration of $200 \mu \mathrm{M}$ was chosen to specifically study effects of $\mathrm{Ca}^{2+}$ on high affinity binding sites. Through binding of $\mathrm{Ca}^{2+}$-ions to the $\mathrm{C}_{2}$-domain top loop region a change in the melting temperature is expected. The obtained data show that for some domains the thermal stability is influenced by $\mathrm{Ca}^{2+}$ whereas for other no effect could be detected. Furthermore, it was observed that the combination of different fragments can increase the melting temperature as well. The $\mathrm{C}_{2} \mathrm{ABC}$-fragment was measured alone and in combination with the domains $\mathrm{C}_{2} \mathrm{~B}, \mathrm{C}_{2} \mathrm{C}, \mathrm{C}_{2} \mathrm{E}$ and $\mathrm{C}_{2} \mathrm{~F}$. All combinations were tested both in absence and presence of $\mathrm{Ca}^{2+}$. The $\mathrm{C}_{2} \mathrm{ABC}$ showed no indication of a higher thermal stability with or without $\mathrm{Ca}^{2+}$. Similar observations were made in combination with the $\mathrm{C}_{2} \mathrm{C}$-domain. The melting temperature of a mixture containing the $\mathrm{C}_{2} \mathrm{ABC}$ - and the $\mathrm{C}_{2} \mathrm{~B}$-fragment increased about $1^{\circ} \mathrm{C}$. A $1^{\circ} \mathrm{C}$ higher melting temperature was observed before for the single $\mathrm{C}_{2} \mathrm{~B}$-domain. The addition of $\mathrm{Ca}^{2+}$ to both samples did not result in any changes. This suggests that the $\mathrm{C}_{2} \mathrm{~B}$-domain forms a complex with the $\mathrm{C}_{2} \mathrm{ABC}$-fragment which is more stable than $\mathrm{C}_{2} \mathrm{ABC}$ alone. The same results were obtained for the combination of a fragment containing only the $\mathrm{C}_{2} \mathrm{~A}-$ and $\mathrm{C}_{2} \mathrm{~B}$-domains of the protein together with the single $\mathrm{C}_{2} \mathrm{~B}$-domain. In case of $\mathrm{C}_{2} \mathrm{AB}$ the addition of the single $\mathrm{C}_{2} \mathrm{C}$-domain resulted as well in an increased melting temperature. Additionally, the combination of $\mathrm{C}_{2} \mathrm{~B}$ and $\mathrm{C}_{2} \mathrm{C}$ showed a higher thermal stability in complex whereas the addition of $\mathrm{Ca}^{2+}$ did not significantly change the melting temperature of afore mentioned combinations. Based on made structure predictions and the absence of aspartate residues in the top loop regions it was proposed that neither of these domains are able to bind $\mathrm{Ca}^{2+}[20]$. Beside these results are in good agreement with the obtained results by MST. From this follows the question which function these non $\mathrm{Ca}^{2+}$-binding $\mathrm{C}_{2}$-domains have in the overall structure of the protein. Several $\mathrm{C}_{2}$-domains are reported not to bind $\mathrm{Ca}^{2+}$, in some cases these domains are responsible for folding of the overall structure or protein-protein interactions [29,31]. The increased temperature especially through addition of $\mathrm{C}_{2} \mathrm{~B}$ suggests that the domains $\mathrm{C}_{2} \mathrm{~B}$ and $\mathrm{C}_{2} \mathrm{C}$ are able to stabilize the formed complex.

In contrast to the first three $\mathrm{C}_{2}$-domains of otoferlin a different observation was made for the domains $\mathrm{C}_{2} \mathrm{E}$ and $\mathrm{C}_{2} \mathrm{~F}$. The addition of these two domains to the $\mathrm{C}_{2} \mathrm{ABC}$ - or $\mathrm{C}_{2} \mathrm{AB}$-fragment did not result in an increase of the melting temperature. But the addition of $\mathrm{Ca}^{2+}$ to the samples causes this effect. In both cases the melting 
temperature rises at least $1^{\circ} \mathrm{C}$. This result is also in accordance with the data from literature and the results from our MST studies. The last three $\mathrm{C}_{2}$-domains were proposed to bind $\mathrm{Ca}^{2+}[20]$. For the $\mathrm{C}_{2} \mathrm{~F}$-domain of the protein we could confirm the made assumption by performing MST measurements.

Based on these findings it can be hypothesized that the first three $\mathrm{C}_{2}$-domains play an important role in structural arrangement and stability of the protein. Furthermore they can be involved in protein-protein interactions. The last three $\mathrm{C}_{2}$-domains on the contrary are probably responsible for $\mathrm{Ca}^{2+}$-binding which might lead to the activation of the protein. Similar findings were reported for example in case of synaptotagmin the activation of which is triggered by $\mathrm{Ca}^{2+}$ [132] just as PKC activation results from interactions with $\mathrm{Ca}^{2+}$ and phospholipids [133]. In case of Syt 3 it was shown that the binding to $\mathrm{Ca}^{2+}$ changes the tertiary structure of the $\mathrm{C}_{2}$-domains [45]. Esyt 2 in contrast shows no conformational changes in absence or presence of $\mathrm{Ca}^{2+}$ [43]. The different overall arrangement of the two mentioned proteins may result because they belong to different topology types. Syt 3 exists in the type I topology whereas Esyt 2 is type II $[42,44]$. Based on the fact that otoferlin $\mathrm{C}_{2}$-domains are predicted to be as well in a type II topology it might be possible that a similar behavior like for Esyt 2 occurs. The linker region between the $\mathrm{C}_{2} \mathrm{~A}$ and $\mathrm{C}_{2} \mathrm{~B}$ in Syt 3 contains seven amino acids and the Esyt 2 linker 14 amino acids [43,44]. In otoferlin the linker regions are much longer suggesting that it might be possible that in case of otoferlin no direct interaction between the domains takes place. The shortest otoferlin linker is between the $\mathrm{C}_{2} \mathrm{~B}$ - and $\mathrm{C}_{2} \mathrm{C}$-domain. It consists of 41 amino acids therefore a high flexibility in the $\mathrm{C}_{2}$-domain arrangement is likely. All other linkers in otoferlin are at least 120 amino acids in length [20].

As an additional experiment the I515T-mutant was tested for thermal stability in comparison to the wild type fragment. The exchange of isoleucine to threonine in the $\mathrm{C}_{2} \mathrm{C}$-domain of the protein leads to a temperature sensitive mutant. If the body temperature of affected people rises $1^{\circ} \mathrm{C}$ they become deaf [51]. In experiments studying recombinant proteins, the melting temperature for $\mathrm{I} 515 \mathrm{~T}$ was found to be more than $1{ }^{\circ} \mathrm{C}$ lower than for the wild type. The addition of $\mathrm{Ca}^{2+}$ in both cases did not change the temperature. These findings explained for the first time the phenomenon of temperature sensitive deafness on a molecular level. This confirms the assumption that the mentioned amino acid exchange is responsible for the behavior of the protein.

To sum it up the thermal shift assay is a nice method to perform protein stability tests. The advantages of this method are (i) only a small amount of protein is needed, (ii) the $\mathrm{T}_{\mathrm{M}}$ value is determined with high precision and (iii) a multiplicity of reaction 
conditions can be tested in parallel [134]. To confirm the obtained data with another method circular dichroism spectroscopy measurements can be tried in the future $[43,135,136]$. The results of the performed thermal shift experiments show that the $\mathrm{C}_{2}$-domains of otoferlin behave differently. For some of the tested domains an increase of the melting temperature was measured by adding either other $\mathrm{C}_{2}$-domains or through addition of $\mathrm{Ca}^{2+}$. Using a dilution series of $\mathrm{Ca}^{2+}$-concentrations it might even be possible to determine a $K_{\mathrm{d}}$ value for $\mathrm{Ca}^{2+}$-binding of some proteins. 


\subsection{Crystallization of otoferlin}

Almost all purified otoferlin fragments were tested in several crystallization screens with different protein concentrations and temperatures. Only for the protein fragment containing the domains $\mathrm{C}_{2} \mathrm{~A}, \mathrm{C}_{2} \mathrm{~B}$ and $\mathrm{C}_{2} \mathrm{C}$ very small crystals were obtained. Curiously the gained crystals resulted from a condition that was tested before multiple times with the same concentrations and temperature but no crystals grew in the previous trials. Through condition optimization the size of the crystals could be increased and a data set of the native crystal was collected. Solving the structure by molecular replacement using the known structures of otoferlin $\mathrm{C}_{2} \mathrm{~A}$ or other $\mathrm{C}_{2}$-domains was not successful. In order to solve the phase problem, protein expression containing selenomethionine was tried but unfortunately no protein could be expressed. Further trials to obtain an anomalous signal from iodine, bromide or mercury failed as well. Either the co-crystallized or soaked ion was not found within the crystal or mostly the tested crystal did not exist as a single crystal. Seeding was tried for native single crystal formation. Neither the addition of the diluted crystal solution by pipetting nor streak-seeding resulted in any crystals. The structure solving is a still ongoing project which requires more tests to gain the optimal crystal. 


\section{REFERENCES}

1 Hudspeth, A. J. (1997) How hearing happens. Neuron 19, 947-50.

2 Fettiplace, R. and Hackney, C. M. (2006) The sensory and motor roles of auditory hair cells. Nat. Rev. Neurosci. 7, 19-29.

3 Leibovici, M., Safieddine, S. and Petit, C. (2008) Mouse models for human hereditary deafness. Curr. Top. Dev. Biol., Elesvier Inc. 84, 385-429.

4 Neff, D. L. (1995) Springer Handbook of Auditory Research. Ear Hear. 16, 545.

5 Dror, A. a and Avraham, K. B. (2010) Hearing impairment: a panoply of genes and functions. Neuron, Elsevier Inc. 68, 293-308.

6 Fernández-Chacón, R., Königstorfer, A., Gerber, S. H., García, J., Matos, M. F., Stevens, C. F., Brose, N., Rizo, J., Rosenmund, C. and Südhof, T. C. (2001) Synaptotagmin I functions as a calcium regulator of release probability. Nature 410, 41-9.

7 Chapman, E. R. (2002) Synaptotagmin: a Ca(2+) sensor that triggers exocytosis? Nat. Rev. Mol. Cell Biol. 3, 498-508.

8 Sutton, R. B., Fasshauer, D., Jahn, R. and Brunger, A. T. (1998) Crystal structure of a SNARE complex involved in synaptic exocytosis at 2.4 A resolution. Nature 395, 347-53.

9 Brunger, a T. (2001) Structural insights into the molecular mechanism of calcium-dependent vesicle-membrane fusion. Curr. Opin. Struct. Biol. 11, 16373.

10 Safieddine, S. and Wenthold, R. J. (1999) SNARE complex at the ribbon synapses of cochlear hair cells: analysis of synaptic vesicle- and synaptic membraneassociated proteins. Eur. J. Neurosci. 11, 803-12.

11 Roux, I., Safieddine, S., Nouvian, R., Grati, M., Simmler, M.-C., Bahloul, A., Perfettini, I., Le Gall, M., Rostaing, P., Hamard, G., et al. (2006) Otoferlin, defective in a human deafness form, is essential for exocytosis at the auditory ribbon synapse. Cell 127, 277-89.

12 Beurg, M., Michalski, N., Safieddine, S., Bouleau, Y., Schneggenburger, R., Chapman, E. R., Petit, C. and Dulon, D. (2010) Control of exocytosis by synaptotagmins and otoferlin in auditory hair cells. J. Neurosci. 30, 13281-90.

13 Reisinger, E., Bresee, C., Neef, J., Nair, R., Reuter, K., Bulankina, A., Nouvian, R., Koch, M., Bückers, J., Kastrup, L., et al. (2011) Probing the functional 
equivalence of otoferlin and synaptotagmin 1 in exocytosis. J. Neurosci. 31, 4886-95.

14 Ramakrishnan, N. a, Drescher, M. J. and Drescher, D. G. (2009) Direct interaction of otoferlin with syntaxin $1 \mathrm{~A}$, SNAP-25, and the L-type voltagegated calcium channel Cav1.3. J. Biol. Chem. 284, 1364-72.

15 Johnson, C. P. and Chapman, E. R. (2010) Otoferlin is a calcium sensor that directly regulates SNARE-mediated membrane fusion. J. Cell Biol. 191, 187-97.

16 Morton, N. E. (1991) Genetic epidemiology of hearing impairment. Ann. N. Y. Acad. Sci. 630, 16-31.

17 Marlin, S., Feldmann, D., Nguyen, Y., Rouillon, I., Loundon, N., Jonard, L., Bonnet, C., Couderc, R., Garabedian, E. N., Petit, C., et al. (2010) Temperature-sensitive auditory neuropathy associated with an otoferlin mutation: Deafening fever! Biochem. Biophys. Res. Commun., Elsevier Inc. 394, 737-42.

18 Yasunaga, S., Grati, M., Cohen-Salmon, M., El-Amraoui, A., Mustapha, M., Salem, N., El-Zir, E., Loiselet, J. and Petit, C. (1999) A mutation in OTOF, encoding otoferlin, a FER-1-like protein, causes DFNB9, a nonsyndromic form of deafness. Nat. Genet. 21, 363-9.

19 Robertson, N. G. and Morton, C. C. (1999) Beginning of a molecular era in hearing and deafness. Clin. Genet. 55, 149-59.

20 Jiménez, J. L. and Bashir, R. (2007) In silico functional and structural characterisation of ferlin proteins by mapping disease-causing mutations and evolutionary information onto three-dimensional models of their C2 domains. J. Neurol. Sci. 260, 114-23.

21 Washington, N. L. and Ward, S. (2006) FER-1 regulates Ca2+-mediated membrane fusion during C. elegans spermatogenesis. J. Cell Sci. 119, 2552-62.

22 Lek, A., Evesson, F. J., Sutton, R. B., North, K. N. and Cooper, S. T. (2012) Ferlins: regulators of vesicle fusion for auditory neurotransmission, receptor trafficking and membrane repair. Traffic 13, 185-94.

23 Han, R. and Campbell, K. P. (2007) Dysferlin and muscle membrane repair. Curr. Opin. Cell Biol. 19, 409-16.

24 McNeil, P. L. and Kirchhausen, T. (2005) An emergency response team for membrane repair. Nat. Rev. Mol. Cell Biol. 6, 499-505.

25 Lek, A., Lek, M., North, K. N. and Cooper, S. T. (2010) Phylogenetic analysis of ferlin genes reveals ancient eukaryotic origins. BMC Evol. Biol. 10, 231.

26 Nouvian, R., Neef, J., Bulankina, A. V, Reisinger, E., Pangršič, T., Frank, T., Sikorra, S., Brose, N., Binz, T. and Moser, T. (2011) Exocytosis at the hair cell ribbon 
synapse apparently operates without neuronal SNARE proteins. Nat. Neurosci., Nature Publishing Group 14, 411-3.

27 Uthaiah, R. C. and Hudspeth, a J. (2010) Molecular anatomy of the hair cell's ribbon synapse. J. Neurosci. 30, 12387-99.

28 Pangrsic, T., Lasarow, L., Reuter, K., Takago, H., Schwander, M., Riedel, D., Frank, T., Tarantino, L. M., Bailey, J. S., Strenzke, N., et al. (2010) Hearing requires otoferlin-dependent efficient replenishment of synaptic vesicles in hair cells. Nat. Neurosci. 13, 869-76.

29 Nalefski, E. A. and Falke, J. J. (1996) The C2 domain calcium-binding motif: structural and functional diversity. Protein Sci. 5, 2375-90.

30 Nishizuka, Y. (1988) The molecular heterogeneity of protein kinase C and its implications for cellular regulation. Nature 334, 661-5.

31 Cho, W. and Stahelin, R. V. (2006) Membrane binding and subcellular targeting of C2 domains. Biochim. Biophys. Acta 1761, 838-49.

32 Rizo, J. and Südhof, T. C. (1998) C2-domains, structure and function of a universal Ca2+-binding domain. J. Biol. Chem. 273, 15879-82.

33 Verdaguer, N., Corbalan-Garcia, S., Ochoa, W. F., Fita, I. and Gómez-Fernández, J. C. (1999) $\mathrm{Ca}(2+)$ bridges the $\mathrm{C} 2$ membrane-binding domain of protein kinase Calpha directly to phosphatidylserine. EMBO J. 18, 6329-38.

34 Helfmann, S., Neumann, P., Tittmann, K., Moser, T., Ficner, R. and Reisinger, E. (2011) The crystal structure of the $\mathrm{C}_{2} \mathrm{~A}$ domain of otoferlin reveals an unconventional top loop region. J. Mol. Biol. 406, 479-90.

35 Ramakrishnan, N. a, Drescher, M. J., Morley, B. J., Kelley, P. M. and Drescher, D. G. (2014) Calcium regulates molecular interactions of otoferlin with soluble NSF attachment protein receptor (SNARE) proteins required for hair cell exocytosis. J. Biol. Chem. 289, 8750-66.

36 Ubach, J., Zhang, X., Shao, X., Südhof, T. C. and Rizo, J. (1998) Ca2+ binding to synaptotagmin: how many Ca2+ ions bind to the tip of a C2-domain? EMBO J. 17, 3921-30.

37 Garcia, J., Gerber, S. H., Sugita, S., Südhof, T. C. and Rizo, J. (2004) A conformational switch in the Piccolo C2A domain regulated by alternative splicing. Nat. Struct. Mol. Biol. 11, 45-53.

38 Essen, L. O., Perisic, O., Lynch, D. E., Katan, M. and Williams, R. L. (1997) A ternary metal binding site in the $\mathrm{C} 2$ domain of phosphoinositide-specific phospholipase C-delta1. Biochemistry 36, 2753-62.

39 Grobler, J. A., Essen, L. O., Williams, R. L. and Hurley, J. H. (1996) C2 domain conformational changes in phospholipase C-delta 1. Nat. Struct. Biol. 3, 788-95. 
40 Sutton, R. B., Davletov, B. a, Berghuis, a M., Südhof, T. C. and Sprang, S. R. (1995) Structure of the first $\mathrm{C} 2$ domain of synaptotagmin I: a novel Ca2+/phospholipid-binding fold. Cell 80, 929-38.

41 Shao, X., Davletov, B. a, Sutton, R. B., Südhof, T. C. and Rizo, J. (1996) Bipartite Ca2+-binding motif in $\mathrm{C} 2$ domains of synaptotagmin and protein kinase $\mathrm{C}$. Science 273, 248-51.

42 Schauder, C. M., Wu, X., Saheki, Y., Narayanaswamy, P., Torta, F., Wenk, M. R., De Camilli, P. and Reinisch, K. M. (2014) Structure of a lipid-bound extended synaptotagmin indicates a role in lipid transfer. Nature, Nature Publishing Group 510, 552-5.

43 Xu, J., Bacaj, T., Zhou, A., Tomchick, D. R., Südhof, T. C. and Rizo, J. (2014) Structure and $\mathrm{Ca}^{2+}$-binding properties of the tandem $\mathrm{C}_{2}$ domains of E-Syt2. Structure 22, 269-80.

44 Vrljic, M., Strop, P., Ernst, J. A., Sutton, R. B., Chu, S. and Brunger, A. T. (2010) Molecular mechanism of the synaptotagmin-SNARE interaction in Ca2+triggered vesicle fusion. Nat. Struct. Mol. Biol. 17, 325-31.

45 Sutton, R. B., Ernst, J. A. and Brunger, A. T. (1999) Crystal structure of the cytosolic C2A-C2B domains of synaptotagmin III. Implications for $\mathrm{Ca}(+2)-$ independent snare complex interaction. J. Cell Biol. 147, 589-98.

46 Fuson, K. L., Montes, M., Robert, J. J. and Sutton, R. B. (2007) Structure of human synaptotagmin $1 \mathrm{C} 2 \mathrm{AB}$ in the absence of $\mathrm{Ca} 2+$ reveals a novel domain association. Biochemistry 46, 13041-8.

47 Yasunaga, S., Grati, M., Chardenoux, S., Smith, T. N., Friedman, T. B., Lalwani, a K., Wilcox, E. R. and Petit, C. (2000) OTOF encodes multiple long and short isoforms: genetic evidence that the long ones underlie recessive deafness DFNB9. Am. J. Hum. Genet. 67, 591-600.

48 Rodríguez-Ballesteros, M., Reynoso, R., Olarte, M., Villamar, M., Morera, C., Santarelli, R., Arslan, E., Medá, C., Curet, C., Völter, C., et al. (2008) A multicenter study on the prevalence and spectrum of mutations in the otoferlin gene (OTOF) in subjects with nonsyndromic hearing impairment and auditory neuropathy. Hum. Mutat. 29, 823-31.

49 Starr, A., Sininger, Y., Winter, M., Derebery, M. J., Oba, S. and Michalewski, H. J. (1998) Transient Deafness Due To Temperature-Sensitive Auditory Neuropathy. Ear Hear. 19, 169-179.

50 Wang, D.-Y., Wang, Y.-C., Weil, D., Zhao, Y.-L., Rao, S.-Q., Zong, L., Ji, Y.-B., Liu, Q., Li, J.-Q., Yang, H.-M., et al. (2010) Screening mutations of OTOF gene in Chinese patients with auditory neuropathy, including a familial case of temperaturesensitive auditory neuropathy. BMC Med. Genet. 11, 79. 
51 Varga, R., Avenarius, M. R., Kelley, P. M., Keats, B. J., Berlin, C. I., Hood, L. J., Morlet, T. G., Brashears, S. M., Starr, A., Cohn, E. S., et al. (2006) OTOF mutations revealed by genetic analysis of hearing loss families including a potential temperature sensitive auditory neuropathy allele. J. Med. Genet. 43, 576-81.

52 Matsunaga, T., Mutai, H., Kunishima, S., Namba, K., Morimoto, N., Shinjo, Y., Arimoto, Y., Kataoka, Y., Shintani, T., Morita, N., et al. (2012) A prevalent founder mutation and genotype-phenotype correlations of OTOF in Japanese patients with auditory neuropathy. Clin. Genet. 82, 425-32.

53 Padmanarayana, M., Hams, N., Speight, L. C., Petersson, E. J., Mehl, R. a and Johnson, C. P. (2014) Characterization of the lipid binding properties of Otoferlin reveals specific interactions between PI(4,5)P2 and the C2C and C2F domains. Biochemistry 53, 5023-33.

54 Schwander, M., Sczaniecka, A., Grillet, N., Bailey, J. S., Avenarius, M., Najmabadi, H., Steffy, B. M., Federe, G. C., Lagler, E. a, Banan, R., et al. (2007) A forward genetics screen in mice identifies recessive deafness traits and reveals that pejvakin is essential for outer hair cell function. J. Neurosci. 27, 2163-75.

55 Laemmli, U. K. (1970) Cleavage of structural proteins during the assembly of the head of bacteriophage T4. Nature 227, 680-5.

56 Burger, P. M., Mehl, E., Cameron, P. L., Maycox, P. R., Baumert, M., Lottspeich, F., De Camilli, P. and Jahn, R. (1989) Synaptic vesicles immunoisolated from rat cerebral cortex contain high levels of glutamate. Neuron 3, 715-20.

57 Studier, F. W. (2005) Protein production by auto-induction in high-density shaking cultures. Protein Expr. Purif. 41, 207-234.

58 Kabsch, W. (2010) Integration, scaling, space-group assignment and postrefinement. Acta Crystallogr. D. Biol. Crystallogr., International Union of Crystallography 66, 133-44.

59 Kabsch, W. (2010) XDS. Acta Crystallogr. D. Biol. Crystallogr. 66, 125-32.

60 Wu, Y., O’Toole, E. T., Girard, M., Ritter, B., Messa, M., Liu, X., McPherson, P. S., Ferguson, S. M. and De Camilli, P. (2014) A dynamin 1-, dynamin 3- and clathrin-independent pathway of synaptic vesicle recycling mediated by bulk endocytosis. Elife 3, e01621.

61 Faelber, K., Posor, Y., Gao, S., Held, M., Roske, Y., Schulze, D., Haucke, V., Noé, F. and Daumke, 0. (2011) Crystal structure of nucleotide-free dynamin. Nature 477, 556-60.

62 Fröhlich, C., Grabiger, S., Schwefel, D., Faelber, K., Rosenbaum, E., Mears, J., Rocks, O. and Daumke, O. (2013) Structural insights into oligomerization and mitochondrial remodelling of dynamin 1-like protein. EMBO J. 32, 1280-92. 
63 Ford, M. G. J., Jenni, S. and Nunnari, J. (2011) The crystal structure of dynamin. Nature, Nature Publishing Group 477, 561-6.

64 Boller, T., Meier, C. and Menzler, S. (2002) EUPERGIT Oxirane Acrylic Beads: How to Make Enzymes Fit for Biocatalysis. Org. Process Res. Dev. 6, 509-519.

65 Aitken, A. (2002) Functional specificity in 14-3-3 isoform interactions through dimer formation and phosphorylation. Chromosome location of mammalian isoforms and variants. Plant Mol. Biol. 50, 993-1010.

66 Collins, B. M., McCoy, A. J., Kent, H. M., Evans, P. R. and Owen, D. J. (2002) Molecular architecture and functional model of the endocytic AP2 complex. Cell 109, 523-35.

67 Praefcke, G. J. K. and McMahon, H. T. (2004) The dynamin superfamily: universal membrane tubulation and fission molecules? Nat. Rev. Mol. Cell Biol. 5, 133-47.

68 Tanifuji, S., Funakoshi-Tago, M., Ueda, F., Kasahara, T. and Mochida, S. (2013) Dynamin isoforms decode action potential firing for synaptic vesicle recycling. J. Biol. Chem. 288, 19050-9.

69 Meese, S., Gahlen, F., Adams, C. M., Ficner, R., Ricci, A. J., Heller, S., Reisinger, E. and Herget, M. Activity dependent phosphorylation by CaMKII delta alters the Ca $2+$ affinity of otoferlin. submitted.

70 Sahdev, S., Khattar, S. K. and Saini, K. S. (2008) Production of active eukaryotic proteins through bacterial expression systems: a review of the existing biotechnology strategies. Mol. Cell. Biochem. 307, 249-64.

71 Ericsson, U. B., Hallberg, B. M., Detitta, G. T., Dekker, N. and Nordlund, P. (2006) Thermofluor-based high-throughput stability optimization of proteins for structural studies. Anal. Biochem. 357, 289-98.

72 Van den Bogaart, G., Meyenberg, K., Diederichsen, U. and Jahn, R. (2012) Phosphatidylinositol 4,5-bisphosphate increases Ca2+ affinity of synaptotagmin-1 by 40-fold. J. Biol. Chem. 287, 16447-53.

73 Rellos, P., Pike, A. C. W., Niesen, F. H., Salah, E., Lee, W. H., von Delft, F. and Knapp, S. (2010) Structure of the CaMKIIdelta/calmodulin complex reveals the molecular mechanism of CaMKII kinase activation. PLoS Biol. 8, e1000426.

74 White, R. R. (1998) Definition of Optimal Substrate Recognition Motifs of Ca2+Calmodulin-dependent Protein Kinases IV and II Reveals Shared and Distinctive Features. J. Biol. Chem. 273, 3166-3172.

75 Sun, P., Enslen, H., Myung, P. S. and Maurer, R. a. (1994) Differential activation of CREB by Ca2+/calmodulin-dependent protein kinases type II and type IV involves phosphorylation of a site that negatively regulates activity. Genes Dev. 8, 2527-2539. 
76 Ando, S., Tokui, T., Yamauchi, T., Sugiura, H., Tanabe, K. and Inagaki, M. (1991) Evidence that Ser-82 is a unique phosphorylation site on vimentin for Ca2(+)calmodulin-dependent protein kinase II. Biochem. Biophys. Res. Commun. 175, 955-62.

77 Roggero, C. M., Tomes, C. N., De Blas, G. a, Castillo, J., Michaut, M. a, Fukuda, M. and Mayorga, L. S. (2005) Protein kinase C-mediated phosphorylation of the two polybasic regions of synaptotagmin VI regulates their function in acrosomal exocytosis. Dev. Biol. 285, 422-35.

78 Pepio, a M. and Sossin, W. S. (2001) Membrane translocation of novel protein kinase Cs is regulated by phosphorylation of the C2 domain. J. Biol. Chem. 276, 3846-55.

79 Gijón, M. A., Spencer, D. M., Kaiser, A. L. and Leslie, C. C. (1999) Role of phosphorylation sites and the $\mathrm{C} 2$ domain in regulation of cytosolic phospholipase A2. J. Cell Biol. 145, 1219-32.

80 Kang, C. H., Moon, B. C., Park, H. C., Koo, S. C., Chi, Y. H., Cheong, Y. H., Yoon, B.-D., Lee, S. Y. and Kim, C. Y. (2013) Rice small C2-domain proteins are phosphorylated by calcium-dependent protein kinase. Mol. Cells 35, 381-7.

81 Yáñez, M., Gil-longo, J. and Campos-toimil, M. (2012) Calcium Signaling (Islam, M. S., ed.), pp 461-482, Springer Netherlands, Dordrecht.

82 Van den Bogaart, G., Meyenberg, K., Diederichsen, U. and Jahn, R. (2012) Phosphatidylinositol 4,5-bisphosphate increases Ca2+ affinity of synaptotagmin-1 by 40-fold. J. Biol. Chem. 287, 16447-53.

83 Perisic, O., Fong, S., Lynch, D. E., Bycroft, M. and Williams, R. L. (1998) Crystal Structure of a Calcium-Phospholipid Binding Domain from Cytosolic Phospholipase A2. J. Biol. Chem. 273, 1596-1604.

84 Tokmakov, A. a, Kurotani, A., Takagi, T., Toyama, M., Shirouzu, M., Fukami, Y. and Yokoyama, S. (2012) Multiple post-translational modifications affect heterologous protein synthesis. J. Biol. Chem. 287, 27106-16.

85 Seo, J. and Lee, K.-J. (2004) Post-translational modifications and their biological functions: proteomic analysis and systematic approaches. J. Biochem. Mol. Biol. 37, 35-44.

86 Wong, A. B., Rutherford, M. a, Gabrielaitis, M., Pangrsic, T., Göttfert, F., Frank, T., Michanski, S., Hell, S., Wolf, F., Wichmann, C., et al. (2014) Developmental refinement of hair cell synapses tightens the coupling of $\mathrm{Ca} 2+$ influx to exocytosis. EMBO J. 33, 247-64.

87 Radhakrishnan, A., Stein, A., Jahn, R. and Fasshauer, D. (2009) The Ca2+ affinity of synaptotagmin 1 is markedly increased by a specific interaction of its C2B domain with phosphatidylinositol 4,5-bisphosphate. J. Biol. Chem. 284, 2574960 . 
88 Brose, N., Petrenko, a G., Südhof, T. C. and Jahn, R. (1992) Synaptotagmin: a calcium sensor on the synaptic vesicle surface. Science 256, 1021-5.

89 Guerrero-Valero, M., Ferrer-Orta, C., Querol-Audí, J., Marin-Vicente, C., Fita, I., Gómez-Fernández, J. C., Verdaguer, N. and Corbalán-García, S. (2009) Structural and mechanistic insights into the association of PKCalpha-C2 domain to PtdIns(4,5)P2. Proc. Natl. Acad. Sci. U. S. A. 106, 6603-7.

90 Huang, W. and Erikson, R. L. (1994) Constitutive activation of Mek1 by mutation of serine phosphorylation sites. Proc. Natl. Acad. Sci. U. S. A. 91, 89603.

91 Strickfaden, S. C., Winters, M. J., Ben-Ari, G., Lamson, R. E., Tyers, M. and Pryciak, P. M. (2007) A mechanism for cell-cycle regulation of MAP kinase signaling in a yeast differentiation pathway. Cell 128, 519-31.

92 Coudevylle, N., Montaville, P., Leonov, A., Zweckstetter, M. and Becker, S. (2008) Structural determinants for Ca2+ and phosphatidylinositol 4,5-bisphosphate binding by the C2A domain of rabphilin-3A. J. Biol. Chem. 283, 35918-28.

93 Sutton, R. B. and Sprang, S. R. (1998) Structure of the protein kinase Cbeta phospholipid-binding C2 domain complexed with Ca2+. Structure 6, 1395-405.

94 Bross, P., Corydon, T. J., Andresen, B. S., Jørgensen, M. M., Bolund, L. and Gregersen, N. (1999) Protein misfolding and degradation in genetic diseases. Hum. Mutat. 14, 186-98.

95 Wigge, P., Köhler, K., Vallis, Y., Doyle, C. A., Owen, D., Hunt, S. P. and McMahon, H. T. (1997) Amphiphysin heterodimers: potential role in clathrin-mediated endocytosis. Mol. Biol. Cell 8, 2003-15.

96 Wigge, P., Vallis, Y. and McMahon, H. T. (1997) Inhibition of receptor-mediated endocytosis by the amphiphysin SH3 domain. Curr. Biol. 7, 554-60.

97 Duncker, S. V, Franz, C., Kuhn, S., Schulte, U., Campanelli, D., Brandt, N., Hirt, B., Fakler, B., Blin, N., Ruth, P., et al. (2013) Otoferlin couples to clathrin-mediated endocytosis in mature cochlear inner hair cells. J. Neurosci. 33, 9508-19.

98 Wang, L. H., Südhof, T. C. and Anderson, R. G. (1995) The appendage domain of alpha-adaptin is a high affinity binding site for dynamin. J. Biol. Chem. 270, 10079-83.

99 David, C., McPherson, P. S., Mundigl, O. and de Camilli, P. (1996) A role of amphiphysin in synaptic vesicle endocytosis suggested by its binding to dynamin in nerve terminals. Proc. Natl. Acad. Sci. U. S. A. 93, 331-5.

100 Tomizawa, K., Sunada, S., Lu, Y.-F., Oda, Y., Kinuta, M., Ohshima, T., Saito, T., Wei, F.-Y., Matsushita, M., Li, S.-T., et al. (2003) Cophosphorylation of amphiphysin I and dynamin I by Cdk5 regulates clathrin-mediated endocytosis of synaptic vesicles. J. Cell Biol. 163, 813-24. 
101 Slepnev, V. I. (1998) Role of Phosphorylation in Regulation of the Assembly of Endocytic Coat Complexes. Science (80-. ). 281, 821-824.

102 Solomaha, E., Szeto, F. L., Yousef, M. a and Palfrey, H. C. (2005) Kinetics of Src homology 3 domain association with the proline-rich domain of dynamins: specificity, occlusion, and the effects of phosphorylation. J. Biol. Chem. 280, 23147-56.

103 Ringstad, N., Nemoto, Y. and De Camilli, P. (1997) The SH3p4/Sh3p8/SH3p13 protein family: binding partners for synaptojanin and dynamin via a Grb2-like Src homology 3 domain. Proc. Natl. Acad. Sci. U. S. A. 94, 8569-74.

104 Sundborger, A., Soderblom, C., Vorontsova, O., Evergren, E., Hinshaw, J. E. and Shupliakov, O. (2011) An endophilin-dynamin complex promotes budding of clathrin-coated vesicles during synaptic vesicle recycling. J. Cell Sci. 124, 13343.

105 Cremona, O., Di Paolo, G., Wenk, M. R., Lüthi, A., Kim, W. T., Takei, K., Daniell, L., Nemoto, Y., Shears, S. B., Flavell, R. A., et al. (1999) Essential role of phosphoinositide metabolism in synaptic vesicle recycling. Cell 99, 179-88.

106 Conner, S. D. and Schmid, S. L. (2003) Regulated portals of entry into the cell. Nature 422, 37-44.

107 Jackson, L. P., Kelly, B. T., McCoy, A. J., Gaffry, T., James, L. C., Collins, B. M., Höning, S., Evans, P. R. and Owen, D. J. (2010) A large-scale conformational change couples membrane recruitment to cargo binding in the AP2 clathrin adaptor complex. Cell 141, 1220-9.

108 Hoppins, S., Lackner, L. and Nunnari, J. (2007) The machines that divide and fuse mitochondria. Annu. Rev. Biochem. 76, 751-80.

109 Raimondi, A., Ferguson, S. M., Lou, X., Armbruster, M., Paradise, S., Giovedi, S., Messa, M., Kono, N., Takasaki, J., Cappello, V., et al. (2011) Overlapping role of dynamin isoforms in synaptic vesicle endocytosis. Neuron 70, 1100-14.

110 Williamson, M. P. (1994) The structure and function of proline-rich regions in proteins. Biochem. J. 297 ( Pt 2, 249-60.

111 Haslam, R., Koide, H. and Hemmings, B. (1993) Pleckstrin domain homology. Nature 363, 309-310.

112 Clayton, E. L., Anggono, V., Smillie, K. J., Chau, N., Robinson, P. J. and Cousin, M. A. (2009) The phospho-dependent dynamin-syndapin interaction triggers activity-dependent bulk endocytosis of synaptic vesicles. J. Neurosci. 29, 770617.

113 Anggono, V., Smillie, K. J., Graham, M. E., Valova, V. A., Cousin, M. A. and Robinson, P. J. (2006) Syndapin I is the phosphorylation-regulated dynamin I partner in synaptic vesicle endocytosis. Nat. Neurosci. 9, 752-60. 
114 Anggono, V. and Robinson, P. J. (2007) Syndapin I and endophilin I bind overlapping proline-rich regions of dynamin I: role in synaptic vesicle endocytosis. J. Neurochem. 102, 931-43.

115 Marsh, M. and McMahon, H. T. (1999) The structural era of endocytosis. Science 285, 215-20.

116 Gallop, J. L., Jao, C. C., Kent, H. M., Butler, P. J. G., Evans, P. R., Langen, R. and McMahon, H. T. (2006) Mechanism of endophilin N-BAR domain-mediated membrane curvature. EMBO J. 25, 2898-910.

117 Masuda, M., Takeda, S., Sone, M., Ohki, T., Mori, H., Kamioka, Y. and Mochizuki, N. (2006) Endophilin BAR domain drives membrane curvature by two newly identified structure-based mechanisms. EMBO J. 25, 2889-97.

118 Weissenhorn, W. (2005) Crystal structure of the endophilin-A1 BAR domain. J. Mol. Biol. 351, 653-61.

119 Heymann, J. a W. and Hinshaw, J. E. (2009) Dynamins at a glance. J. Cell Sci. 122, 3427-31.

120 Ringstad, N., Gad, H., Löw, P., Di Paolo, G., Brodin, L., Shupliakov, O. and De Camilli, P. (1999) Endophilin/SH3p4 is required for the transition from early to late stages in clathrin-mediated synaptic vesicle endocytosis. Neuron 24, 14354.

121 McPherson, P. S., Garcia, E. P., Slepnev, V. I., David, C., Zhang, X., Grabs, D., Sossin, W. S., Bauerfeind, R., Nemoto, Y. and De Camilli, P. (1996) A presynaptic inositol-5-phosphatase. Nature 379, 353-7.

122 Micheva, K. D., Kay, B. K. and McPherson, P. S. (1997) Synaptojanin Forms Two Separate Complexes in the Nerve Terminal: INTERACTIONS WITH ENDOPHILIN AND AMPHIPHYSIN. J. Biol. Chem. 272, 27239-27245.

123 Clokie, S., Falconer, H., Mackie, S., Dubois, T. and Aitken, A. (2009) The interaction between casein kinase Ialpha and 14-3-3 is phosphorylation dependent. FEBS J. 276, 6971-84.

124 Herget, M., Scheibinger, M., Guo, Z., Jan, T. a, Adams, C. M., Cheng, A. G. and Heller, S. (2013) A simple method for purification of vestibular hair cells and non-sensory cells, and application for proteomic analysis. PLoS One 8, e66026.

125 Chavrier, P. and Goud, B. (1999) The role of ARF and Rab GTPases in membrane transport. Curr. Opin. Cell Biol. 11, 466-75.

126 Pereira-Leal, J. B. and Seabra, M. C. (2000) The mammalian Rab family of small GTPases: definition of family and subfamily sequence motifs suggests a mechanism for functional specificity in the Ras superfamily. J. Mol. Biol. 301, 1077-87. 
127 Bhuin, T. and Roy, J. K. (2014) Rab proteins: The key regulators of intracellular vesicle transport. Exp. Cell Res. 328, 1-19.

128 Fischer von Mollard, G., Stahl, B., Khokhlatchev, A., Südhof, T. C. and Jahn, R. (1994) Rab3C is a synaptic vesicle protein that dissociates from synaptic vesicles after stimulation of exocytosis. J. Biol. Chem. 269, 10971-4.

129 Olichon, A., Guillou, E., Delettre, C., Landes, T., Arnauné-Pelloquin, L., Emorine, L. J., Mils, V., Daloyau, M., Hamel, C., Amati-Bonneau, P., et al. (2006) Mitochondrial dynamics and disease, OPA1. Biochim. Biophys. Acta 1763, 5009.

130 Davies, V. J., Hollins, A. J., Piechota, M. J., Yip, W., Davies, J. R., White, K. E., Nicols, P. P., Boulton, M. E. and Votruba, M. (2007) Opa1 deficiency in a mouse model of autosomal dominant optic atrophy impairs mitochondrial morphology, optic nerve structure and visual function. Hum. Mol. Genet. 16, 1307-18.

131 Amati-Bonneau, P., Milea, D., Bonneau, D., Chevrollier, A., Ferré, M., Guillet, V., Gueguen, N., Loiseau, D., de Crescenzo, M.-A. P., Verny, C., et al. (2009) OPA1associated disorders: phenotypes and pathophysiology. Int. J. Biochem. Cell Biol. 41, 1855-65.

132 García, R. a, Forde, C. E. and Godwin, H. a. (2000) Calcium triggers an intramolecular association of the $\mathrm{C} 2$ domains in synaptotagmin. Proc. Natl. Acad. Sci. U. S. A. 97, 5883-8.

133 Ponting, C. P. and Parker, P. J. (1996) Extending the C2 domain family: C2s in PKCs delta, epsilon, eta, theta, phospholipases, GAPs, and perforin. Protein Sci. 5, 162-6.

134 Matulis, D., Kranz, J. K., Salemme, F. R. and Todd, M. J. (2005) Thermodynamic stability of carbonic anhydrase: measurements of binding affinity and stoichiometry using ThermoFluor. Biochemistry 44, 5258-66.

135 Liang, Y. (2008) Applications of isothermal titration calorimetry in protein science. Acta Biochim. Biophys. Sin. (Shanghai). 40, 565-576.

136 Greenfield, N. J. (2006) Using circular dichroism spectra to estimate protein secondary structure. Nat. Protoc. 1, 2876-90. 


\section{APPENDIX}

\subsection{Oligonucleotides}

Table 6-1 List of oligonucleotides used for restriction site or StarGate cloning and for creation of point mutations.

\begin{tabular}{|c|c|c|}
\hline $\mathrm{Nr}$ & Name & Sequence \\
\hline 1 & mOtof_C2A_SH_F & GAGAGGATCCATGGCCCTGATTGTTCACCTCAAG \\
\hline 2 & mOtof_C ${ }_{2}$ B_SH_R & GAGAGAATTCTAGTCGTCCTCATCCGTCTCGTTG \\
\hline 3 & $\mathrm{C}_{2} \mathrm{~B}$-BamHI_F & ATATGGATCCATGGAGGACCTGGACCACC \\
\hline 4 & $\mathrm{C}_{2} \mathrm{~B}$-EcoRI_R & ATATGAATTCTAGTCATCCTCATCTGTCTCGTTG \\
\hline 5 & $\mathrm{C}_{2} \mathrm{C}$-BamHI_F & TGGATCCACAGATGAGGATGACATTGAAGG \\
\hline 6 & $\mathrm{C}_{2} \mathrm{C}$-EcoRI_R & TGAATTCTACTCTGAGACAGGTGTGGCCTG \\
\hline 7 & $\mathrm{C}_{2} \mathrm{E}-\mathrm{BamHI} \mathrm{F}$ & ATATGAATTCTACTCATCTGTGGGCTTCСTCTG \\
\hline 8 & $\mathrm{C}_{2}$ E-EcoRI_R & ATATGAATTCTACTCATCTGTGGGCTTCCTCTG \\
\hline 9 & $\mathrm{C}_{2} \mathrm{~F}-\mathrm{BamHI} \mathrm{F}$ & ATATGGATCCAACCCTGACAAGCCAGGC \\
\hline 10 & $\mathrm{C}_{2} \mathrm{~F}$-EcoRI_R & ATATGAATTCTAGTCAGGTTCATTGCGAGCCAG \\
\hline 11 & $p g a-\mathrm{fwd} 1$ & CAGCAGGAGGGCAAACAGGACACAGACGTAC \\
\hline 12 & $p g a-\mathrm{fwd} 2$ & ATATGGATCCAACCCTGACAAGCCAGGC \\
\hline 13 & pga-rev1 & ATATGAATTCTAGTCAGGTTCATTGCGAGCCAG \\
\hline 14 & pga-rev2 & GTCCTGTTTGCССTCCTGCTGGCCСТTCAG \\
\hline 15 & $\mathrm{C}_{2} \mathrm{ABC} \mathrm{SG} F$ & AGCGGCTCTTCAATGATGGCCCTGATTGTTCACCT \\
\hline 16 & $\mathrm{C}_{2} \mathrm{ABC}$ SG R & AGCGGCTCTTCTCСССТCCGAGACAGGCGTGGC \\
\hline 17 & SG-C $\mathrm{C}_{2} \mathrm{ABC}-\mathrm{kurz}-\mathrm{R}$ & AGCGGCTCTTCTCCCGGCCCGGAAGGACACACC \\
\hline 18 & mOtof_C 2 D_SH_F & GAGAGGATCCAAGCTGGAGCTCTACCTGTG \\
\hline 19 & mOtof_C ${ }_{2} F_{-} S H_{-} R$ & GAGAGAATTCTAATCAGGTTCATTGCGAGCCAG \\
\hline 20 & R-mDyn1-PRD & AGCGGCTCTTCTCCCCGTGCTGACGGTGGTCGT \\
\hline 21 & F-mDyn1-PRD & AGCGGCTCTTCAATGATGGGCAACCACGGCATG \\
\hline 22 & I515T-F & ATGAAGGTGCAGACCCGGGACTCTGAC \\
\hline 23 & I515T-R & GTCAGAGTCCCGGGTCTGCACCTTCAT \\
\hline
\end{tabular}




\begin{tabular}{lll}
24 & F-43-G541S & CCAGCCTGGGTGAACATGTACAGCTCCACG \\
25 & R-43-G541S & TGTGTAGTTGCGCGTGGAGCTGTACATGTT \\
26 & C $_{2}$ C-Thr->Asp-F & CTGCCCCGGATGAACGACAGCCTCATGGCCAAC \\
27 & C $_{2}$ C-Thr->Asp-R & GTTGGCCATGAGGCTGTCGTTCATCCGGGGCAG \\
28 & D1N-F & GGAGAGAAGTCCAGTAATATTTTTGTGAGGG \\
29 & D1N-R & CCCTCACAAAAATATTACTGGACTTCTCTCC \\
30 & DN-fwd3 & CACCCTGCAGATATGGAACGCTAACATCGGCTGACGAC \\
31 & DN-rev1 & ATATGAATTCTAGTCAGGTTCATTGCGAGCCAG \\
32 & DN-fwd2 & CACCCCCTCACAAAAATGTTAGAGCTCTTCTCTCCCGTG \\
33 & DN-rev3 & GTCGTCAGCCGAGAAGTGGTTAGCGTTCCATATCTGCAGG \\
& & GTG \\
34 & DN-fwd1 & CACGGGAGAGAAGAGCTCTAACATTTTTGTGAGGGGTG \\
35 & DN-rev2 & ATATGGATCCAACCCTGACAAGCCAGG \\
36 & D4N-F & GCCAATAACTTCCTGGGGGCCATCGAGCTGGACCTG \\
37 & D4N-R & GGCCCCCAGGAAGTTATTGGCTGAGAAGTGGTCAGC \\
38 & E1804del-F & TACCTGGCGGCCGAAAAGATCGTTATGTCC \\
39 & E1804del-R & GGACATAACGATCTTTTCGGCCGCCAGGTA \\
\hline
\end{tabular}




\subsection{Tested crystallization conditions}

Table 6.2-1 Crystallization trials of the $\mathrm{C}_{2} \mathrm{ABC}-\mathrm{His}_{6}$-fragment of otoferlin. Eleven different crystallization screens were used. The different tested protein concentrations and temperatures are shown in the left column. X indicates that the named conditions were tested within the marked crystallization screen.

\begin{tabular}{|c|c|c|c|c|c|c|c|c|c|c|c|}
\hline & $\begin{array}{l}\stackrel{L}{\sim} \\
\stackrel{1}{\dot{1}} \\
\stackrel{1}{+} \\
\stackrel{1}{1}\end{array}$ & $\begin{array}{l}0 \\
\cdots \\
0 \\
1 \\
\hat{1} \\
\vdots \\
\underbrace{\prime} \\
\underbrace{\prime}\end{array}$ & 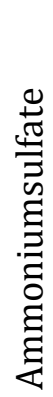 & $\begin{array}{l}n \\
\frac{n}{0} \\
\frac{2}{2} \\
\overbrace{2}^{0} \\
\sum\end{array}$ & 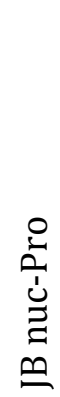 & U్ & 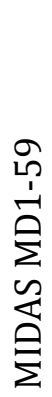 & 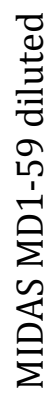 & 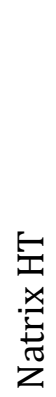 & 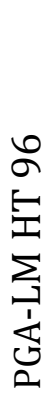 & 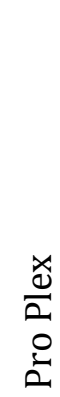 \\
\hline $\begin{array}{l}\mathrm{C}_{2} \mathrm{ABC}-\mathrm{His}_{6} \\
3 \mathrm{mg} / \mathrm{ml} \\
\left(20^{\circ} \mathrm{C}\right)\end{array}$ & $x$ & $x$ & $\mathrm{x}$ & $\mathrm{x}$ & $x$ & $x$ & $x$ & $x$ & $x$ & $x$ & $x$ \\
\hline $\begin{array}{l}\mathrm{C}_{2} \mathrm{ABC}-\mathrm{His}_{6} \\
3.48 \mathrm{mg} / \mathrm{ml} \\
\left(20^{\circ} \mathrm{C}\right)\end{array}$ & $x$ & $x$ & $x$ & $x$ & $x$ & $x$ & $\mathrm{X}$ & $x$ & $\mathrm{X}$ & $x$ & $\mathrm{X}$ \\
\hline $\begin{array}{l}\mathrm{C}_{2} \mathrm{ABC}-\mathrm{His}_{6} \\
3.48 \mathrm{mg} / \mathrm{ml} \\
\left(4^{\circ} \mathrm{C}\right) \\
+\mathrm{Ca}^{2+}\end{array}$ & $\mathrm{x}$ & $x$ & $\mathrm{x}$ & $\mathrm{x}$ & $x$ & $x$ & $x$ & $\mathrm{x}$ & $x$ & $x$ & $x$ \\
\hline $\begin{array}{l}\mathrm{C}_{2} \mathrm{ABC}-\mathrm{His}_{6} \\
4 \mathrm{mg} / \mathrm{ml} \\
\left(20^{\circ} \mathrm{C}\right)\end{array}$ & $\mathrm{x}$ & $x$ & $x$ & $x$ & $x$ & $x$ & $x$ & $x$ & $x$ & $x$ & $x$ \\
\hline $\begin{array}{l}\mathrm{C}_{2} \mathrm{ABC}-\mathrm{His}_{6} \\
4 \mathrm{mg} / \mathrm{ml} \\
\left(20^{\circ} \mathrm{C}\right) \\
\mathrm{BL} 21 \text { (DE } 3)\end{array}$ & $x$ & $x$ & $x$ & $x$ & $x$ & $x$ & $x$ & $x$ & $x$ & $x$ & $x$ \\
\hline $\begin{array}{l}\mathrm{C}_{2} \mathrm{ABC}-\mathrm{His}_{6} \\
5 \mathrm{mg} / \mathrm{ml} \\
\left(20^{\circ} \mathrm{C}\right)\end{array}$ & $x$ & $x$ & $x$ & $x$ & $x$ & $x$ & $x$ & $x$ & $x$ & $x$ & $x$ \\
\hline $\begin{array}{l}\mathrm{C}_{2} \mathrm{ABC}-\mathrm{His}_{6} \\
5 \mathrm{mg} / \mathrm{ml} \\
\left(20^{\circ} \mathrm{C}\right) \\
\text { Chelex }\end{array}$ & $x$ & $x$ & $\mathrm{x}$ & $\mathrm{x}$ & $\mathrm{x}$ & $\mathrm{x}$ & $x$ & $\mathrm{x}$ & $x$ & $x$ & $x$ \\
\hline $\begin{array}{l}\mathrm{C}_{2} \mathrm{ABC}-\mathrm{His}_{6} \\
5.29 \mathrm{mg} / \mathrm{ml} \\
\left(20^{\circ} \mathrm{C}\right)\end{array}$ & $x$ & $x$ & $\mathrm{x}$ & $x$ & $x$ & $x$ & $x$ & $x$ & $x$ & $x$ & $x$ \\
\hline $\begin{array}{l}\mathrm{C}_{2} \mathrm{ABC}-\mathrm{His}_{6} \\
3.61 \mathrm{mg} / \mathrm{ml} \\
\left(20^{\circ} \mathrm{C}\right)\end{array}$ & $x$ & $\mathrm{X}$ & $\mathrm{x}$ & $\mathrm{x}$ & & & & & & & \\
\hline $\begin{array}{l}\mathrm{C}_{2} \mathrm{ABC}-\mathrm{His}_{6} \\
3.48 \mathrm{mg} / \mathrm{ml} \\
\left(4^{\circ} \mathrm{C}\right)\end{array}$ & $x$ & $x$ & $x$ & $x$ & $x$ & $x$ & $x$ & $x$ & $x$ & $x$ & $\mathrm{x}$ \\
\hline
\end{tabular}




\begin{tabular}{|l|c|c|c|c|c|c|c|c|c|c|c|}
\hline $\begin{array}{l}\mathrm{C}_{2} \mathrm{ABC}-\mathrm{His} \\
(48 \mathrm{mg} / \mathrm{ml} \\
\left(4^{\circ} \mathrm{C}\right) \\
+\mathrm{Ca}^{2+}\end{array}$ & $\mathrm{x}$ & $\mathrm{x}$ & $\mathrm{x}$ & $\mathrm{x}$ & $\mathrm{x}$ & $\mathrm{x}$ & $\mathrm{x}$ & $\mathrm{x}$ & $\mathrm{x}$ & $\mathrm{x}$ & $\mathrm{x}$ \\
\hline $\begin{array}{l}\mathrm{C}_{2} \mathrm{ABC}-\mathrm{His}_{6} \\
4 \mathrm{mg} / \mathrm{ml}\left(4^{\circ} \mathrm{C}\right)\end{array}$ & $\mathrm{x}$ & $\mathrm{x}$ & $\mathrm{x}$ & $\mathrm{x}$ & $\mathrm{x}$ & $\mathrm{x}$ & $\mathrm{x}$ & $\mathrm{x}$ & $\mathrm{x}$ & $\mathrm{x}$ & $\mathrm{x}$ \\
\hline $\begin{array}{l}\mathrm{C}_{2} \mathrm{ABC}-\mathrm{His}_{6} \\
5 \mathrm{mg} / \mathrm{ml}\left(4^{\circ} \mathrm{C}\right)\end{array}$ & $\mathrm{x}$ & $\mathrm{x}$ & $\mathrm{x}$ & $\mathrm{x}$ & $\mathrm{x}$ & $\mathrm{x}$ & $\mathrm{x}$ & $\mathrm{x}$ & $\mathrm{x}$ & $\mathrm{x}$ & $\mathrm{x}$ \\
\hline $\begin{array}{l}\mathrm{C}_{2} \mathrm{ABC}-\mathrm{His}_{6} \\
5 \mathrm{mg} / \mathrm{ml}\left(4^{\circ} \mathrm{C}\right)\end{array}$ & $\mathrm{x}$ & $\mathrm{x}$ & $\mathrm{x}$ & $\mathrm{x}$ & $\mathrm{x}$ & $\mathrm{x}$ & $\mathrm{x}$ & $\mathrm{x}$ & $\mathrm{x}$ & $\mathrm{x}$ & $\mathrm{x}$ \\
$\mathrm{Chelex}$
\end{tabular}

Table 6.2-2 Crystallization trials of the $\mathrm{His}_{6}-\mathrm{C}_{2} \mathrm{AB}$-fragment of otoferlin. Eleven different crystallization screens were used. The different tested protein concentrations and temperatures are shown in the left column. $\mathrm{X}$ indicates that the named conditions were tested within the marked crystallization screen.

\begin{tabular}{|c|c|c|c|c|c|c|c|c|c|c|c|}
\hline & 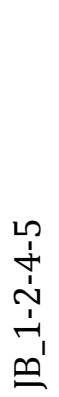 & \begin{tabular}{l}
0 \\
\multirow{1}{1}{} \\
0 \\
1 \\
1 \\
0 \\
0 \\
$\underbrace{\prime}$
\end{tabular} & 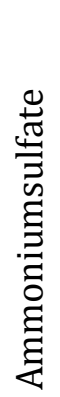 & $\frac{n}{2}$ & 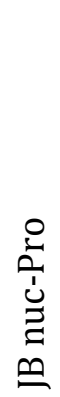 & U్ & 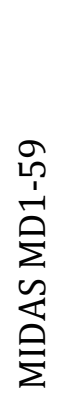 & 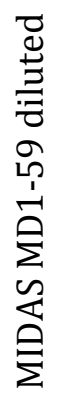 & 点 & 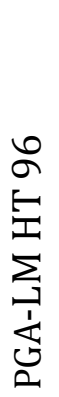 & $\begin{array}{l}\frac{x}{2} \\
\frac{⿱ 亠 乂}{2} \\
\vdots\end{array}$ \\
\hline $\begin{array}{l}\mathrm{His}_{6}-\mathrm{C}_{2} \mathrm{AB} \\
23.01 \mathrm{mg} / \mathrm{ml} \\
\left(20^{\circ} \mathrm{C}\right)\end{array}$ & $x$ & $x$ & $x$ & $x$ & & & & & & & \\
\hline $\begin{array}{l}\mathrm{His}_{6}-\mathrm{C}_{2} \mathrm{AB} \\
23.01 \mathrm{mg} / \mathrm{ml} \\
\left(4^{\circ} \mathrm{C}\right)\end{array}$ & $x$ & $x$ & $x$ & $x$ & & & & & & & \\
\hline $\begin{array}{l}\mathrm{His}_{6}-\mathrm{C}_{2} \mathrm{AB} \\
5 \mathrm{mg} / \mathrm{ml} \\
\left(20^{\circ} \mathrm{C}\right)\end{array}$ & $\mathrm{x}$ & $x$ & $x$ & $\mathrm{X}$ & $x$ & $x$ & $\mathrm{x}$ & $x$ & $x$ & $\mathrm{X}$ & $x$ \\
\hline $\begin{array}{l}\mathrm{His}_{6}-\mathrm{C}_{2} \mathrm{AB} \\
5 \mathrm{mg} / \mathrm{ml}\left(4^{\circ} \mathrm{C}\right)\end{array}$ & $x$ & $x$ & $x$ & $x$ & $x$ & $x$ & $x$ & $x$ & $x$ & $x$ & $\mathrm{x}$ \\
\hline
\end{tabular}


Table 6.2-3 Crystallization trials of the GST- $\mathrm{C}_{2}$ E-fragment of otoferlin. Eleven different crystallization screens were used. The different tested protein concentrations and temperatures are shown in the left column. X indicates that the named conditions were tested within the marked crystallization screen.

\begin{tabular}{|c|c|c|c|c|c|c|c|c|c|c|c|}
\hline & $\begin{array}{l}\stackrel{1}{1} \\
\dot{1} \\
\stackrel{1}{1} \\
\stackrel{+}{1} \\
\stackrel{0}{=}\end{array}$ & $\begin{array}{l}0 \\
\stackrel{1}{1} \\
\infty \\
1 \\
\hat{1} \\
b^{\prime} \\
\vartheta^{\prime}\end{array}$ & 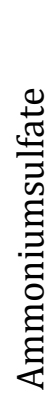 & $\begin{array}{l}\frac{n}{2} \\
\frac{2}{2} \\
\sum \\
\sum \\
\Sigma\end{array}$ & 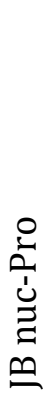 & ک્ & 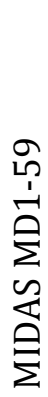 & 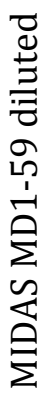 & 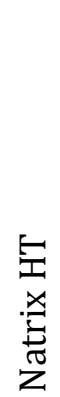 & 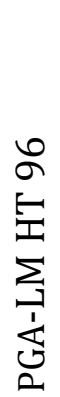 & $\frac{\underset{d}{Q}}{2}$ \\
\hline $\begin{array}{l}\mathrm{GST}-\mathrm{C}_{2} \mathrm{E} \\
5.4 \mathrm{mg} / \mathrm{ml} \\
\left(20^{\circ} \mathrm{C}\right)\end{array}$ & $\mathrm{X}$ & $X$ & $\mathrm{X}$ & $\mathrm{X}$ & & & & & & & \\
\hline $\begin{array}{l}\mathrm{GST}-\mathrm{C}_{2} \mathrm{E} \\
3.86 \mathrm{mg} / \mathrm{ml} \\
\left(20^{\circ} \mathrm{C}\right)\end{array}$ & $\mathrm{X}$ & $\mathrm{X}$ & $\mathrm{X}$ & $\mathrm{X}$ & $\mathrm{X}$ & $\mathrm{X}$ & $\mathrm{X}$ & $\mathrm{X}$ & $\mathrm{X}$ & $\mathrm{X}$ & $\mathrm{X}$ \\
\hline
\end{tabular}

Table 6.2-4 Crystallization trials of the GST- $\mathrm{C}_{2} \mathrm{~B}$-fragment of otoferlin. Eleven different crystallization screens were used. The different tested protein concentrations and temperatures are shown in the left column. X indicates that the named conditions were tested within the marked crystallization screen.

\begin{tabular}{|c|c|c|c|c|c|c|c|c|c|c|c|}
\hline & 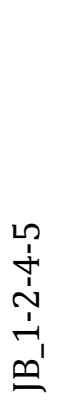 & 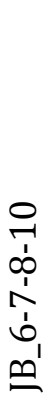 & 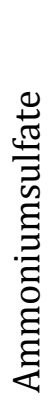 & $\frac{n}{2}$ & Oِ & $\underset{\mho}{\widetilde{U}}$ & 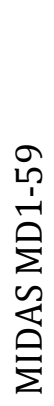 & 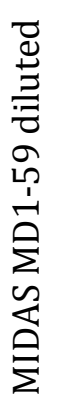 & 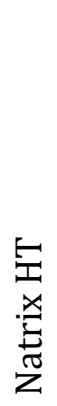 & 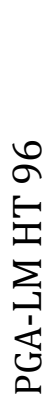 & $\frac{\substack{e \\
a}}{0}$ \\
\hline $\begin{array}{l}\mathrm{GST}-\mathrm{C}_{2} \mathrm{~B} \\
12.65 \mathrm{mg} / \mathrm{ml} \\
\left(20^{\circ} \mathrm{C}\right)\end{array}$ & $\mathrm{X}$ & $\mathrm{X}$ & $\mathrm{X}$ & $X$ & $\mathrm{X}$ & $\mathrm{X}$ & & & $\mathrm{X}$ & $\mathrm{X}$ & $\mathrm{X}$ \\
\hline $\begin{array}{l}\mathrm{GST}-\mathrm{C}_{2} \mathrm{~B} \\
10.33 \mathrm{mg} / \mathrm{ml} \\
\left(20^{\circ} \mathrm{C}\right)\end{array}$ & $X$ & $X$ & X & $X$ & $X$ & $\mathrm{X}$ & & & $\mathrm{X}$ & $X$ & $\mathrm{X}$ \\
\hline $\begin{array}{l}\mathrm{GST}-\mathrm{C}_{2} \mathrm{~B} \\
8.75 \mathrm{mg} / \mathrm{ml} \\
\left(4^{\circ} \mathrm{C}\right) \\
+\mathrm{Ca}^{2+}\end{array}$ & $X$ & $\mathrm{X}$ & $X$ & $\mathrm{X}$ & & $\mathrm{X}$ & $\mathrm{X}$ & $\mathrm{X}$ & & $\mathrm{X}$ & \\
\hline $\begin{array}{l}\mathrm{GST}-\mathrm{C}_{2} \mathrm{~B} \\
7.5 \mathrm{mg} / \mathrm{ml} \\
\left(20^{\circ} \mathrm{C}\right)\end{array}$ & $\mathrm{X}$ & $\mathrm{X}$ & $\mathrm{X}$ & $\mathrm{X}$ & $\mathrm{X}$ & $\mathrm{X}$ & $\mathrm{X}$ & $\mathrm{X}$ & $\mathrm{X}$ & $\mathrm{X}$ & $\mathrm{X}$ \\
\hline $\begin{array}{l}\mathrm{GST}-\mathrm{C}_{2} \mathrm{~B} \\
6.9 \mathrm{mg} / \mathrm{ml} \\
\left(20^{\circ} \mathrm{C}\right) \\
+\mathrm{Ca}^{2+}\end{array}$ & $\mathrm{X}$ & $\mathrm{X}$ & $\mathrm{X}$ & $\mathrm{X}$ & $\mathrm{X}$ & $\mathrm{X}$ & $\mathrm{X}$ & $X$ & $\mathrm{X}$ & $\mathrm{X}$ & $\mathrm{X}$ \\
\hline
\end{tabular}


6 Appendix

\begin{tabular}{|c|c|c|c|c|c|c|c|c|c|c|c|}
\hline $\begin{array}{l}\mathrm{GST}-\mathrm{C}_{2} \mathrm{~B} \\
5 \mathrm{mg} / \mathrm{ml} \\
\left(20^{\circ} \mathrm{C}\right)\end{array}$ & $\mathrm{x}$ & $\mathrm{x}$ & $\mathrm{x}$ & $\mathrm{x}$ & $\mathrm{x}$ & $\mathrm{x}$ & $\mathrm{x}$ & $\mathrm{x}$ & $x$ & $x$ & $x$ \\
\hline $\begin{array}{l}\mathrm{GST}-\mathrm{C}_{2} \mathrm{~B} \\
5 \mathrm{mg} / \mathrm{ml} \\
\left(20^{\circ} \mathrm{C}\right) \\
+\mathrm{Ca}^{2+}\end{array}$ & $x$ & $\mathrm{x}$ & $x$ & $\mathrm{x}$ & $x$ & $\mathrm{x}$ & $\mathrm{x}$ & $\mathrm{x}$ & $\mathrm{x}$ & $x$ & $\mathrm{x}$ \\
\hline $\begin{array}{l}\text { GST }-\mathrm{C}_{2} \mathrm{~B} \\
12.65 \mathrm{mg} / \mathrm{ml} \\
\left(4^{\circ} \mathrm{C}\right)\end{array}$ & $\mathrm{x}$ & $\mathrm{x}$ & $\mathrm{x}$ & $\mathrm{X}$ & $\mathrm{x}$ & $\mathrm{x}$ & & & $\mathrm{x}$ & $\mathrm{X}$ & $\mathrm{x}$ \\
\hline $\begin{array}{l}\text { GST }-\mathrm{C}_{2} \mathrm{~B} \\
10.33 \mathrm{mg} / \mathrm{ml} \\
\left(4^{\circ} \mathrm{C}\right)\end{array}$ & $\mathrm{x}$ & $\mathrm{x}$ & $\mathrm{x}$ & $\mathrm{X}$ & $\mathrm{x}$ & $\mathrm{x}$ & & & $\mathrm{x}$ & $\mathrm{x}$ & $\mathrm{x}$ \\
\hline $\begin{array}{l}\text { GST- } C_{2} B \\
7.5 \mathrm{mg} / \mathrm{ml} \\
\left(4^{\circ} \mathrm{C}\right)\end{array}$ & $\mathrm{x}$ & $\mathrm{x}$ & $\mathrm{x}$ & $\mathrm{x}$ & & & & & & & \\
\hline $\begin{array}{l}\mathrm{GST}-\mathrm{C}_{2} \mathrm{~B} \\
6.9 \mathrm{mg} / \mathrm{ml} \\
\left(4{ }^{\circ} \mathrm{C}\right) \\
+\mathrm{Ca}^{2+}\end{array}$ & $\mathrm{x}$ & $x$ & $x$ & $\mathrm{X}$ & $\mathrm{x}$ & $\mathrm{x}$ & $\mathrm{x}$ & $\mathrm{x}$ & $x$ & $\mathrm{x}$ & $\mathrm{X}$ \\
\hline $\begin{array}{l}\text { GST-C } C_{2} \text { B } \\
5 \mathrm{mg} / \mathrm{ml}\left(4^{\circ} \mathrm{C}\right)\end{array}$ & $\mathrm{x}$ & $\mathrm{x}$ & $\mathrm{X}$ & $\mathrm{X}$ & $\mathrm{x}$ & $\mathrm{x}$ & $\mathrm{x}$ & $\mathrm{x}$ & $\mathrm{x}$ & $x$ & $\mathrm{x}$ \\
\hline $\begin{array}{l}\mathrm{GST}-\mathrm{C}_{2} \mathrm{~B} \\
5 \mathrm{mg} / \mathrm{ml}\left(4^{\circ} \mathrm{C}\right) \\
+\mathrm{Ca}^{2+}\end{array}$ & $\mathrm{x}$ & $\mathrm{x}$ & $\mathrm{x}$ & $\mathrm{X}$ & $\mathrm{x}$ & $\mathrm{x}$ & $\mathrm{x}$ & $\mathrm{x}$ & $x$ & $x$ & $\mathrm{X}$ \\
\hline
\end{tabular}

Table 6.2-5 Crystallization trials of the Strep- $\mathrm{C}_{2} \mathrm{ABC}$-fragment of otoferlin. Eleven different crystallization screens were used. The different tested protein concentrations and temperatures are shown in the left column. $\mathrm{X}$ indicates that the named conditions were tested within the marked crystallization screen.

\begin{tabular}{|c|c|c|c|c|c|c|c|c|c|c|c|}
\hline & 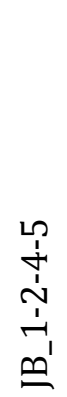 & $\begin{array}{l}0 \\
7 \\
0 \\
0 \\
1 \\
0 \\
0 \\
\varrho^{\prime}\end{array}$ & 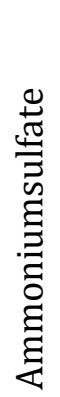 & $\frac{n}{\frac{n}{2}}$ & $\begin{array}{l}0 \\
\vdots \\
\vdots \\
\vdots \\
\vdots \\
\varrho \\
\varrho\end{array}$ & $\stackrel{\mathscr{U}}{\breve{S}}$ & 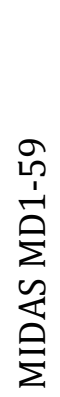 & 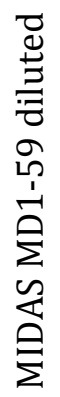 & 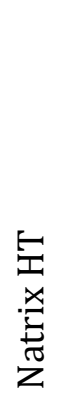 & 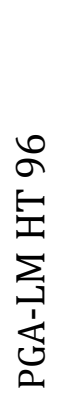 & $\begin{array}{l}\frac{x}{2} \\
\frac{⿱}{2} \\
\vdots\end{array}$ \\
\hline $\begin{array}{l}\text { Strep- } \mathrm{C}_{2} \mathrm{ABC} \\
4.61 \mathrm{mg} / \mathrm{ml} \\
\left(20^{\circ} \mathrm{C}\right)\end{array}$ & $x$ & $\mathrm{x}$ & $\mathrm{x}$ & $x$ & $\mathrm{x}$ & $x$ & $x$ & $\mathrm{x}$ & $x$ & $x$ & $x$ \\
\hline $\begin{array}{l}\text { Strep- } \mathrm{C}_{2} \mathrm{ABC} \\
4.61 \mathrm{mg} / \mathrm{ml} \\
\left(4^{\circ} \mathrm{C}\right)\end{array}$ & $x$ & $x$ & $x$ & $x$ & $x$ & $x$ & $x$ & $x$ & $x$ & $x$ & $x$ \\
\hline
\end{tabular}


Table 6.2-6 Crystallization trials of the GST- $\mathrm{C}_{2} \mathrm{~F}$-fragment of otoferlin. Eleven different crystallization screens were used. The different tested protein concentrations and temperatures are shown in the left column. X indicates that the named conditions were tested within the marked crystallization screen.

\begin{tabular}{|c|c|c|c|c|c|c|c|c|c|c|c|}
\hline & $\begin{array}{c}n \\
1 \\
i \\
1 \\
1 \\
1 \\
\underbrace{\prime}\end{array}$ & 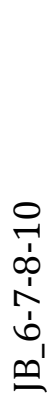 & 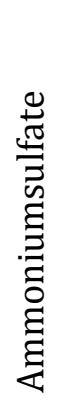 & $\frac{n}{2}$ & 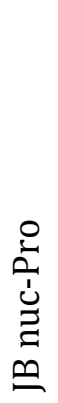 & $\underset{\underbrace{}}{\mathscr{U}}$ & 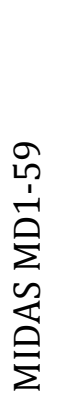 & 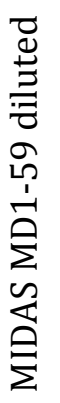 & 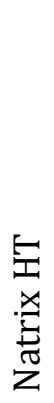 & 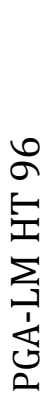 & $\frac{\underset{d}{a}}{a}$ \\
\hline $\begin{array}{l}\mathrm{GST}-\mathrm{C}_{2} \mathrm{~F} \\
3.65 \mathrm{mg} / \mathrm{ml} \\
\left(20^{\circ} \mathrm{C}\right)\end{array}$ & $\mathrm{X}$ & $\mathrm{X}$ & $\mathrm{X}$ & $\mathrm{X}$ & $\mathrm{X}$ & $\mathrm{X}$ & $\mathrm{X}$ & & $\mathrm{X}$ & & \\
\hline $\begin{array}{l}\mathrm{GST}-\mathrm{C}_{2} \mathrm{~F} \\
4 \mathrm{mg} / \mathrm{ml} \\
\left(20^{\circ} \mathrm{C}\right)\end{array}$ & $\mathrm{X}$ & $\mathrm{X}$ & $\mathrm{X}$ & $\mathrm{X}$ & $X$ & $\mathrm{X}$ & $\mathrm{X}$ & $\mathrm{X}$ & $\mathrm{X}$ & $\mathrm{X}$ & $\mathrm{X}$ \\
\hline $\begin{array}{l}\mathrm{GST}-\mathrm{C}_{2} \mathrm{~F} \\
5.07 \mathrm{mg} / \mathrm{ml} \\
\left(20^{\circ} \mathrm{C}\right) \\
+\mathrm{Ca}^{2+}\end{array}$ & $\mathrm{X}$ & $\mathrm{X}$ & $X$ & $X$ & $\mathrm{X}$ & $\mathrm{X}$ & $X$ & $\mathrm{X}$ & $\mathrm{X}$ & $\mathrm{X}$ & $\mathrm{X}$ \\
\hline $\begin{array}{l}\mathrm{GST}-\mathrm{C}_{2} \mathrm{~F} \\
5.07 \mathrm{mg} / \mathrm{ml} \\
\left(20^{\circ} \mathrm{C}\right)\end{array}$ & $\mathrm{X}$ & $\mathrm{X}$ & $\mathrm{X}$ & $X$ & $\mathrm{X}$ & $\mathrm{X}$ & $\mathrm{X}$ & $\mathrm{X}$ & $\mathrm{X}$ & $\mathrm{X}$ & $\mathrm{X}$ \\
\hline $\begin{array}{l}\mathrm{GST}-\mathrm{C}_{2} \mathrm{~F} \\
5.86 \mathrm{mg} / \mathrm{ml} \\
\left(20^{\circ} \mathrm{C}\right) \\
+\mathrm{Ca}^{2+}\end{array}$ & $\mathrm{X}$ & $\mathrm{X}$ & $\mathrm{x}$ & $\mathrm{X}$ & $\mathrm{X}$ & $\mathrm{X}$ & $\mathrm{X}$ & $\mathrm{X}$ & $\mathrm{X}$ & $\mathrm{X}$ & $\mathrm{X}$ \\
\hline $\begin{array}{l}\mathrm{GST}-\mathrm{C}_{2} \mathrm{~F} \\
3.61 \mathrm{mg} / \mathrm{ml} \\
\left(4^{\circ} \mathrm{C}\right)\end{array}$ & $\mathrm{X}$ & $\mathrm{X}$ & $X$ & $X$ & & $\mathrm{X}$ & $\mathrm{X}$ & & & & \\
\hline $\begin{array}{l}\mathrm{GST}-\mathrm{C}_{2} \mathrm{~F} \\
4 \mathrm{mg} / \mathrm{ml}\left(4^{\circ} \mathrm{C}\right)\end{array}$ & $\mathrm{X}$ & $\mathrm{X}$ & $X$ & $\mathrm{X}$ & $\mathrm{X}$ & $\mathrm{X}$ & $\mathrm{X}$ & $\mathrm{X}$ & $\mathrm{X}$ & $\mathrm{X}$ & $\mathrm{X}$ \\
\hline $\begin{array}{l}\mathrm{GST}-\mathrm{C}_{2} \mathrm{~F} \\
5.07 \mathrm{mg} / \mathrm{ml} \\
\left(4^{\circ} \mathrm{C}\right)\end{array}$ & $\mathrm{X}$ & $\mathrm{X}$ & $\mathrm{X}$ & $\mathrm{X}$ & $\mathrm{X}$ & $\mathrm{X}$ & $\mathrm{X}$ & $X$ & $\mathrm{X}$ & $\mathrm{X}$ & $\mathrm{X}$ \\
\hline $\begin{array}{l}\mathrm{GST}-\mathrm{C}_{2} \mathrm{~F} \\
5.07 \mathrm{mg} / \mathrm{ml} \\
\left(4^{\circ} \mathrm{C}\right)\end{array}$ & $\mathrm{X}$ & $\mathrm{X}$ & $\mathrm{X}$ & $\mathrm{X}$ & $X$ & $\mathrm{X}$ & $X$ & $\mathrm{X}$ & $\mathrm{X}$ & $\mathrm{X}$ & $\mathrm{X}$ \\
\hline
\end{tabular}


Table 6.2-7 Crystallization trials of the GST- $\mathrm{C}_{2} \mathrm{C}$-fragment of otoferlin. Eleven different crystallization screens were used. The different tested protein concentrations and temperatures are shown in the left column. X indicates that the named conditions were tested within the marked crystallization screen.

\begin{tabular}{|c|c|c|c|c|c|c|c|c|c|c|c|}
\hline & 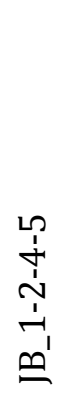 & 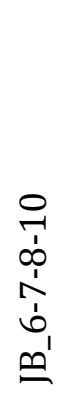 & 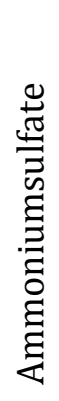 & $\frac{\varrho_{0}^{0}}{\frac{d}{2}}$ & $\begin{array}{l}0 \\
\vdots \\
\vdots \\
\vdots \\
\vdots \\
\varrho\end{array}$ & 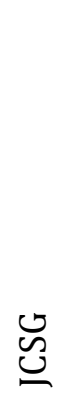 & 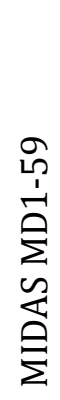 & 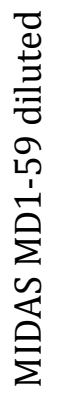 & 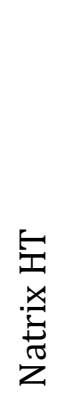 & 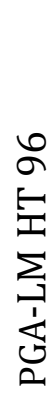 & $\begin{array}{l}\frac{x}{a} \\
\frac{0}{2} \\
\frac{0}{2}\end{array}$ \\
\hline $\begin{array}{l}\text { GST }-\mathrm{C}_{2} \mathrm{C} \\
4.95 \mathrm{mg} / \mathrm{ml} \\
\left(20^{\circ} \mathrm{C}\right)\end{array}$ & $\mathrm{X}$ & $\mathrm{x}$ & $\mathrm{X}$ & $\mathrm{X}$ & & $\mathrm{x}$ & $\mathrm{x}$ & & & & \\
\hline $\begin{array}{l}\mathrm{GST}-\mathrm{C}_{2} \mathrm{C} \\
4.94 \mathrm{mg} / \mathrm{ml} \\
\left(4^{\circ} \mathrm{C}\right)\end{array}$ & $\mathrm{X}$ & $\mathrm{X}$ & $\mathrm{X}$ & $\mathrm{X}$ & & $\mathrm{x}$ & $\mathrm{x}$ & & & & \\
\hline
\end{tabular}

Table 6.2-8 Crystallization trials of the GST- $\mathrm{C}_{2} \mathrm{~F}$-phos-fragment of otoferlin. Eleven different crystallization screens were used. The different tested protein concentrations and temperatures are shown in the left column. $\mathrm{X}$ indicates that the named conditions were tested within the marked crystallization screen.

\begin{tabular}{|c|c|c|c|c|c|c|c|c|c|c|c|}
\hline & 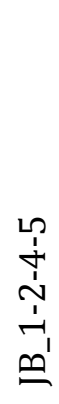 & 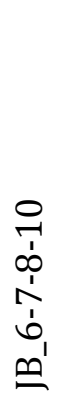 & 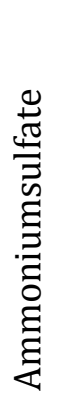 & $\frac{n}{2}$ & 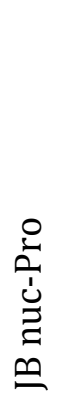 & Uئ & 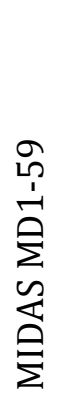 & 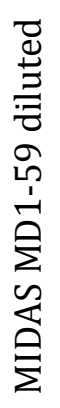 & 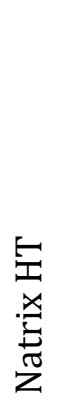 & 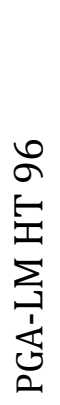 & $\frac{\stackrel{x}{a}}{2}$ \\
\hline $\begin{array}{l}\text { GST-C }{ }_{2} \mathrm{~F} \text { phos } \\
4 \mathrm{mg} / \mathrm{ml} \\
\left(20^{\circ} \mathrm{C}\right)\end{array}$ & $\mathrm{x}$ & $x$ & $x$ & $\mathrm{X}$ & & $x$ & $x$ & & & $x$ & \\
\hline
\end{tabular}


Table 6.2-9 Crystallization trials of the GST-C $\mathrm{C}_{2} \mathrm{~F}-\mathrm{D} 1 \mathrm{~N}$-fragment of otoferlin. Eleven different crystallization screens were used. The different tested protein concentrations and temperatures are shown in the left column. X indicates that the named conditions were tested within the marked crystallization screen.

\begin{tabular}{|c|c|c|c|c|c|c|c|c|c|c|c|}
\hline & 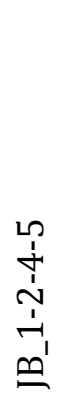 & $\begin{array}{l}0 \\
\overrightarrow{1} \\
0 \\
1 \\
1 \\
b_{1} \\
\varrho^{\prime}\end{array}$ & 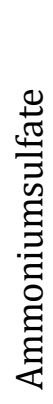 & $\frac{\overbrace{0}^{2}}{\frac{d}{2}}$ & 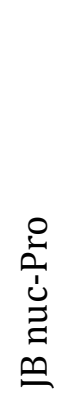 & U్ & 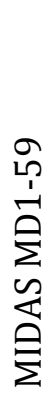 & 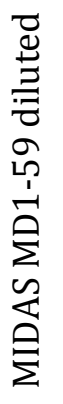 & 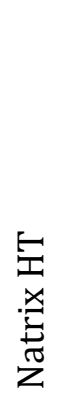 & 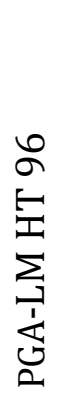 & $\begin{array}{l}\frac{x}{2} \\
\stackrel{0}{0} \\
\dot{D}\end{array}$ \\
\hline $\begin{array}{l}\text { GST-C } 2 \text { F-D1N } \\
4 \mathrm{mg} / \mathrm{ml} \\
\left(20^{\circ} \mathrm{C}\right)\end{array}$ & $\mathrm{x}$ & $\mathrm{x}$ & $\mathrm{x}$ & $\mathrm{x}$ & & $x$ & $\mathrm{x}$ & & & & \\
\hline $\begin{array}{l}\text { GST-C } \mathrm{C}_{2} \mathrm{~F}-\mathrm{D} 1 \mathrm{~N} \\
4 \mathrm{mg} / \mathrm{ml}\left(4^{\circ} \mathrm{C}\right)\end{array}$ & $\mathrm{X}$ & $\mathrm{x}$ & $\mathrm{x}$ & $\mathrm{x}$ & & $x$ & $\mathrm{x}$ & & & & \\
\hline
\end{tabular}

Table 6.2-10 Crystallization trials of the GST-C $\mathrm{C}_{2} \mathrm{~F}-\mathrm{D} 2,3 \mathrm{~N}$-fragment of otoferlin. Eleven different crystallization screens were used. The different tested protein concentrations and temperatures are shown in the left column. X indicates that the named conditions were tested within the marked crystallization screen.

\begin{tabular}{|c|c|c|c|c|c|c|c|c|c|c|c|}
\hline & 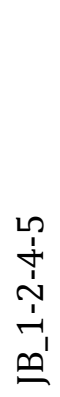 & $\begin{array}{l}0 \\
\overrightarrow{1} \\
0 \\
1 \\
1 \\
b_{1} \\
\varrho^{\prime}\end{array}$ & 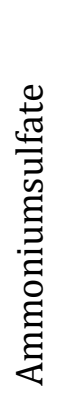 & $\frac{\frac{n}{2}}{\frac{2}{2}}$ & 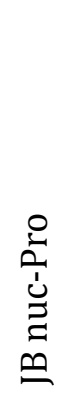 & U్ & 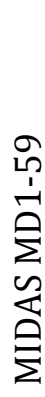 & 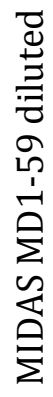 & 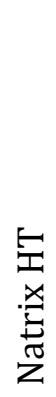 & 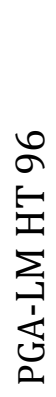 & $\frac{\substack{e \\
L}}{0}$ \\
\hline $\begin{array}{l}\text { GST-C }{ }_{2} \text { F-D2,3N } \\
4 \mathrm{mg} / \mathrm{ml} \\
\left(20^{\circ} \mathrm{C}\right)\end{array}$ & $\mathrm{X}$ & $\mathrm{X}$ & $\mathrm{x}$ & $x$ & $\mathrm{X}$ & $x$ & $\mathrm{x}$ & $X$ & $x$ & $\mathrm{X}$ & $\mathrm{X}$ \\
\hline $\begin{array}{l}\text { GST-C } \mathrm{C}_{2} \mathrm{~F}-\mathrm{D} 2,3 \mathrm{~N} \\
4 \mathrm{mg} / \mathrm{ml}\left(4^{\circ} \mathrm{C}\right)\end{array}$ & $x$ & $\mathrm{X}$ & $\mathrm{x}$ & $\mathrm{x}$ & $\mathrm{X}$ & $x$ & $\mathrm{x}$ & $X$ & $x$ & $x$ & $\mathrm{X}$ \\
\hline
\end{tabular}


Table 6.2-11 Crystallization trials of the GST-C $\mathrm{C}_{2} \mathrm{~F}-\mathrm{D} 1,2,3 \mathrm{~N}$-fragment of otoferlin. Eleven different crystallization screens were used. The different tested protein concentrations and temperatures are shown in the left column. $\mathrm{X}$ indicates that the named conditions were tested within the marked crystallization screen.

\begin{tabular}{|c|c|c|c|c|c|c|c|c|c|c|c|}
\hline & 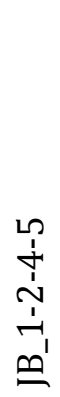 & 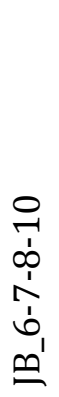 & 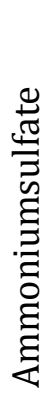 & $\frac{n}{2}$ & 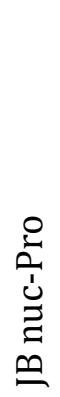 & U్ & 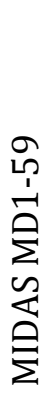 & 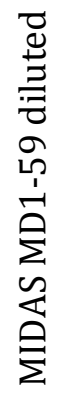 & 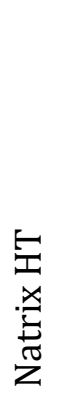 & 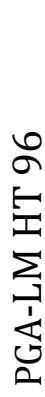 & 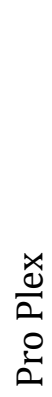 \\
\hline $\begin{array}{l}\text { GST-C }{ }_{2} \text { F-D } 1,2,3 \\
\mathrm{~N} \\
4 \mathrm{mg} / \mathrm{ml}\left(20^{\circ} \mathrm{C}\right)\end{array}$ & $x$ & $x$ & $x$ & $x$ & & $x$ & $\mathrm{X}$ & & & $\mathrm{x}$ & \\
\hline $\begin{array}{l}\text { GST-C } 2 \text { F-D } 1,2,3 \\
\mathrm{~N} \\
4 \mathrm{mg} / \mathrm{ml}\left(4^{\circ} \mathrm{C}\right)\end{array}$ & $\mathrm{x}$ & $x$ & $\mathrm{X}$ & $x$ & & $\mathrm{x}$ & $\mathrm{x}$ & & & $\mathrm{x}$ & \\
\hline $\begin{array}{l}\text { GST-C }{ }_{2} \text { F-D } 1,2,3 \\
\mathrm{~N} \\
4 \mathrm{mg} / \mathrm{ml}\left(4^{\circ} \mathrm{C}\right)\end{array}$ & & & & & $\mathrm{x}$ & & & $x$ & $x$ & $\mathrm{x}$ & $\mathrm{x}$ \\
\hline
\end{tabular}

Table 6.2-12 Crystallization trials of the GST- $\mathrm{C}_{2} \mathrm{~F}-\mathrm{pg}$-fragment of otoferlin. Eleven different crystallization screens were used. The different tested protein concentrations and temperatures are shown in the left column. $\mathrm{X}$ indicates that the named conditions were tested within the marked crystallization screen.

\begin{tabular}{|c|c|c|c|c|c|c|c|c|c|c|c|}
\hline & 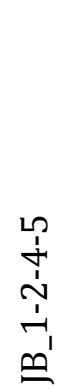 & 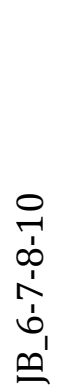 & 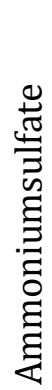 & $\frac{\substack{0 \\
0}}{\frac{2}{2}}$ & $\begin{array}{l}0 \\
\vdots \\
\vdots \\
\vdots \\
\vdots \\
\vdots \\
\varrho\end{array}$ & $\underline{\underline{y}}$ & 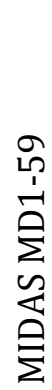 & 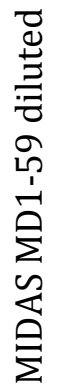 & 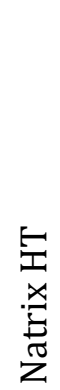 & 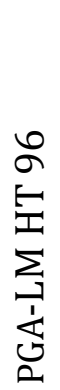 & $\frac{\substack{e \\
D}}{0}$ \\
\hline $\begin{array}{l}\text { GST-C }{ }_{2} \mathrm{~F}-p g a \\
2.77 \mathrm{mg} / \mathrm{ml} \\
\left(20^{\circ} \mathrm{C}\right)\end{array}$ & $\mathrm{X}$ & $\mathrm{X}$ & $\mathrm{x}$ & & & $\mathrm{X}$ & & & & & \\
\hline
\end{tabular}


Table 6.2-13 Crystallization trials of the GST- $\mathrm{C}_{2} \mathrm{~F}-\mathrm{E} 1804$ del-fragment of otoferlin. Eleven different crystallization screens were used. The different tested protein concentrations and temperatures are shown in the left column. $\mathrm{X}$ indicates that the named conditions were tested within the marked crystallization screen.

\begin{tabular}{|c|c|c|c|c|c|c|c|c|c|c|c|}
\hline & 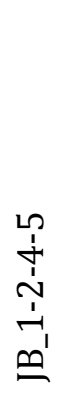 & $\begin{array}{l}0 \\
\overrightarrow{1} \\
0 \\
1 \\
1 \\
b_{1}^{\prime} \\
\varrho^{\prime}\end{array}$ & 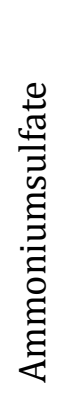 & $\frac{n}{2}$ & 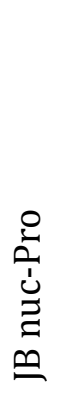 & U్ & 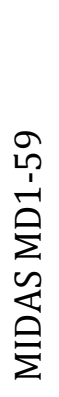 & 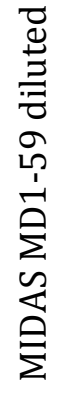 & 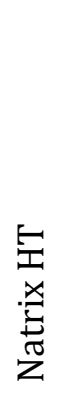 & 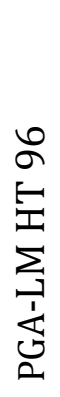 & $\frac{\substack{e \\
\alpha}}{o}$ \\
\hline $\begin{array}{l}\mathrm{GST}-\mathrm{C}_{2} \mathrm{~F} \\
-\mathrm{E} 1804 \mathrm{del} \\
2.4 \mathrm{mg} / \mathrm{ml} \\
\left(20^{\circ} \mathrm{C}\right)\end{array}$ & $\mathrm{X}$ & $\mathrm{x}$ & $\mathrm{X}$ & & & $\mathrm{x}$ & & & & & \\
\hline
\end{tabular}




\section{CURRICULUM VITAE}

\section{Sandra Meese}

Georg-August-University Göttingen

Department for Molecular Structural Biology

Justus-von-Liebig Weg 11

Göttingen, Germany

E-mail: smeese1@gwdg.de

\section{Personal data}

Date of birth: $\quad$ March 21 1986

Place of birth: Holzminden (Germany)

Nationality: German

\section{Scientific education}

2011-2015 PhD program "basic biology program" at Georg-August-University School of Science (GAUSS)

Doctoral thesis: "Biochemical studies of the synaptic protein otoferlin"; in the department for Molecular Structural Biology under the supervision of Prof. Dr. Ralf Ficner

Diploma in Chemistry - Georg-August-University Göttingen

Diploma thesis: "Protein Interaktionsstudien mittels NMR"; in the department for NMR-based Structural Biology under the supervision of Prof. Dr. Christian Griesinger 